\title{
Exploring the use of Social Media by Australian Small Business managers
}

A thesis submitted in in fulfilment of the requirements for the degree of Doctor of Philosophy

\author{
Benjamin Kar Chun Leong \\ BSc (Honours), University of Melbourne \\ Grad Dip (Professional Communication), Deakin University \\ School: Graduate School of Business \\ College: College of Business \\ RMIT University
}

July 2019 


\section{Candidate Statement}

I certify that except where due acknowledgement has been made, the work is that of the author alone; the work has not been submitted previously, in whole or in part, to qualify for any other academic award; the content of the thesis is the result of work which has been carried out since the official commencement date of the approved research program; any editorial work, paid or unpaid, carried out by a third party is acknowledged; and, ethics procedures and guidelines have been followed.

I acknowledge the support I have received for my research through the provision of an Australian Government Research Training Program Scholarship.

Benjamin Leong, July 2019 


\section{Acknowledgements}

I would like to thank several people for making this thesis possible:

My family for their ongoing support, patience and encouragement throughout the research - both those who have known me the longest, and my two children, who were born during the long completion of this research! In particular, I thank Louise, Ariadne, Nathaniel, Margaret, Bethany, Andrew, Owen and Jack.

My friends Hannah, Rebecca, Jye, Scott, Lon, Emily, Stefan and Sarah: for helping me stay connected to the world away from my research, and providing endless support.

My colleagues at RMIT in the Graduate School of Business, particularly to my supervisors Margaret and Supriya, assistance in the final stages from Paul and Mark, and other members of the Smart Services research group: Jonathan, Yvonne, Anuja, Meredith, Marita, Clive, Mary, Lillian, Joann and Vinita.

Finally, this research could not have been conducted without the support of the Smart Services CRC: both in the form of a research scholarship, and the assistance and advice of the CRC staff and other research students. Special thanks are due to Julien, Daniel, Terri, Annette, Allen and Warren.

In memory of my father, Leong Wai Sing who introduced me to what life is like in a small business. 


\section{Table of Contents}

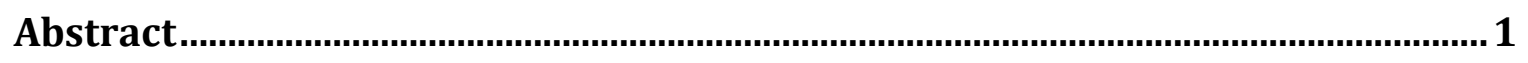

1. Introduction........................................................................................

1.1 Background to research problem ......................................................................

Motivations/rationale for this research ...................................................................................................5

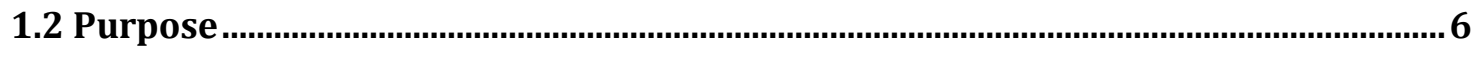

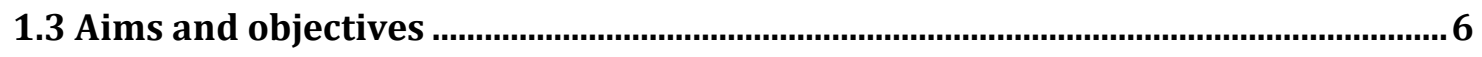

Aims................................................................................................................................................................6

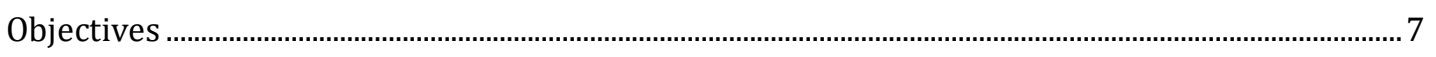

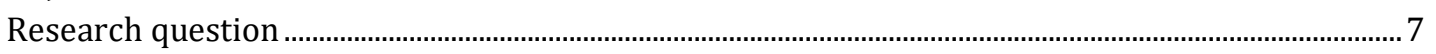

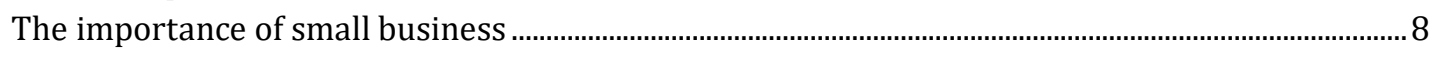

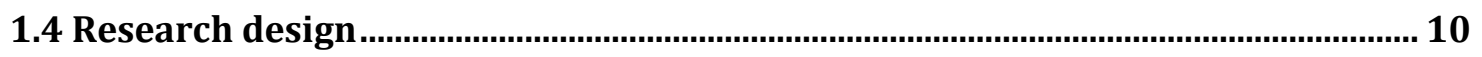

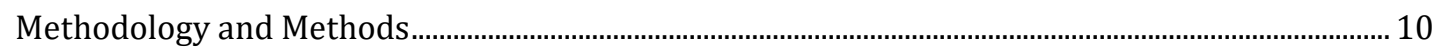

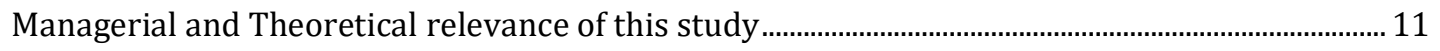

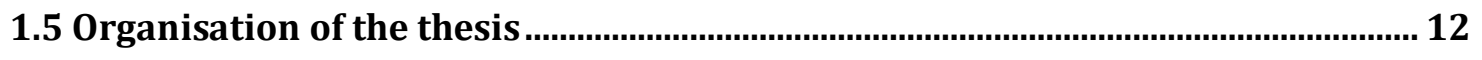

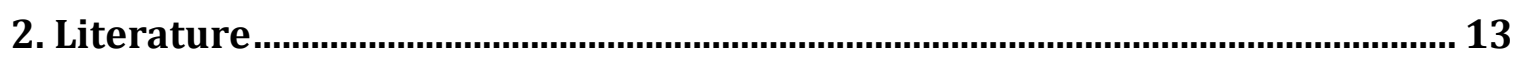

2.1 Small businesses and technology adoption ........................................................... 13

Small businesses and the internet................................................................................................................ 13

Small businesses and social networks...............................................................................................................14

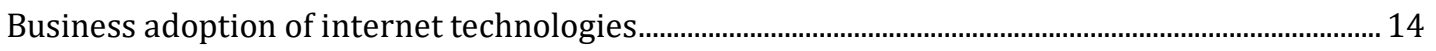

Meta-analyses and literature reviews ..........................................................................................................12

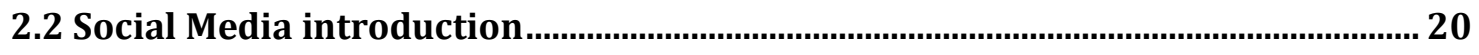

What is social media? ....................................................................................................................................20

Social media in Australia .............................................................................................................................22

Social media and small business ......................................................................................................................23

Timeline of major developments in social media ......................................................................................25

2.3 Social Media overview.................................................................................................... 28

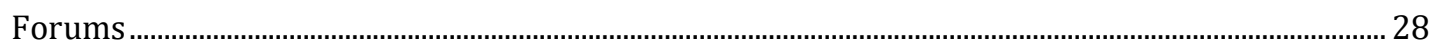

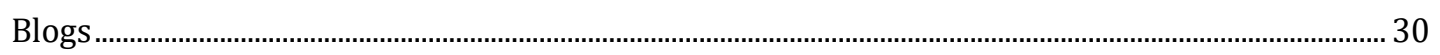

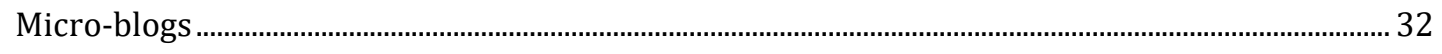

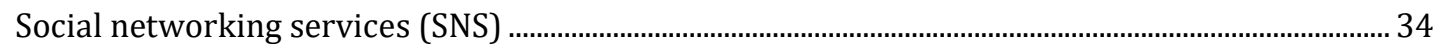

Professional networking services (PNS) ....................................................................................................35

Video and image sharing services....................................................................................................37

2.4 Technology adoption: Diffusion of Innovations (DoI) ………………………………. 37

Innovation-decision process .................................................................................................................3

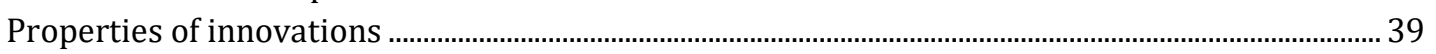

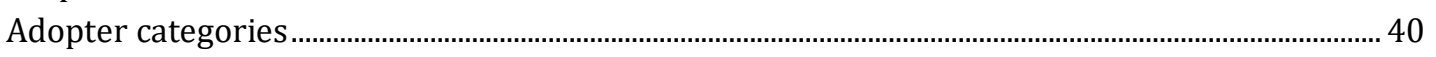

Diffusion of innovations within organisations ....................................................................................... 41

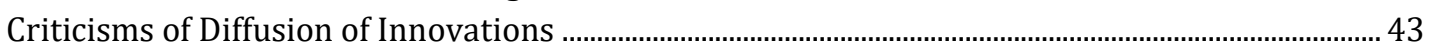

2.5 Social capital and network structure …………………………………………… 45

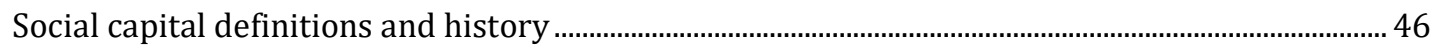

Social network characteristics ...............................................................................................................4 49

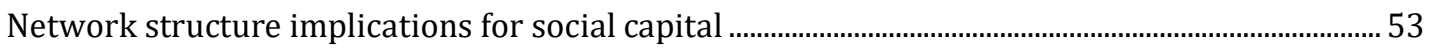

Social capital and small business ................................................................................................................5 55

2.6 Conclusions ....................................................................................................... 57 
3. Research methodology and methods ............................................................... 58

3.1 Introduction ................................................................................................................58

3.2 Theoretical framework and research paradigm.................................................... 58

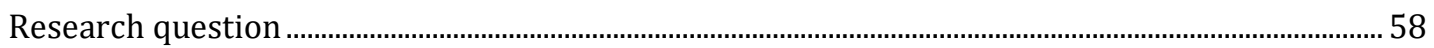

Research paradigm and theoretical perspective................................................................................. 58

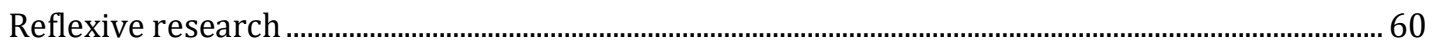

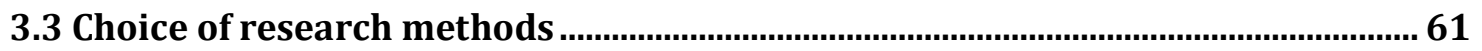

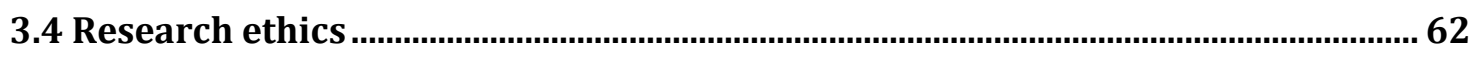

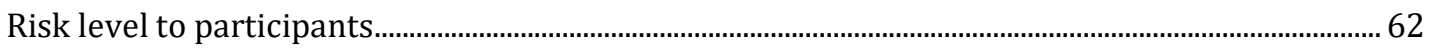

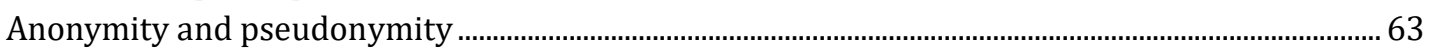

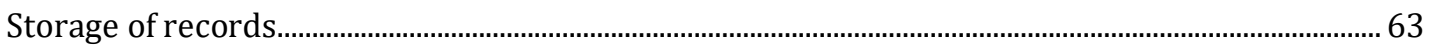

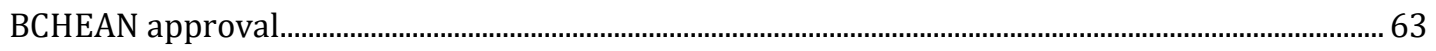

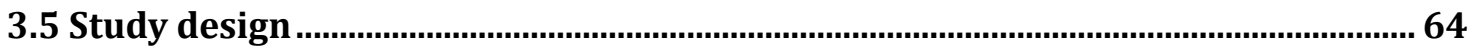

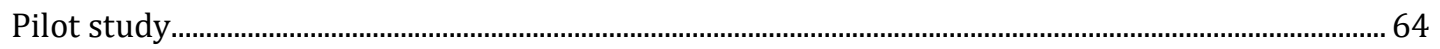

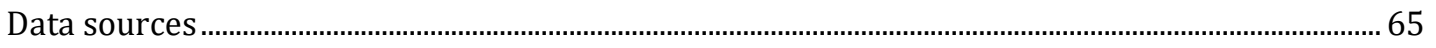

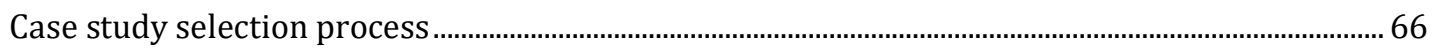

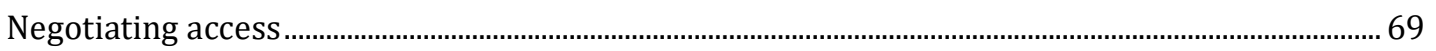

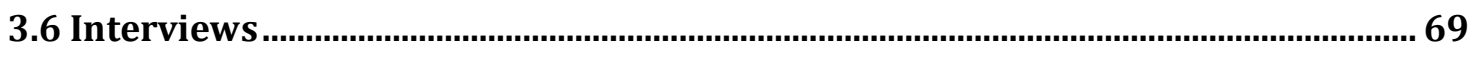

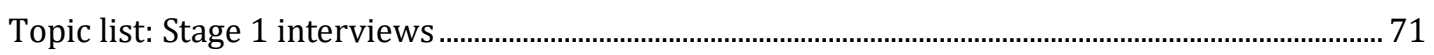

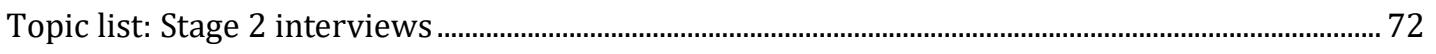

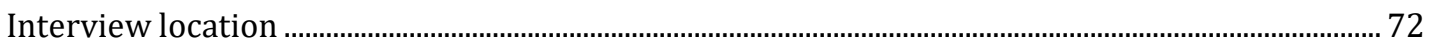

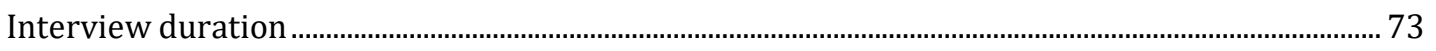

Interview notes and recording methods ............................................................................................ 73

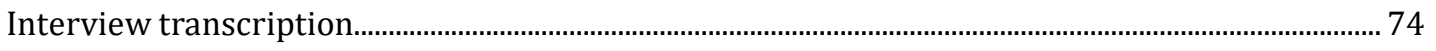

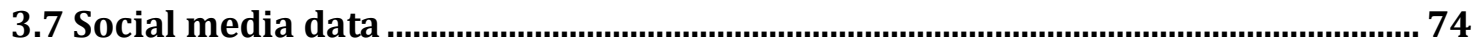

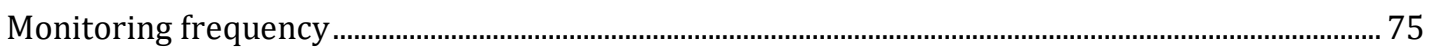

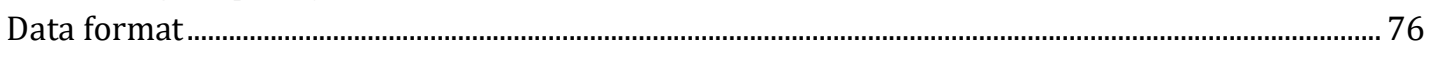

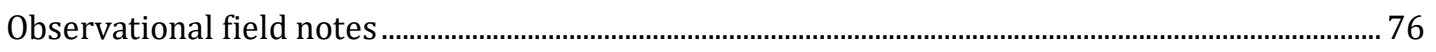

Minimising visibility for online participant observation........................................................................... 77

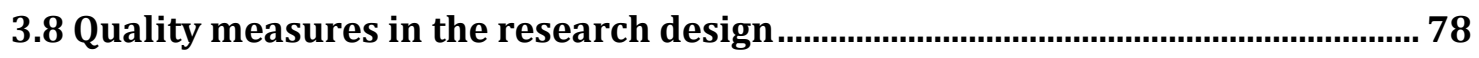

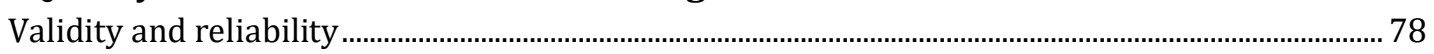

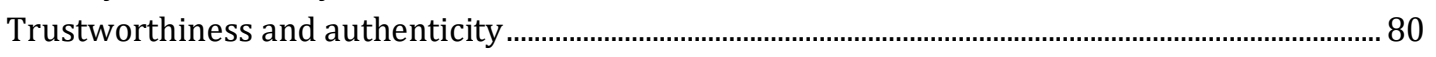

3.9 Computer-assisted qualitative data analysis techniques ........................................... 80

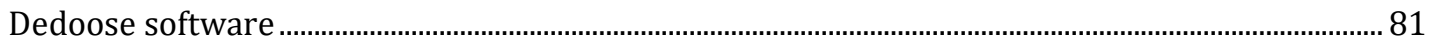

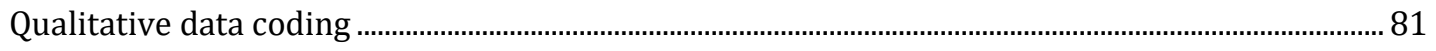

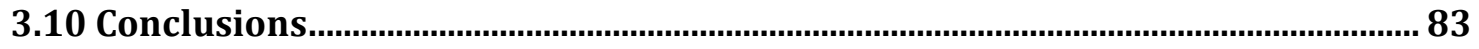

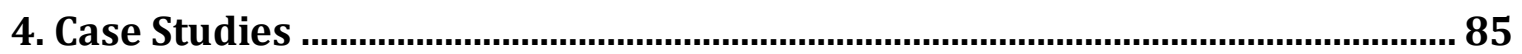

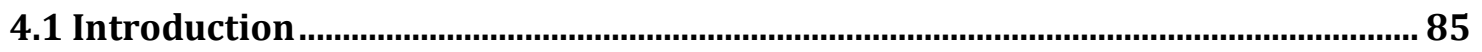

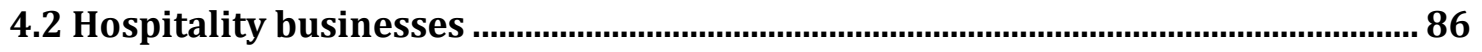

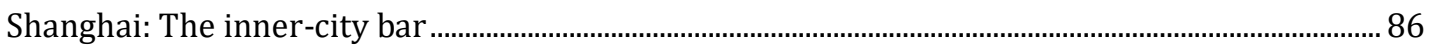

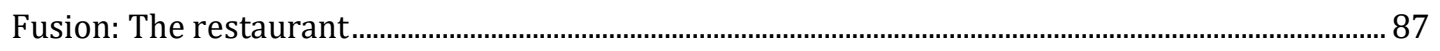

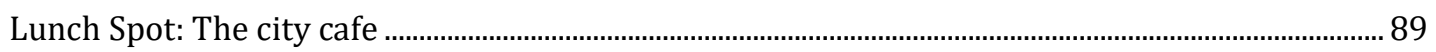

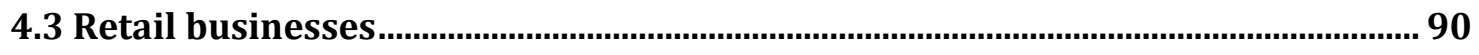

Model Madness: The model store ...................................................................................................... 90

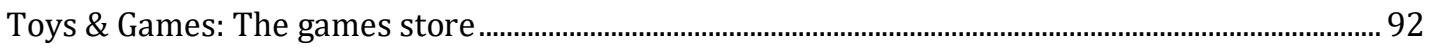

Fashion on Wheels: The cycling accessories store ............................................................................ 94

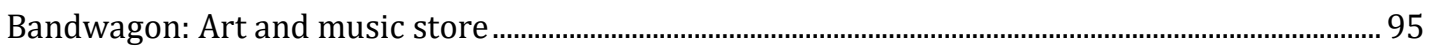

4.4 IT startups 
Videogame Network: The forum builders ............................................................................................98

SocialSearch: The social network archivists......................................................................................100

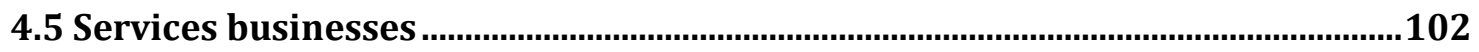

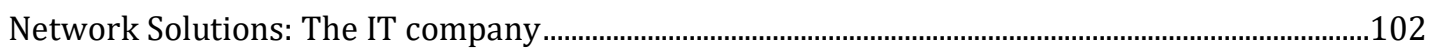

Central PR: The public relations agency .......................................................................................104

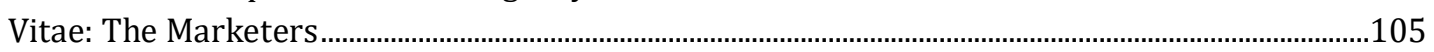

Cover Story: The Freelance Writer .......................................................................................................107

Building Blocks: The Recruiters ……….................................................................................................108

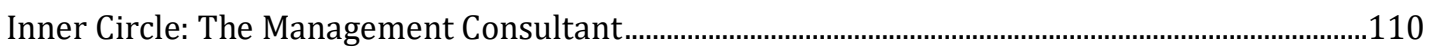

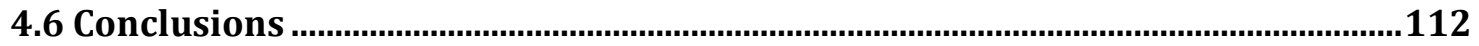

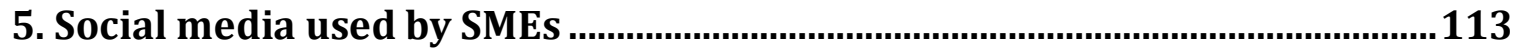

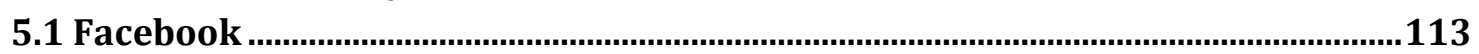

Personal accounts on Facebook........................................................................................................113

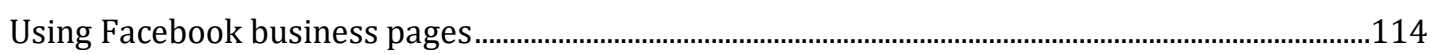

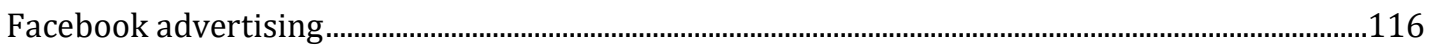

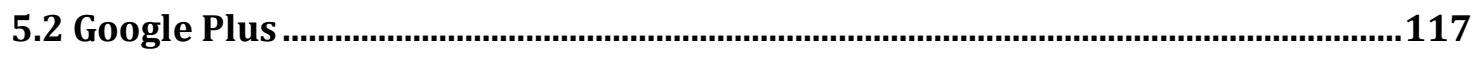

Accessing niche audiences via Google Plus .......................................................................................117

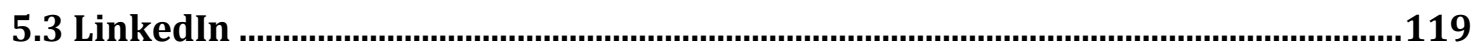

Maintaining professional profiles........................................................................................................19

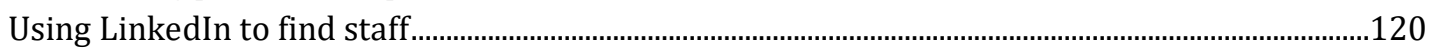

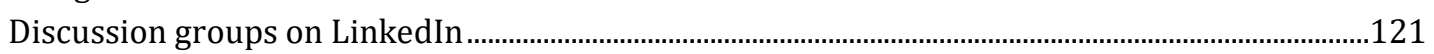

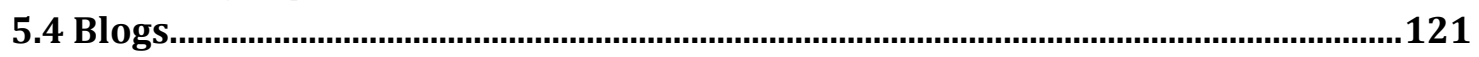

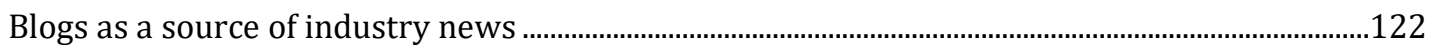

Accessing communities of other bloggers .......................................................................................122

Blog reviews and reputation management .......................................................................................123

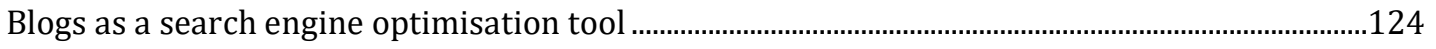

5.5 Twitter

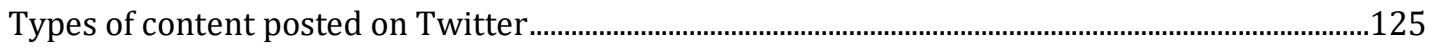

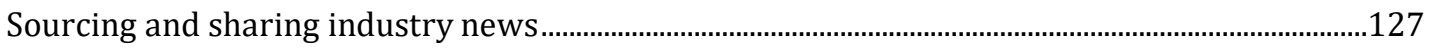

Facilitating introductions and bridging connections ......................................................................128

Conflict between personal and professional Twitter accounts ..............................................................130

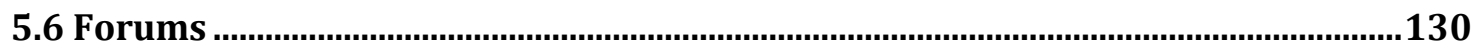

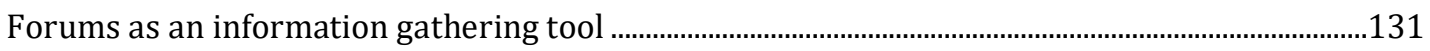

Customer communication via forums...........................................................................................132

Using forums to facilitate networking activities...........................................................................134

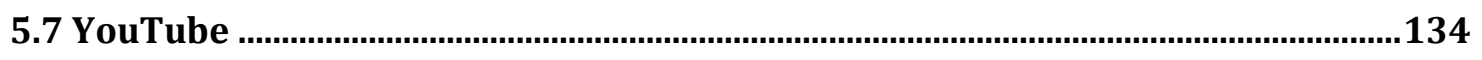

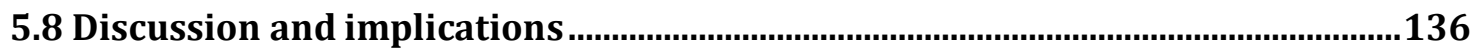

Adoption theme - Perceived low risk ................................................................................................138

Adoption theme: Fear of missing out................................................................................................... 140

Outcome themes: Visibility, insight and social capital.........................................................................141

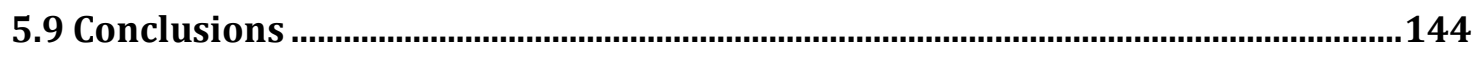

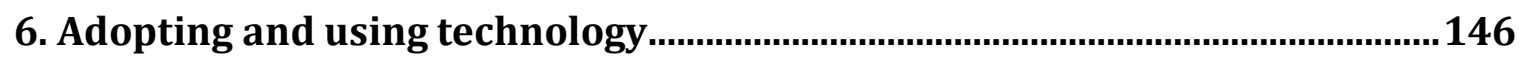

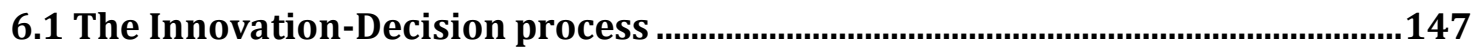

Awareness, technical and principles knowledge.................................................................................147

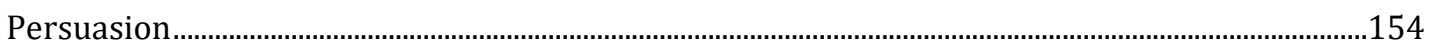

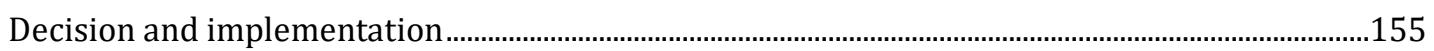

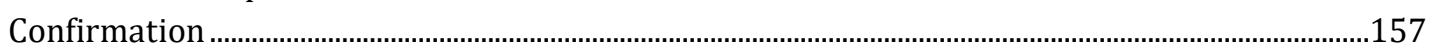

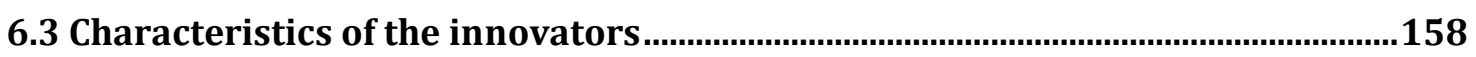




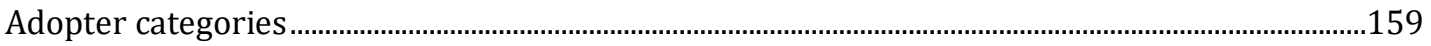

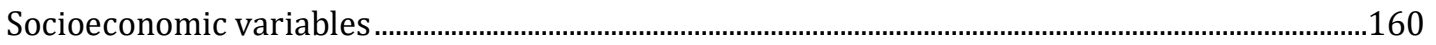

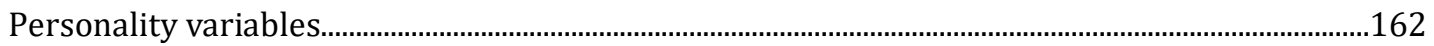

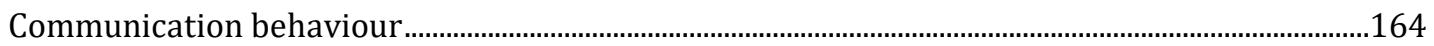

6.4 Characteristics of social media technologies ..................................................... 166

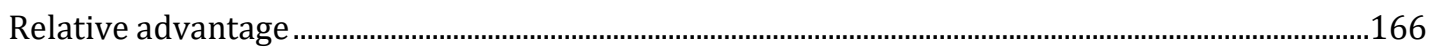

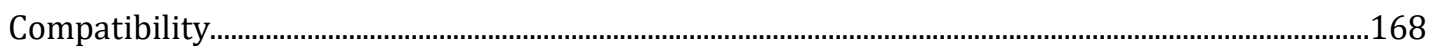

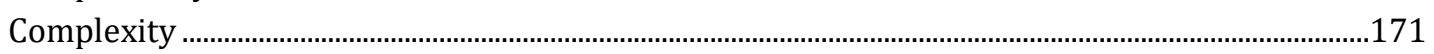

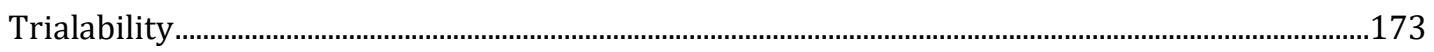

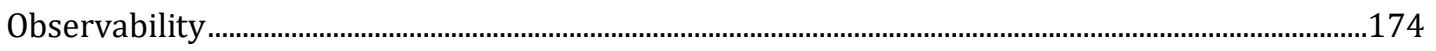

6.5 Conclusions ................................................................................................... 175

7. Building and maintaining social capital ............................................................ 178

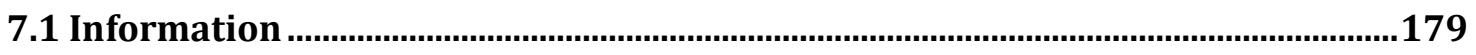

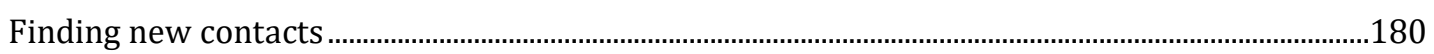

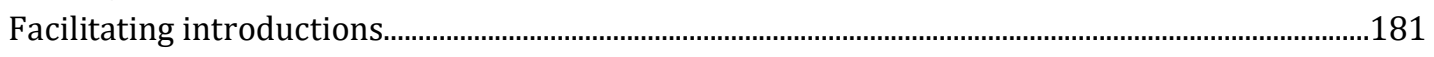

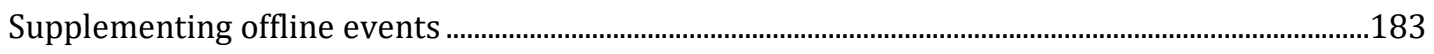

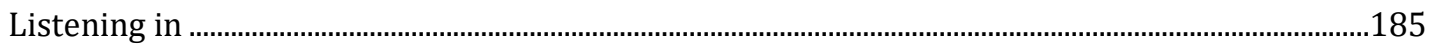

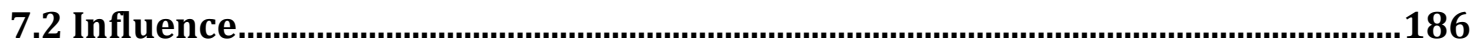

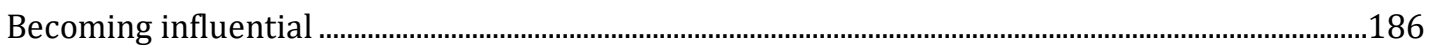

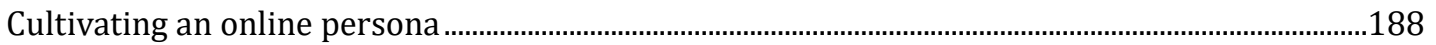

Increasing the visibility of the business...............................................................................................190

7.3 Solidarity.................................................................................................................. 192

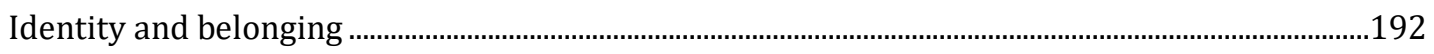

Customer communities ....................................................................................................................................193

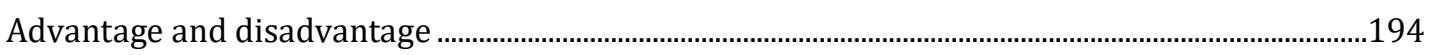

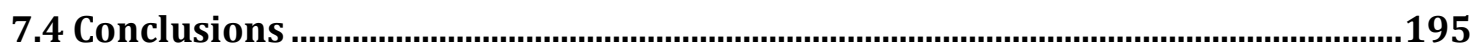

Information outcomes and implications for the fear of missing out ....................................................196

Influence and solidarity outcomes,

and implications for social media use as a low-risk strategy ...............................................................197

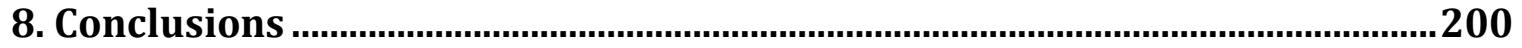

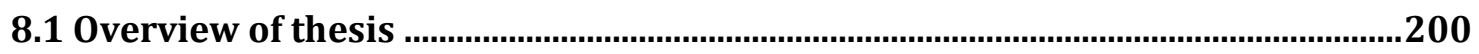

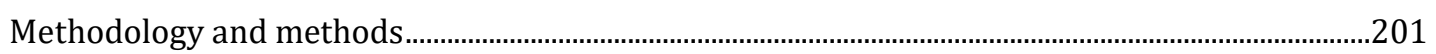

8.2 Social media services and business outcomes ..................................................202

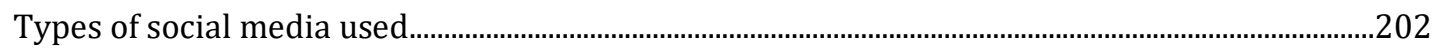

Outcomes derived from social media use: a three-stage model.............................................................204

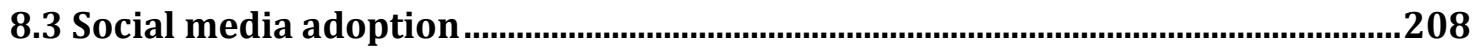

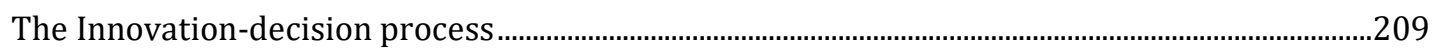

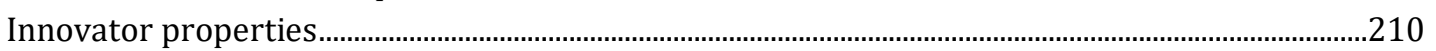

Innovation properties......................................................................................................................................2 212

8.4 Using social media to support networking activities ............................................214

8.5 Implications ................................................................................................................................ 217

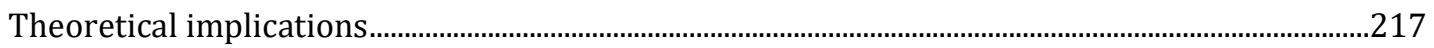

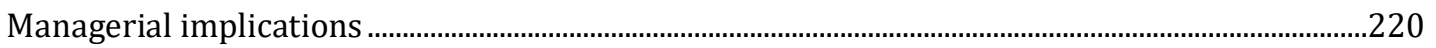

8.6 Future research directions ................................................................................222

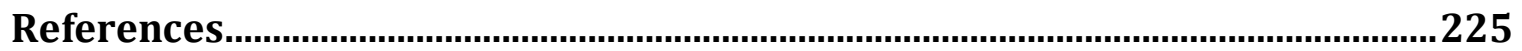

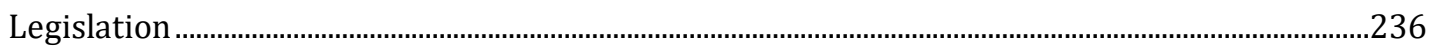




\section{Abstract}

Small business managers face a constantly changing technological environment. Over the past decade, Facebook achieved mainstream adoption and became the dominant social media platform used in Australia, with Twitter and LinkedIn also experiencing rapid uptake among Australian users. Today, there is a constant stream of new social media services, and existing services continue to evolve. These have the potential to help small business managers enhance traditional strengths and mitigate weaknesses, providing a competitive advantage to small, agile businesses that could quickly take advantage of opportunities that these new tools make available.

This research explores the adoption, use, and outcomes of social media services by a group of Australian small businesses. While studies in this area have criticised for overreliance on 'snapshot' studies of technology adoption, I use a series of 15 longitudinal case studies to show how a range of different social media services were and how social media use developed and matured over time, using a combination of qualitative interviewing and online ethnographic research methods.

Participants for this study were selected from the professional services, retail and hospitality sectors in Melbourne, Australia. Management of all companies used a wide range of different social media services for their businesses, including Facebook, Twitter, LinkedIn, Google Plus, YouTube and numerous blogs and forums.

Two key themes driving social media adoption are identified in this study. The first is a fear of missing out as managers see other SMEs seeming to achieve significant benefits from the adoption. The second is the perception of social media use as a low-risk strategy for growth by building relationships and networks of customers, business peers and personal contacts in order to increase the potential reach of their promotions. I also explore the outcomes that managers received from their use of online social networks, in the form of visibility, insight and social capital. I examine the use of online networks to support existing professional networking activities, and the network structures that help business managers to access information, influence and solidarity from their contacts.

Interpersonal relationships and business networks appear to play an important role in discovering and learning to use new social media services. Services adopted during this study were generally first encountered via the managers' social networks and 
contacts. By placing managers in contact with other technology users as they experimented with using these new tools, social media facilitated rapid learning, adoption and - hopefully - set the SME on a strategic growth trajectory.

Managers also used their social networks to strengthen network ties more operationally, becoming embedded within networks of peers and customers. The managers sought to cultivate reputations as influential, knowledgeable and trustworthy thought leaders in their industry; well-connected and actively supported by network members. They relied heavily on social media to stay in regular contact with increasingly larger networks. Over time, this helped to develop the critical mass of "people, discussions and emotion" that Rheingold (1993) describes as the foundation for online community formation. These tactics created networks with higher degrees of closure: a structural requirement for the development of influence and solidarity.

The findings of this study contribute to social capital theory in terms of how new technologies create, or fail to create, social capital for a small business. Managers often began using social media in their business to support their marketing and promotional activity, seeking greater visibility to potential customers. As these networks grow and mature, structural features of these networks such as brokerage and closure (Burt, 2005) also helped the managers gain access to social capital resources in the form of information, influence and solidarity. These provide a broader range of potential outcomes from social media use, and have complex interactions with the key adoption factors that emerge from this research. The 'fear of missing out' is an early adoption driver, fuelled by the public nature of social media use, and by the exposure to information provided by broad, weak-tie contacts via brokerage effects within a network. Greater appreciation of the risks involved, challenging the 'perceived low-risk' adoption factor, comes from interaction with strong-tie contacts. These interactions can use closure effects to provide managers with valuable influence and solidarity, or to present barriers when managers attempt to deal with cliques of customers or peers that possess high in-group solidarity among members.

Interestingly, the data also reveals that some SME have a more strategic approach to social media adoption than others. For some SMEs, their diverse online social networks provided information on industry developments and customer activity, and brokerage opportunities that allowed the managers to gain advantages from this information. 
There are two primary managerial implications of this research. The first is to dispute the perception of social media adoption as a low-risk strategy, due to hidden costs in terms of staff time and knowledge acquisition. The services used in this study all required additional work, in terms of developing principles knowledge and building networks, that was not previously anticipated by the managers. This translated into placing additional demands on the manager's time in order to use these services effectively. The second is that managers should consider a broader range of potential outcomes for their social media use, and plan for these from the outset. In this study, each manager initially viewed social media purely as a marketing and promotional tool, extending their potential reach at a minimal cost compared to traditional advertising. However, social media also provided those managers with a tool for the deliberate cultivation of reputation - both as an individual entrepreneur and for their business. They used their chosen social media services to access insights into customer behaviour, industry trends, and feedback into their product offerings. They also used those services to assist in more efficiently building and maintaining the networks of contacts that made information, influence and solidarity available to them - social capital outcomes derived from the structure and content of their relationships with other users. Wider awareness of these potential outcomes could enable managers to strategically build their networks, producing an asset that delivers greater value for SME's. 


\section{Introduction}

This thesis involves an investigation of small business use of social media, including a review of relevant literature and a series of longitudinal case studies. This chapter introduces the research objectives and methods utilised, and concludes by highlighting the significance of this research and outlining the structure that will be used for the following chapters.

\subsection{Background to research problem}

Social media emerged as a defining feature of the online environment during the shift towards 'Web 2.0'. While the many different social media services offered increasingly sophisticated tools to their users, these services shared a common foundation: using technology to facilitate connections between individuals, allowing them to form or join networks of contacts online. This is a property of immense value to small business managers. It allows SME's to identify niches relevant to their products or services, and to participate in communities of current or potential customers. Beyond this, it allows them to connect with a broader network of support in the form of other business managers and service providers. This provides managers with access to social resources in the form of information, influence, and solidarity among their network contacts.

In many cases, the rapid growth in social media adoption across all kinds of adopters has exceeded the capacity of research institutions and business education programs to identify and acknowledge industry 'best practice' in the adoption and use of social media within organisations. Small businesses are of particular importance in this area. They possess characteristics that can strongly benefit from participation in online social networks, allowing them to compete more effectively with larger organisations. Despite this, small businesses can be among the slowest to adopt new information technology innovations due to issues of resource scarcity in the form of capital, training and access to information. Understanding how small businesses adopt and use social media is therefore an important area of research, capable of producing relevant outcomes for small businesses, business support agencies, and the developers of future technologies aimed at a small business market. 


\section{Motivations/rationale for this research}

This research explores a gap in the literature regarding small business use of social media, contributing longitudinal research focused on the activities and experiences of individual small business managers, and an exploration of the ways that managers adopt such technologies, and use them to access resources in the form of social capital.

Small business use of social media is still a relatively under-researched area (Burgess et al, 2017, p.1) in comparison to consumer or large-firm studies. Social media is still a recent phenomenon (Cesaroni \& Consoli, 2015, p.65), first gaining widespread awareness with the rapid growth of platforms such as Facebook and Twitter during the last decade. By examining the features of small business managers and the social media technologies they choose to use, this research presents a unique perspective into technology adoption among the small business sector.

Previous research into small business use of other information technology innovations has focused heavily on 'adoption factor' studies, informed by theories such as Diffusion of Technologies (Rogers, 2003) and the Technology Acceptance Method (Davis, 1989). My research is informed by these adoption factor studies, but attempts to conduct a deeper exploration of the ways that these technologies are used.

The lack of longitudinal research into small business technology adoption highlighted by Parker \& Castleman (2007, p.33) has prevented a detailed exploration of the effects of "experience, experimentation and intervention by third-parties." While other studies in this field are now beginning to emerge, these typically focus on snapshots of use at a specific moment, via observed use or short interviews. For example, Burgess \& Bingley's (2014) snapshot of Australian SME web presence from 2011-12 used websites, search results and directory listings. Burgess et al. (2015) explored similar themes via questionnaires and interviews with Australian small and micro businesses between 2012-13, revealing widely varying views on the success of social media across SMEs. Similarly, Bosua \& Evans (2017) interviewed regional Australian SME managers in 201315 , providing a snapshot of the use of online social networks at that time. Longitudinal data is a key contribution of my research, allowing for a detailed exploration of the ways that technology use changes over time. Additionally, my use of a multiple case-study approach provides opportunities to explore "how and why" questions (Eisenhardt \& Graebner, 2007, p. 26) regarding the use of social media in small businesses. 


\subsection{Purpose}

The purpose of this research is to provide insight into how Australian small business managers use social media in their organisations. My research focuses on three major areas. Firstly, I present a series of longitudinal case studies providing an exploration of the adoption and use of social media, profiling both the businesses and the capabilities of the social media services available. I also explore two issues that are largely independent of the specific tools used by any given business. The first of these is the process of technology adoption within a small business, given the publicly visible nature of both the tools being used, and the activities of others who were learning or leading behaviour online. Finally, I explore the ways that online social networks provide resources and opportunities to the small business manager as a growth strategy.

By presenting a series of case studies that show how social media use developed and matured among a group of Melbourne small business managers, I explore how different social media services are used to address strategic needs for each business. While the specific details of how any given service is used within each case will not be generalizable across other businesses, insights from this research will provide recommendations that will assist small business managers in assessing and integrating new social media into their own businesses.

Fifteen business owner-managers based in Melbourne, Australia were selected from across four industry types: professional services, retail, IT startups and hospitality. A combination of qualitative interviewing and online ethnographic research methods were used in this research, in order to prepare detailed case studies of each business.

\subsection{Aims and objectives}

\section{Aims}

In this research, I explore a gap in current knowledge regarding how small business managers adopt and use social media services, and how these support the formation and maintenance of interpersonal networks. This will assist other business managers and support organisations to better understand the range of social media services that are being used, and the purposes they are applied to. 


\section{Objectives}

This research explores small business social media use via a series of longitudinal case studies from four industry sectors. These required the identification, selection and recruitment of appropriate businesses from each sector. The case studies combine semistructured interviews with each owner/manager and extensive observations of the manager's social media, following their online activities across a 12-month period. These data have been used to develop case study profiles for each of the businesses in the study. Data analysis will focus on themes relating to social media adoption and use, and the role that social media has played in supporting the networking activities of the managers.

\section{Research question}

How do Australian small business managers adopt and use social media, and what are the outcomes for their businesses?

This question enables a detailed investigation of the use of social media services and the range of business tasks that these were used for. Much of the research into social media has overlooked the rapidly changing nature of these services. I use a series of longitudinal case studies to explore this, combining multiple interviews with ongoing observations of how social media services are used by each manager.

I address the ways in which business managers adopt and integrate new technologies into their businesses by drawing upon the existing body of research into technology adoption among small businesses, particularly focusing on Rogers' (2003) Diffusion of Innovations model. The services used to address small business problems are all relatively new, and there is a constant flow of new technologies becoming available. Understanding the process of adoption and integration is vital to providing ongoing support to SMEs in the future.

I also explore the outcomes that managers received from their use of social media to support networking activities, enabling the development and maintenance of interpersonal networks. I address this question via the lens of social capital theory, examining the structural and relational aspects of each business manager's online network of contacts, and the social capital resources of information, influence and solidarity that these make available to each business. This allows me to examine the 
methods used by managers to find, contact and stay in touch with broad networks of friends, family, business peers and customers.

\section{The importance of small business}

Small businesses play a vital role in the economies of almost all developed economies (Storey, 2010). They serve as key drivers of employment and economic growth, and act as a source of innovation and a 'seedbed' for the development of new industries - a property recognised by the Bolton Committee (1971) in their detailed report on the role of small businesses within the United Kingdom. Further, Storey (2010, p. 307) notes that small firms "in most developed economies are currently more important in terms of contribution to GDP and employment growth than was the case twenty years ago."

Australian small businesses follow these global trends in many respects. In their analysis of statistical data on Australian small businesses, Clark et al. (2011) note that "small businesses make a significant contribution to the Australian economy, accounting for almost half of industry employment and contributing over a third of industry value added in 2009-10." However, there is no universal definition of a 'small business', as category definitions vary by country and industry. Australian small business definitions can be traced back to the Wiltshire Report (Department of Trade and Industry, 1971), which attempted to categorise small business for the federal government. At this time, similar initiatives were underway in other countries - the UK published the Bolton Report (1971) in the same year. The decades that followed saw a rapid growth in both the number of small businesses operating in Australia, and in the recognition of their economic importance (Schaper, 2012).

Businesses are commonly categorised by their annual turnover or number of employees - either as a general count of staff employed by the business, or expressed as number of full-time equivalent staff. An understanding of how these definitions vary is needed to compare studies conducted in different countries. For statistical purposes, the Australian Bureau of Statistics (2001) defines small businesses as those with fewer than 20 employees, with sub-categories for 'micro' businesses employing fewer than 5 staff, and non-employing businesses. In 2001, around 96\% of Australian private sector businesses were included in the small, micro and non-employing sub-categories. Together these businesses employed 3.3 million people, representing $47 \%$ of the total 
non-agricultural private sector workforce (ABS, 2001, p.7). I have focused primarily on micro- and non-employing small businesses for this research.

Similar descriptive categories are used overseas, though the size of businesses in each category varies. New Zealand uses similar definitions to Australia for non-employer, micro and small business (NZMED, 2008). The EU and UK use a larger cut-off point, defining small businesses as those with fewer than 50 FTE staff. Additionally, the EU includes a category for micro firms (fewer than 10 employees), though this category is not used by the UK (European Commission, 2003; Companies Act 2006). In the USA, official small business definitions are complex and vary by industry (Small Business Act 1953), but typically refer to businesses with fewer than 250 employees (US SBA, 2013).

The economic importance of these organisations is not the only factor that makes them valuable candidates for research in the field of technology adoption. Small businesses are often resource-poor, especially in the areas of staff time and expertise. This can force them to innovate and re-purpose existing technologies, as the cost of developing specialised IT solutions may be prohibitive. Their small size can allow them to be extremely agile, able to react to a changing technology environment more easily than larger organisations. Additionally, the opinions of the owner/manager are crucial in determining the actions taken by the business. This allows research focussing on small business owner/managers to draw upon elements from both individual and organisational studies.

Caldeira \& Ward (2003, p.128) note that small businesses are "significantly different from large enterprises, and theory and management frameworks developed for large organisations frequently do not fit." This is a common theme in many recent small business studies, rejecting an earlier trend towards viewing these organisations as smallscale versions of larger firms. Extending this further, Martin (2005, p.191) recommends that the heterogeneity of small businesses should be taken into account, rather than regarding (and researching) them as a single 'sector' - given their wide variation in "location, specific business sector, size and type of operation, together with the managerial and entrepreneurial competency of the key decision makers."

Welsh \& White (1981, p.46) argue that the very size of a small business creates a special condition that distinguishes them from their larger counterparts. They refer to this as resource poverty, and describe three factors in its formation. Firstly, small 
businesses tend to cluster in highly fragmented industries that have many competitors, and are vulnerable to price-cutting. Secondly, the salary of the owner/manager represents a much larger percentage of revenue than in a larger business, leaving little to pay additional managers, reward investors, adequately test or train new staff and pay for professional services. Thirdly, external forces such as changes to tax laws, government regulations or interest rates can affect a greater percentage of revenue than for a larger business. These limitations combine to ensure that few small businesses have an opportunity to survive mistakes or misjudgements. Welsh \& White conclude that owner/management of a small business is a distinct discipline, characterised by "severe constraints on financial resources, a lack of trained personnel, and a short-range management perspective imposed by a volatile competitive environment" (1981, p.58). They note that small companies typically do best with conservative growth rates, and that an effective small business owner/manager must be able to tolerate disorder, switch from one role to the next, and stick to fundamentals: in many respects, a sharp contrast to the levels of specialisation and sophistication required by larger organisations.

\subsection{Research design}

\section{Methodology and Methods}

I have taken an interpretivist approach for this exploratory study, using qualitative methods to develop detailed case studies of small businesses and their owner/managers (Eisenhardt, 1989; Yin 2009). My research explores questions of what social media technologies are being used, how and why they are adopted and used by each business, and how these technologies affect the business and its networks. Saunders et al. (2003, p.93) recommend using case study research in cases where a rich understanding of the context of the research and the processes being enacted is required, enabling questions of 'why' and 'how' to be addressed. I aim to explore small business adoption and use of social media technologies in depth, using a combination of interview and observation methods to provide longitudinal data about the changing use of social media over time.

Online participant observation is a key aspect to this research. Spradley (1980, p. 58) distinguishes between different types of participation based on an individual's degree of involvement. These range from complete non-participation, through passive, moderate, 
active and complete participation, as the degree of involvement increases. For most social media services, true 'non-participant' observation is impossible, as many services require a connection from an individual's account to another profile or account, in order to view or subscribe to posts and updates. Accordingly, my own participation is passive to moderate, on all social media services used by the study participants.

Small businesses are selected from the greater Melbourne area, across the industry sectors of Retail, Hospitality and Professional Services. In order to be eligible for inclusion in this study, businesses must conform to the ABS definitions of Small, Micro or Nonemploying businesses. Additionally, the manager of each business must be currently using at least one form of social media in their business, with the intention of continuing to use social media throughout the study. Full details on the methodology and research methods used in this research are provided in Chapter 3.

\section{Managerial and Theoretical relevance of this study}

This research contributes to theory by exploring the overlap between technology adoption and social capital, in the context of small business adoption and use of social media. I examine the ways in which network structure considerations from social capital theory can affect the drivers for social media adoption, particularly as they generate outcomes that influence the perceived value of these technologies. The high degree of observability and trialability for social media services, both key features of innovations in Rogers' (2003) Diffusion model, are also explored in relation to the effects these have on peer learning, knowledge acquisition and perceived ease of use - factors affecting the innovation-decision process.

Additionally, the research contributes to practice by providing recommendations for more effective use of social media by small business managers. These aim for earlier alignment between practices and outcomes, based on observations of how each business changed their approach during the study period. By raising awareness of a broader range of possible social media objectives relating to customers, peers, information and influence, managers can modify their practices to support these through strategic online network building, and interaction with other social media users. 


\subsection{Organisation of the thesis}

The following chapters of this thesis will use the following format:

In Chapter 2, I examine the history and definition of the label 'social media,' and review the range of technologies that it is applied to. Particular attention is given to the specific examples of social media that have been used by the managers. This chapter also introduces the two theoretical approaches that I have applied: Diffusion of Innovations and social capital. These are covered in more detail during Chapters 6 and 7.

Methodology and methods are the focus of Chapter 3. In this chapter I introduce the combination of concepts and methods drawn from traditional ethnographic research, translated into an online context. This chapter also discusses the longitudinal focus of the study, and how I have used both interviews and participant observation to support this.

The businesses participating in this study are introduced in Chapter 4. Here, an overview of the managers and their businesses are provided for each of the case studies, including a brief introduction to the types of social media used by each.

Chapter 5 explores the social media use of each business in detail. This chapter looks at the social media categories defined in Chapter 2, providing examples of the specific services used by each business manager, and the tasks that these have been used for. This chapter concludes with an overview of the themes inducted from the research data.

Chapter 6 focuses on the adoption of social media by small businesses, examining the applicability of Rogers' (2003) Diffusion of Innovations in this context. This chapter includes a detailed examination of the properties of both technologies and the managers involved in this study, and of the way these properties interact during the innovationdecision process as managers adopt and integrate social media into their businesses.

Chapter 7 explores the ways managers use social media to support their business networking activities, helping them to access information, influence and solidarity: three resources encompassed by the concept of social capital. This chapter focuses on the role of structural network elements in the generation of social capital.

Finally, Chapter 8 contains my conclusions from this research. These include implications for business managers and the contribution this thesis makes to theory. The chapter concludes with future directions for research in this rapidly evolving field. 


\section{Literature}

This chapter covers four major areas. It begins with a review of literature covering small businesses and technology adoption, from internet use to social media. Following this are more detailed reviews of social media, and the two theoretical lenses that are used in later chapters: diffusion of innovations and social capital.

\subsection{Small businesses and technology adoption}

\section{Small businesses and the internet}

Internet technologies have long been recognised as offering many potential benefits for small businesses. For example, Poon \& Swatman $(1997 ; 1999)$ explored issues relating to internet adoption and new market opportunities for Australian small businesses, long before the creation of the social media services described in this research. In his study of eCommerce use among several Australian SME's, Chau (2003, p.59) lists a number of areas where small businesses could potentially reduce their costs by using e-commerce, including "communications, publishing, marketing, product demonstrations, production costs, supply chain costs and product delivery"; noting that a common cost saving was in the area of internal and external communications. For specialist firms, the internet may allow then to access niche markets that would be unviable on a local scale.

These are not without risk, however: many applications require specialist knowledge to set up effectively, and can require transformative changes in business operations in order to use them to their potential. This is particularly relevant when examining the adoption of social media technologies, as they can place demands on the business to respond to queries with greater immediacy or out of standard business hours, and may require a greater degree of transparency when previously 'hidden' aspects of the business are placed on public display. A wide range of technological, environmental and organisational factors may affect the adoption of these technologies, such as manager preconceptions, IT knowledge, financial and staffing resources, and the presence of peers or industry-specific groups using social media in the business' operating environment (Calli \& Clark, 2015). 


\section{Small businesses and social networks}

Social networks are vital to small business as they can allow a resource-poor firm to compensate for a lack of other resources (BarNir \& Smith, 2002). For this study, I define a participant's network as the individuals who provide business information to the participant, following Frazier \& Niehm's (2004) research into off-line business networks. These include both formal and informal networks. Formal businesses networks may be formed through industry associations or a local chamber of commerce. Informal networks might include friends, family and clients. Small business research (Frazier \& Niehm, 2004; Gibbs et al., 2007; Frazier \& Huddleston, 2009) suggests that small business owners rely heavily on these informal networks to gather information on their customers, competitors and suppliers. They also use these networks to discover and learn about new technologies.

Malecki \& Veldhoen (1993) described how contact networks can provide a vital competitive advantage to small firms, particularly in terms of providing access to information via the dense networks of connections with other small firms. While their research focused on small American manufacturing firms in a period before social media platforms were available, the study still provides important insight into the role of information access in small firm competitiveness. Access to this information resource is directly enhanced by the involvement of small business managers in the social media networks that I explore in my own research.

Durkin, McGowan \& McKeown (2013) examine the important role that personal contact networks play for small businesses, focusing on the role that these play in maintaining relationships between an SME and its customer base. These networks form a key resource for small businesses. With the advent of social media, the way that contacts are "found, fostered and maintained" (p.718) has changed - presenting managers with a new set of opportunities and challenges.

\section{Business adoption of internet technologies}

The closest parallel to small business use of social media is the wealth of studies into small business adoption of 'Web1.0' technologies such as email, websites and online payment systems. These include exploratory research into small business internet use (Poon \& Swatman, 1997; Poon, 1999; Dandridge \& Levenburg, 2000), case studies 
(Mehrtens et al., 2001), and explanatory studies developing and testing theories of internet and e-commerce adoption (Grandon \& Pearson, 2004; Al-Qirim, 2007). The overwhelming majority of these studies have examined factors affecting the adoption of IT by individuals and organisations. However, relatively few studies have focused specifically on the use of social media by small business managers, and the effects that access to online social networks have on these businesses and their managers.

In Australia, both Sensis and MYOB conduct regular studies characterising small business behaviour, sending out quarterly surveys to large numbers of small and medium businesses. However, reports available at the beginning of the study were of an extremely general nature, and of limited relevance to research into social media usage: the Sensis Business Index defined its primary objectives as "tracking business activity, performance and overall confidence" (Sensis, 2009). The MYOB Business Monitor had a similarly broad scope, examining "perceptions of business performance, business revenue, staffing issues, and perceptions of State and Federal government performance in contributing to Australian small business" (MYOB Technology, 2014).

Sensis also conduct an annual e-Business survey, specifically focussed upon online activity. However, during the study period for my research the e-Business reports also used very broad categories to define business internet use, such as "communicating via email" and "using a website to advertise or promote business" (Sensis, 2008, p.13). Additionally, the nature of these surveys precludes them from exploring questions of why technologies are chosen, and how they are used. Sensis reports only began to regularly examine the social media use of Australians towards with the launch of the first Yellow Social Media Report in 2011 (Sensis, 2011).

An early Australian study (Poon \& Swatman 1997, Poon 1999) conducted exploratory research into how Australian small and medium businesses were using the internet. The study combined quantitative (mailed survey forms) and qualitative (semi-structured interviews and site visits) methods, and found that small business use of the internet was at a formative state. Business managers were optimistic about the potential benefits of using the internet, but mostly viewed it as a way to enhance existing processes such as business-customer communications. There was a general lack of integration between internal systems and business websites, and almost no widely adopted mechanism for conducting financial transactions on the internet. Their study is of interest as it parallels 
some aspects of my own: at the time of Poon \& Swatman's research, internet adoption was at a similar stage of development to the social media environment observed during my own research.

Poon \& Swatman (1998) also published a longitudinal study of the adoption and ongoing use of eCommerce in small business, exploring changing expectations of eCommerce among Australian small businesses during 1995 and 1997. In both cases, they noted that micro-sized businesses were the most active participants - refuting earlier predictions that these firms would be unlikely to reap any significant benefit from using the internet. Instead, micro firms were using the internet's global connectivity to take advantage of previously unviable niche markets. During the study, Poon \& Swatman (1998) found that use of the internet had helped to achieve better customer relationships, but that relationships with suppliers were largely unchanged. A business web presence had changed from a potential advantage to a competitive necessity, and firms conducting business online began to regard the internet as integral to their business strategy.

A later study by Chau (2003) examined the theory and practice of e-business systems among small and medium firms in Tasmania and Western Australia, aiming to shed light on the differences between SMEs and larger organisations. Chau developed qualitative case studies of 34 businesses, discovering six major types of eCommerce activity: electronic banking, sales \& marketing, communications, customer service, cost reduction, and substantial change to existing business processes. This with earlier studies that had shown eCommerce was largely restricted to communications, concluding that "the potential benefits derived from eCommerce increase where businesses engage in a process of business transformation" (Chau, 2003, p.63).

More recently, Burgess \& Bingley (2014) present a snapshot of social media use and the web presences of Australian small businesses from 2011-12. They found minimal social media activity taking place directly on the websites of each small business, but a much greater potential for activity on third-party websites such as social media platforms and online directories.

Burgess et al (2015) interviewed Australian small business managers from Melbourne, Coffs Harbour and the Gold Coast during 2012-13, exploring the methods of social media engagement used by each business. They noted similar themes of resource poverty to those discussed previously (e.g. BarNir \& Smith, 2002; Malecki \& Veldhoen, 
1993), suggesting that Australian small businesses used social media at lower levels than larger firms, and that when this usage did occur, it varied significantly between small businesses and across different industry sectors.

Bosua \& Evans (2017) interviewed managers of rural Australian SMEs in Victoria and South Australia, focusing on the knowledge-sharing activities and social capital development via the use of social media platforms such as Facebook, Twitter and YouTube. While the challenge of physical distance from other network members are particularly acute for rural business managers, this is also applicable to any businesses that operate in narrow industry niches. Bosua \& Evans identified three levels of social networking usage that impact the development of social capital among business managers, describing several cases of 'marginal' and 'active' use that parallel the experiences of managers in my own research. I discuss the implications for social capital development in more detail in Chapter 7.

Finally, Burgess et al (2017) apply an Innovation Diffusion approach to examining social media adoption among small businesses, in their study of Australian regional and metropolitan businesses using Facebook, Twitter and YouTube. Their study explores similar themes to my own, particularly in terms of the Innovation Decision process (Rogers, 2003) and the facilitators and inhibitors of social media adoption among business managers (Burgess et al, 2017, p.18). I discuss the implications for my own research in Chapter 6.

\section{Meta-analyses and literature reviews}

Research in the areas of internet marketing and internet technology adoption has rapidly grown since the late 1980s, although the majority of studies have been published from the mid 1990s onwards, when access to the World Wide Web became commonplace. Reviews and meta-analyses of this literature are discussed here.

Ngai (2003) reviewed and classified 270 internet marketing articles published between 1987 and 2000. These were published across three areas: economics, business \& management; marketing, and information technology. The overwhelming majority of these articles were published after 1996. Analysis of these studies revealed a fragmented body of work, with three major themes emerging by the end of the sampling period: management, planning and strategy; consumer behaviour, and channels of distribution (Ngai, 2003, p.36). 
Premkumar (2003) conducted a meta-analysis of Information Systems research on IT implementation in small business, identifying a number of key factors affecting technology adoption. The variables providing the most consistent results were perceived usefulness, compatibility, ease of use, cost, top management support, competitive advantage and business size. These were empirically tested using a series of telephone interview with 207 small firms, selected randomly from a directory of businesses in the Midwestern United States. Premkumar noted that the most significant variables were competitive advantage and top management support. Communications technologies were seen as interdependent innovations, relying upon a firm's business partners to also adopt the innovation: increasing the utility of the innovation as more people adopt it (Premkumar, 2003, p.114) - a finding of particular relevance to social media during my fieldwork, as social media platforms such as Facebook and Twitter achieved mainstream adoption. Top management support was considered critical in small business technology adoption, as the business owner is the primary decision maker.

Premkumar's meta-analysis was later criticised by Teo et al. (2004) for limiting its focus to IS journals, and therefore not capitalising on findings presented in prominent small business journals outside the IS discipline. In their own meta-analysis of factors affecting eCommerce adoption by SMEs, Teo et al. identified areas that they consider to be adequately studied in the literature, in order to provide suggestions for new research directions. They concluded that the factors affecting technology adoption are highly complex, and that existing studies often produce contrasting results when examining the relationships between individual factors on a micro scale. They also found that a large body of research focuses on initial SME eCommerce adoption decisions, with little research into how these businesses continued to adopt technology beyond this stage.

In another review of early (pre-2000) research, Jeyaraj et al. (2006) reviewed 99 studies on individual and organisational IT adoption, published between 1992 and 2003. Common theories used by these studies include the Technology Acceptance Model (TAM) and Diffusion of Innovations (DoI), though DoI is considered the more valuable of the two for its applicability to both individual and organisational studies. This review examined potential research biases in existing adoption studies, highlighting a need for studies of actual system use to overcome self-reporting bias. They found that the best predictors for IT adoption include perceived usefulness, top management support, computer 
experience, behavioural intention and user support, at the individual level. At the organisational level, top management support, external pressure, the professionalism of the IS unit and external information sources are considered the best predictors of technology adoption. However, other researchers such as Parker \& Castleman (2007, p.22) warn that such meta-analyses of adoption factors may perpetuate the tendency to focus only on adoption factor research in the literature.

Simmons et al. (2008) focused on the adoption of websites by small businesses, reviewing the determinant factors of website adoption, and examining the role of internet marketing among small businesses. They argue that "marketing, in the small business context, will constitute an important influence on small business website adoption along with more generic website adoption determinants relevant to businesses large and small" (Simmons et al., 2008, p.353).

Dahnil et al (2014) briefly reviewed the literature on social media marketing adoption factors among SMEs, finding similar themes to the studies on website, eCommerce and organisational IT adoption described above. Of particular relevance to my research is their summary of adoption factors (pp.123-124), categorising these as End User, Organisational, Technological, Management and Business Environment aspects. The perceived competitive advantage of using social media is an important environmental factor, enhanced by the visible presence of competitors using these services.

Parker \& Castleman (2007) proposed a number of new directions for research on SME-eBusiness, based on their analysis of journal articles from 2003 - 2006. Small businesses are often treated as a homogenous group in the literature (Calli \& Clark, 2015, p.59), and work exploring their heterogeneity could explore their differences in strategic focus, social network participation, and owner attitude towards new technologies. In particular, Parker \& Castleman identified a need for more detailed examination of the internal and external parties that business managers trust for business advice, support and services. Two shortcomings common to most existing studies include a lack of longitudinal data seen as essential for "understanding the effect of experience, experimentation and intervention by third parties" (Parker \& Castleman, 2007, p.33), and the need for data collection methods that include observation of actual use, rather than relying upon participant recall and perceptions of use. 
Both of these considerations have shaped my own research design. As I will describe in the following section, longitudinal data collected via observation of social media use is central to my research, allowing me to present findings that directly address these shortcomings in prior research on this topic.

\subsection{Social Media introduction}

This section introduces the concept of social media, including a brief history of the term. I then describe the range of technologies that were used by the small business managers, giving examples of the most popular services in each category.

The range of available social media services is in constant flux. New services launch, and older services are discontinued or integrated into other products. The range of features incorporated into each service will also continue to change over time, as each social media service evolves according to changing business or user needs. This chapter explores the major social media services available during the 2010 - 2012 period of field research, and the major features of each service. It is highly likely that following the publication of this research, many of these services will be discontinued or significantly change the features that were available. This chapter documents the state of play during the study, in order to provide context for this research.

It is important to note the ways in which my research context shapes the view of social media presented here. This study focuses on small business managers, and the social media services they use for promotion and participation in networks of their peers and customers. Within that scope, there are many different services. However, this view also excludes a number of social web technologies that could otherwise be considered. For example, these businesses have little use for enterprise social networking tools, due to the small number of employees who would use them. Similarly, wikis and other collaboration tools were not used in this context. Many of these services are included on the timeline of that appears later in this chapter, to provide context, but they have not been considered in detail within the scope of this research.

\section{What is social media?}

'Social media' technologies have evolved into a mainstream phenomenon over the past five years. They can be highly disruptive innovations, changing the way in which 
businesses communicate with their customers and suppliers. They are interactive, facilitating two-way communication. They also facilitate communication with social networks of friends, advisors and peers.

Bruns and Bahnisch (2009, p.5) define social media as "websites which build on Web2.0 technologies to provide space for in-depth interaction, community formation, and the tackling of collaborative projects." The 'Web2.0' label encompasses technologies such as social networking, podcasting and blogs. The term has been widely used to describe user-generated content since 2005, although some of these technologies have been in use since the late 1990s. O'Reilly (2006) defined Web2.0 as "a platform where applications harness network effects, to get better the more people use them."

Implicit in these definitions is a social component: the combination of Web2.0 technologies and community interaction is a defining characteristic of social media. Without the engagement and involvement of an online community, services that rely upon user-generated content quickly become virtual ghost towns. To this end, many studies have been conducted into the mechanisms that help online communities to form and function. In his seminal work into virtual communities, Rheingold (1993) provided a broad definition of online community as a social aggregation that emerges from the internet, when "enough people carry on those public discussions long enough, with sufficient human feeling, to form webs of personal relationships in cyberspace". Each of the social media types explored in this chapter relies upon clusters of users interacting with each other. Though the processes differ, elements of online community are central to the effective function of all of these services.

Major social media providers such as Facebook and Twitter position their services as 'platforms' - a term that can carry many meanings (Gillespie, 2010), from technical architecture to figurative or political metaphors. For this research, I focus on social media as a service, made available by software, with content and virtual environments that are jointly constructed by the software and the users of that service. This aligns with the concept of social media services as mediators of social interaction (van Dijk, 2013), viewing the role of these services as actively shaping interaction, rather than merely facilitating connections between users. 


\section{Social media in Australia}

In 2007, Australia lagged behind countries such as the US and UK in its uptake of social network services like Facebook, though it was beginning to catch up on adoption of MySpace and services such as the online photo storage Photobucket (Future Exploration Network, 2007). By the beginning of this study in 2009, this trend had reversed, with Australian users rapidly adopting social media. In January 2010, Nielsenwire (2010) reported that Australians now spent more time on social networks than any other country, averaging six hours and 52 minutes a month, per individual - over 40 minutes per month more than our closest rivals, the USA and UK.

What triggered such a dramatic change? A key driver of social media uptake is access, both to technology and networks of users. During this period, Internet-capable mobile devices became far more widely used in Australia. At the beginning of the $2010,41 \%$ of Australians used their mobile phones to access the internet - a sudden increase from only $26 \%$ in the previous year (Sensis, 2010, p.20). The availability and relative affordability of internet-capable mobile devices gave people the ability to use social media while on the move. This increased the relevance and perceived usefulness of geolocation services and status updates on social networks and micro-blogs, allowing these to become a part of everyday life, rather than an adjunct to it.

Dawson (2010) suggests a number of cultural and economic reasons why our initial uptake of social media may have been hampered, including attitudes about the individual, the advent of Twitter and 'conversational' media, cultural adaptiveness, corporate risk aversion, mobile data affordability, and the broad geographic dispersion of our population - both within Australia and around the globe. The effects of this dispersion may also contribute to our stronger late adoption of technology. In their study of internet use by the Australian diaspora, Fullilove \& Flutter (2004) described this group as prosperous, well-educated, well connected, and making up almost $5 \%$ of our total population. These individuals are well positioned for exposure to new technology trends around the world, and they can adopt these to more easily communicate with friends, relatives and colleagues at home. The effects of this type of adoption would be expected to show a natural lag before reaching mainstream adoption back in Australia, as the uptake of these technologies is limited by local constraints on hardware availability, internet speed and affordability. 
The annual Yellow Social Media Report began to examine the social media use of Australians in 2011. The first of these reports showed that $62 \%$ of Australian internet users were active on one or more social media platforms, though only $14 \%$ of small businesses had a social media presence (Sensis, 2011b, p. 30). This figure remained fairly stable throughout the study. However, the frequency of social media use continued to rise - with a steady increase in the number of people using social media on a daily basis, as shown in the graph below.

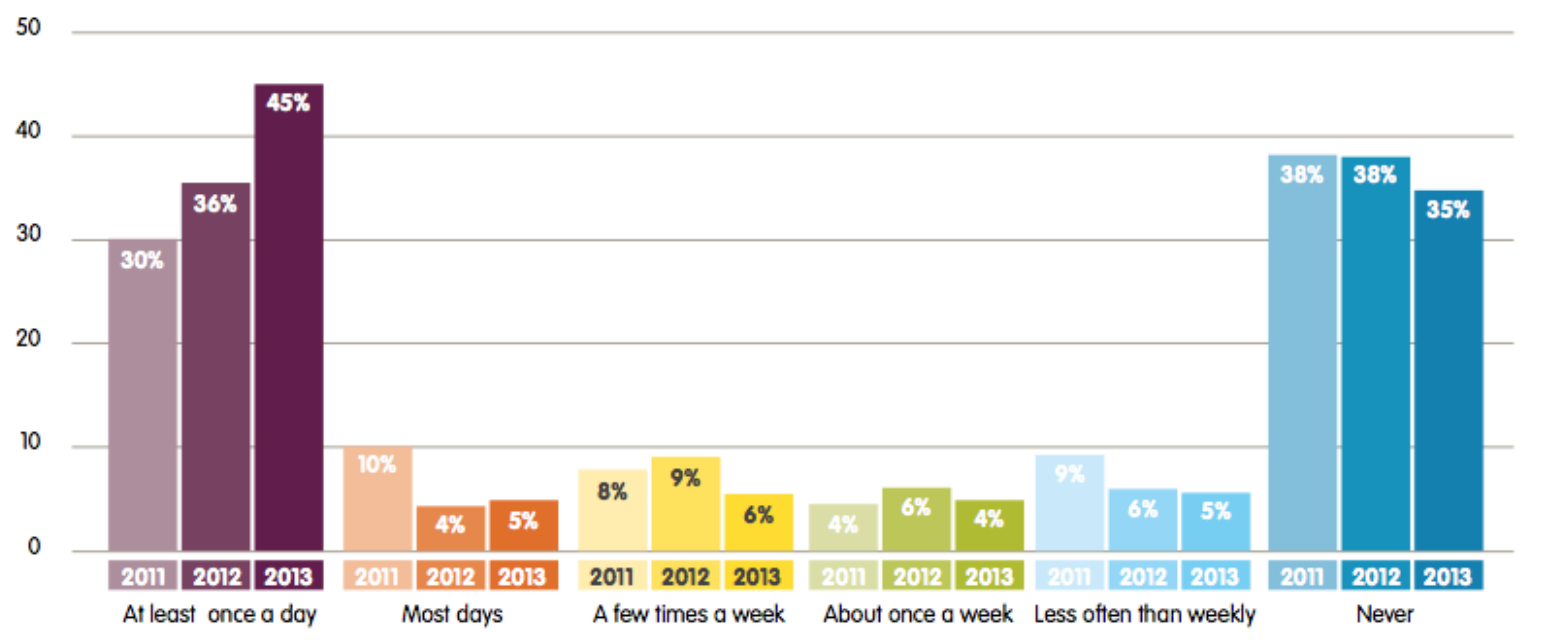

Image: "Frequency of Australians using social media - trends" (Sensis, 2013b, p. 9)

\section{Social media and small business}

A study by Lee, DeWester and Park (2008) examined the range of Web2.0 services that were available immediately prior to the start of this research, and the opportunities that these services created for small business. They saw the potential for Web2.0 technologies to assist small business in "developing new products and services, offering better support for existing products and services, increasing sales, increasing customer satisfaction, and attracting new customers" (Lee et al., 2008, p. 36). Small business managers can use social media to interact with their customers, gather business information and develop networks with support organisations and other businesses.

Maintaining a business social media presence is an ongoing task that combines elements of customer service, communications, marketing and public relations. In a larger organisation, responsibility for these roles is often scattered across multiple departments. This can cause social media adoption to be a disruptive change, requiring intensive collaboration between departments. In small and micro businesses these public-facing roles are frequently the responsibility of a single employee, and roles may 
not be so rigidly defined. For these reasons, small businesses have the potential to reduce many of the disruptive effects associated with social media adoption. This may allow these businesses to more readily adopt these new technologies.

Since 1995, the Yellow Pages Small Business Index and Sensis eBusiness reports have tracked the adoption of internet technologies by Australian small businesses. Examples of these include Yellow Pages (1995) and Sensis (2010; 2011a, 2012a; 2013a). These provide valuable context to my research. At the beginning of the study, data on social media in business was limited to questions such as whether a business allowed employees to use social networking sites while at work; whether the respondent used social media for business purposes, and broad categories of social media use. These help to understand how social media has been used, but raise additional questions. How and why do small business managers select the social media their organisation will use? To what extent do the uses of these evolve over time, rather than being strategically selected at an earlier stage? How do businesses benefit from their connections to customers and business peers? These are areas that I explore in my own research.

Only $8 \%$ of Australian small businesses used social media for business purposes at the beginning of this study (Sensis, 2010). This number increased dramatically during the study period, with $26 \%$ of small businesses on social media by the end of the study (Sensis, 2012a), rising further to 35\% in the following year (Sensis, 2013a).

Business use of social media closely paralleled their uptake of internet-enabled phones, showing a similar trend to that displayed by individuals. In $2010,62 \%$ of small businesses owned a phone with internet access (Sensis, 2010a). By the end of the study, this had risen to $67 \%$ (Sensis, 2013a). Mobile access and an abundance of social networking applications allowed smartphones to play a major role in this. Apple's iPhone dominated the Australian smartphone market throughout the study, and Apple's iOS remained the most popular operating system in Australia until being overtaken by Android in late 2012 (Telsyte, 2012). Both Apple and Android phones typically include a suite of features and applications designed to harness the social web, such as web browsers, dedicated social networking software, cameras and GPS. As later chapters will discuss, mobile access to social media was an important trigger for its adoption by the managers. As the following figure shows, small business social media adoption has continued to grow. 


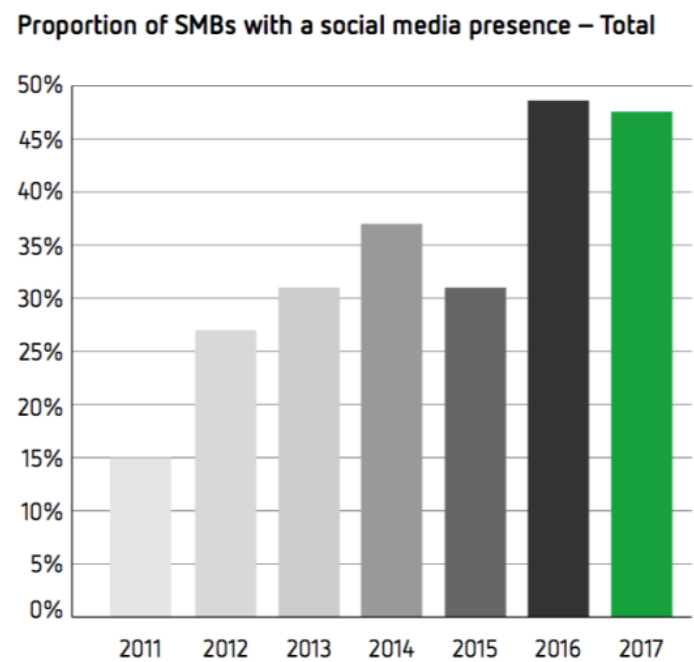

Image: "Proportion of SMBs with a social media presence" (Sensis, 2017b, p. 11)

\section{Timeline of major developments in social media}

The following timeline is modified and updated from boyd and Ellison (2007). It is not intended as a comprehensive list of all 'social' technology platforms. Instead, it gives an overview of when important developments were made, focussing on the major services that were used by small business managers (shown in bold), the precursors that led to them, and other major platforms that launched before the end of the study. 


\begin{tabular}{|c|c|c|c|}
\hline Year & Month & Title & Type \\
\hline $\begin{array}{l}\text { 1960s- } \\
\text { 1990s }\end{array}$ & & $\overline{B B S}$ & Bulletin board \\
\hline $\begin{array}{l}\text { Mid } \\
\text { 1990s }\end{array}$ & & Early web forums & Forum \\
\hline 1997 & & SixDegrees.com & SNS \\
\hline \multirow[t]{4}{*}{1999} & April & Livejournal & Blog \\
\hline & May & WordPress & Blog \\
\hline & July & Pbase & Photo sharing \\
\hline & August & Blogger & Blog \\
\hline 2000 & & (SixDegrees closes) & SNS \\
\hline 2001 & July & BitTorrent released & File sharing \\
\hline \multirow[t]{3}{*}{2002} & March & Last.FM & Net radio/SNS \\
\hline & March & Friendster & SNS \\
\hline & May & Fotolog & Photo blog \\
\hline \multirow[t]{7}{*}{2003} & & tribe.net & SNS \\
\hline & May & LinkedIn & PNS \\
\hline & June & Hi5 & SNS/social gaming site \\
\hline & August & MySpace & SNS \\
\hline & September & Delicious & Social bookmarking \\
\hline & November & XING & PNS \\
\hline & & Photobucket & Image sharing \\
\hline \multirow[t]{9}{*}{2004} & January & CouchSurfing & Hospitality \\
\hline & January & Orkut & SNS \\
\hline & February & Flickr & Image sharing \\
\hline & February & Facebook (Harvard only) & SNS \\
\hline & May & Viadeo & PNS \\
\hline & & Dodgeball & Geolocation \\
\hline & October & Yelp & Business ratings and reviews \\
\hline & November & Vimeo & Video sharing \\
\hline & December & Digg & Social bookmarking \\
\hline \multirow[t]{7}{*}{2005} & January & BeBo (launch) & SNS \\
\hline & February & YouTube (launch) & Video hosting \\
\hline & March & Yahoo! $360^{\circ}$ (launch) & SNS \\
\hline & March & Dailymotion (launch) & Video hosting \\
\hline & June & Etsy (launch) & Marketplace \\
\hline & September & Facebook (high school launch) & SNS \\
\hline & October & Ning (launch) & Wiki \\
\hline
\end{tabular}




\begin{tabular}{|c|c|c|c|}
\hline & October & Google Reader (launch) & Blog RSS aggregator \\
\hline \multirow[t]{3}{*}{2006} & June & Google Picasa (launch) & Image sharing \\
\hline & July & Twitter (launch) & Microblog \\
\hline & September & Facebook (public launch) & SNS \\
\hline \multirow[t]{3}{*}{2007} & March & Tumblr (launch) & Microblog/SNS \\
\hline & March & uStream (launch) & Video streaming \\
\hline & November & Facebook (business pages) & SNS \\
\hline \multirow[t]{5}{*}{2008} & March & BeBo (acquired by AOL) & SNS \\
\hline & June & Dreamwidth (launch) & Blog \\
\hline & July & Posterous (launch) & Blog \\
\hline & September & Yammer Enterprise (launch) & Microblog \\
\hline & November & Groupon USA (launch) & Social coupon \\
\hline \multirow[t]{2}{*}{2009} & March & Foursquare (launch) & Geolocation \\
\hline & November & Formspring (launch) & Social Q\&A \\
\hline \multirow[t]{4}{*}{2010} & February & Google Buzz (launch) & SNS/microblogging \\
\hline & March & Pinterest (launch) & Social bookmarking \\
\hline & August & Facebook Places (launch) & Geolocation \\
\hline & October & Instagram (launch) & Photo sharing \\
\hline \multirow[t]{3}{*}{2011} & September & Google+ (launch) & SNS \\
\hline & September & Snapchat (launch) & Photo sharing \\
\hline & November & Google+ (Business Pages) & SNS \\
\hline \multirow[t]{5}{*}{2012} & January & Facebook Ads (launch) & SNS \\
\hline & May & Facebook (IPO) & SNS \\
\hline & September & Tinder (launch) & Dating \\
\hline & October & Vine (Twitter acquisition) & Video sharing \\
\hline & December & Snapchat (adds video sharing) & Video sharing \\
\hline \multirow[t]{4}{*}{2013} & January & Vine (public launch) & Video sharing \\
\hline & January & MySpace relaunches & SNS \\
\hline & September & Orkut (closes) & SNS \\
\hline & November & Twitter (IPO) & Microblogging \\
\hline \multirow[t]{4}{*}{2015} & January & Periscope (Twitter acquisition) & Video sharing \\
\hline & May & Discord (launch) & Chat \\
\hline & June & Friendster (closes) & SNS \\
\hline & September & Instagram (Ads launch) & Photo sharing \\
\hline 2017 & March & Snapchat (IPO) & Photo sharing \\
\hline 2018 & June & Instagram (IGTV launch) & Video sharing \\
\hline 2019 & April & Google + (closes) & SNS \\
\hline
\end{tabular}




\subsection{Social Media overview}

This study mostly focuses on five key social media categories used: forums, blogs, microblogging, social and professional networking services. These are briefly defined below, with an overview of the features that each category included. Also discussed in this section are three additional social media types: social bookmarking sites, video sharing sites, and geo-location services. Overall, this section provides more richness around some key social media platforms around during the time of study.

\section{Forums}

Online forums are the oldest social media format included in this study, serving a similar purpose to the online bulletin boards that have been in use since the 1970s. The first modern webforum, WIT ("WWW Interactive Talk") was created after the 1994 W3C conference, in order to provide a more structured environment for technical discussions (Luotonen, 1995). Forums remain an important medium for niche communities.

\footnotetext{
A WIT discussion has a certain structure to allow people (or programs) to see what the state of play is. It is an attempt to improve on the mayhem of newsgroups and mailing lists, where you can't see whether a point has been settled, and it is very easy to bring up the same point again and again. If you contribute to a WIT, your message will not evaporate after a few days, but will be part of the knowledge structure of the database. (Luotonen \& Berners-Lee, n.d.)
}

Since 1994, hundreds of forum services have been created. Unlike most other forms of social media considered in this chapter, forum software tends to share many common features across different service providers. Forums typically exist to service a specific niche, such as an industry, hobby, or lifestyle. This can make them valuable tools for a small business manager, providing access to highly focussed groups.

There are two important types of forums for small business managers to consider: those operated by the business itself, and relevant forums operated by third parties. In the former case, the business staff would create a forum community from scratch: either drawing on customers already associated with the business, or attempting to draw in new members from other online channels. In either case, good community management practices are key to building a successful forum: ensuring a regular influx of new members, and encouraging existing members to take more active roles. This generates 
the ongoing engagement that helps to develop a sense of community among members, and ultimately determines the long-term success of these forums.

In the latter case, business managers can tap into pre-existing communities that may find their products or services of interest. This removes the need to create a community from scratch, but carries a different set of problems. When entering an existing community, managers need to gauge how receptive the audience may be to commercial interests - some audiences are particularly hostile to 'sales' material intruding into their community, and entering these forums can damage the reputations of the business or its manager among valuable groups of customers or industry peers.

Forum users typically need to create an account on the site in order to post, as unregistered or anonymous posting is vulnerable to undesirable content such as spam. Their messages are marked with a username or pseudonym, linked to a profile containing additional information such as the user's location, date of joining the site, and number of posts. Unlike the social networking services discussed later, a user's profile is a relatively minor part of their involvement in most forums. The primary content on forums takes the form of discussion topics and replies to these. Repeated conversation on topics of mutual interest helps to create a sense of community among users. The strong ties that this creates can contribute to the value long-term members receive from participation, but risks creating cliques that discourage newcomers.

Kim (2000) proposed a 'membership lifecycle' for online communities, developed primarily through her research into online forums. This model involves several developmental stages: visitors (or 'lurkers') may begin their involvement with a forum by reading discussions, often before creating an account on the site. Later, they may become novice participants, contributing to a small number of discussions themselves. Eventually, they may go on to become more active regular members, or even leaders or 'elders' in the community. The lifecycle model has been applied to several types of online community, such as forums and blogs. A similar model can be found in Lave and Wenger (1991)'s work on 'legitimate peripheral participation', where participants take different trajectories during their transition from outsider to active participant.

While it was common for forums to require membership in order to post, most forum content was publicly viewable by default. This assisted forums in attracting new members, allowing visitors to see the type of community that they would be joining. 
Public content is also accessible by search engines, allowing these to index content posted to the forum. This provides another source of traffic and new members.

Large and active forum communities can generate tremendous volumes of content, so many forums offer a range of ways to keep track of specific discussions. These included subscriptions to a specific topic or subforum, and notifications (via private message or email) whenever a new topic was posted to their areas of interest. For infrequent visitors to a forum, these tools assist them in keeping track of specific areas: for example, a business manager may wish to be notified when a specific type of product is discussed. Alternatively, they may need to monitor feedback and discussions about their business.

Forums typically develop a code of conduct to guide user behaviour in their community. These might range from general edicts such as 'be polite,' to detailed lists of offences and penalties forming a user agreement that must be accepted before joining. While each forum defines its own hierarchy of membership types, these typically include three major categories. Administrators control the site itself, defining the rules of the community, and managing the forum database. Moderators work on the 'front end' of the forums; closing or moving topics where needed, and enforcing the community rules. Members also reinforce the social norms adopted by the forum. Their use of language and choice of topics helps to define the types of user-generated content seen on the forums. Their behaviour towards other members - especially members who are acting in a contrary fashion - enforces social pressure on other members to conform. Many forums incorporate some form of crowd-sourced reporting feature, allowing users to flag inappropriate posts for moderator attention.

\section{Blogs}

Blogs are typically used to post long-form text content, embedding other media such as images and video. Public-facing blogs provided a publishing platform for news, opinions and commentary, often allowing readers to post their own comments in response. Collating these at the bottom of each article allowed for dialogue between commenters and the author, and many active blogs developed a community of regular members.

Ahuja and Medury (2010, p. 91) described business blogs as "online repositories serving as a virtual storehouse of information, where organisations post content for consumer consumption." However, this view considers blogs as primarily a passive tool, used for one-to-many publication of content. While the individual or organisation 
running a blog will have a great degree of editorial control over the content of each post, the ability to interact with online content allows readers to take a more active role in the discussion; sharing links to articles, commenting on posts, and linking to related discussions on other sites. Ahuja and Medury identified three major types of blog content, noting that relational content (measured in the form of user comments) induced far greater volumes of consumer engagement.

Articles are the primary form of content posted to blogs. These provide an opportunity for in-depth discussion or analysis: articles have no character restrictions or word count limits, and single-author blogs provide opportunities for a business manager to write on any subject that interests them. Comments on these articles are an important secondary form of blog content, providing the option for limited dialogue between author and audience. Posting these comments in the context of an individual article allows each article to potentially host discussions with a new audience. Blog comments are typically displayed in a threaded format similar to that used by forums.

As blogs are often hosted on the business' website, there are several issues to consider when establishing a moderation strategy for a business blog's posts and comments. Wherever public comments are allowed, offensive or malicious content is a potential liability. Comments may also come from human contributors, or from automated 'spambot' programs. To reduce spam, most blogging platforms required some form of automated verification in order to post comments.

Blogs typically display a selection of recent posts, either in their complete form, or in the form of titles and short excerpts. Excerpting serves two major functions. In the case of particularly long articles, it prevents these from dominating the main page of the site - showing an introductory paragraph from several articles as examples of the range of content that the site covered. Forcing readers to take an action on the site (clicking 'read more') also assists in monitoring traffic via website analytics. Building a detailed understanding of reader activity - what they read most often, what they commented on, where they came from and what they did after reading the articles - helps authors to strategically manage their blogs. An alternative to reading content on the main website involves using an aggregator service to subscribe to the blog. These allow users to aggregate and read content from many different sources at a central location. 
Perhaps more so than any other social media services considered here, blogs are used to build decentralised communities of authors. Unlike a forum or social networking service, no single website links all contributors together. Bloggers can customise and individualise their sites to an enormous degree. When disconnected from a wider community, blogs can be very isolated: relying on traffic from search engines, or visitors to the main site that hosts the blog. However, when the blog authors connect to others in their field, links begin to form: comments left on one site can be traced back to the author's blog; 'blogroll' links at the side of a page directed visitors to other sites. Livejournal was an early pioneer of this style of blogging community, providing tools for multi-author blogs that helped these niche communities to flourish.

\section{Micro-blogs}

Micro-blogs differ from more 'traditional' blogs in their structure, and in the size of messages posted. While a blog post may be intended as an opinion piece or public letter open to comment, micro-blogging primary content and replies are typically short statements or observations. Kaplan \& Haenlein (2011, p. 106) describe micro-blogs as allowing users "to exchange small elements of content such as short sentences, individual images, or video links." The medium was designed for immediacy, allowing conversations to take place in approximations of real time. The brevity of messages encourage use of these services as a distribution channel, linking to content such as videos or blog posts.

As the most widely used micro-blogging service, I use Twitter as the primary example of this type of service. Twitter allows users to send status updates in the form of short messages: typically text (initially limited to a maximum of 140 characters per message), although it later incorporated images and video. Twitter launched in 2006, and experienced rapid growth after the 2007 South By Southwest Interactive (SXSWi) conference (Douglas, 2007). In 2010 Twitter delivered 65 million tweets per day, and had 150,000 registered software applications that connected to their servers. One year later, this had grown to over one million applications, and 200 million tweets per day (Twitter, 2011). Stone (2011) commented that it had taken 18 months to sign up the first 500,000 accounts, but that by 2011 the site saw almost that number created each day. Taylor (2011) placed the total number of users at 300 million in mid 2011. In early 2019, Twitter (2019) published a shareholder letter listing monthly active users at 330 million, and daily active users at 134 million during Q1. 
Twitter has been described as an "asymmetric" (Gruzd et al., 2011) or "nonreciprocal" (Marwick and boyd, 2011) social networking service - allowing users to connect to others with no explicit obligation or requirement for them to follow them back, although there may be implicit social obligations to do so. Gruzd et al. (2011, p. 1296) highlight the asymmetric nature of these connections, noting that "the norm for those following more than 100 people is to have many more following them."

Truly anonymous posting is not possible on Twitter, as users must create an account in order to post content. However, accounts are free to create and simply require a unique username and email address. This allows for posting via pseudonyms that can highlight or conceal a user's identity. Unlike Facebook, Twitter's terms and conditions allow users to create multiple accounts. This is often done for personal or professional branding reasons - changing identity, or promoting a business name.

By default, Twitter is a broadcast medium. Content posted on a Twitter account is publicly viewable, and indexed by search engines. However, it is possible to restrict access to an account, making tweets visible only to other accounts that share a reciprocal link with the account holder. In addition to this, Twitter allows users to send direct, private messages to individual users, only visible to the sender and recipient. Private messages can only be sent when the recipient already follows the sender, in order to limit the potential abuse of unsolicited direct messages. However, this also limits the effectiveness of direct messages for privately solving customer service issues: even if a business follows all its customers, those customers are not guaranteed to follow company accounts back: particularly if they are dissatisfied with a product or service.

Twitter uses 'hashtags' as an important tool for increasing the exposure and audience reach of content, allowing users to make their content visible to a wider audience. These are strings of characters beginning with a hash (\#) symbol, designed to allow users to easily search for other content using that hashtag. This enables users to find discussions happening about that topic from outside their immediate contacts.

While there are multiple ways to post messages to Twitter, there are far more ways to read it. 'Following' a user ensures that updates from that user will appear in your newsfeed. Likewise, when followed by another user, that user can see your public updates in their feed. Throughout the study, Twitter's default newsfeed was an unfiltered stream of all recent posts made from accounts that a user followed. This remained the 
case until an algorithmic "top posts" newsfeed was introduced (Twitter, 2016), filtering the posts that are displayed to each user. Content posted to Twitter is also available via Twitter's web interface, mobile apps and numerous third-party 'client' programs that offer a range of additional features, customising the interface for specific uses such as monitoring several channels via a multi-column layout, or posting to multiple accounts.

While Twitter is by far the largest and best-known example of a micro-blogging service, many alternatives exist. Two of these are briefly discussed here. Tumblr is a micro-blogging service commonly used to post images, rather than text. Tumblr users are encouraged to 'reblog' content from other accounts, re-posting it on their own accounts with a link automatically providing attribution. Yammer is an intra-organisational microblogging service, filling a role somewhere between a social networking service and a micro-blog for internal communications in large organisations. In general, enterprise micro-blogging tools were not widely used by the small business managers due to the compact nature of their businesses.

\section{Social networking services (SNS)}

Social networking services (SNS) provide a range of features designed to let users connect and communicate with other users. boyd and Ellison (2007, p. 2) defined social network sites as "web-based services that allow for individuals to construct a public or semi-public profile within a bounded system," allowing individuals to connect with other users and develop a larger network via the sharing of contacts.

I use Facebook as my primary SNS example, as it possesses most of the archetypal features of this type of social media, and had the largest user base by a significant margin. The rise of Facebook from its beginnings as a Harvard college network in 2004 has been a global phenomenon, and Facebook made history in May 2012 with the largest IPO for an internet company. Their prospectus included detailed statistics on their number of users, and the frequency of using the site. Facebook also published regular statistics on their Monthly Active Users (MAUs) - defined as those who have accessed the site at least once in the previous month. This was provided as a measurement of active accounts, rather than a simple tally of all accounts created during the site's history. Prior to starting the fieldwork for this research, Facebook reported over 400 million active users (Facebook, 2010). One year later, that figure had grown to 845 million (Facebook, 2011). 
On Facebook, a user profile contains information such as their name, location, and other networks (workplace, university, school) they are part of, and a link allowing others to invite that individual to join their own networks. The visibility of an individual's profile information is governed by the site's privacy settings: allowing each profile element to be set as either publicly viewable, viewable only by existing contacts (or 'friends of friends'), or completely private. Content posted to Facebook typically involves short 'status updates' - similar to the micro-blogging content described in the previous section, but with the potential to include images or video.

Before the rise of Facebook, MySpace dominated the social networking market. From 2003 until early 2008, the site was the most visited social networking service in the world; a position it eventually lost to Facebook. Since 2008 the site experienced a rapid decline in membership; later attempting to reinvent itself as an entertainment website via sub-sites such as Myspace Music.

Google also launched a new social networking service during the research period, known as Google Plus or G+. This offered many of the same features as Facebook, such as status updates, image and video sharing, and profile-based networks. Unlike Facebook, Google Plus used a feature known as 'circles' to assist users in managing their streams of incoming information, and the different levels of privacy and access needed in a multicontext network. This was a key feature of the service, drawing upon UX research conducted by Adams (2010). Google Plus launched in late 2011, but struggled to attract significant numbers of active users and began closing down in late 2018 (Google, 2018).

\section{Professional networking services (PNS)}

Closely linked to the services described in the previous section, professional networking services (PNS) are a subset of social networking services, designed to support a more professional, industry-focussed market. LinkedIn is the most prominent of these, and has been used as the primary example below. Rival sites such as XING and Viadeo, both popular in Europe, have not achieved significant market penetration into Australia.

LinkedIn officially launched in May 2003, with 350 invited members. The service grew to 4,500 users by the end of its first month of operation, and continued to grow rapidly - recording over 100 million users by March 2011. Prior to my fieldwork commencing in 2010, LinkedIn had almost 1 million Australian users. By March 2012, this number had tripled (Canning, 2012) - making the service one of the fastest growing 
social media services in Australia. In addition to user profiles, LinkedIn incorporates two key features. Company profiles were added in March 2008, providing businesses with a 'corporate' profile that is separate from the profiles of individual staff members, allowing users to track specific organisations. LinkedIn Groups also allow users to form and join communities of practice, giving members access to professional discussion forums.

User profile information is the primary form of content on LinkedIn, used to a far greater extent than on social networking services like Facebook. During account creation, users were prompted to add their current and past jobs, education and experience, and other information - using the site as an online version of their resume or CV. Users could choose to make their entire profile, an extract (containing name, location and current position title), or just their name visible when in search results, while full details would be displayed to the user's immediate contacts.

LinkedIn users can post short status updates, similar to those found on Twitter or Facebook. These are displayed on their profile, and shown to the user's contacts in their news feed. Updates to other profile fields can also be displayed in the news feed. Anderson Analytics (2008) found that most people actively use LinkedIn only when looking for new work, and that broadcasting profile changes often signalled an intention to change jobs. By default, new user profiles are publicly viewable. Privacy settings allow users to turn activity broadcasts on or off; select who could see their activity feed; control what others can see on their profile, and who can see their connections.

LinkedIn defines an individual's network as their immediate personal contacts, their second-degree 'friend of friend' connections, and the third degree 'friend of friend of friend' contacts. The concept of 'in-network' contacts is important, as it affects a number of features on the site. In general, free account holders can only access full profile information for users in their own network. Messages can be sent directly to contacts within a user's network via LinkedIn, similar to sending them an email.

By default, LinkedIn promotes strong-tie connections, warning users to only send network invitations to people they know well. This reinforces the reputation of the site: any member might be contacted by a potential employer or recruiter, and asked to vouch for one of their contacts. In contrast to this, user-led groups such as the LinkedIn Open Network (LION) aim to create vast weak-tie networks, often containing tens of thousands of members (Lynch, 2008). LION members can show a membership badge on their profile 
or add 'LION' to their usernames, for visibility in searches. That group has a series of rules: chief among them, that members must not reject invitations from other members, as this can have negative consequences for other group members. In return, group members can freely connect with any other members.

LinkedIn can be used to search for individual users, companies or groups. The basic search functions do not require an account, but account holders can typically access more complete results. Generally, full user profiles are only viewable when those users are part of the searcher's network. Discussions specific to an industry or other niche category can be found in LinkedIn Groups. These function in a similar fashion to a forum, containing threaded conversations, and a directory of members. Group memberships can also be displayed on a user's profile.

\section{Video and image sharing services}

Video and image sharing sites also incorporate many 'social' elements focused on sharing content and interacting with other users. Sites such as Vimeo, DailyMotion and YouTube have become popular as internet connection speeds increased. YouTube is the largest such service, incorporating social networking elements such as a personal profile, the ability to comment on videos and send private messages to other users.

User-generated content is central to these platforms. However, further interaction between users is relatively limited. In the example of YouTube, video ratings are made anonymously, and the number of comments left on channels and videos reflects only a small fraction of the total membership base. For the vast majority of users, social interaction is not a major feature of the service - instead, they are primarily used to locate and watch videos provided by other users. The use of channel subscriptions, ratings and comments on YouTube videos are examined in more detail in Chapter 5.

\subsection{Technology adoption: Diffusion of Innovations (Dol)}

Rogers' (2003) Diffusion of Innovations (DoI) theory attempts to explain the social and relational aspects of innovation diffusion over time, in a social system. Rogers describes four main elements in the diffusion process: the innovation itself, communication channels, time, and the social system of the innovators (p.11). The importance placed on 
communication channels is of particular interest, as many Web2.0 technologies directly increase the ability of business managers to communicate with other innovators.

The DoI model predicts that innovations will diffuse through a social system following an 'S-shaped curve' when the number or percentage of adopters are plotted against the time until adoption is made. New innovations are adopted slowly at first, as awareness of the innovation slowly spreads through the system. This is followed by a period of much faster adoption, when the innovation reaches mainstream use by the majority of potential users. At the end of the DoI cycle, the rate of adoption slows again to encompass the 'laggards' - a minority, encompassing those who are resistant to change for various reasons. This pattern has been supported by many empirical studies during the long history of diffusion theory.

Rogers' work addresses several other aspects to the diffusion of innovations: the generation of innovations, the process by which they are adopted, attributes of the innovation and of its adopters, and the role of networks in diffusion. In this chapter, I focus on three of these issues: the innovation-decision process, and the characteristics of both innovation and adopter.

The study of diffusion processes has its roots in the earliest forms of sociology and anthropology, but Rogers was the first to popularise the concept as a universal process for the spread of innovations. Rogers cites the work of Professors George Beal and Joe Bohlen - for example, see Beal, Rogers \& Bohlen (1957) as major influences on the development of his theory. Both Beal and Bohlen worked in the field of Rural Sociology, but were called upon to give presentations to a wide range of industry types as diffusion research grew in popularity. Today, DoI has been applied to the individual and organisational adoption of ideas, physical products, electronic data formats and any number of other innovations.

\section{Innovation-decision process}

Rogers' (2003) innovation-decision process describes the steps that an individual goes through when deciding whether to adopt an innovation. This occurs over time, and consists of five phases.

- Three types of knowledge acquisition relate to the innovation-decision process. These are the knowledge that an innovation exists (awareness), how it works (how-to) and why it works (principles knowledge). 
- Persuasion occurs when an individual forms attitudes towards the innovation. As this phase is difficult to observe, it is best explored via interview questions.

- Decision takes place when the individual engages in activities that lead to a choice to adopt or reject the innovation. This may be a process of trial and experimentation, with new technology gradually becoming a regular part of the business, being discarded, or being put aside until further resources (information, skills, time, money) became available.

- Implementation occurs when the innovation is put to use. Implementation is typically the easiest stage to observe: most social media technologies are publicfacing. In this research, I consider a social media account to be implemented at the point when it goes 'live.'

- Confirmation takes place when an individual seeks reinforcement of the decision they have already made. That decision may be changed later on, if they are exposed to conflicting messages about the innovation.

These stages have also been explored by Burgess et al (2017) in their study of social media adoption, who examined the stages of technology adoption for three platforms: Facebook, Twitter and YouTube. That study concerned a later (2013-15) research period than my own, and revealed a notable increase in the proportion of YouTube-using businesses compared to Sensis' national Social Media reports. Similarly, Burgess \& Paguio (2016) applied an innovation-decision framework to their study of ICT adoption among Australian home-based business, including Facebook and Twitter use. They note that it is valuable to "go beyond the simple measure of adoption rates" (p.295) for ICT use, and found the innovation-decision model useful for achieving this.

I examine the five Innovation Decision phases in detail in Chapter 6 - providing examples of each phase as encountered in the small business case studies. Later sections will address the properties of social media technologies that may help or hinder their adoption by business managers, and the characteristics of the managers.

\section{Properties of innovations}

Rogers also identifies five general attributes of innovations, and defined them as relative advantage (perceived improvement of the innovation over its precursor), compatibility (with the users of the innovation), complexity (perceived difficulty of use), observability (are the results observable to others?) and trialability (can it be experimented with 
before adoption?). Moore and Benbasat (1991) adapted elements from Diffusion of Innovations for their study of individual technology acceptance, focusing in particular on how the perception of IT characteristics affects its adoption.

These elements shape how individuals respond to each of the innovation-decision stages described above, and help determine the decision that is made about whether to implement a new technology. Observability, trialability and perceived complexity are key attributes for each of the social media services in this study. The public nature of most social media services ensures that implementation examples are easily accessible for all but the earliest of adopters, allowing individuals an opportunity to learn from their peers. In Chapter 6, I explore the extent to which this may affect the perceived risk or ease of use for social media in a business context.

\section{Adopter categories}

Perhaps the most widely recognised aspect of Rogers' Diffusion theory is the use of a standard set of descriptive categories for types of adopter. These are labelled innovators, early adopters, early majority, late majority and laggards, referring to individuals adopting an innovation at different stages.

These categories are typically illustrated on a bell curve, representing a population group (such as people within a business, or businesses within a region) in its entirety. Together, these adopter categories cover the 'S-shaped curve' that is typically seen when the adoption of an innovation or new technology is measured over time: starting with only a small following, rapidly gaining speed as the majority of the population begin using it, and then slowing down when only a small number of individuals who have not already adopted the technology remain. Together, the adopter categories form a life cycle for the adoption of new technologies: starting with a small number of innovators, progressing to early adopters, and then into mainstream use by the majority of the population.

The attributes associated with each of the adopter categories are all relative to the population being studied: comparatively higher income, greater appetite for risk and higher social status are often associated with the innovators and early adopters. Where these characteristics are based more on the perception of others than any innate qualities, this has interesting implications where interactions are primarily online. Here, it is easier to cultivate multiple personas, brands or identities. Some managers in the 
study discuss the advantages and difficulties of maintaining different roles for different audiences, and the role of identity and presentation is explored further in Chapter 6.

Moore (2002) builds on this concept of a technology adoption life cycle, describing gaps that separate each group on the diffusion curve. These, he claims, are the points at which both change agents and marketers can fail to attract a wider audience for their products. These are caused by differences in approach and goals between the adopter types. They are typically made visible in failed marketing campaigns, where marketers have attempted to present products to new user groups in the same manner as used to attract previous customers. Technologies do not smoothly transition between each group on the user life cycle, as each group has different needs. He describes the most significant of these as "a deep and dividing chasm that separates the early adopters from the early majority" (Moore, 2002, p. 19), arguing that there is a key difference in the features these groups look for in an innovation. Early adopters follow the innovators, seeking products that solve problems in novel ways, affecting disruptive change. The early majority are motivated more by efficiency, wanting products that take existing work patterns and improve them in an incremental fashion.

\section{Diffusion of innovations within organisations}

Diffusion theory can also be applied to organisations, although consideration must be given to the ways that these differ from individuals. The earliest studies of diffusion focussed on individual decision makers - famously, the case of Iowan farmers deciding whether to plant hybrid corn in their fields (Rogers, 2003). Later studies examined individuals who were more tightly bound by the decisions and characteristics of their employing organisations, such as doctors within hospitals, and teachers within schools.

I propose that small businesses are good candidates for the application of Diffusion theory, as the operation of each firm relies almost entirely on the decisions of the business manager. This gives them a high degree of agility, as a single decision is typically needed to approve the trial or adoption of new technologies or processes. In the specific example of the fifteen businesses in this study, the business managers - all currently integrating social media into their businesses - are likely to be relatively innovative when compared to the wider population. This will be reflected in the behaviour of their organisation as a whole. 
Earlier work on innovativeness in corporate organisations suggests the opposite to this: that larger organisations tend to be more innovative, as shown in research by Mahler \& Rogers (1999). Rogers (2003, p. 412) describes four structural variables that relate to the innovativeness of an organisation, suggesting that these predispose larger organisations to higher degrees of innovativeness.

- Complexity encourages organisations to more easily recognise the value of innovations: it describes the level of knowledge and expertise among members, such as formal training or industry experience. More complex organisations will contain staff with a deep understanding of the requirements of their position, and the ways that current processes and technology could be improved. However, divergent opinions from too broad a range of specialities can make it harder to reach a consensus about implementing them.

- Formalisation measures how bureaucratic an organisation is. This has positive and negative implications for innovativeness: an organisation that is too formal will not consider innovations as readily, but without some degree of emphasis on rules and procedures the organisation will struggle to implement an organisation once the decision to adopt it has been made.

- Interconnectedness describes the density of connections within interpersonal networks among members, and is positively related to the innovativeness of an organisation. It is also a variable highly suited to small organisations, as they are less likely to have information gaps created by a lack of connections between staff.

- Organisational slack is the degree to which uncommitted resources are available to an organisation. Rogers suggests that relatively higher levels of organisational slack help to explain why larger organisations tent to have a higher level of innovativeness. This variable is where small and micro businesses differ most from larger organisations: they rarely have any significant resources that are not already in use. Lack of time or money was a common theme among the case studies in my research, and much of the adoption process for social media technologies formed additional work beyond the manager's regular workload.

The organisations in this study typically involve a high degree of complexity in staff knowledge and experience, while being small and focussed enough to avoid significant differences of opinion. They are relatively informal, and highly interconnected: where the 
businesses are large enough to include multiple staff, all staff work closely with each other, and also maintain close ties to networks outside the business. These characteristics suggest that the small businesses are likely to be open to new innovations, able to recognise potential value in changing technologies and processes, and that they are exposed to new ideas from across their networks. However, low levels of formal rules and processes, when combined with a general lack of resources, mean that these organisations are likely to have difficulties implementing many of the innovations that they have seen or experimented with.

\section{Criticisms of Diffusion of Innovations}

Rogers groups criticism of diffusion research into four categories: pro-innovation bias, individual-blame bias, recall bias and the issue of equality in the diffusion of innovation. These are broader criticisms of research conducted in this field, rather than addressing specific criticism of the diffusion model. For example, pro-innovation bias is the implication that innovations should be diffused to all members of a social system, that the diffusion should occur rapidly, and that the innovation should be neither re-invented or rejected (Rogers, 2003, p. 134). Many early diffusion studies were subject to this, portraying innovation and change as both necessary and positive. Rogers suggests two causes for this. The first is the inherent pro-innovation bias of the organisations funding these studies: typically change agencies, innovation and research centres, dedicated to the promotion (and development, in many cases) of innovations. More subtle bias is seen in the methods used to observe the diffusion process. Innovations that are 'successful' according to the diffusion model are more likely to leave a visible trail that can be identified and reconstructed by researchers (Rogers, 2003, p. 110). Unsuccessful innovations may be more difficult to identify, and typically will not leave the same traces for researchers to follow. Further muddying the waters, significant re-invention of an innovation can create difficulties in classifying exactly what 'adoption' means.

The vulnerability of DoI research to recall bias - that is, problems in measuring the time of adoption or determining causality caused by reliance on the subject's memory of events - is also of note. This is less a structural weakness in the model itself, and more closely associated with the specific methods chosen by each study. The earliest studies in this field of research relied heavily upon single-instance surveys, capturing the diffusion of an innovation at a particular point in time. These asked research subjects to recall 
historical details about their adoption of a particular technology, potentially stretching back several years. I have attempted to minimise the impact of recall bias by using a combination of multiple interview stages and ongoing observation of actual technology use, as discussed in Chapter 3.

DoI has a long history in fields ranging from anthropology and sociology, to geography, industrial engineering, marketing and public health. In order to understand why Rogers' model has retained its popularity through several editions and over four decades, McAnany (1984) reviewed Diffusion theory from a critical theory perspective. The model has its origins in quite specific contexts: beginning with studies of agricultural innovation among Iowan farmers, and encompassing communications theory and international development issues in later editions. Despite these criticisms, McAnany (1984, p. 440) recognised Rogers' “ability to 'read' the social signs of the times, and [re]focus his model on important, emerging innovations." Through each edition of Diffusion of Innovations, Rogers has adapted the core concepts of his model to apply them to current issues, building a more comprehensive model that is accessible to researchers from many different fields.

McAnany raised a more fundamental issue with the model by questioning the epistemological assumption that it is possible to 'build up' a social theory from the many small empirical studies that have contributed to the DoI model. This assumption is central to Rogers' work, aiming to determine laws that can predict the behaviour of individuals or groups. It remains a point of contention between DoI and other social science traditions that seek less generalizable and predictive, more context-sensitive and interpretivist models. However, McAnany also noted that much of the appeal of Rogers' model lies in its focus on pragmatic, action-oriented advice - aimed at audiences who typically consider more critical theory as being too abstract to have relevance to their needs. In this way, DoI has been well received among groups who have been willing to put it into practice: shaping policy, marketing plans, and other outcomes that have become the focus of subsequent studies.

Lyytinen \& Damsgaard (2001) examined the applicability of DoI to the field of information technology, using the example of EDI (electronic data interchange) diffusion in three countries. They identified weaknesses in the model, proposing modifications to overcome these when studying complex, networked (and in their case, standards-driven) 
technologies. While the social media technologies used in the current research are not bound by the same institutional regulation and standards as EDI, they share several of the features that Lyytinen \& Damsgaard use to define "complex and networked" technologies. These include an inter-organisational focus, reliance upon complex telecommunications infrastructure that creates dependencies with other components of the technological system, and the requirement of a considerable user mass in order to be efficiently deployed (Lyytinen and Damsgaard, 2001, p. 3).

Traditionally, DoI has been used to explain the adoption of static technological artefacts (hybrid corn seed, specific pesticides, colour television sets) in relatively homogenous, bounded populations. By taking six conjectures or generalisations from DoI theory and offering counterexamples to refute these, Lyytinen \& Damsgaard suggest ways that the model should be modified for application to IT innovations. They dispute the claims that adoption choices are made solely upon available information and the properties of the adopters, and that IT innovations can be considered as discrete packages. In the former case, adoption choices can be influenced heavily by the actions of others in a social system: network effects can make technologies more attractive options when they have a significant number of existing users, causing adopters to pass over technologies that may be objectively 'better' for their needs. In the latter, 'interpretive flexibility' affects the significance of a technology as groups construct different meaning for that technology (Lyytinen and Damsgaard, 2001, p. 7; Pinch \& Bijker, 1987).

Instead, Lyytinen \& Damsgaard recommend that an improved DoI theory for complex and networked technologies should seek accuracy over generalisability and simplicity relying less upon simple metaphors, and instead focussing on "process-based, contextual and non-deterministic" models that can identify the conditions necessary for adoption (Lyytinen and Damsgaard, 2001, p. 13). In my own research, I remain mindful of these suggestions and attempt to display the complex, networked and learning-intensive features of the technologies under consideration.

\subsection{Social capital and network structure}

The range of resources that managers sought to access as a result of their networking activities are best described by the concept of 'social capital' - a resource that encompasses the goodwill or reputation that each manager has described, and that is 
gained as a result of their interaction with others. This section introduces the theories of social capital and social networks, reviewing their history and exploring their applicability to small business research. Combining the two theoretical perspectives allows a broader exploration of small business networking activities, and avoids the research dilemma described by Jack, Moult, Anderson \& Dodd (2010, p. 317), who ask whether research focuses on networking or networks. Focusing on either one of these aspects presents a necessarily incomplete view, and risks overlooking the important role that network structure plays in shaping the type and effectiveness of networking activities conducted within social networks.

\section{Social capital definitions and history}

In its broadest definition, social capital describes how social ties of one kind may be used for different purposes - for example, calling upon friendship ties, goodwill or reputation in order to access expert advice or material support. As a collection of concepts and theories from several authors, social capital has become increasingly popular in disciplines ranging from family sociology to economic development or political science. Social capital brings a concept more commonly used in economics into the field of sociology, where it could be used to describe and explain social action.

In his introduction to this field of research, Burt (2005, p. 5) described social capital as "the Wild West of academic work" - a place where the contributions of authors from fields such as economics, political science and sociology vary in quality, "from rigorous research to devotional opinion, from carefully considered to bromide blathering." Before entering into this contested territory, I will review some of the history behind the concept and present a definition that I will use for this research.

Perhaps the most popularly known application of social capital is Robert Putnam's (2000) Bowling Alone: America's Declining Social Capital - an exploration of the concept as a resource possessed by groups, such as formal or informal clubs and associations, city-states and nations. This book brought the concept to mainstream recognition, and developed the concept in the field of political science. However, Portes (1998) challenged Putnam's view, disputing the application the concept to 'civic' behaviour among city populations. In order to avoid tautological definitions such as "well governed cities are those in which the population co-operates in maintaining good government," Portes 
suggested a number of logical cautions that he believed had been overlooked in the reinterpretation of social capital as a feature of cities and countries:

First, separating the definition of the concept, theoretically and empirically, from its alleged effects; second, establishing some controls for directionality so that the presence of social capital is demonstrable prior to the outcomes that it is expected to product; third, controlling for the presence of other factors that can account for both social capital and its alleged effects; fourth, identifying the historical origins of community social capital in a systematic manner (Portes, 1998, p. 20).

I concentrate on social capital as an individual resource that is developed by small business owner-managers through their involvement in networks. While the concept can be extended to all forms of social interaction, I focus specifically on how social capital is expressed, developed and used via online social networks.

In their detailed review of social capital research across multiple discipline areas, Adler \& Kwon (2002) describe Pierre Bourdieu as one of the pioneers of the concept. Portes (1998, p. 3) also credits Bourdieu with producing "the first systematic contemporary analysis of social capital." Bourdieu's early work in this area did not receive widespread attention, as it was primarily published in French journals such as the Actes de la Recherche en Sciences Sociales (Bourdieu, 1980). In 1986, an English translation of Bourdieu's 'The forms of capital' brought the concept to greater attention among English-speaking scholars. In this essay, Bourdieu (1986, p. 241) argued "it is in fact impossible to account for the structure and functioning of the social world, unless one reintroduces capital in all its forms, and not solely in the one form recognised by economic theory." Bourdieu presented a framework for describing three fundamental forms of capital: economic, cultural (including embodied, or human capital) and social capital. Bourdieu's definition of social capital focuses on "the benefits that accrue to individuals by virtue of their participation in groups, and on the deliberate construction of sociability for the purpose of creating this resource" (Portes, 1998, p. 3).

Shortly after the English publication of Bourdieu's work, Coleman (1988) made a similar attempt to introduce the concept into contemporary social theory, using it to analyse the role that social capital plays in the creation of human capital. Coleman defined social capital by its function, not as a single entity but as "a variety of entities with two elements in common: they all consist of some aspect of social structures, and they 
facilitate certain action of actors - whether persons or corporate actors - within the structure" (Coleman, 1988, p. S98). Coleman locates social capital not in the individual actor, but in their relationship with other actors. Coleman's approach, while able to encompass a broad range of activity, is perhaps too nebulous a definition to build upon: the substance, sources and effects are mixed and cannot easily be separated.

Questions may arise as to whether social capital is truly a form of 'capital' in the sense used by economic theorists. Adler \& Kwon (2002) examine the similarities and differences between social capital and other forms of capital in detail. Like financial capital, social capital is a long-lived asset into which other resources can be invested, with the expectation of a future (albeit uncertain) flow of benefits. It is both "appropriable" (Coleman, 1988) and "convertible" (Bourdieu, 1986) into other forms of capital, and as such it may substitute for or complement other resources. These qualities are important when considering the resource-poor nature of many small and micro businesses (Welsh and White, 1981), as they suggest a reason why the owner/managers of these firms place such a high value on the development of this resource. Unlike financial capital, social capital requires maintenance, and loses value over time if it does not receive this. This property is shared with physical and human capital, though (unlike the case of physical capital) depreciation does not occur at a predictable rate.

Social capital differs from financial capital in other ways. Social capital is by nature an intangible resource, and difficult to quantify in any direct fashion. Some forms of social capital are 'collective goods,' (Coleman, 1988) and do not solely belong to those who benefit from them. This makes social capital vulnerable to problems of exploitation, embezzlement and misappropriation (Bourdieu, 1986, p. 248); described by Adler \& Kwon (2002) as 'free-rider' problems and their resultant 'tragedy of the commons' risks. Despite these differences, Adler \& Kwon (2002, p. 22) conclude that social capital "falls squarely within the broad and heterogeneous family of resources commonly called 'capital'," noting that while some uses of the term are metaphorical, "these metaphorical uses are widespread, and it is difficult to see what harm they do."

Portes (1998, p. 9) described three basic functions of social capital: as "a source of social control; a source of family support; and as a source of benefits through extrafamiliar networks." It is this third function that has attracted much attention across disciplines and contexts, and is most relevant to small business networks. This area has 
also been addressed by Granovetter (1973; 1983; 1985), Burt (1992; 2004), Lin et al. (1981) and Coleman (1988), and is discussed in more detail in this chapter.

Although the concept has been in use for over four decades, there remain almost as many attempts to define social capital as there are theorists. In an attempt to promote dialogue between the competing perspectives on the sources of social capital, Adler \& Kwon (2002) proposed a conceptual framework that integrates social capital research from several disciplines. Their approach is deliberately broader in scope than those taken by Burt (2000), Lin (1999) or Portes (1998), which tend to focus on the application of social capital theory within specific disciplinary domains. Adler \& Kwon use the following working definition:

Social capital is the goodwill available to individuals or groups. Its source lies in the structure and content of the actor's social relations. Its effects flow from the information, influence, and solidarity it makes available to the actor (Adler and Kwon, 2002, p. 23).

This clearly differentiates between the substance, sources and effects of social capital, and is the definition that I have adopted for my own research.

\section{Social network characteristics}

Several characteristics can be used to describe social networks. Network size, in terms of number of contacts, is perhaps the most obvious structural characteristic. In the remainder of this section, I introduce an additional characteristic that influences how networks function: the strength (or weakness) of each social connection, and the effects that network structure has on the availability of resources.

Bourdieu (1986, p. 246) described the 'volume' of an individual's social capital as dependent on "the size of the network of connections he can effectively mobilise, and on the volume of the capital possessed in his own right by each of those to whom he is connected," providing aspects of both quality and quantity to a social network. By developing connections with more people, an individual increases their potential ability to benefit from social capital resources. Most of the managers spoke about a desire to increase their number of social networking contacts: more Twitter followers, more LinkedIn connections, more Facebook friends. Network size was easy to measure and compare progress against. By having a larger network to draw upon, the managers reasoned that they must be able to receive greater benefits from being a part of it. 
Quality was harder to measure. It is influenced by the social capital possessed by each contact, and also the ties that connect an individual to those contacts. Early research in this area has focussed on one of two types of network connections: internal (bonding) and external (bridging) ties, often in the form of contacts within a company or beyond its borders. The term 'bridging' social capital typically refers to a focus on external relations, whereas 'bonding' social capital describes internal ties between members of collective groups. However, Adler and Kwon (2002, p. 35) suggest that organisational research would benefit if we avoided this tendency to split research between the two strands, noting that "external ties become internal ties at a higher level of analysis, and, conversely, internal ties become external at the lower levels." Many of the phenomena that are studied within organisations involve both forms of social capital - and so it is more important to examine the concept of network ties in a more general sense.

Granovetter (1973) coined the concept of 'the strength of weak ties' to explain the effect that peripheral contacts had on an individual's ability to find employment. This formed the basis of his network theory: suggesting that "our acquaintances (weak ties) are less likely to be socially involved with one another than are our close friends (strong ties)" (Granovetter, 1983, p. 201). This theory was developed to bridge the gap between micro-level sociological studies of personal interaction, and macro-level studies of communities and organisations. Granovetter argued that "through networks of social contacts, small-scale interaction becomes transformed into large-scale patterns, and that these feed back into small groups" (Granovetter, 1973, p. 1360). Granovetter's (1973; 1983) work focuses on the structure of a network, rather than the processes that occur within it - specifically focusing on the differences between strong and weak ties. This emphasis on structural elements remained central to much of the literature that followed: for example, Burt (1992; 1997; 2004), Lin (1999) and Lin et al. (1981).

These concepts of network ties and structural elements are applied to a broad range of small business topics. For example, Atanassova \& Clark (2015) discuss the important role that 'weak tie' connections can play in knowledge development - noting that social media use "enables knowledge-accumulation mechanisms and behaviour, facilitates connectedness and sharing, and could be particularly important in the knowledge absorption process" (p.170). Their research highlights the importance of considering the 
broader environment that each small business operates in, rather than focusing on a narrow 'inside-out' view of the business' outward-facing social media activities.
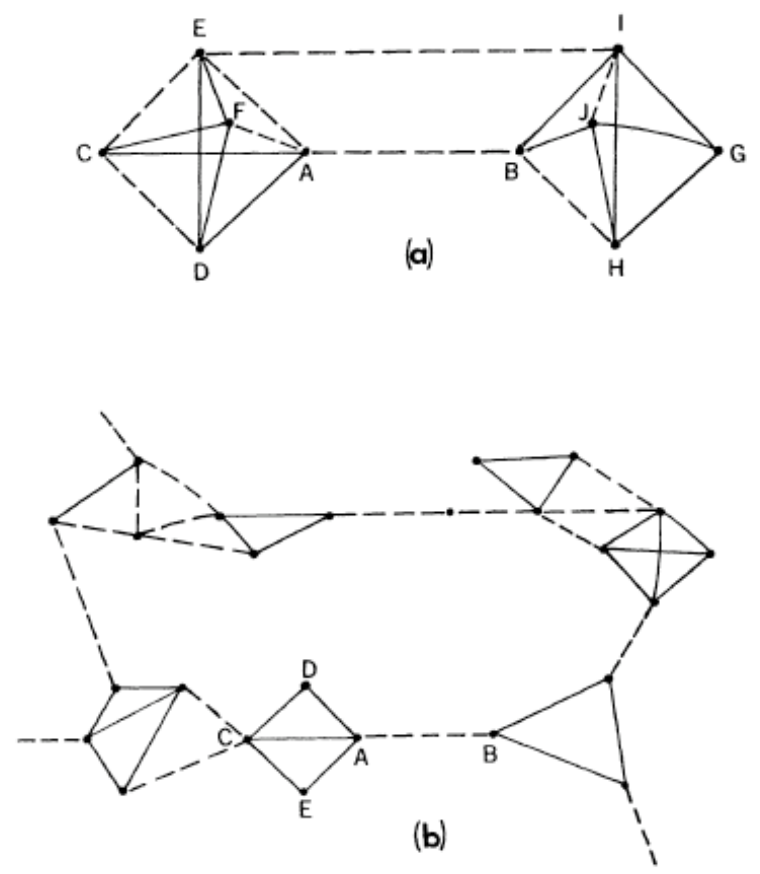

Fig. 2.-Local bridges. $a$, Degree $3 ; b$, Degree $13 .-=$ strong tie; $---=$ weak tie.

Image: Network types, from Granovetter (1973, p.1365) showing weak and strong ties.

Granovetter's early work on this concept included conducted a study of recent jobseekers in professional, technical and managerial roles (Granovetter, 1973). At that time, it was understood that job seekers across a range of industries found out about new jobs far more commonly through their personal contacts than by any other method, though the nature of the tie between job seeker and the contact who had provided them with information was poorly understood. Granovetter asked how often job seekers saw their contact at the time they received this information, using this as a measure of the strength of the relationship. In many cases, the contact was only a marginal contact in the job seeker's network. This led to the theory that less dense networks (those containing a greater number of weak ties) were more effective in supporting job-seeking activity. Granovetter (1973, p. 1378) noted that his model offered only a "fragment of theory," focussing only on the strength of ties and ignoring other important factors, such as their content. Despite these limitations, it offered an important tool for understanding the structure of social networks, and the way they could be used to spread information. 
A decade after the publication of the Strength of Weak Ties, Granovetter (1983) examined the wealth of empirical studies testing his earlier hypotheses, refining these further. From Coser's (1975) work, the role of weak ties of different value emerged, and bridging ties - those linking different groups - were considered far more likely to connect individuals that are significantly different to each other (Granovetter, 1983, p. 204). Not all weak ties are capable of acting in this fashion, but "the significance of weak ties is that they are far more likely to be bridges than are strong ties" (Granovetter, 1983, p. 208). Walker, Kogut \& Shan (1997, p. 109) describe the relationship between bridging and bonding ties as the "fundamental conflict in the formation of a network," arguing that the formation of any network is determined by the opposition of these two forces. Dense network relationships form a valuable resource for members, providing an incentive to reproduce these network structures. The presence of these dense clusters, however, provides an incentive for individuals to alter the network structure by acting as bridges between different clusters of members.

This concept of bridging ties was further developed by Burt (1992), leading to his seminal work describing the role of 'structural holes' within social networks. This aspect of Burt's work involves a form of social capital that is reliant on the scarcity of network ties, as found in low-density networks. The central theme to Burt's work was that "behaviour, opinion, and information, broadly conceived, are more homogeneous within than between groups" (Burt, 2004, p. 353). This internal homogeneity creates holes in the information flow between groups: a structural phenomenon for which he coined the label 'structural holes'. Viewed in this way, social capital is seen as a function of brokerage opportunities within a network (Burt, 1997): it is a resource that allows an individual to bridge that gap, and access information held by members of other groups.

Strong network ties also play an important role. In contrast to the 'weak ties' approach, Lin et al. (1981) examined the role that strong ties play in occupational status attainment. This work led to the development of a theory of social resources: defined in later work as resources that are accessed and used in a temporary, borrowed fashion, via one's direct and indirect ties (Lin, 1999). Lin's 'social resources' bear many similarities to social capital, though his research focused upon status attainment within an organisation, such as the attainment of higher wages or managerial positions. However, by attaining a higher degree of social status in a central organisation, individuals should 
also be positioned to better access social resources from across their network - an important feature for the manager of a small business.

Later work by Jack et al. (2004) examined the nature, process and content of strong ties, as they apply to entrepreneurial networks. While that study did not focus on online networking, it is particularly relevant to the types of small business network ties seen in this research. Jack et al. (2004, p. 107) describe three basic nodal types of strong tie: family, business contacts, and a third group encompassing suppliers, customers and competitors. Of these three types, they identified family nodes as playing an important role in entrepreneurial development (particularly at the startup stage), and these were highly valued for their reliability. Business contacts, defined here as contacts the entrepreneur had been linked to in prior business contexts, provided business information and advice, idea validation, and introductions to new contacts. The broader node of customers, competitors and suppliers typically provided market information, allowing entrepreneurs to become aware of trends in their industry, and understand why these changes are happening. It is this third group that appears most accessible via social media. Family and business contacts are necessarily drawn from pre-existing contacts, and social media supports these by facilitating easier maintenance of these networks typically via informal 'checking in' behaviour. The broad network relied upon for market information still needs to be maintained, but also benefits from continually finding and adding new members. By exposing the business owner to many potential contacts, and reducing the barrier to establishing ties with these people, social media has an important role to play in the supporting the growth of this third type of 'strong tie' node.

\section{Network structure implications for social capital}

In terms of outcomes of social media adoption, there is consensus that social capital is important in an entrepreneurial context (Cope et al., 2007; Westlund, 2006) and can provide a lens to investigate outcomes (Krishen et al, 2018) regarding the role of network structure in producing these outcomes. The primary theoretical lens that I have used to examine social capital in the networks of small business managers is Burt's (2005) concept of social capital as a product of both brokerage and closure in a social network. This model builds upon Burt's earlier work that identified and defined structural holes (Burt, 2000) and the brokerage opportunities (Burt, 2004) that they create within networks, introducing closure as a contrasting factor to brokerage. Together, these 
concepts assist with understanding the social capital value gained from different types of network ties. They also provide a method for examining how and why particular network structures provide these advantages.

Burt (2005) describes three elements to the tension between brokerage and closure in the creation of social capital: the network structure, its content, and the people who are affected by it. In a structural sense, third parties play different roles in the two mechanisms. In network closure, third parties help to corroborate information - making it easier to detect bad behaviour or misinformation, and increasing the value of the social capital generated in this way. In the brokerage model, social capital is created by the formation of bridges between different groups, and the presence of third parties leads to redundant connections that degrade the value of that capital. The information content that flows through social networks also plays different roles in each of the mechanisms. Burt notes here that brokerage "creates value by exposing people to variation in information," while closure creates value by "driving variation out of the closed network" (Burt, 2005, p. 163). Finally, he considers the two mechanisms to have quite different targets. In brokerage, the target is the individual; exposing them to a more diverse range of information. Closure affects behaviour within a group.

Brokerage helps to account for the information benefits derived from broad, weak-tie networks. This form of social capital is most valuable to managers who can bridge gaps between different groups, accessing diverse information sources. This enables the managers to act directly on this information, or to gain value from passing that information on to other contacts. Burt argues that this form of social capital is "more valuable to the manager with few peers" (Burt, 1997, p. 361) - an observation of particular relevance to the small business managers involved. By definition, these managers have limited of peers in their organisation, and must draw on external contacts to support their activities. Information and brokerage are the focus of section 7.3.

Closure is defined as a contrasting element to brokerage: a concept that describes the degree of redundancy in network connections. In a completely closed network, each actor would be connected directly to every other in the network. Closure reduces the opportunity for individuals to act as information brokers: a risk that Adler \& Kwon (2002) describe as a potential trade-off between the information and power benefits of social capital. A manager who possesses many contacts may draw upon a wider range of 
information. However, if those contacts are themselves connected to many others, the power obtained via 'brokerage' of information may be eroded, as it is more likely that alternate bridges will exist between the different clusters within the network. This observation supports the view that closure can undermine the social capital generated by brokerage activities. However, it does not consider the additional effect of closure on the development of trust.

Closure also serves to reinforce social norms within a group's behaviour, acting as a governance mechanism. The presence of multiple people acting in a similar way helps to enforce particular behaviours, while excluding others. By reinforcing positive behaviour, closure encourages the development of trust: in groups with greater closure, information can be verified through multiple sources, improving trust in information brought in from beyond the group. These additional contacts can also monitor 'bad' or antisocial behaviour, adding a reputation cost (Burt, Kilduff and Tasselli, 2013, p.541) to such behaviour. This assists actors with a high degree of closure to act with more effective power: providing more surety that their information will be heard, accepted and acted upon by other group members.

For small business managers who are attempting to establish broad, far-reaching networks of contacts beyond their own organisation, low closure creates problems when they attempt to exert influence within these networks. While these managers occupy an ideal position for brokerage, the valuable information they can bring to their weak-tie contacts is diminished when they lack status or power in these distant groups.

\section{Social capital and small business}

The information, influence and solidarity resources that managers access via social capital are all valuable to small businesses - allowing them to overcome problems of resource scarcity and compete more effectively against larger organisations. In their exploratory investigation of SME social media adoption, He et al. (2015) propose that "the fundamental objective of adopting social media by a small business is to build social capital in a cost-effective way" (p. 157). Their research focuses on the role of social capital in customer relationships. I have taken a broader view of networking activities to develop social capital resources among all of a manager's contacts. This allows consideration of the important contributions of knowledge development and market intelligence (Atanassova \& Clark, 2015), in addition to the direct benefits of sales from customers. 
Burt (2005, p. 7) discusses a perennial question among his business students: given the intra-company nature of most social capital research, is social capital relevant to a small organisation where all staff members know each other? This type of environment is seen in each of the case studies examined in my research: businesses with few employees, all of whom work closely with each other. In response, Burt argues that "managers in all settings have contacts in their immediate workgroup, as well as in the rest of the world." For a large company, the rest of the world often includes those located elsewhere in the organisation, in different divisions or departments. For the manager of a small business, their broader network is typically comprised of those external to the business: an environment that includes customers, competitors and suppliers.

Information on the business' operating environment is vital, and managers rely heavily on network contacts from outside their company to access this. This resource assists managers in finding new ideas, driving innovation. It also enables managers to monitor product offerings and pricing from their competitors, and to identify trends and future demand for new products. Access to this information requires managers to develop and maintain a diverse range of contacts, positioning the manager in a way that benefits from structural holes in information flow. Burt, Kilduff and Tasselli (2013, p. 536) argue that the advantage of accessing structural holes "is defined entirely by the diversity of ego's own contacts, not the diversity of her friends' contacts." This implies that advantage does not result purely from proximity to diverse sources of information it is a by-product of the manager's ability to process the information that they receive, favouring their direct contacts. This observation supports the role of agency and personality in network advantage, but does not detract from the importance of building networks that allow a manager to bridge between knowledge clusters. Access to diverse information is an important prerequisite to gaining advantage.

Influence affects issues of trust and reputation, and is used to change the way that others perceive or react to the business. Similarly, solidarity assists small businesses to coordinate their activities, and is particularly relevant to the formation of formal or informal alliances and partnerships. In their study of small manufacturing firms in the northeast United States, BarNir \& Smith (2002) explored whether the social networks of small firm executives could be used to facilitate the establishment of inter-firm alliances. They found the networks of business managers to be particularly beneficial to small firms 
and businesses with limited resources, as these networks form a resource that may compensate for the lack of other resources. Their research focussed on two major types of inter-firm alliance: resource-intensive technology or manufacturing alliances, and support alliances that involve the sharing of resources. Of these, support alliances are likely to be the most relevant to the small and micro firms involved in my research. For this form of alliance, BarNir and Smith identified two important factors: the executive's propensity to network, and the strength of these networking ties.

More recently, Bosua \& Evans (2017) discussed the role of social media in supporting the development of social capital among rural Australian businesses. Their research examined a period immediately after my own research (2013-15), during which time rural businesses would have experienced a similar widespread level of social media adoption to that previously seen in metropolitan regions. They found that the development of online social capital was a progressive journey, building towards unbounded knowledge sharing across multiple channels.

\subsection{Conclusions}

This chapter has introduced the concept and history of the term 'social media,' including a timeline of major developments that led to the range of services available during this study. The major types of social media that were available to business managers during this research included forums, blogs, social and professional networking services and micro-blogging services. Within these categories, I have described the major features of the most popular services in more detail. These were selected due to their large number of Australian users, and for their ability to illustrate the most commonly offered features available within each category. The services featured in detail in this chapter are Facebook, Google Plus, LinkedIn, Twitter and YouTube.

The following chapter will outline the methodology and methods that have been used to conduct this research. 


\section{Research methodology and methods}

\subsection{Introduction}

This chapter introduces both the methodology and methods used in this research. I begin by defining the research questions and the research paradigm that I have adopted in order to answer these questions. Following this, I introduce the ethical considerations and the research ethics approval process that concern this research. The remainder of this chapter contains a detailed account of the research methods that I have used. I have chosen to use a multiple case study approach (Yin, 2009), adopting the traditional ethnographic methods of semi-structured interviews and participant observation, and modifying these for research into online activity using the framework proposed by Kozinets (1997; 2010). I include detailed accounts of the participant selection process, the negotiation of access to each manager's activities, and the combination of online and interview data collection. Finally, I address the quality measures that have been incorporated into these methods, and the ways that data analysis - supported by qualitative analysis software - has been conducted.

\subsection{Theoretical framework and research paradigm}

\section{Research question}

This research explores the range of ways in which small business managers are adopting and using social media technologies, in order to understand how these are integrated into the operations of a small business, what purposes they are used for, and the types of outcomes these generate for the managers. As discussed in Chapter 1, this research was guided by one primary question:

How have Australian small business managers adopted and used social media, and what are the outcomes for their businesses?

\section{Research paradigm and theoretical perspective}

The theoretical perspective I have adopted for this research draws on the epistemology of social constructionism. When approaching this research, I sought to understand how 
the phenomena of interest - in this case, technology-assisted online communications with individuals and communities - develop within the social contexts of a series of small businesses. The experiences of each business manager would be influenced by their background and environment, and my own interpretation of these would depend on my ability to understand these experiences from the perspective of the business managers. This viewpoint, considering meaning as "not discovered, but constructed ... not inherent in the object, but constructed by humans as they engage with the world they are interpreting" (Crotty, 1998, p. 42) guides the choice of methodology and methods that I selected to answer these research questions. It suggests that a subjective, qualitative approach would be best suited to exploring the subject. This allows me to use my own background and personal influences to shape my interpretation of the data.

Saunders et al. (2003, p. 93) recommend using case study research in cases where a rich understanding of the context of the research and the processes being enacted is required, enabling questions of "why" and "how" to be addressed. Similarly, Yin (2009, p.4) recommends the case study method when research questions require extensive and 'in-depth' descriptions of social phenomena.

I have opted to use a multiple case-study approach involving the selection of businesses and business managers from across several industry sectors, for comparisons both within and between each business type (Stake, 2006). This provides opportunities for theory-building, through "recursive cycling amongst the case data, emerging theory, and extant literature" (Eisenhardt \& Graebner, 2007, p.25). Participant selection is discussed in more detail in Section 3.5. This research is designed to explore issues of technology use from the perspective of small business managers interviewed, but is not intended to be generalizable across all businesses of this size, or across a specific sector. Instead, I seek to draw out issues of interest - those that cause or address significant problems for the business managers, and those focussed upon by existing literature on small business technology adoption.

Perren and Ram (2004) discuss the range of paradigms adopted by small business case study researchers, suggesting that two key dimensions can be used to map the range of approaches that may be taken. The first ranges from the objective to the subjective, dividing research that seeks to understand the social world as a "hard, external reality" from that which seeks to understand how individuals create, modify and interpret the 
world. The second dimension that they consider is whether the research focuses on a "milieu of social actors," or on the individual owner/manager. I have chosen a subjective, personal-story approach in order to focus on the personal entrepreneurial story of each business manager, and the ways they manage the boundaries between their personal and professional activities online. This approach affords an opportunity to gain insight into each manager's interpretation of their world, potentially engendering empathy and a personal reflexive response from the reader.

\section{Reflexive research}

Where research focuses on questions of how individuals make sense of the world around them, Bryman \& Bell (2007) stress the importance of the researcher "bracketing out" preconceptions in their grasp of the world. These preconceptions will necessarily limit my own understanding of the social worlds I explore in this study: both in the representation of data through my writing, and in the selection or legitimation of these data. Brewer (2000, p. 127) describes reflexivity as "a bridge between interpretation and the process by which it is conveyed in text" and it is my aim to introduce the backgrounds that I bring as a researcher, a small business owner, and an active participant within many online communities, across many different social media services. While shaping my understanding of the data, my background in these fields has aided in the recognition of 'valuable' data amongst the countless tiny interactions played out in, and recorded upon virtual space. This helps to improve the legitimation of this data - a process Denzin and Lincoln (1998, p. 278) refer to as "validity-as-reflexive accounting."

Brewer (2000, p. 132) suggests that reflexivity is improved by reflection on the wider relevance of the setting and topic; the features of that setting left un-researched (including reasons for these decisions, and their implications); the theoretical framework the researcher operates within, and the broader values and commitments that the researcher brings to his or her work. The researcher's integrity may then be critically assessed via the grounds on which knowledge claims have been justified, and their background and experiences in the setting: both prior to and during the research. I have attempted to ensure that each of these features are presented clearly, both within this chapter and across this thesis as a whole. The theoretical framework used for this research has been described earlier in this chapter, while the values and other commitments I bring to this research have been presented in Chapter 1. Reflections upon 
the broader context of this work and the aspects requiring further research may be found in the conclusion of each chapter, and are the focus of Chapter 8.

\subsection{Choice of research methods}

This research explores the ways that business managers use social media to interact with online audiences, and on how each manager's online and offline (or work and private) activities intersect. To achieve this, I use methods drawn from traditional ethnography, such as semi-structured interviews and participant observation, applying these to the online environment. Brewer (2000, p. 59) describes ethnography "not as a particular method of data collection, but a style of research that is distinguished by its objectives, which are to understand the social meanings and activities of people in a given 'field' or setting, and an approach, which involves close association with, and often participation in, this setting." Similarly, Johnstone (2007) describes ethnographic methods as "flexible and unstructured," designed to understand meaning from the viewpoint of the research subjects. When adapting these methods for an online context, Hine (2008, p. 259) notes that "the key ethnographic principle, of developing understanding through participation and through a progressive collection of data and focusing of enquiry, remains consistent with more traditional approaches."

These methods are typically characterised by extensive and immersive fieldwork, allowing the ethnographer to observe actions and interactions while attempting to minimise the impact of their presence. Naturally, the requirement for informed consent on the part of participants meant that all business managers in the study were aware of my presence, which would naturally affect the actions they took online. The steps that I took to mitigate this are discussed later in the current chapter.

A wide range of labels have been given to this type of research, such as online ethnography, digital ethnography, webnography and network ethnography. I have chosen to adopt the methods, approach, and standards of evaluation used by Kozinets (1997; 2010), designed to address the requirements of research into online communities. Using a consistent methodological approach will enable better comparisons with other work in this field.

Kozinets (2010, p. 63) makes a distinction between research into 'online communities' and 'communities online.' The former describes research into phenomena 
that relate directly to online communities and online culture itself, such as online identity and cybercultures. The latter is concerned with social phenomena that exist beyond the internet and purely online interactions, though those interactions may still play a key role among the group's members. This latter description is best suited to the businesses involved in my research. While the online activities of each business manager are central to my research questions, they are also part of a larger view of the ways that small business managers are using new technologies. To explore the ongoing adoption, adaptation and outcomes of social media use within small businesses, a blend of online and face-to-face interaction and data collection is required.

My research can be broadly divided into five major stages: planning and negotiating access to participants, ethical considerations, data collection, data analysis, and finally the representation and evaluation of that data. However, it is important to note that these stages do not form a linear progression from problem definition, through data collection and analysis, and on to a conclusion. In his work on participant observation, Spradley (1980) describes how the ethnographic research process tends to follow a cyclical, rather than linear format. An iterative approach was taken at each stage of this research. During the study, stages ranging from entrée through to data analysis were continually repeated, as each new business case was added to the research. This provided flexibility: as new insights were discovered during analysis, these suggested new directions to explore in later stages of fieldwork, leading to the addition of new business case studies or sectors.

Two primary research methods have been used in this research. Semi-structured interviews provide 'offline' access to participants, allowing direct exploration of the key issues with each manager. Notes and transcripts from face-to-face interviews with business managers are detailed in Section 3.6. Online access to participants was provided by a form of participant observation, enabling the collection of data from the online activities of each participant. These are described in more detail in Section 3.7.

\subsection{Research ethics}

\section{Risk level to participants}

This research has been assessed at Risk Level 2 (minimal risk) by the RMIT College of Business Human Research Ethics Committee (HREC). There were minimal risks to 
participants as information obtained in the observational work and interviews remains private and confidential. Interviews with business managers were taped; however, participants had the right to have the tape turned off at any time during the session.

\section{Anonymity and pseudonymity}

Participants had the option of remaining anonymous upon request. All reports and documents generated from this research will refer to businesses and their managers by pseudonym only. Material allowing a direct identification (website snapshots) will not be used in any public document arising from the research.

Business names have not been used in this thesis or in any publications arising from the work, as all businesses and study participants have been referred to by pseudonyms. The majority of business managers had no issue with identifying their business, but I have taken this measure to ensure that all businesses have an equal measure of anonymity. Some case studies cover businesses in a small industry niche, and directly identifying one business may assist in the identification of other participants.

\section{Storage of records}

Digital recordings of the group discussions and interviews with businesses were transcribed, with copies of the recordings to be stored securely in the RMIT Graduate School of Business and Law for a period of five years after the completion of the study, in accordance with RMIT requirements. Hardcopy transcripts were stored in locked offices and filing cabinets. Digital copies of audio recordings and interview transcripts have been saved on the hard disk of a password-protected computer.

Where data was analysed using the Dedoose software package, it has been stored online on the Dedoose servers. This is a necessary step, as Dedoose is a cloud computing service, and requires all data to be uploaded to the Dedoose servers before use. This data is stored in an encrypted, password-protected format, and can only be accessed by the primary researcher. Additionally, the primary researcher can delete this data at any time.

\section{BCHEAN approval}

Research at RMIT requires approval by the university ethics board. Based on the considerations outlined above, this research was assessed as a Minimal Risk (Category 2) 
project, and received approval from the RMIT Business College Human Ethics Advisory Network (Application No. 1000103).

\subsection{Study design}

A longitudinal, multiple case-study approach has been selected for this research, in order to explore social media use among small business managers from four industry types. The research combines interview and online observational data, collecting data across a 12-month period for each case study and including multiple interviews with each participant. This section describes the stages involved in the study design. It identifies the key decisions that have been made regarding sampling, access, data sources and data collection, and the reasoning behind each of these decisions. Specific details of the two primary data collection methods used in the study are covered below.

\section{Pilot study}

A pilot study was conducted in order to refine the methods that would be used in this project. This consisted of a single case study, interviewing and observing the online activity of a retail business manager. Initially, each case study was intended to cover a much shorter span of time: three to six months, focussed on real-time monitoring of social media and two interviews with the business manager. This was modified for two reasons.

Firstly, the study period of the three-month pilot was too short, and too heavily influenced by the time of year that had been chosen. The pilot study took place near the end of the Australian financial year. During this time, the business manager was occupied with seasonal tasks, higher demand from customers and the need to finalise the year's financial statements. Unsurprisingly, this was not a time in which any significant work was done on developing an online presence for the business. Staff had little time available to undertake training or self-directed learning, create or maintain social media accounts, or do any tasks beyond the immediate requirements of the business - such as making time to speak to a researcher about what they had (or had not) been doing online. In the following month, the manager took a well-deserved holiday. They left their business in the hands of another staff member, who was reluctant to develop the business' social media profile without the input of their manager. Only during the final month did the 
business become more active online - trialling and implementing ideas that the manager had spoken about months earlier.

Secondly, the decision to focus on real-time monitoring of social media content proved unfeasible. Postill \& Pink (2012, p.131) note that social media ethnography "does not mean doing fieldwork in or about one particular social media platform - such as Facebook, Twitter or YouTube... While the latter is possible, it is complicated by the fact that most internet users constantly criss-cross a range of platforms." This was readily observed in my research: rather than operating a website and a business social media account, each manager attempted to simultaneously maintain accounts on many different social media services. The volume of content generated across these became a challenge to adequately cover in any depth, and any attempt to do this for several businesses at once would be impossible. However, most online conversations were recorded and preserved on the services that hosted them. As the study progressed, new tools became available for exporting archives of content from each account.

In light of these discoveries, the research design for subsequent case studies was modified to incorporate a longer period of observation, and a different approach to sampling and observing online data. By extending the study to spend 12 months with each business, it became possible to see how each manager operated throughout that year - reducing the effect of any particular external factors on their time. I was also able to make greater use of archived data as it became available, and concentrated on specific 'site visits' for my participant-observation sessions.

\section{Data sources}

I selected 15 small businesses, choosing examples from among the Retail, Services and Hospitality sectors. These sectors were chosen as they each contained a large number of potential businesses, and it was anticipated that businesses in each sector would have different social media requirements in terms of their customers, and the types of content the managers wished to publish. Two types of data have been collected from each business. Semi-structured interviews, conducted at the beginning and end of each case study, form the primary data collection method. These focussed on business owners or managers, as they were best equipped to represent the views of their firm: in such small organisations, the personal characteristics of the owner/manager were expected to have a significant impact on how and why social media is used by the business. Bryman \& Bell 
note some of the advantages and disadvantages of using a single respondent to represent an organisation:

One of the advantages of gathering data from a single executive respondent is that it enables a larger number of organisations to be surveyed with a lower investment of time and resources than if multiple respondents were surveyed within each organisation. However, it can also be argued that it is unwise to rely on a single respondent to know everything about the organisation ... It is therefore important to acknowledge the potential limitations associated with such a sampling strategy (Bryman \& Bell, 2007, p. 197).

Most of the businesses fall into the ABS categories of 'micro' (fewer than 5 full time staff) or 'non-employing.' In these cases, the possibility of the manager not knowing important information about their organisation is assumed to be minimal, as the owner/manager is likely to be involved in all aspects of business operation.

The second form of data consists of observations of the communications to or from each business, in the form of messages (text, images, audio and video) posted on the business' social media profiles. Notes and reflections upon these observations have been used in addition to copies of the original messages, often recorded in the form of screenshot images. These were collected throughout the case study duration, over a period of around 12 months. A longitudinal approach was selected in order analyse how each business changed its online presence over time.

Brundin (2007, p. 296) warns that focussing on the day-to-day activities of an entrepreneur and their immediate environment might overstate local effects, and recommends including the entrepreneurial context in a wider sense - such as the organisational, regional and industry levels. The majority of my data focuses explicitly on these day-to-day activities, through interviews and observation. However, I also compare and contrast the experiences of participants within this study to the wider population, as presented through Australian social media and business reports. These include the Yellow Social Media and Sensis e-Business reports, as discussed in Chapter 2.

\section{Case study selection process}

The list of participating businesses was developed throughout the study, rather than choosing all participants at an early stage. Ethnographic case studies are distinguished by exploration of the cases "as they present themselves naturally in the field, and by the 
researcher's direct involvement and participation in them" (Brewer, 2000, p. 77). It was therefore important to remain flexible, selecting and inviting new participants in order to explore new insights. Eisenhardt (1989, p. 537) describes this as a process of theoretical sampling, as distinct from sampling approaches that aim for statistical representation: new cases are selected throughout the research in order to replicate previous cases, or to explore emergent theory.

Neergard (2007) addresses the issue of sampling among the types of business that I have used for my research. Identification of the target population, the overall small size of that population and limited access to proprietary databases are mentioned as major difficulties for entrepreneurial research, influencing the choice of research strategy.

Businesses were selected to:

- Represent a range of industry sectors, in order to compare and contrast the activities of managers in different sectors. Each sector was expected to place its own particular set of demands upon businesses.

- Provide internal comparisons by using multiple examples from within each sector.

- Focus on businesses that were already using social media in some capacity, or intended to do so during the study. I deliberately excluded non-adopters, as my intent was not to discover reasons for non-use of social media. Instead, this study explores the range of uses that each manager developed.

The following selection criteria were used when selecting businesses:

Business size and type: The focus of this project is on small $(<20$ full time employees), micro (<5 FTE) and non-employing businesses, using the Australian Bureau of Statistics definitions of business size. Individually owned and operated businesses were chosen over other operational types such as franchises, as franchisees typically have less direct control over the marketing and advertising of their business.

Location: All businesses were physically based in the greater Melbourne metropolitan region, Australia. However, they may service local, national or international markets online. Two face-to-face interviews are required with each owner/manager, and so limiting the study to Melbourne small businesses allows for easier access to these participants. Additionally, selecting businesses operating in a similar socio-economic context allows for easier comparison between each case study. 
Use of technology: As this study examined questions of how and why owner/managers use social media, all businesses were either currently using one or more forms of social media, or preparing to do so within the duration of the study. I used a broad definition of social media technologies that included blogs, social networking services and forums. Other forms of internet technology that lack the explicitly social, many-to-many elements described in the introductory chapters of this thesis, such as a business web page, are not sufficient to qualify for this criterion.

Industry: Case studies from several industry sectors allowed an exploration of whether similar issues were experienced by small businesses across industry sectors, during the adoption of new technologies. Within the sample group, clusters of businesses within related industries (specialty retailers, professional services firms, inner-city bars and restaurants, growth-oriented IT startups) were used in order to allow for both interand intra-group comparisons.

In order to assemble a group of potential businesses that meet the above criteria, I initially used a 'snowball sampling' method - drawing on businesses involved in networking and 'meetup' events such as the weekly Social Media Melbourne breakfasts in the Melbourne CBD. Snowball sampling is a form of convenience sample that involves making initial contact with a small group of individuals who possess qualities relevant to the study, and using these to establish contact with others. Bryman \& Bell (2007) describe some of the limitations and strengths of this approach:

A snowball sample is in no sense random, because there is no way of knowing the precise extent of the population from which it would have to be drawn. In other words, there is no accessible sampling frame for the population from which the sample is to be taken, and the difficulty of creating such a sampling frame means that such an approach is the only feasible one ... Concerns about external validity and the ability to generalise do not loom as large within a qualitative research strategy as they do in a quantitative research one. In qualitative research, the orientation to sampling is more likely to be guided by a preference for theoretical sampling (Bryman and Bell, 2007, p. 2007).

A total of 46 business managers were approached in the early stages of this research, after having been identified as meeting the basic requirements for business size, type and location. After initial contact was made with the business owner or manager, I discussed the research aims and requirements for technology use. Fourteen business managers 
chose not to participate further at this stage. Other managers expressed an interest in the study, but were unable to make time available for interviews. This was particularly common amongst the hospitality businesses due to long hours and demanding schedules.

Once potential businesses had been identified and interviews have been conducted with the initial participants, a process of theoretical sampling was used to select appropriate case studies for this research. Bryman and Bell (2007, p. 459) describe theoretical sampling as "an ongoing process of data collection for generating theory, rather than a distinct and single stage," requiring the analyst to jointly collect and analyse data. By allowing the choice of business case studies to be driven by concepts from the emerging theory, this approach maximises the opportunity to explore these concepts.

Two additional case studies were selected from the Hospitality sector, in order to compare their experiences to those of the existing case studies in that sector. This left a total of 15 businesses participating in the study. These case study profiles are introduced in detail in the following chapter.

\section{Negotiating access}

Beyond simply gaining access to the direct participants in this research, it was necessary to develop some level of access to the online communities where these participants were most active. Direct participation is straightforward, though negotiating access proved time consuming - especially when attempting to contact business managers during busy periods. The main outcome of this type of access was the ability to spend some amount of time interviewing the manager, in order to discuss the ways that the business was using social media. Once suitable businesses were identified, I contacted the managers by phone, email, or in person, inviting them to take part in the study. Prospective study participants were provided with plain-language statements that gave an overview of the project and its requirements.

\subsection{Interviews}

Semi-structured interviews form the primary data-collection method for this project. I have used two stages of interviews with each business owner/manager, in order to explore how their use of and attitude towards social media has changed over time. The use of multiple interviews also mitigates the "recall problem" (Rogers, 2003, p. 126) 
commonly encountered in research into the adoption of a technology, where a single interview is conducted at the end of a process. Single-interview studies rely heavily on the clarity of the individual interviewee's recollections.

The first interview stage took place at the beginning of each case study, and was used to collect initial data on the business owner/managers and their firms. Storey (2010) describes a number of 'antecedent influences' on the small business owner/manager, such as their age, sector experience, local embeddedness, experience and entrepreneurial history. These influences appear often in the small business literature, such as in Richbell et al.'s (2006) study of business planning behaviour among owner/manager, and I have attempted to record these areas of potential influence early in each case study. Also at this stage, I enquired into business characteristics including the business type, size, age, and customer demographics, as well as environmental factors such as other businesses competing in the same area.

Brewer (2000) notes that unstructured or semi-structured interview formats are valued by the qualitative researcher for their ability to produce rich, deep data, typically in the form of extracts or natural language. However, he cautions that these are more demanding on the interviewer than more rigid, formalised interviews. They depend on the development of a good relationship between interviewer and interviewee, and require constant work to "sustain and control conversation, to know when to probe, prompt, and when to listen and remain silent, and to read the social cues from respondents and know when to stop pushing a line of questioning" (p. 66). The interview process described below reflects these elements. It opens with a simple overview of the business, serving two roles: first, as an icebreaker that helps to get conversation flowing. This introductory discussion also provides useful details on the way the business operates, and how this has changed over time - factors that will be drawn on later, in order to link discussions on social media use with the ways these tools have been integrated with the business.

The majority of Stage 1 interviews were conducted in mid 2010. Stage 2 interviews were conducted in September and October 2011. 


\section{Topic list: Stage 1 interviews}

\section{Section 1: Introduction ( $5 \mathrm{~min})$}

Detailed explanation of the project outline and reasons why the participant has been approached for the project. At this stage, participants sign a consent form that includes questions regarding anonymity (for themselves, and for their business) and privacy.

\section{Section 2: Background of business operations (10min)}

Discuss the industry sector, how long the business has been in operation, staff numbers and the business history. The personal story of the business manager is also explored here, with an aim to discovering their motivations for starting their business, and the goals (if any) that they have set for it.

\section{Section 3: Market segmentation and customer profiles (10min)}

Managers are asked to describe the key features of their customers. The extent of their market knowledge is explored here - what kind of data do they collect on their customers? To what extent is their target market imagined, rather than known? Do they target multiple segments? How are these segments targeted?

\section{Section 4: Social media in the business (20min)}

Which technologies are being used currently, and have different technologies been trialled in the past? How are these used to connect with customers? How are these used to network with other businesses? How much focus is given to personal communication, rather than a company or industry line?

\section{Section 5: Adoption of new technology (5min)}

Examines the manager's attitude towards new technology, and the steps that they take when choosing selecting a new technology and learning to use it.

\section{Section 6: Conclusions (5min)}

Review of interview notes with participant, allowing them an opportunity to verify or correct details as needed. 


\section{Topic list: Stage 2 interviews}

\section{Section 1: Introduction (5min)}

Briefly review of how the research project has progressed during the past year, setting out areas for discussion later in the interview.

\section{Section 2: Review of changes (15 min)}

Discuss any changes that occurred during the year: channels that have been adopted or rejected, and changes in the ways these channels are now used. Changes in the business environment and their effect on social media use are also discussed here. Finally, managers are asked how they perceive the overall success of their business' involvement in social media.

\section{Section 3: Discussion of a successful aspect (10 $\mathrm{min})$}

Managers are asked about an aspect of their social media use that they considered a success, and reflect upon the factors that made this successful. The channel used, the purpose it achieved, and the methods in which it was used are explored here.

\section{Section 4: Discussion of an unsuccessful aspect (10 $\mathrm{min})$}

Managers are asked to describe an aspect of their social media use that did not meet expectations, and what has been done to address this.

\section{Interview location}

Interviews were conducted on campus at RMIT, in the workplaces of the business owner/managers and in cafes. The participants chose the location for each interview, in order to fit in with their schedule and preferences.

Most interviews were conducted at the RMIT Graduate School of Business and Law. This location offered a controlled environment in the form of quiet, private meeting rooms, suitable for conducting and recording interviews. Originally proposed as a venue for after-hours interviews, RMIT became a popular interview location for many participants who felt they would be unable to remove themselves from the activity of their workplace while other staff members were around. 
Interviews were only rarely conducted in the participant's workplace. Often the interviewees worked from home, or shared a small office with several other staff. These businesses rarely have access to a space free from interruption or distractions, and the presence of a researcher in their work environment is considered to be highly disruptive, both to the business' operations, and to the interview itself. One home-office interview was conducted in two stages, separated by a lengthy business phone call.

As an alternative to the workplace meetings, some participants opted to be interviewed in local cafés. These had the advantage of being 'neutral territory' and were often chosen as halfway points between the university and the participant's workplace. They also proved convenient for interviews conducted during lunch breaks, as food and drinks were available. However, these locations tended to have the highest levels of background noise, and proved to be highly distracting environments.

\section{Interview duration}

The first stage of interviews was designed to be as open-ended as possible, and generally took around one hour to complete. During this stage, it became apparent that busy, timepoor business owners found the time requirement a significant barrier to becoming involved in the research project: many had other commitments during or after their working day, and sometimes pre-work or lunchtime interviews were the only available time. These interviews were often rescheduled several times, drawing out the first interview phase over several months.

Stage 2 interviews were more focussed, informed by a year's monitoring of the business through its social media presence (discussed further in Section 3.7), and experience interviewing other business owner/managers. These interviews no longer needed to cover basic details on the business or the owner/manager, and could immediately delve into areas of interest to the project. These were designed to run for 30-45 minutes, in order to fit more easily into the busy schedules of the participants.

\section{Interview notes and recording methods}

Immediately following each interview, I wrote detailed field notes on the major topics covered, and on peripheral details not addressed directly in the interviews. These were often used as a summary when referring back to interviews prior to formal analysis, and gave an additional point to triangulate conclusions about less tangible factors such as the 
interviewee's level of enthusiasm for social media technologies. Eisenhardt (1989) discusses the importance of field notes as a mechanism for enabling the overlap between data collection and data analysis - allowing emergent concepts to be explored throughout the fieldwork period.

All interviews were recorded using a smartpen device that created digital copies of both the written notes and their accompanying audio. Directly linking the two allowed easy navigation through the recording, to play back audio from the moment each note was written. This feature was of great assistance when preparing field notes, allowing for rapid cross-referencing to clarify details directly from the interview recording.

\section{Interview transcription}

I manually transcribed nine of the fifteen Stage 1 interviews. This process was valuable, as it gave an opportunity to re-listen to the complete recording from interviews. While field notes were made immediately after conducting each interview, transcription typically took place weeks or months later.

The remaining six Stage 1 interviews, and all Stage 2 interviews, were transcribed by an external transcription service. These transcripts were proofread while listening to the original interview audio, in order to ensure the highest degree of accuracy. An external transcription service was primarily chosen due to time constraints. Investing in outsourced interview transcription often requires careful proofreading to avoid discrepancies caused by a change of transcriber. However, this process assisted me in maintaining a similar level of immersion in this data when compared to the earlier selftranscribed interviews. The shift to third-party transcription also saved valuable time in the latter part of this research, allowing me to spend more time comparing the two stages in order to observe how social media adoption and use changed over time.

\subsection{Social media data}

The second form of data collection involved regular monitoring of the social media posting by each business. This involved regular observation of each manager's online activity, approached in a similar manner to the participant observation methods used in traditional ethnographic research. These observations followed similar structure to the "catching up, sharing, exploring, interacting and archiving" practices described by Postill 
\& Pink (2012, p. 128), though my research attempted to minimise interaction with study participants where possible. Brewer (2000, p. 59) describes participant observation as "data gathering by means of participation in the daily life of informants in their natural setting: watching, observing and talking to them, in order to discover their interpretations, social meanings and activities". Further to this, Brewer notes that researchers who become participant observers must develop certain qualities, as the main instrument involved in this form of data collection is the individual researcher. These qualities include a balance between 'insider' and 'outsider' status: allowing the researcher to identify with those they study, but remaining a professional distance that allows them to perform their role as observers and collectors of data.

Two major types of social media use have been explored in this study, which I define by separating active and passive behaviour. Active behaviour involves posting content: updating a blog, joining conversations on social networking services and Twitter. Passive behaviour, often referred to as 'lurking,' describes the time spent reading, watching and listening to social media channels. While passive activity was not directly monitored, it was discussed during interviews with each of the managers. Lurking behaviour typically leaves no direct record, and data on this behaviour is not readily available for many social media services. I have focused on observing active social media use in the form of content posted by each business, and the discussions that they take part in. I have also asked managers to reflect on both their active and passive use of social media during their interviews. This helps to identify other channels that they have considered valuable, and provides an opportunity to explore how they find value in these peripheral activities.

\section{Monitoring frequency}

I attempted to monitor each business during the times they were most active. This varied depending on the manager's workload, and their audience: there would be little value in posting content aimed at the business' customers during times when those customers are not online. Each social media type carries a different set of expectations in regard to time of posting. Blog posts are often read by visitors to the business' web page, or indexed by RSS readers. In both cases, content can be posted ahead of time, and will be read at a time that the audience finds convenient. Forum posts have sequential replies, giving them a certain degree of immediacy: if a conversation moves too fast, a latecomer will find little value in responding to comments made several pages earlier. However, by grouping posts 
in threaded conversations, the forums allow people to easily join or leave conversations, reading over recent posts when they return. Micro-blogging services like Twitter have the greatest expectation of immediacy. With a continual stream of incoming information, there is no expectation that any user will be aware of all the posts made by their followers - especially if that stream has continued throughout the night, or across a weekend. Instead, most conversation happens between users who are online at the same time.

It soon became apparent that while archives of online activity were available on most platforms, it would not be feasible to attempt an analysis of the entire contents of each social media account. Instead, a series of observation periods were chosen for each business in order to provide a range of different contexts. These varied by their time of day (early morning, lunch breaks, afternoon, evening), day of the week (weekdays and weekends), and time of year (early or late in the month, over several months of the year). It is easy to imagine how a business manager's level of online activity could vary between the stress and deadlines at the end of financial year, to public holidays or weekends.

'Real time' observation was the preferred method of data collection, as it was easier to read cues such as the timeliness of replies. In busy forums, or where several platforms were used, real-time monitoring also made it possible to quickly locate contextual information alluded to in conversations, but not always presented in the same medium.

\section{Data format}

Where the business website has been updated, I have attempted to capture this in several ways. The simplest method is to record screenshots of relevant content - preserving the exact appearance of the site at that point in time. This has the added benefit of being able to capture static images of content such as videos and animations, which were more difficult to record by other methods. Where more lengthy content has been added, I have used Zotero (a reference manager add-on for the Firefox web browser) to record 'snapshots' of web pages: saving offline versions of the site's text, images and layout.

\section{Observational field notes}

It rapidly became apparent that no amount of 'snapshots' could give a full understanding of the business' social media activity. Instead, I opted to use participant observation methods to immerse myself in the social media environment surrounding each business. This involved a large amount of time observing conversations and events on social 
networking sites, forums and Twitter. Field notes were recorded using the Evernote software program, and tagged with descriptive identifiers to facilitate easier sorting and location of relevant information during analysis. This approach mirrored the process used for interview notes, in order to overlap data collection and data analysis activities (Eisenhardt, 1989, p. 539).

\section{Minimising visibility for online participant observation}

Rogers (2003) describes four methods that are commonly used to identify opinion leadership and network links: sociometric techniques applied to large numbers of respondents; interviewing key informants; self-designation and observation - noting that observation methods typically have a high degree of validity, where network links are appropriately observed. However, traditional observation techniques can be highly obtrusive, and the visible presence of the observer can change the behaviour they are observing. By conducting observations remotely and observing online communications over a long period of time, I have attempted to minimise the degree to which I am visible to the study participants.

In addition to this, the online message types used in this study can typically be easily seen, recorded and searched through after they have been posted. This allowed me to observe each business in ways that I could not have done face to face. At the beginning of the study, I examined material that had been publicly posted before I began actively observing each manager. This gave an indication of what had already been done prior to the study period: which services were in use, and how they were being used. It also provided an example of how the managers used social media when they weren't aware of being watched by a researcher. I compared this with observations made of material posted during the first month of the study, immediately before and after interviewing the business manager. During this time, I expected that my impact would be greatest: by meeting a researcher and discussing aspects of how they communicated online, the managers would be more conscious of how they did this in the following weeks. After this period of direct contact, I anticipated that their social media use would return to a more normal level: informed by discussions they had during their interview, but not actively considering the researcher as a constant secondary 'audience' for their activity. 


\subsection{Quality measures in the research design}

Kozinets (2010, p. 162) proposes ten evaluative standards for quality assessment in online ethnographic research. At a basic level, these focus on coherence, rigour and groundedness. In this context, coherence refers to the extent to which each interpretation is free from internal contradictions, and able to present a unified pattern to the reader. Rigour is described in terms of adherence to procedural standards, while groundedness describes the connection between the theoretical representation and the data, with clear and convincing links between the two. These are discussed throughout this chapter.

Literacy is demonstrated via recognition of and knowledge about the relevant literature and research approaches, while innovation describes the extent to which the constructs, ideas, frameworks and narrative provide new and creative ways of understanding systems, structures, experience or actions. Criteria for evaluating the work based on resonance and verisimilitude are drawn from the postmodern approach, and focus on standards to "emphasise the emotional connection that the representation is able to offer its readers, and the lifelike qualities of that representation," (Kozinets, 2010, p. 162) describing the extent to which the work presents a personalised connection with the cultural phenomena. Finally, Kozinets proposes reflexivity, emphasising openness of the text; praxis, encouraging a pragmatic focus on social concerns; and intermix, a focus of the interconnection between online and off-line social worlds. This final criterion is of particular relevance here: as this study explores how managers act in and engage with online communities that are intrinsically connected to off-line groups, I have attempted to show the deeply intertwined nature of the two in each case study.

\section{Validity and reliability}

The concepts of validity and reliability, as they are applied to quantitative studies, are difficult to translate directly into a qualitative study. In particular, the external reliability or replicability of such a study is impossible to guarantee: each case study within this project represents a business at a particular period in time. The technological and social environments in which the owner/managers operate are in constant flux, and their experience using the technology is continually evolving. Each business case study has involved unique factors affecting the decisions that managers have made, and there is no guarantee they would make the same decisions again if the study were repeated. 
Similarly, my own experience as a researcher has increased throughout the project, affecting the type of insights that I develop from my observations. Bryman \& Bell (2007, p. 410) note that 'it is impossible to 'freeze' a social setting and the circumstances of an initial study to make it replicable in the sense the word is usually employed". However, by presenting as much contextual detail as possible about each case study and the means by which I have developed it, I can improve the quality and rigour of the research.

In order to improve the validity of the interpretations used in this study, I have used a process of triangulation to critically examine my findings. Brewer (2000) describes triangulation as a routine element of any ethnography, helping to ensure a more rounded picture by the use of various sources of data. In this study, data triangulation has involved drawing upon data gathered via several different methods (post-interview notes, interview transcripts, website snapshots and field notes).

Denzin (1970) argued that triangulation should not be limited only to data, but also to the use of multiple investigators, methodological and theoretical frameworks. Similarly, Golafshani (2003, p. 604) describes the use of multiple methods as leading "to more valid, reliable and diverse construction of realities," and Ratcliffe (2002) suggests involving multiple researchers in the data analysis process in order to benefit from multiple perspectives. While the use of multiple primary investigators is not possible in the scope of a doctoral research project, I have drawn upon the insights of colleagues both in industry, and in a cross-disciplinary research school, in order to challenge my own assumptions about the findings of this research.

The presence of a single researcher in this process removes issues of inter-rater (internal) reliability, however. Where possible, I have involved the study participants asking them to conduct a 'member check' of notes from their interviews and observations. This helps to enhance the validity of the research by confirming the accuracy of transcribed material. It also has the added benefit of strengthening ties with the participants by involving them in the analysis. Where possible, I have discussed themes and hypotheses as they arose to check for potential weak points in logic or method. Regular meetings with my supervisor, and with a network of other students involved in similar research, formed another valuable tool. These provided opportunities to debrief, and to continually test hypotheses. 


\section{Trustworthiness and authenticity}

Lincoln \& Guba (1985) and Guba \& Lincoln (1994) propose 'trustworthiness' and 'authenticity' as more intuitive alternatives to validity and reliability, in the field of qualitative research. Their definition of trustworthiness is comprised of four elements: credibility, transferability, dependability and confirmability. Credibility may be enhanced by critical analysis of conclusions drawn from the data, and can include both peer debriefing and member checking, as described above. Transferability refers to the degree to which results can be applied to other settings, and can be enhanced by providing sufficient descriptive data about the research process to allow other researchers to evaluate the work for themselves.

The concept of dependability in this context is closest to reliability, as it would be defined in quantitative research. While the results of qualitative interviews are generally not replicable, internal consistency in the research methods is still an important consideration. The following section describes how I use multiple stages of coding when analysing study data, in order to reflect upon themes and coding decisions during the analysis. As themes emerge, re-assessing data from previous interviews provides an opportunity to confirm or question impressions formed earlier in the project.

Confirmability relates to the degree to which others can objectively confirm the conclusions drawn. This may be enhanced by making both the data, and the conclusions drawn from them, as transparent as possible. Where possible, I will present direct quotes from transcripts in order to maximise the transparency of my conclusions. As some participants have requested anonymity, I have limited these to quotes from within interviews, rather than providing example text from their social media profiles. This choice was made as providing readers with access to source material may allow them to identify participants who requested to remain anonymous, by using search engines to discover the original source of this text.

\subsection{Computer-assisted qualitative data analysis techniques}

Throughout the analysis stage of this research, I have used software to assist with the management and interrogation of my data. After consideration and trials of several products, I selected Dedoose as my CAQDAS (computer-assisted qualitative data analysis software) tool of choice. The use of software in qualitative analysis appears to vary widely 
depending on the background and training of the individual researcher. However, these tools offer several advantages over 'hardcopy' techniques. Though they describe Nvivo in their own study, Wakkee, Englis \& During (2007, p. 344) succinctly describe the benefits of software to assist with qualitative analysis: it "allows for the creating and editing of primary or secondary data to facilitate their exploration, organisation and linking, as well as the searching, modelling and theorising of an emerging analysis."

\section{Dedoose software}

Dedoose is a 'cloud based' software tool designed for qualitative and mixed-methods data analysis. Unlike earlier forms of CAQDAS software (such as Nvivo, HyperResearch or Atlas.ti), Dedoose is accessed via a web browser rather than being installed to a local machine. This enabled far greater accessibility, as access to the software and project data was available on any computer with a relatively current browser. It also supports crossplatform use, which was a major factor in my choice of software: the lack of Mac OS support was a critical failing of other software tools tested during this research.

All interviews were digitally recorded, and transcribed. This allowed text and images to be imported into Dedoose, ready to begin a more detailed analysis. I refer to these data items as 'records' - most commonly each record is a passage of text from observational notes or an interview transcript. The software allowed me to code data according to broad themes that emerged during the analysis, and also provided a series of powerful tools to aid in performing the data analysis. These include text searches to quickly find related quotes and annotations; Boolean searches to find cases containing specific combinations of themes, and the ability to easily perform negative case analyses to test for elements in the data that may contradict patterns or theoretical explanations.

\section{Qualitative data coding}

Richards (2009) describes three major types of coding that are used in qualitative analysis: descriptive, topic and analytical. Descriptive coding occurred at an early stage in this research, often immediately after data was collected. This provided information about each case, and was applied to whole records rather than elements within them. While descriptive coding is essential for navigation through the large volume of data accumulated during the research, it serves as a precursor to more detailed analysis. 
Topic coding was the second stage in this process; applied to elements within a record, such as individual sentences or paragraphs in a transcript. The purpose of this stage was to categorise data within each case, preparing for analysis. This involved the labelling of text with the category or categories that it applies to. Here, the advantage of using software became apparent: a given section of text could be simultaneously assigned to any number of topics, readily accessible when searching for data that relate to any of these. While this would still be possible with physical methods, it risks incoherence (when a transcript is obscured by too many layers of highlighting and annotations), or requires multiple copies of each section in order to physically separate topic material. I applied this form of coding to my data after importing text and screenshots into Dedoose. This stage was informed by theory, which helped to identify topics of specific interest for example, discussions about the difficulty of learning to use social media services, or those relating to observing other social media users. Other categories included social media services, and the integration of these within a business. The category list was refined during the process, with additional categories added as they were observed.

The final stage in this process was analytical coding: applied in my research primarily from a 'bottom up' approach, inducting themes and connections. This involved several iterations of coding, applied in a similar fashion to previous stage. This process aims for induction, interpretation and reflection, linking data to concepts and theories. I have used a 'tree' structure (Richards, 2009, p.118) when developing codes to categorise and interrogate my data. The primary nodes of this data structure were drawn from the research question, exploring factors associated with adoption, use or outcomes of social media. At this stage, I also considered features present in the Diffusion of Innovations framework, exploring aspects related to properties of the social media technologies, and to the business managers themselves. However, it was also vital to remain flexible in the use of this coding structure throughout the analysis, so my emphasis remained on inductive coding. This led to further exploration of networking activities and social capital, as those factors emerged as an important business outcome generated by social media use. Themes relating to this are explored further in Chapter 7.

As new themes were inducted from the data, they raised questions that could be explored for potential insight into the research as a whole. For example, discussion within Stage 1 interviews drew attention to the fact that several managers appeared to see no 
downside to leaving disused social media profiles public. This tied in to their attitudes towards creating new accounts, and to their perception of how customers would look for their business online. Temporary new nodes and branches were created for these codes. This allowed more detailed consideration of these issues, reflecting upon their relevance to the project. In some cases, the questions raised by these proved to be outside the scope of the current research. In others, such as comments regarding 'trust' and 'influence,' they became central to understanding the online behaviour of each participant.

\subsection{Conclusions}

This chapter has outlined the research methodology and methods that I have used in this research. My research is exploratory and qualitative, using a longitudinal, multiple casestudy approach (Eisenhardt, 1989) to investigate social media use by local small business managers. I have adopted ethnographic research methods, adapted for use in an online environment using Kozinets' (2010) framework, and further informed by the virtual ethnography approach described by Hine (2008). This approach addresses the appropriateness of methods such as observation and interviewing in an online context, and outlines measures to improve the quality of both data and conclusions drawn from such methods. Initial candidates were identified using a 'snowball' sampling method to produce a pool of potential candidates that met the criteria of location, business type, industry type and social media use. Following this, a process of theoretical sampling resulted in the selection of a total of fifteen managers who joined the study, representing businesses from the hospitality, retail, professional services and IT startup sectors.

Data for this research have been collected via semi-structured interviews with business manager, and through a 12-month period of online participant observation of each manager's social media use. All managers were interviewed at the beginning of their involvement with the project, to explore their current level of social media use, and their goals for the following year. Follow-up correspondence with each manager, in the form of email, phone calls or further face-to-face interviews, took place at the end of the study.

Interview transcripts and observation notes were then analysed for common themes using a series of qualitative 'coding' stages, inducting theory from the data. This began with specific observations, and later encompassed broader concepts associated with the adoption of social media, and the outcomes that managers received from their social 
media usage. Throughout this process, the Dedoose software package was used to assist with the management and interrogation of data records - in particular, helping to conduct 'within-case' and 'cross-case' analysis of emergent themes (Eisenhardt, 1989), to shape and validate hypotheses.

The following chapter introduces the managers and businesses that took part in this research, providing background information and context for each case study. 


\section{Case Studies}

\subsection{Introduction}

This chapter introduces the case studies used in my research. They are grouped into four major industry categories: hospitality businesses, retailers, IT startups and services businesses. I introduce each business and its manager (or managers, in the case of coowned firms) below, in order to provide context for understanding each manager's technology choices. Those choices will be explored further in Chapter 5.

\begin{tabular}{llll}
\hline & Business Name & Manager(s) & Industry \\
\hline $\mathbf{1}$ & Shanghai & Alex & Hospitality \\
$\mathbf{2}$ & Fusion & Lee & Hospitality \\
$\mathbf{3}$ & Lunch Spot & Ben and Eleanor & Hospitality \\
$\mathbf{4}$ & Model Madness & Matt & Retail \\
$\mathbf{5}$ & Toys and Games & Jennifer & Retail \\
$\mathbf{6}$ & Fashion on Wheels & Christine & Retail \\
$\mathbf{7}$ & Bandwagon & Liz and Graham & Retail \\
$\mathbf{8}$ & Videogame Network & Robert & Services (IT startup) \\
$\mathbf{9}$ & SocialSearch & Eric and John & Services (IT startup) \\
\hline $\mathbf{1 0}$ & Network Solutions & Luke & Services \\
$\mathbf{1 1}$ & Central PR & Jess & Services \\
\hline $\mathbf{1 2}$ & Vitae & Sarah & Services \\
$\mathbf{1 3}$ & Cover Story & Mel & Services \\
$\mathbf{1 4}$ & Building Blocks & Allana and Dean & Services \\
$\mathbf{1 5}$ & Inner Circle & Mary & Services \\
\hline & & & \\
\hline
\end{tabular}




\subsection{Hospitality businesses}

\section{Shanghai: The inner-city bar}

\section{Overview and description of business}

Like many of Melbourne's bars, Shanghai could be difficult to find on a first visit. On one of the city's many laneways, a small sign marked the top of a staircase leading down to the bar, hidden below street level. The sign bore no name: just a symbol in red and yellow that provided little information to the casual passer-by. Other venues crowded the laneway: restaurant tables filled the street, and waiters eagerly encouraged visitors to stop and examine menus. The lane was hardly a thoroughfare, but in the evenings it filled with people. In contrast, the small doorway beneath the red sign remained quiet. On busy nights, a security guard stood vigil at the entrance: signalling that something must be happening down below. At other times, the stairway was easily overlooked.

The bar's low profile was a deliberate move by the manager, based on years of experience in the Melbourne bar scene. "The more hidden away a place is," he explained, "the more people talk about it. It's because they have a sense of ownership, like it's their secret to share with their friends."

Shanghai was a cocktail bar, with an extensive list of specialities and spirits from around the world. The bar staff were experts at their trade, and a collection of awards hung from a wall just inside the entrance. It was marketed as an experience - a place for a special night out, to be remembered by stories and photos shown to friends. The bar's target market were young professionals who lived or worked in the inner city. All aspects of the bar - its decor, seating arrangements, location, drinks list and pricing - were carefully designed to attract these customers, and to exclude others.

\section{Owner profile: Alex}

Alex was a successful entrepreneur, with a series of other ventures behind him. Shanghai was his latest bar, although he opened another late in the study period. He was well connected in the Melbourne bar scene, and his businesses had won many awards. Industry experience, built up over several years, gave him an instinctive understanding of how to develop, launch and manage hospitality businesses in the CBD. A designer by 
training, he had no formal qualifications in marketing or public relations. Despite this, his businesses consistently attracted favourable media coverage and reviews, through online and traditional channels.

Alex kept track of trends in the hospitality sector through his personal connections to other bar owners, and regular trips abroad to see how things were done in the world's biggest cities. Twitter appealed to him for its immediacy and ability to make customers feel included in the bar's activities: tipping them off when new cocktails appeared on the menu, or when a rare bottle of spirits would be opened up behind the bar. Early in the study, Alex' business partner began using Facebook to promote events at the bar. They did not advertise overtly, preferring to list events that their customers could invite friends along to.

Like many of the city's bar owners, Alex rarely paid to advertise his business. He relied on his customers finding information in the same way as he and his staff: through word of mouth, reviews in websites and magazines, and by searching online. Instead, he developed a rapport with the editors of Melbourne's magazines and venue guides: making a habit of responding quickly whenever a call for content was made, and providing access to the bar and its staff when journalists were producing stories. His intent was clear: in his industry, a bar's reputation came not from what it said about itself, but from what others said about it.

\section{Fusion: The restaurant}

\section{Overview and description of business}

Located on a busy shopping and restaurant strip in Melbourne's inner south, Fusion competed for the attention of large numbers of visitors through the precinct. Named for its mix of different cuisines, the restaurant served modern reinterpretations of traditional dishes from India, Japan, China and South-East Asia. The building itself was decorated in a fusion of different styles, to complement the mix of cultures present on the restaurant's menu - high ceilings and ornate decorations were retained from the venue's past life as a grand hotel foyer, providing contrast for a series of bright murals.

Despite its promising location in an affluent suburb, the restaurant struggled to attract customers from the local area. The manager hoped that locals would quickly adopt the new venture, but it soon became apparent that the area's restaurants had far lower 
foot traffic during the evenings - particularly on weekends, when the area's nightclubs attracted rowdy crowds looking for a night on the town, rather than fine dining. Few locals walked down the main street in the evenings, and the dinner service did not draw as many customers as the owners had hoped.

During the study, the restaurant worked to develop an identity - opening shortly before the study period, and changing focus several times during the following year. For the majority of this time, Fusion was positioned as a high-end restaurant; applying modern cooking techniques and presentation style to classic dishes. Later in the study period, this shifted towards a more accessible style, with an expanded lunch offering and family-oriented prices. The restaurant's marketing, on and offline, was focussed on attracting new customers and making them aware of the new business.

\section{Owner profile: Lee}

Lee initially worked in finance, before retraining as a chef. Her business and management skills helped to establish her first restaurant in the heart of the Melbourne CBD, and the business grew rapidly. Born in Singapore, Lee's fascination with food drew on the cooking skills and dishes from her childhood, supplemented by regular trips home to research new recipes. Fusion was the latest in a series of Melbourne restaurants that she operated with her husband.

Soon after the restaurant opened, a member of staff created Facebook and Twitter profiles for the business. These were used sporadically, and abandoned after that chef left the business. Months later, Lee decided to explore the use of these herself. Access to mobile technology was a crucial factor in her early experimentation with social media: Twitter was easy to use from work, but she found the Facebook mobile interface significantly harder to navigate on her Blackberry phone. As a result, her early ventures in social media focussed entirely on Twitter, and it was through this platform that she came into contact with members of Melbourne's food blogging community.

These contacts helped to give her business a new lease of life - attracting reviewers and bloggers who helped to raise awareness of the restaurant, and filling the tables each night. Special events such as menu launches or themed dinners proved popular among the city's food enthusiasts, helping her to develop a rapport with this community. 


\section{Lunch Spot: The city cafe}

\section{Overview and description of business}

Lunch Spot was a cafe in the Melbourne CBD, specialising in gourmet sandwiches. The lunch trade was busy, with customers lining up out the door and into the courtyard. Inside, a team prepared house specialities fit for a fine dining restaurant, while the front counter staff greeted regular customers by name. The cafe catered to customers who valued the prestige that came from eating at a 'known' institution, rather than finding the most convenient option for lunch - often travelling across the CBD to visit. From bread to sandwich fillings, the provenance of each ingredient was announced on menus, taking advantage of the city's growing fascination with food.

The business opened in early 2011, and quickly became a popular lunch venue. Located in the corporate heartland of the CBD, white-collar workers from nearby banks and law firms formed its core customer segment during weekday lunch hours. During the study the cafe managers experimented with different hours of operation, trialling evening shifts and special events. These were later dropped, as the staff opted to focus on their core market instead.

Like Shanghai and many other small hospitality businesses in the city, the cafe's relatively obscure location was made to work in its favour. First-time visitors could easily miss the cafe, giving regular customers an opportunity to share the 'secret' venue location with their friends. This led to an increased sense of ownership among the regular customers: a feeling that the cafe was their secret, to share among trusted friends. Customers often used social media to plan a visit to the cafe with their friends - tagging them into posts on Twitter or Facebook.

\section{Owner profiles: Ben and Eleanor}

The business was run by Ben and Eleanor; a couple with extensive experience in Melbourne's restaurant community. Before starting their own business, they worked in high profile restaurants in the Southbank fine dining precinct. Neither had launched or managed a business prior to opening Lunch Spot. Despite this, they quickly established a following of loyal customers, and received press coverage in major newspapers within weeks of opening their doors. A major factor in this was the degree to which the pair were embedded in the city's online communities food bloggers, restauranteurs and reviewers. 
Both managers relied heavily on social media to establish a presence in Melbourne's busy restaurant and cafe landscape. No traditional print or broadcast advertising was used when launching the business - instead, each stage of the business' development was covered on a blog. A self-described 'food nerd,' Eleanor began blogging about food and restaurants three years prior to opening her own business. Through this blog, she made many contacts among other bloggers and reviewers, and drew upon these to help launch her new venture.

After the business launched, time constraints made it impossible for Eleanor to continue regular blog updates. Despite this, the business continued to receive a steady flow of reviews and commentary from other bloggers. "I thought I was going to be the last food blogger in Melbourne to visit them," wrote one reviewer, commenting on how the local food blogs seemed almost over-saturated with news about the cafe. The cafe's high profile among bloggers also helped it to receive attention from mainstream media, with the new cafe being listed in major publications like The Age newspaper's Good Food Guide within months of opening.

Ben supported his front-of-house role by managing the cafe's presence on Twitter, favouring the micro-blogging service for its ease of use while standing at the register. In quiet moments during the afternoon, he checked to see what customers were saying about the business, re-tweeting and responding to these. This provided a regular stream of content, presenting customers with the image of a business at the centre of a thriving customer community.

\subsection{Retail businesses}

\section{Model Madness: The model store}

\section{Overview and description of business}

Model Madness operated out of Melbourne's inner northern suburbs, occupying a former office building on a busy road with few neighbouring retail businesses. A handful of factory outlets lay closer in to the city, and rows of densely packed houses lined the streets to the north. Inside, the store was filled with racks of model kits and components; glass display cabinets and a notice board covered in flyers for local events. 
The manager considered links to existing customer groups to be essential to the success of his business, noting that his policy was "to support any of the clubs that keep people involved in this hobby ... Anybody coming in with a valid membership card for any club will get the same discount here."

The store was a short walk from two university campuses, and most of its regular customers were current students or recent graduates. In addition, parents brought their children in to the store on weekends, and Matt had regular mid-afternoon visits from a handful of retirees - "the historical crowd," he joked, noting their preference for historical figures depicting regiments from the Napoleonic era or earlier. In other cabinets, the bright colours and fantastical creatures decorating the boxes of fantasy and sciencefiction models drew a younger crowd.

\section{Manager profile: Matt}

The store was Matt's first solo business venture, after leaving a well-paid IT career to follow his dreams of owning a model store. His family actively supported his decision: his younger brother working occasional shifts on the register, while his father checked in to offer advice in the evenings. Through family contacts, Matt had access to experienced mentors who help him to plan for the business' growth. During quiet periods, Matt still worked on contract IT projects - keeping his programming skills current, and helping to ease the financial burden of launching a new business.

A self-confessed tinkerer, Matt continually worked on the store's website and social media accounts. The site had been built from the ground up, incorporating features beyond the reach of most micro retail businesses. These included automated SMS notifications when customer orders arrived in stock, a custom-built online shopping cart, forums and image galleries. Matt's computer sat behind the store counter; web browser filled with tabs containing technical support and troubleshooting advice. The site was a constant work in progress, and as much a matter of pride as the store itself.

Matt was an avid fan of YouTube, and had started his own channel prior to opening a store. This became an important link to the wider world: a retail startup could be a lonely venture, and Matt shared his experiences with viewers and subscribers from around the world. Most of his videos were tutorials or reviews, with the occasional tour of his store to show new developments. He personally knew many of the people who commented on his videos, often responding to these at the end of each new video: thanking other 
'YouTubers' who contributed over the previous week, and recommending other channels for his viewers to watch.

Many of Matt's customers used forums to discuss modelling techniques, new product releases and game tournaments, and he was heavily involved with two of these. The Model Madness website had its own forum, used by a small group of regular customers to organise events in the store. Matt also paid for advertising on a larger forum, and used that site to keep an eye on discussions that were relevant to his business. These ads raised awareness of his store, directing people back to the website for more information. Perhaps even more important was the time that Matt invested in building relationships with people on that site: offering advice and sharing tips with other model-builders, and regularly offering sponsorship and prizes for competitions and events around the country. Many of his customers ordered online and had never met him in person, but were fiercely loyal towards the store: often entering discussions to direct new customers to the Model Madness website, recommending both the business and its manager.

\section{Toys \& Games: The games store}

\section{Overview and description of business}

Located in Melbourne's outer suburbs, Toys \& Games seemed an unlikely addition to the bulk-goods stores that lined the surrounding highways. While neighbouring retailers sold furniture or electrical goods, the toy store used its large floor area to display intricate dioramas of miniature landscapes, and game pieces used upon them. The store shared many stock lines with Model Madness, but the two took very different approaches to operating their businesses.

The large venue that Toys \& Games occupied during the study was the second they had operated from. The store's original location had been a tiny shopfront, hidden down a laneway behind the main row of shops. The store quickly outgrew these premises and moved to far a more spacious alternative at the opposite end of the main street. The new premises occupied a high-exposure site on a major road, and were significantly larger allowing the store to host regular tournaments and competitions for the games they sold. This allowed the store to introduce a new generation of customers to a hobby that experienced its primary growth during the 80s and 90s, and now suffered attrition among its customer base. The larger floor area also allowed Toys \& Games to build display 
tables of models and scenery, which they used to host weekend and school holiday events attracting younger customers and their parents.

Their commitment to hosting regular events also helped to establish the store among the local communities of collectors and games clubs. These groups typically attracted a different type of customer: more accustomed to searching for bargains among online stores, and less likely to visit a brick and mortar store. The managers recognised this, and worked to build a reputation for their store as an integral part of the game community: supporting local groups by offering venue hire, discounts, and prize support for competitions. This gave the older customers more reason to visit the store in person, and gave a human face to the business - helping to differentiate them from the online retailers that had become their major competition.

\section{Manager profiles: Jennifer}

Jennifer co-founded Toys \& Games with her husband Alan in 2010, and managed the business while Alan continued with his primary job. Alan had noticed a lack of stores in the outer suburbs that carried products he was interested in, and the two had decided to start their own. Neither had launched or managed a business before, so they drew on their experiences as customers and consumers to create their "ideal" business. The couple had two young children, and needed more flexibility in their working hours than a regular 9-5 job would allow.

Jennifer took pride in her knowledge of other business owners in her industry, and had attempted to set up a social group for store owners to "talk shop, and share ideas." Soon after opening Toys \& Games, the store's major supplier ran an annual sales training program for their stockists. Jennifer valued this program for the opportunities it gave her to meet others in the industry, in addition to its original purpose of helping store owners to develop their product knowledge and sales skills. She regarded local brick and mortar stores as allies more than competitors, seeing much greater risk in the competition from the deep-discounting online stores that threatened to make physical stores obsolete. However, this view was not widely shared by other local store owners during the study, and her attempts at connecting her industry peers were unsuccessful.

Jennifer experimented with Twitter and Facebook shortly after her business launched, but had limited success with either. She did not use either service outside of the business, and commented on the difficulty in finding enthusiasm for attempting to 
start a business community from scratch. The majority of her customers were already active forum users, so she focussed her attention on two local forums, and several in North America. Each of these served different purposes. A large Australian forum was used for advertising and business promotion, and Jennifer regularly posted there in response to questions about finding rare or unusual products. The smaller local forum was home to a different audience segment, and allowed her to develop her business' reputation as a specialist stockist for the parts and equipment used by those customers. Finally, she used international forums as a way of identifying trends before they appeared among local customers. This allowed her to order popular products early, giving her an advantage over other local stores.

\section{Fashion on Wheels: The cycling accessories store}

\section{Overview and description of business}

Fashion on Wheels had no physical shopfront, but their distinctive products were highly visible on the streets of Melbourne and other major cities along the east coast of Australia. This online store opened in mid 2010, selling speciality clothing and fashion accessories for cyclists. Many of their products came from cities in Europe and Asia, where cyclist fashion was a more developed industry. By importing products that were difficult to find locally, the store capitalised on Melbourne's growing number of urban cyclists and its reputation as a city of fashion.

As an online business, Fashion on Wheels sold to customers from around the country - sending regular orders to every state and territory. Most customers were located in the eastern capital cities: Melbourne, Sydney and Brisbane. This was unsurprising - in addition to their large populations, the three cities were also home to the most active cycling groups, and the majority of the store's media coverage appeared in those areas. Many of the store's customers were women, who Christine describes as "very underrepresented in this particular market ... if you go into any bike shop, it's going to be very male-orientated and very sports-orientated."

\section{Owner profile: Christine}

Fashion on Wheels was Christine's first business, beginning as a part-time operation supported by her regular job. She had been looking for a business idea to develop for 
some time, after returning from several years overseas. While living in Europe, she became aware of a fashion niche that was not being addressed back in Australia, and decided to follow up on this when returning to Melbourne.

Christine relied heavily on social media for most aspects of her business marketing. This choice was initially made in order to keep costs down, as most of the social media services used by the business were free. It also allowed her to draw on her experience using WordPress, Twitter and Facebook. Christine had been an active blogger since 2007; starting a travel diary while living in the UK, and writing a personal guide to the city's shopping, food and events after returning to Melbourne.

The business website incorporated a blog and online store. Regular blog updates introduced new stock items, and alerted readers to local events. Content posted to the blog and YouTube channel was distributed on other networks using services like Facebook, Twitter and Pinterest, ensuring that a wide audience saw each new video or article. Since launching her business, Christine used two Twitter accounts: one specifically for the business, branded with the business name, and the other for personal posts. The separation between personal and business content gradually became less pronounced during the study, as her business developed. Christine initially avoided LinkedIn as she wanted to avoid promoting her new business to the colleagues while still in a full-time job, but began using the service in order to keep in contact with former coworkers after leaving to run Fashion on Wheels full time.

The greatest return on Christine's social media time came from Facebook and Twitter, where she operated business-focussed accounts that aimed to provide interesting, relevant information to potential customers rather than purely focussing on sales. She found relatively few forums that were directly relevant to her industry niche, and she found it difficult to join those communities of cycling or fashion consumers when representing a business.

\section{Bandwagon: Art and music store}

\section{Overview and description of business}

Bandwagon operated as a distributor for music and artwork, helping artists to sell their products. The business had no physical shopfront, using an online store to sell to 
customers around the world. Established in 2008, the business initially focused on retail sales. A wholesale arm was added later, and this became a major focus during the study.

The business made a clear distinction between music distribution and record labels, only taking on self-produced bands that did not have a recording contract. This frequently caused confusion among potential clients, despite clear and careful wording on the Bandwagon website and information packs sent to potential new artists: as a distributor, the business did not provide advance payments to artists that are yet to produce albums. Instead, they assisted artists to get their work into stores, and sold products online directly to customers.

Bandwagon's concept was developed when the two managers noticed that their friends in the music industry were having trouble finding distributors who could get their recordings into stores. Bands without recording deals were forced to use small, unreliable distribution firms, which frequently went out of business at short notice. After some investigation, Liz and Graham decided that other businesses in the area typically suffered cash flow issues arising from poorly developed business models. The basic principles behind running a distribution business appeared sound, and so the pair decided to launch their own operation.

Late in the study Bandwagon opted to focus exclusively on music distribution, as art pieces such as photography prints and paintings had proven more difficult to sell. The managers concentrated on bands that they already had a relationship with, and reduced the range of 'random' products listed on their webstore. This gave a clearer purpose to the business; an important consideration when needing to explain the business to prospective clients.

\section{Owner profiles: Liz and Graham}

The business was jointly run by Liz and Graham, both in their twenties. Both had some experience with startups prior to launching Bandwagon: Liz had launched a business producing custom T-shirt prints, while Graham had run a small IT consultancy. They were also supported by an experienced business mentor and family friend of Liz. This advisor provided marketing advice and a sounding board for the managers to seek honest feedback on their business decisions. During the study, both managers worked part-time on Bandwagon while continuing with their original roles in communications and IT. 
Both managers were keen social media users, with personal and business profiles on most popular services. Many of their business profiles were used for a short period and then abandoned - leaving outdated content, but also containing a profile link that could direct visitors to the business website. At the beginning of the study, the two managers noted that their Myspace profile was being deliberately phased out, as it had not been used in several years. When the social network reinvented itself as a music-focussed community, Bandwagon's page seemed likely to become a useful part of the business' social media portfolio. However, declining user numbers made it difficult for the managers to justify remaining on the platform, and they later closed their account.

This decision was made primarily on the perceived future value of the social network, rather than for a lack of resources to keep the account updated. Neither manager was concerned about the impression that disused accounts would leave with potential customers. To Liz, Graham, and many of their customers, social media platforms and accounts came and went, and there was no expectation that all accounts should be active or current. Several inactive social media accounts were allowed to sit dormant awaiting potential future uses, such as Bandwagon's YouTube channel.

\subsection{IT startups}

Two IT startups are introduced in this section. These are described separately from the six Professional Services businesses: the two startups shared much in common with each other, and were quite different from the other Services businesses described later in this chapter. Both shared a focus on high growth: neither Videogame Network nor SocialSearch had managers who were content to aim for a stable income stream sufficient to pay their bills. Business growth was an implied goal among interviews with all the managers, but these businesses focus upon it to a much higher degree: aiming to build their businesses quickly, with the potential for venture capital funding.

The IT startups also shared a similar type of product. Online software, sold in the form of 'Software as a Service' was the core business of both. Within their areas of expertise, both businesses continually changed and evolved their product offering during the study- following 'agile' software development methodologies. They differed in their approach to these new ideas: SocialSearch took elements from previous designs and incorporates them into the newest product. Videogame Network preferred to add new 
ideas to their existing mix of products, building an impressive back catalogue of stillactive websites. Beyond their direct products, the two businesses also sold the expertise of their staff and their intellectual property: building on earlier product development work to create products for new clients.

\section{Videogame Network: The forum builders}

\section{Overview and description of business}

Videogame Network was one aspect of a web development agency that produced online community software for client websites around the world. The Videogame Network group of websites were at the centre of that network: home to the earliest of the company's forums, and the place where new software elements could be implemented and tested. The company was not only focussed on technical aspects of their products, however. Forum moderation and content curation formed important aspects of the business, with staff leading groups of volunteers who oversaw the daily operation of the company's online gaming forums.

Some of the company's coding work was outsourced to a development team in China, though the bulk of their work was conducted in Melbourne. Early in the study, staff in the business worked remotely from home offices. Most roles on the website were handled by part-time staff, with only two full-time employees in the company. Later in the study, growing numbers of staff and clients allowed the business to expand into dedicated offices in an inner Melbourne suburb.

Community management roles for Videogame Network were filled by a mix of paid staff and volunteers, recruited from among the active members of the site's forums. The manager described this process as 'bubbling up' - over time, people who shared the company's goals and community values took on leadership roles in the community. Site moderation on the company forums used a system of groups and sub-groups, with more experienced moderators taking responsibility for groups of other volunteers. The most senior of these were offered paid positions with the company, ensuring that both staff and management had an opportunity to see how well they work together before new members were hired. 


\section{Manager profile: Robert}

Robert was a self-described 'serial entrepreneur,' continually looking for new business opportunities. After completing a Computer Science degree, he developed his own forum software while working full time: using it as an opportunity to refine his programming skills, and building a far more customised platform than he had access to through existing free or paid forum software products. Robert spent several years as an engineer in the telecommunications industry, before launching a business that allowed him to draw on the experience gained from his years running electronic gaming sites.

After launching his business, Robert expanded the range of videogames covered by the network. Initially, each new games platform had its own forum site and domain name. Early in the study period this changed, as all websites were integrated a central site. This was a major undertaking for the company. On a technical level, user accounts and profiles needed to be merged across each of the original sites. These changes also disrupted the social structure of each forum community, bringing together groups that had previously occupied different niches on separate sites.

To manage the change, Robert took an active role in communicating the reasons behind the site merger to the community - attempting to keep the process as transparent as possible, and acting on the feedback of existing forum members. Robert considered himself a leader, both in the online communities that he manages, and in Melbourne's emerging technology startup community. Recognising that new business owners need connections and access to information about the successful businesses that had gone before them, he was an early member of a monthly networking group aimed at new digital entrepreneurs. This group grew strongly throughout the study, as both entrepreneurs and investors saw the potential for turning Melbourne into a launching point for the next wave of high-tech startups.

Robert was an early adopter of most web technologies - continually looking for new innovations that may give his business a competitive edge. Despite this, his heavy focus upon forums as a social platform caused the company to avoid putting resources into experimenting with other services in any depth. Robert had registered a Twitter account within weeks of that company's debut at the SXSWi convention, but after an initial flurry of activity he abandoned it when it became apparent that few locals were using the service. During the study, his business made limited use of other social media services: 
restricted primarily to integrating Facebook Connect as a way of logging in to their websites, and broadcasting links to new content via Twitter. Expanding into other popular social networks was considered an important area for future development, but not acted on during the study period.

\section{SocialSearch: The social network archivists}

\section{Overview and description of business}

SocialSearch was a young software development company, focussed on creating online software-as-a-service products. Conducting business in this area required highly agile organisations, able to respond to changing customer needs, and other developments in their industry. The two co-founders were its only two full-time staff; employing others as required: in particular, drawing on one co-founder's network of contacts in China to outsource some of their development work.

SocialSearch was founded in 2009, by two IT professionals who had left corporate careers to start their new venture. Neither of the owners considered SocialSearch to be a traditional "small business" - contrasting what they did with more established small business types, such as retailers. "We're an internet startup," Eric explained. "Our vision of the company is that it's boom or bust ... we continually iterate on ideas, to get the idea that's going to make us rich and famous." That model required continual change, both in terms of product development and business models. Eric referred to this as 'pivoting' - a process drawn from his software engineering background; taking elements from each previous design and repurposing them to create a new product.

By 2010 the company had gone through several product ideas. Despite receiving some interest from potential customers, each earlier product had been retired when it became apparent that the target market would be enterprise clients. Neither manager wanted to rely on a few large contracts to keep their business operating: enterprise software involved long lead times and heavy restrictions on the type of system used, and hiring specialist enterprise sales staff to bring new customers in was seen as beyond the budget of their new company. Instead, they took aspects from their earlier products and tried using these to produce a consumer-focussed product, tied into the rapidly growing social media environment. 
Their most successful product drew upon elements of their earliest design: an information discovery tool initially aimed at the complex networks within large organisations. These networks were even more widely dispersed among the general public, and so the searching and archiving tools were adapted to use Twitter.

\section{Manager profile: Eric}

Eric was one of the two co-founders of SocialSearch, sharing management of most dayto-day operations with his co-founder John. Prior to launching SocialSearch, Eric worked in the Information Architecture division of a large firm. In this role, he managed several small teams of software engineers. The management skills he developed in this industry helped to prepare him for his role with SocialSearch, but he left his former job wanting to work in a more entrepreneurial role.

Eric met his co-founder at a Startup Bootcamp event, where the two discovered that they had many shared interests. While both had several different ideas for the type of business they should start, they saw high growth potential in online software. "Starting a business isn't rocket science," Eric explained. The major areas he saw as important in the pre-startup phase were determining which products his business would produce, and how to reach the market for those products.

To Eric, the 'foot traffic' for an internet business came from social media. He considered direct search engine optimisation (SEO) methods to be a lower priority for SocialSearch as relied on having potential customers identify that they have a specific problem, and then search for answers to it. Instead, active use of social media allowed SocialSearch to proactively engage their market, discovering problem areas and presenting content to help address these. SocialSearch's online activity was also designed have an indirect effect on their search engine performance: for example, Eric carefully selected keywords to write blog articles on, assisting the company website to receive wider exposure from search engine traffic.

Eric considered networking - both online and offline - to be a vital activity for any business owner. Discussing his use of online networking, he noted "I can directly link every single customer we've got, back to someone that I met through someone else on Twitter." Online networking activities had the potential to be more efficient, generating more leads and more sales than he would have time to set up face to face - particularly while the business was developing a customer base in North America. Connecting to 
other business people online helped Eric to support his offline networking activities, giving context and helping him to set up informal meetings.

\subsection{Services businesses}

The final set of case studies is comprised of six professional services businesses - the largest and most diverse group in the study. These businesses cover a range of different industries and stages of development, but share many common aspects in their management style and approach to using social media.

\section{Network Solutions: The IT company}

\section{Overview and description of business}

Network Solutions was the oldest business in this study, established in 2001. Initially a non-employing business, it now employed six staff. The manager also retained a range of consultants, who could be called in where specific expertise is needed. Accompanying this growth was a change in focus for the manager and his employees: leading to greater specialisation, and the development of a reputation within the business' industry niche.

The business began as a basic technical support service, working on hardware and software issues for a group of local clients. As the manager developed expertise in other areas, the business focus changed: while Network Solutions still aimed to be a 'one-stop shop' for IT issues, their primary offering focused on complex network connections. Luke described his network engineering role as "finding how to connect A to B in interesting ways" - understanding how to use the range of different tools available to connect disparate parts of a computing network within a home or office, and across multiple sites.

This changing focus meant that business clients now made up the majority of Network Solutions' clients, replacing the domestic customers that had provided almost $90 \%$ of work during the early years of running the business. Customers were located throughout Victoria, with many from the Eastern suburbs close to the business' offices. Although work was typically conducted online or at a client's office, the manager noted that many clients preferred to hire a business that was be part of the local community. This provided a level of perceived security: if problems arose, the clients valued the ability to easily arrange face-to-face meetings with Network Solutions staff. 


\section{Manager profile: Luke}

Luke moved into IT after completing an undergraduate degree in Biology; retraining with a Masters degree in Information Systems. Unlike many of his peers in the IT industry, he placed little value in industry certification and other qualifications - preferring to tinker with systems directly, in order to fully understand how to implement or troubleshoot issues that arise from them.

Most of Luke's business came via word of mouth referrals. To trace the source of each lead, new customers were asked how they discovered the business: most were referred directly by current clients, or from upstream vendors and suppliers who recommended Luke as a specialist in his field. Despite remaining busy with new clients throughout the past decade, he had not seen any direct benefits from his experiments with paid advertising campaigns. He preferred to work through existing networks where possible, rather than trying to find and appeal to customers who had no previous contact with the business or its clients.

Luke had not actively pursued social networking channels as a tool for his business, as his experience focussed on personal accounts on sites like Facebook and Myspace. Several customers had begun using Facebook messages as an email replacement, contacting him about potential new jobs. While this led him to reconsider how the business might use such services in future, he remained opposed to the idea of creating a dedicated business page on Facebook - seeing it as overly promotional and "a bit pretentious," advertising on a platform that he used to keep in contact with friends and family. Instead, he saw forums as the areas of greatest potential benefit to his business. Developing a reputation for his business as knowledgeable, approachable and clientfocussed was a key goal for Network Solutions, and guided Luke's choice and usage of social media services. Industry forums like Whirlpool were home to in-depth discussions about new industry developments, allowing his staff to remain on top of new trends. These forums were also frequently used to ask for technical advice. By sharing tips and helping with minor support issues, Luke saw an opportunity for his staff to refine their customer service skills. These discussions occurred in a public forum, allowing others to see the quality of work given by his staff - further reinforcing the reputation that he wished to cultivate for his business. 


\section{Central PR: The public relations agency}

\section{Overview and description of business}

Central PR was a small public relations firm, founded in 2003. At the beginning of the study the company employed three staff, having downsized from seven during the global financial crisis. In addition to offering traditional full-service PR consultancy services, the business sold a series of resources and contact lists designed to provide a 'do it yourself' public relations toolkit for small, medium and home-based businesses. This approach proved to be popular among startup and micro businesses. Those businesses often could not justify the expense in seeking professional public relations advice, and saw greater value in skills development for their staff.

Individual clients paid significantly less for DIY resources in comparison to Central $P R$ 's full-service consulting jobs. However, this model required minimal work for the business when taking on new clients: once resources had been developed for a particular industry, they could easily be sold to other clients with similar needs. These resource packs were continually updated, and new packs were added when the company had conducted enough research into each industry niche. Resource packs were sold directly through the Central PR website as PDF downloads.

During the study, Central PR periodically added new resource packs to their list of DIY products. These encompassed new industry types and special events like the Christmas/New Year period. The business also expanded internationally, partnering with a business in the USA to deliver North American media lists using the same business model. Shortly after the study concluded, the business expanded further into the UK and New Zealand markets.

\section{Manager profile: Jess}

Jess started her business in 2003, after being referred to her first client by a friend. After this, her business grew steadily - employing additional staff, and working closely with a business partner, with whom Jess launched several other ventures. Jess had a strong entrepreneurial outlook, demonstrated by her continual evolution of her business model and product lines.

Like many other business managers in this study, lifestyle considerations after starting a family were a high priority for her new business. Both Jess and her business 
partner worked from home, using Skype and email to keep in regular contact, and leasing a small office space for client meetings.

Jess was a highly active networker, both online and in person. Despite her heavy use of social media to promote the DIY aspect of her business, Jess admitted that it had never featured within the range of traditional PR services that she offered to clients. "That's much more about media relations," she explains. When launching her business on social media, she drew upon personal experimentation with new services, and asked for advice from friends who ran successful social media accounts for their own businesses.

She used a combination of Twitter, Facebook, LinkedIn and various small business forums to promote her business and find industry information, and had an infrequently updated blog on the Central PR website. Of these, forum posts often generated the most direct business, with a spike in new registrations and sales following periods when she spent time replying to forum discussions about launching new businesses. However, she commented that it could be difficult finding enough time to become familiar enough with the audience of any particular forum. On one popular site, moderators asked her to refrain from directly posting promotional information - preferring that she join existing conversations in a more natural fashion. Overall, this approach had worked well for her but it was time consuming, and often easier to simply choose a different site that allowed more direct business promotion.

\section{Vitae: The Marketers}

\section{Overview and description of business}

Vitae was a small 'boutique' marketing agency, established in 2005. The company focussed on high-level strategic planning and research for marketing campaigns. Generally, Vitae did not directly manage the creative output of these campaigns; contracting to other specialist companies to produce advertising campaign materials. Around half of the company's income came from consumer behaviour research, with the remaining income derived from consulting, facilitation and public speaking.

The company worked for clients across the public and private sectors, producing marketing strategies using a variety of different techniques and tools. With their emphasis on research, each job was unique: strategies developed for one product line 
were rarely applicable to another client, although the underlying marketing theory and expertise remained the same.

Vitae incorporated several popular social media services into their website during the study, including a Facebook page, Twitter account, and links to the manager's personal LinkedIn profile. Most of these were only rarely updated, and had been started in order to explore how each service worked. Blogs and other content-rich materials were the manager's preferred digital outputs, allowing Vitae to demonstrate their expertise in a format that could be shared among current and prospective clients.

\section{Manager profile: Sarah}

Sarah was Vitae's founder and director. She preferred to keep her business "lean and agile," employing a minimum of staff and relying on contract work to outsource specialist tasks that fell outside of her area of expertise. In its fifth year of operation, the business had only two full-time employees, but had achieved an annual turnover of over $\$ 1$ million.

Like many of the business managers in this study, Sarah moved away from a busy corporate career in order to start her own business. Prior to launching Vitae, she had been a director of one of Australia's largest advertising agencies. After starting a family, she found the corporate environment lacking the lifestyle flexibility that she needed, and decided to start her own business instead. Growth had not initially been an important goal for Vitae - Sarah admits that her original plans were very modest. "I'd aimed to replace my old salary ... to be able to help the kids with their schoolwork when they needed it, and pay the mortgage." Those plans were revised after the first year of operation, when it became apparent that there was a high demand for her services.

Sarah was an active member of a professional roundtable organisation, and used its events and publications as her primary means of discovering new industry trends and technologies. All technological innovations that she introduced into her business originally came from the roundtable's 'boot camp' events. These ranged from online presentation tools to collaboration software and content marketing ideas for her website. While Sarah had only fully adopted a small number of the technologies discussed with her peers in the roundtable group, her awareness of these innovations had helped her to impress clients and win more business.

Unlike many of the other business managers, Sarah was initially quite outspoken in her criticism of social networking services. She saw most personal accounts as of little 
value to her business - finding them to have far too much noise. More professional channels like LinkedIn were full of strangers clamouring for introductions, and generated far too many email notifications for her to manage. She described her use of these as "vaguely participatory" - commenting that as a marketer, it was essential to have some understanding of services like Facebook, but that she didn't consider them relevant for promoting Vitae to its preferred clients.

In contrast to this, Sarah saw great potential for publishing content through blogs on her website, and cross posting this to other sites. As a marketer, she saw this content as an important tool for building a value profile for her business. By positioning her business at a premium price point, she was not worried about the implications of freely giving away her IP in these blog posts, newsletters and eBooks. "At the end of the day," she noted, "if someone thinks it's really an option for them to take the IP and do it themselves, they were never really a [long term] client of ours." Vitae worked for major brands and government departments, and looked for clients with the budget to spend and a need for high level professional advice.

\section{Cover Story: The Freelance Writer}

\section{Overview and description of business}

Cover Story was a sole-trader copywriting and editing business, based in central Melbourne. The manager took freelance contracts for magazines, websites and corporate materials such as annual reports and training documents. This focus on corporate writing was an important aspect of the business, linked to skills and contacts the manager had developed in her previous job.

Clients typically contacted the business directly, commissioning stories for print and online publications. Early in the study, the business began taking on a number of small social media jobs via agencies. These typically involved producing social media content, writing updates for a company or brand's Facebook and Twitter accounts during a particular campaign. Towards the end of the study, the business began to focus more heavily on this work - both in terms of public-facing social media updates, and in researching and writing articles on new technologies for companies that offer social media training and consultation. 
Cover Story researched and wrote on a wide range of topics, though the manager preferred taking on work in the area of ecological and ethical sustainability - often on lifestyle topics such as fashion or food. She noted that her ideal niche probably didn't have a large enough market to support a full-time business, but still aimed to take on as much of this type of work as possible.

\section{Manager profile: Mel}

Mel launched Cover Story as her freelance writing work grew from a hobby into a fulltime job. She had already been writing and editing for a variety of publications, taking on writing jobs in the evening until she needed to turn down work when she reached capacity. At that point, she began thinking more seriously about trying to write full time. Shortly after this, she left her corporate job and started Cover Story.

Mel was an active user of many social media platforms, and used Twitter to link together updates on other sites. She started a blog shortly prior to the study, using it as a tool to promote her business through her writing. Over the years she had experimented with most of the available social media platforms, creating and deleting accounts as her business and promotional goals changed.

Twitter played an important role in helping her to find new work, although she did not actively seek work through it. "It's all been through referrals or people reading my Twitter feed," she noted. "They read my feed, see that I have a particular kind of voice, and they contact me from there." This shaped the way that she used the service, as her awareness of her audience grew. Mel generally refrained from posting negative commentary in her personal reviews and recommendations. She described this as a conscious branding decision: her audience expected to find light-hearted and cheeky commentary, and so she attempted to meet those expectations.

\section{Building Blocks: The Recruiters}

\section{Overview and description of business}

Building Blocks was a digital recruitment agency, placing people into web design, development and programming jobs. The company officially launched during the study, although it had operated in an earlier incarnation for a little under a year before rebranding and launching as Building Blocks. 
The company was founded with a strong ethos of fair working arrangements for both employers and employees. Central to this was a requirement that all employers must be approved by the two business managers. "If we wouldn't work there ourselves," noted one manager, "we won't touch it." Building Blocks received most of its business from direct word of mouth and personal referrals, and the managers sought to maintain good relationships with the people they placed into new jobs.

Their business model was unusual for a recruitment agency, in an industry known for steep prices and finder's fees amounting to a large percentage of the first year's salary for successful placements. Instead, they worked on a fixed-fee model, with no royalties or other payments. Unsurprisingly, this made them popular with both employers and prospective employees, particularly among the smaller design studios.

\section{Manager profiles: Dean and Allana}

Building Blocks grew out of a solo venture that Allana started after a career in branding and advertising. After a year of operating as a specialist freelance recruiter, Dean joined the business as a partner, and the pair began to refine the business processes that Allana had developed during the previous year.

Allana previously managed digital projects in branding and advertising. Her decision to move into recruitment came after a realisation that she typically sat on the 'other side of the desk' for job applications, assessing new applicants and interviewing for positions, and that those skills could potentially be used to prepare applicants for other positions. She had been dissatisfied with the other recruitment firms operating in Melbourne, and saw an opening to create a niche business of her own.

Dean was a web developer, and had spent much of his career being placed into development roles by other recruitment firms. He brought a detailed understanding of the technical requirements for each potential role. During interviews with new clients, Allana sounded out each applicant for their cultural 'fit' with the target organisation, discussing skills, interests and motivations. Dean followed this up with technical questions to determine whether the applicant was capable of doing the required work.

Neither of the managers directly promoted their business online, although both were keen social media users. Instead, they sought to maintain a presence in each digital environment that will be used by employers or employees working in their target industries. The business had been busy since its relaunch, and the managers viewed their 
lack of overt promotion as an asset. "I would rather that the type of person who approaches us has done some homework to find us," notes Allana. "When there are only two of us, we need to make sure all our leads are serious - we don't want time-wasters."

Both Dean and Allana were typically early adopters of technology. Allana described herself as an "online social person," active on forums and instant messaging services since the late 1990s, and starting her first blog in the early 2000s. Dean was similar, beginning blogging in 1997. Building Blocks was the most active user of Google+ in this study. Both managers noted that their experience of the new platform had been contrary to the popular impression of a 'digital ghost town.' Many of their friends, business contacts and potential clients were also innovators and early adopters of technology, and these contacts established a thriving social network on the new social networking service.

For the two managers, some other forms of social media - particularly Facebook took a lower priority since the launch of Google+. Allana theorised that this was because of the way the new social network allowed users to manage multiple discrete circles of contacts, making it flexible enough to serve as both a professional and social network.

Allana and Dean were also active members of several face-to-face networking groups, attending and hosting regular 'meetup' events, organised by industry type (digital communications, web development) or business stage (startups and entrepreneurs). The events were typically organised online, with pre- and post-event discussions on Twitter, Google+ or LinkedIn.

\section{Inner Circle: The Management Consultant}

\section{Overview and description of business}

Inner Circle was a consulting firm, focussing on knowledge and change management. The business was established in 2005, when the founder left a corporate career to start her own business. Shortly after this, the manager was approached by an organisation that wished to employ the new company to facilitate a series of roundtable events for knowledge management experts in the public and private sector.

Multiple revenue streams were important to a consulting business, helping to protect against some of the effects of losing a major client. Ongoing clients also provided the business with a greater degree of flexibility when taking on new work, allowing the consultancy more freedom to pick and choose its clients. 
Initially, direct consulting work was intended to be only a small component of the business. However, the expertise of the Inner Circle staff was in high demand. In an attempt to reduce the demands on her time, the business manager launched a set of props that could be used to assist the facilitators of change management workshops - intending these to provide people with tools to manage their own processes. Promoted via social media and word of mouth, the new products became highly successful. An unanticipated side effect of this success was a surge in enquiries about consulting work, as new prospective clients discovered the company via its facilitator products.

\section{Manager profile: Mary}

Prior to starting her own business, Mary's professional background was in corporate change management. She had built a large network of contacts in both government and the private sector, and was widely respected for her skills in this area. In 2005 she launched her own business, drawing on the many contacts that she had made in her industry. Her initial business model was based on the roundtable events, supported by consulting jobs as needed. Following the launch of her first physical product, there was high demand for her services from new clients needing an experienced consultant to handle complex change management processes.

During the study, Mary's focus was on consolidating and expanding her change management workshop tools, including smartphone and tablet apps. She saw potential in having others run workshops for her, and aimed to bring in experienced facilitators and train them in her methodology. This would allow her to expand her business, as she had reached the limits of her personal capacity for new work.

Mary primarily used Twitter as her social and information gathering tool, and ran discussion groups for roundtable members on LinkedIn. She had two Twitter accounts. The first, more frequently used and with a larger following, was her personal account often used to discuss work-related topics such as knowledge management. The second account was created to help promote her workshop aids. During the study, the businessspecific account had not gained a significant following outside of people who already followed Mary's primary account, and she was considering closing it. Her interests and work areas, friends and colleagues had such a large degree of overlap that she saw little benefit in trying to separate 'work' from 'personal' issues on Twitter, and maintaining two accounts in parallel had become time consuming. 


\subsection{Conclusions}

This chapter has introduced the fifteen businesses that have taken part in this research. These businesses have been selected from small Hospitality, Retail and Professional Services firms in Melbourne, including two fast-growth 'startup' IT businesses.

In addition to providing an overview of the businesses themselves, I have introduced each business' manager (or managers, in cases that involve a partnership or other multiperson arrangement). This provides context for understanding the attitude, priorities, skills and experience that each manager brings to their business. These factors shape the way that each business approaches new technology.

The following chapter explores the range of social media services that were used in each of the fifteen businesses, and the ways in which each service was used. 


\section{Social media used by SMEs}

This chapter explores the types of social media services used by each business manager during the study, and range of purposes that each service was used for. I have grouped my initial observations by platform, focusing on the social media services that were most widely used by the managers: Facebook, Google Plus, LinkedIn, Twitter, YouTube, and various blogs and forums. These observations are then followed by a discussion of the major themes that have emerged concerning the adoption of social media within each business, and the outcomes generated by social media use.

\subsection{Facebook}

Many of the study participants considered Facebook to be synonymous with the term 'social media.' Facebook has been the most widely used social media service in this study, with Twitter a close second. By the end of the fieldwork period for this research, Facebook clearly dominated all other social media services in terms of user numbers, recording over 1 billion monthly active users in late 2012 (Zuckerberg, 2012). This large user base made it attractive to many business managers, due to its perceived reach among their target audiences. The ways in which each business manager has used Facebook are detailed below.

\section{Personal accounts on Facebook}

All of the business managers used, or had previously used, personal Facebook profiles during the study. In most cases, the managers had started personal accounts several years before launching their businesses. Two of the managers created personal accounts in order to understand how to use the service for their businesses, using them to learn how the Facebook interface worked.

Even Luke, who expressed the most negative opinion of Facebook and its potential use as a business tool, reported that his customers had begun to use the service as an informal proxy for email or phone calls. In his interview, he discussed how these contacts used Facebook to ask questions about Network Solutions, providing a source of regular job leads through his personal account. He was reluctant to establish a formal business 
page, however, worrying that the deliberate self-promotion would clash with his business' preferred approach to casual, word-of-mouth referrals.

I think it seems a tad pretentious to do that ... maybe if I knew that a significant proportion of my clientele were on Facebook. But I would say of my clientele only probably about 10 to $20 \%$ would even know what Facebook is and 5 or $10 \%$ would be active users.

In their interviews, most of the business managers described their attempts to separate, or at least manage, the split between their personal and professional lives online. They were aware of a shift towards compartmentalising different aspects of online life: Facebook, for many, had become a service they used primarily to connect with friends and family members. This was particularly common when they no longer saw those people face to face, such as when changing jobs, moving house, or travelling. They found themselves less enthusiastic about interacting with business or brands on Facebook, preferring to use other channels such as Twitter for those conversations.

The managers also used their personal Facebook accounts as a source of information, monitoring businesses in similar industries by 'liking' and following other business and fan pages. In part, this gave the managers another method for keeping on top of industry and competitor news. Another valuable aspect to this was in following other businesses that were new to Facebook, observing how they managed their own social media profiles. Christine described how she used Facebook, along with Google and Twitter, to follow businesses similar to Fashion on Wheels. This allowed her to continually look for new ideas about how to use the social media for her own business, taking the most successful methods from others in her industry.

\section{Using Facebook business pages}

Facebook's business pages were the main professional portal for Facebook, and were used to some extent by most businesses in this study. Unlike personal profiles, business pages were intended to present a professional face for the organisation, disconnecting it from the personal account of the manager. All but two of the managers had created a business page by the end of the study.

These pages were commonly used to post status updates and announcements. This ability to access and update social media services 'on the go' was seen as extremely important to Hospitality managers, as their staff rarely worked at a computer. Ben 
described how mobile devices allowed the Lunch Spot staff to access the business' Facebook and Twitter pages from the café floor when they weren't serving customers.

Where the business managers had limited access to appropriate technology, the business was not active in those areas. For example, Fusion had a Facebook page throughout the study period, but rarely used it at first. When asked about this, Lee described how she would use her phone to access Twitter during quiet moments in the restaurant, but Facebook was more difficult for her to access. Later in the study, she bought a new smartphone with mobile applications for all the business' social media services, and became much more active across the different channels.

Videogame Network experienced very little social media traffic after setting up their Facebook page. They continued to add content by starting discussions, and posting links and images. This activity increased as the company expanded, reflecting the availability of more resources for social media content creation and user engagement. As Robert hired more staff, this gave the business more people who were able to contribute to the page. By the end of the study, the Videogame Network Facebook page was updated several times each week, regularly attracting comments, likes and sharing on other profiles.

Many business managers experimented with methods to automatically re-post content from other social media, by linking those accounts with Facebook. This had the advantage of reducing the amount of work needed to create new content: images shared on Instagram, YouTube videos and blogs posted to WordPress could all be displayed on the business' Facebook page. However, at Model Madness, Matt found that his Facebook page was almost completely devoid of customer activity when he used it solely to automatically post links to content hosted elsewhere. Initially, his Facebook page attracted customer questions about stock levels and opening hours. When customers noticed that the account was only occasionally monitored, they took these queries to email or forums, and the Facebook page was ignored.

Some managers chose not to use Facebook due to the perception that it attracted individual customers, rather than businesses. These managers were responsible for 'B2B' products and services, and saw little value in maintaining a presence for their business on Facebook. Despite this, almost all participants had experimented with some form of Facebook presence for their business. Eric from SocialSearch was one of only two managers in the study who had no business presence on Facebook: 
We don't have a Facebook fan page: we don't feel that it makes sense. The sorts of brands that are buying our products wouldn't be a fan of us on Facebook. I think with our next idea we'll probably branch out into some of that ... I say it's the next idea but a month from now we might change our mind again, right, because we're currently building a beta of it ... We'll have it up and online within a week or two. And then we'll throw it out there and we'll see what happens.

A far more common approach was to create a business Page even when the business had no particular reason for doing so. This provided a low-risk method of trialling the service, additionally motivated by a fear of missing out on marketing exposure that their competitors might benefit from. At Vitae, Sarah focussed her attention on high-end business customers, and disliked the look and feel of Facebook's one-size-fits-all pages. Despite this, her agency still created a business page that that updated infrequently:

We don't actually use it much ourselves to build our business ... I consider that our customer is looking for a premium, expensive service. We're not cheap, which is not to say that, you know, only cheap products and services have a role in social media, but ... we consider ourselves to be very niche.

This tactic led many managers in the study to create Facebook pages that were not in active use by the end of the study, though they remained publicly visible. These 'abandoned' pages typically had small numbers of followers, and little user engagement.

\section{Facebook advertising}

Of note was the use - or rather, non-use - of Facebook's paid advertising options. As reported in their IPO documentation (Facebook, 2011), the majority of Facebook's revenue was generated through targeted advertising. As an advertising platform, Facebook offers a suite of tools to assist business managers in delivering ads, allowing them to target ads to specific customer.

Despite the apparent benefits for small businesses, none of the managers reported any success with the Facebook advertising options. Using these effectively required a good understanding of the business' potential customers, and of the way that Facebook could deliver targeted ads. This combination was uncommon among the study participants: few managers could clearly articulate their customer demographics, and even fewer were comfortable using advertising tools. As a result, the managers saw little value in advertising on Facebook. 
Liz and Graham from Bandwagon were the only managers to use Facebook advertising during the study. They felt that they had a good understanding of their target demographic (primarily from Liz' work using Google Analytics to monitor their website and online store), and Facebook provided a low-risk method for experimenting in this area. However, they saw no proof that paid advertising was working for their business, and subsequently abandoned it after a short trial. Graham suggested that may try again in future if they had a larger budget, but they did not consider their trial to provide enough return, in terms of increased site traffic or sales.

Other businesses avoided Facebook advertising, as the addition of paid features to an otherwise free service presented too high a risk: once money was involved, they wanted to see financial outcomes, and were uncertain how or if these could be measured. However, some managers were optimistic about using paid advertisements for specific products in future. During his interview, Eric commented that he thought SocialSearch would "definitely use Facebook advertising for [their new] product as a way of getting to people, because it's tied in tightly to social media."

\subsection{Google Plus}

Google launched this social networking service during the study period, in September 2010. This provided an opportunity to see how the business managers reacted to a completely new service, in contrast to services like Facebook and Twitter that were already in widespread use during the study. Google Plus launched with individual profiles, and business profiles two months later.

\section{Accessing niche audiences via Google Plus}

As a new social networking service, Google Plus was primarily used by social media 'early adopters' during the study - viewing it as an opportunity to establish an early presence on a major new service, in contrast to older services like Facebook that they feared being too late to join. Half of the managers in this study created and experimented with personal Google Plus profiles in the months immediately following the service's launch, but few of them used the service to any significant degree. The main reasons cited for this were its failure to achieve a 'critical mass' of users, and its similarity to Facebook. Without enough people posting content on the service, there was little incentive for users to visit 
the site frequently. The apparent similarity to existing services like Facebook also discouraged many of the managers from becoming active users: "Why would I need yet another site to replicate that?" was a common response. When Google Plus launched its business profiles soon afterwards, only one manager went on to use that feature. This was a sharp contrast to the widespread adoption of Facebook's business pages.

A small number of business managers did find the new service valuable. These were the managers who needed to tap into the specific niche communities that populated Google Plus in its first year of operation. For the managers of SocialSearch, Videogame Network and Building Blocks, this service helped them to access their core market: techsavvy early adopters who could share useful information and potentially become customers, clients or business partners.

Google Plus was also of interest to the managers who had professional reasons for staying abreast of new social media developments. This links to the common theme of a fear of missing out on potential business advantage, shared by managers across all social media services in this study. At Cover Story, Mel researched and wrote stories on social media for one of her regular freelance clients. Similarly, Eric's business was heavily involved with new developments in the tech industry. Both used their personal profiles to start or join conversations, and to post and share links. Like many of the early Google Plus adopters, Eric's involvement with the service dropped off rapidly after six months. Mel remained active on Google Plus, but primarily used the service to aggregate content that had been posted to other services, in the same fashion as her Facebook page. Neither of these managers created a business account when they became available.

The IT recruiters at Building Blocks found Google Plus to have a much more focussed audience than Facebook, and it became their social networking service of choice within a few months of using the service. Dean described Google Plus as far more "technically aligned" than Twitter, acknowledging that it didn't seem appropriate for many of the mainstream users of those earlier services. Allana agreed, noting that there were "less people involved, but more interaction." For their business, the new social network was far better for engaging and interacting with people than any other they had used. Where blog and twitter posts typically got only a few mentions or responses, each Building Blocks post on Google Plus attracted 15-20 people commenting and contributing to the discussion. Neither manager knew whether high levels of engagement were likely to 
remain a part of the new social networking service, or if the relatively low volume of other content on Google Plus was concentrating viewers onto their posts. However, during the latter half of the study it became the primary focus of their online activities.

For other managers in this study, the perception of Google Plus as a niche service prevented them from committing resources to it: while creating a new profile was a lowrisk activity, uncertainty over the long-term returns most managers to stop using the service and focus on services with high numbers of potential customers.

\subsection{Linkedln}

Almost all the managers had created a LinkedIn account and added some level of personal information, ranging from their name and current job title, through to a complete CV and work history. However, the managers rarely used this service to actively post content or reply to other users. Instead, their profiles were infrequently updated, and remained fairly static during the study.

LinkedIn offered a 'status update' feature, similar to Facebook. This allowed users to post short messages that could be seen by their contacts. The service also published automatic updates when a user profile was updated, informing contacts of changes to jobs and other information among their network. When personal updates were posted, many of these were automatically re-posted from linked services such as Twitter or Facebook: 'broadcasting' these on LinkedIn as a way of increasing the potential audience for each post. These updates seldom resulted in conversations with other users. Instead, managers commonly used the service was as a one-way communication channel, where responses from their network were not expected.

\section{Maintaining professional profiles}

More so than any other social media service, managers considered LinkedIn to be a part of their professional appearance online. Profiles were relied upon to make a business and its staff visible on this social network, promoting achievements and work history. As such, profiles were constructed in a more deliberate way than their equivalents on other sites. Managers used more formal language in their LinkedIn profiles, compared to similar profiles on other social media services. These were generally short and impersonal, using official titles and business descriptions. Graham described the service as "more an 
extension of your company website than a place you chat with friends" - a sentiment echoed by other managers in the study.

LinkedIn was frequently used to maintain a connection to friends or co-workers, although most managers did not actively attempt to maintain these connections through ongoing social activity. Instead, the LinkedIn contact list was seen as an alternative to email or phone numbers: a convenient channel for getting back in touch with people who may have moved or changed jobs. Most of the managers were more open to connecting with new contacts through LinkedIn than through Facebook, despite LinkedIn's official recommendation that its users should "only add connections that you know well." These managers used Facebook to share more personal or private information among their family and friends, while content posted on LinkedIn was intentionally more businesslike, and less risky to share with casual acquaintances. As such, LinkedIn became a tool for establishing connections with business contacts, including people the managers met at conferences and other events.

On an individual's LinkedIn profile, the size of their network was prominently displayed. This contact number featured heavily in opinions of other users: at Videogame Network, Robert suggested that "potential business partners judge you on that - they want to know why you might only have a handful of connections if you're running such a large business." This drove managers to connect with a wider range of individuals than their direct business contacts.

\section{Using LinkedIn to find staff}

Most of the services and IT startup managers used LinkedIn during the study to advertise job openings, or to outsource work to subcontractors and freelancers. This generally occurred via informal word-of-mouth - posting updates asking for recommendations on finding a new barista, editor, or web developer. These calls for recommendations were not limited only to LinkedIn, and were often cross-posted on Twitter and Facebook.

Unsurprisingly, the managers of Building Blocks were far more active in this area than the others in this study. While their business did not hire staff during the study, as a recruitment agency they continually needed to place people into jobs, or find staff to fill vacancies. They did this by advertising jobs in their status updates, and also by using LinkedIn Jobs: a feature that allowed users to place full job advertisements online, and manage applications directly through the LinkedIn platform. 


\section{Discussion groups on LinkedIn}

Most of the managers had joined industry networking groups or alumni forums on LinkedIn Groups. However, few actively contributed to these forums. A common perception among the Professional Services managers was that LinkedIn Groups were too overtly promotional, used primarily for lead generation by directing people to download reports or whitepapers. The main exception to this was the recruitment firm Building Blocks, who had started their own discussion group and were active members of several others. Similar to Google Plus, the community of active LinkedIn users was a good match for their business. They sought an audience of active networkers who typically changed jobs regularly, due to the nature of project-based IT contracts.

The LinkedIn Answers feature allowed any user to post a question, which could be answered by their contacts, or other users who are active in the LinkedIn Answers forum. While this feature was not widely used by managers in this study, those who had tried it considered it valuable: either as a way to access specialist information, or to directly build a professional reputation by demonstrating and sharing knowledge about their industry. The Professional Services and Retail managers typically used LinkedIn Answers to ask new questions, rather than to offer answers. However, Luke described how providing answers was valuable to his team at Network Solutions, noting that:

Staff care about how well they answer questions, because each one could win you a new client down the track. It's also good for keeping their customer service skills up to date, if they put some time into monitoring the site.

\subsection{Blogs}

Eight of the business managers used a blog for their business during the study, and many of the others read blogs regularly. Experience with blogs and blogging software varied: some had maintained one or more personal blogs prior to starting one for their business, while others considered themselves complete novices. For example, Christine had started several blogs before launching Fashion on Wheels. After running a travel blog while living in Europe, she returned to Melbourne and began writing about restaurants and cafes, bringing her into contact with the city's active community of food bloggers. By the time she launched her new business, she had many years of experience using blogging 
software and writing regular articles. In contrast, Mel first started her own blog after launching Cover Story, seeing value in using the blog to show examples of her writing.

\section{Blogs as a source of industry news}

When it came to learning about new developments in social media, blogs were second in popularity only to word of mouth among the business managers. A relatively small number of sites were relied upon for articles about social media and business. Technology blogs such as TechCrunch and Mashable were regularly consulted by many of the managers, and seen as valuable sources of information on new social media developments. However, as the study progressed some managers commented that they were using blogs less often - replacing them with information gathered from their personal networks on Twitter. These managers considered the major technology blogs as being too 'noisy,' and had gradually developed Twitter networks that they considered more efficient at filtering this information and presenting links to relevant stories.

Outside of technology and social media news, the managers still relied heavily on trade publications for industry-specific information. This was most common among the hospitality managers, where managers cited industry magazines as the place each they first encountered examples of innovative ideas among other restaurants, bars and cafes. The managers who maintained blogs regularly consulted other blogs in related content areas. However, this was primarily done in order to assess what other bloggers were doing with their own websites, rather than to learn about industry trends.

\section{Accessing communities of other bloggers}

The managers who were already active bloggers were able to tap into ready-made audiences of fans and supporters when launching their businesses. Lunch Spot manager Ben commented that:

\footnotetext{
Being known by people really helped ... Eleanor talked about starting up the business on her blog, and we started a new blog and Twitter account long before we opened. It meant that by our opening day, a few hundred people already knew about the business.
}

The blurred line between food blogger and business owner may have also helped them to find common ground with the blogging and restaurant reviewing communities, as the Lunch Spot managers commented that they had received consistently good reviews 
online since their opening. "It really feels like we're still treated like 'one of them,' which has been great."

In contrast, Lee was very conscious of the role that blog content could play in managing the reputations of both businesses and independent authors. As a newcomer to her industry and the online communities that surround it, she had been very nervous about first contacting members of Melbourne's food blogging community. Part of this fear stemmed from the potential impacts of bad publicity, getting bloggers 'off side' - a common concern among managers dealing with social media influencers (see Harris and Rae, 2009; Harris and Rae 2010). While Lee was unaware of this happening locally, she had seen examples of conflict between bloggers and restaurant owners in her native Singapore. This caused her to carefully consider any outreach activity with local bloggers, ultimately resulting in more positive relationships with these individuals.

\section{Blog reviews and reputation management}

Blog articles remained accessible for longer than most updates posted to the other social media services covered in this study. In particular, content on a popular blog could remain visible in search engine results for months or years after it was posted. This feature made third-party blogs, often used to post reviews businesses, particularly important to many of the business managers. All four hospitality managers monitored blogs for comments about their business, using a combination of ad-hoc searches (for example, searching for their business name) and checking restaurant review aggregators like Urbanspoon. These aggregators allow users to leave ratings and comments, and also provide links to blog articles and media reviews written about each business.

While it was rare to see a business responding in public to a negative review of their business, each of the hospitality managers discussed their plans for dealing with this potential issue during the first stage of interviews. When asked how they would respond to online criticism, all of the managers preferred to contact the author directly through a more private channel, in an attempt to resolve issues out of the public eye. While none of the managers had a regular schedule for monitoring social media reviews of their business, Shanghai manager Alex stated that "I'd like to clear things up quickly - if I find out we've done something wrong, I want them to know that we're responding to their feedback." Where a post contained misinformation, corrections were given. If the review 
described a poor experience with the food, venue or service, Alex would apologise and provide details on how the feedback was being addressed.

Public responses to criticism during the study were extremely rare during this study. In one of the few examples of this, Lee replied directly to the author of a negative review of Fusion that had appeared on Urbanspoon. She apologised on behalf of her business, but also attempted to clarify points that she felt were misrepresented in the article, asking the author to amend their comments. The author refused to do so, but did not post any further criticism of the restaurant. Despite not achieving the desired result, her comment remained in public view on the blog post, and showed potential customers that her restaurant was attempting to actively respond to feedback. Lee noted that she would prefer to resolve issues privately and avoid direct confrontation in future.

\section{Blogs as a search engine optimisation tool}

Other managers saw blogging as an opportunity to create a repository of information about their business, and were less concerned with the short-term impact of blog posts about their business. These managers described their blogs as part of an active push for better search engine rankings. SocialSearch manager Eric commented that blogs were "basically about building long-tail SEO” (Search Engine Optimisation). Regularly adding relevant material to his website helped the business to rank more highly for terms his customers searched for:

When you write a blog post, it's there forever, and it's indexed forever. We did a lot of analysis on which keywords we want to hit ... we set up the blog and optimised it to make sure we're actually using those keywords in a meaningful way, because otherwise no one reads your content.

The managers of both IT startups were very analytical in their approach to search engine rankings, and attempted to stay on top of new developments in the ways that sites were ranked by search algorithms. These managers again turned to blogs as a source of targeted news and information, as SEO experts typically used blogs to publish information on changes affecting their industry.

Other managers were less technical in their approach, but echoed similar sentiments: blog articles were seen as important not only for their ability to share news and experiences that made each business more open and accessible to their customers, but 
also for the ability to add regular content to the business website. There was a general understanding amongst the managers who maintained blogs that new content, in some way, would improve their ranking in search engines, although the mechanics behind this were not widely understood.

\subsection{Twitter}

Twitter was the second most widely used social media service by managers in this study, only surpassed by Facebook. At the beginning of the study period, only two managers were not using Twitter in any capacity for their business. Neither of these businesses started using the service during the study. The remaining managers fell into two categories. The first of these created one or more accounts and used the service infrequently. These managers used their accounts to experiment with the service, without then continuing on to use it more regularly. The second group used Twitter on a daily or near-daily basis throughout the study. In both groups, managers did not delete any discontinued or abandoned accounts: instead, these accounts remained online throughout the study, showing increasingly dated content. When asked about why these had been left online, the managers explained that they hoped to begin using the accounts again in the future, but had not been able to find enough time to maintain them.

\section{Types of content posted on Twitter}

On a basic level, new Twitter users faced a dilemma: what should they post, and why would anyone want to read it? Twitter's web interface prompted users by asking "What are you doing?" or "What's happening?" to encourage users to post status updates. These personal narrative updates helped to establish a personality for each user, reinforcing what Eisenegger (2009) described as "expressive reputation" - a subjective perception of personal traits and qualities that helps to differentiate the business from its competitors. However, business accounts that relied too heavily on personal status updates had little success at gaining or engaging with followers. Establishing a balance between personal and business-related content was seen as difficult by managers who were new to Twitter, such as the manager of Fusion. She commented:

As a restaurateur... where do you draw the line? I've talked to a few people. One will say "do whatever is interesting and relevant but restaurant based - don't put private things up on 
there." But at the same time, I see all these big names tweeting, and they'll talk about their holidays and everything... It's quite private, and it makes them more human. And so I'm not sure if there's a right and a wrong way to do it.

This deliberate construction of identity by choosing what to say, and how to say it, was a recurring theme through the interviews. Mel described how her Twitter persona for Cover Story was intentionally different to how she acted in other contexts. As a writer, she was keenly aware of how the nuances of an online 'voice' shaped the way that others perceived her professionalism and her reputation.

\footnotetext{
I just don't talk about the experience if it's really bad. I'd never be really obvious, because there's too many people listening ... I think that's probably just a branding thing on my part, really, that people don't expect really negative stuff from me. They expect cheeky. I often say that people who read my Twitter feeds think that I would be like this sugar-and-spice, lovely kind of a person but, you know, I am far more sarcastic. It's more nuanced than that, but it's interesting, I guess it goes to your online brand.
}

Managers also used their Twitter accounts as a distribution channel for other online content. Twitter's short messages limited the detail that could be conveyed in a single message, but made them ideal as a distribution tool for linking to longer content, posted elsewhere. Christine described this process for Fashion on Wheels:

Whenever new content goes up on the blog, I send out a tweet with a link to our site, to let people know about it. I have readers in lots of different time zones, so I use a program that lets you schedule tweets in advance. Sending it out at a couple of different times in the day helps it get seen by people in the US or Europe.

Although these automated tools could help to manage accounts more effectively, overusing them can harm a business' ability to make meaningful connections with their customers. For example, Matt found little traction with Model Madness' Twitter account, in contrast to their highly successful forum and YouTube channel. Unlike the business' accounts on other services, their Twitter account was entirely automated, and used solely for publishing updates about new content on the business' website and YouTube channel. As a result, the Twitter account attracted only a small number of followers during the study. New followers could be seen occasionally inquiring about product release dates and stock levels, only to discover that their questions were not being heard. Instead, they took their questions to the forums, where staff were more likely to respond. 
The retail and hospitality managers also used their accounts to promote specials and other offers. These 'advertising' posts were rarely re-tweeted by others, but were successful in raising awareness among existing followers, who came into stores asking about the new items. Among the most successful of these were announcements from Lunch Spot about menu changes and special events. The cafe's Twitter account was followed by over two thousand customers, and was cited as an influential local example by other hospitality managers in this study. Lunch Spot's managers used their Twitter account in a playful fashion, taking some popular items off the regular menu, and only advertising their availability online. This helped customers feel like they had a closer tie to the cafe by engaging with them on Twitter, joining a 'secret' group with access to special privileges. After this, the café's followers began to more frequently share these special offers with their friends and co-workers.

Twitter's hashtags were often used to create secondary conversation channels related to a specific topic. In some cases, these occurred alongside physical events such as conferences. However, this technique can be used wherever a conversation exists on Twitter. Active hashtags are often read by a wide audience, and Twitter also highlights 'trending topics' to show the most active discussions. Managers included relevant hashtags in their posts in order to have their content seen by a wider audience than just their immediate followers.

\section{Sourcing and sharing industry news}

The managers using Twitter saw it as a highly valued source of news and information. Social sharing tools allow users to easily share links with their Twitter network, and many of the managers made a habit of regularly sharing stories or blog articles related to their industry. According to Eric, "The real value of Twitter isn't the 140 characters. It's the links that get shared across it." While this property had particular relevance to SocialSearch's business model, several managers shared this opinion.

Some managers described the way they managed their list of followed accounts as 'curating' content, carefully choosing accounts to follow for their value as a source of industry information. Twitter's retweet function was widely used to pass interesting content to their own followers. This is an important mechanism for transmitting farreaching messages on Twitter. Even coming from an account with relatively few followers, a message can quickly reach a wide audience when retweeted by more 
influential peers. By actively sharing information, managers take on the role of information brokers to their networks, demonstrating their knowledge and connections in their chosen industry.

Managers also used their extended Twitter networks to ask for advice, recommendations and other forms of information. These requests were often closely related to the type of industry the business belonged to, and the main group of followers their account had. Examples of these include cafe and restaurant managers looking for new staff, retailers asking for new product recommendations, and managers from all business types looking for advice on social media use from other users. However, these requests were not limited to single industries. Between the varied interests of their followers and the ease of widespread transmission via retweets, active Twitter users could use the service to seek information about a broad range of problems. Mel described how Cover Story had reached a "critical mass" of followers who were able to respond promptly about many different topics:

\footnotetext{
I have about 1300 [followers] but they're quite engaged ... there's people who just come out of the woodwork on different subjects. So if I'm talking about social media, or marketing, or restaurants, there's a few people who are in that business who will reply and say they agree or disagree or whatever. I'm really surprised that, for the breadth of stuff that I tweet, they put up with a lot.
}

\section{Facilitating introductions and bridging connections}

Twitter is a powerful tool for building networks, and was widely used by the managers to connect to people they had not met in person. In many cases, these online connections were a prelude to more direct contact. Managers used Twitter to pass on information about jobs, share resources and organise face-to-face meetings. Rather than forming a parallel, alternative source of social contacts, it took on a more deeply interconnected role. In her interview, Mel commented that:

The interesting part of social media for me is the community. But my community - my actual, real community - has come from that, so it's an interesting space.

The managers valued Twitter for the ease with which they could start a conversation with people they didn't already know. Unlike Facebook, where granting access to a user's profile could involve sharing private posts and photos, the brief and spontaneous nature 
of Twitter's messages was better suited to casual conversations. As a non-reciprocal network, it was easy to follow another account without requiring them to approve the connection or do so in return. This casual nature largely extended to sending @replies directed at other users. However, Lee described her apprehension as a new user trying to engage more prominent industry figures:

\footnotetext{
If you tweet at a person and don't get a reply... sometimes you feel like they don't want to be your friend, that sort of thing. And so I'm not quite sure whether it's because it's seen as soliciting new followers, and that's a no-no, or not. But at the end of the day, I am looking for more followers - that's the whole point of it. It's a fine line, as to what you need to do and what you do to get more followers. I guess to get more followers your tweets have to be good, interesting, funny...
}

Robert discussed how Videogame Network could take some of their existing conversations with large brands into the public domain:

The type of conversations we have with Microsoft would probably be of a different nature over Twitter, but I think that if you engage in that social experience - a two-way experience with a corporate account - you will create more followers because of the public conversation.

Like the hospitality managers, Robert saw potential value in being seen publicly talking to influential players in his chosen industry. His business had already established a good range of industry contacts, but he valued the opportunity to be part of public conversations that would help to establish a stronger reputation for his business in the eyes of potential future collaborators.

The managers using Twitter found it to be of great use during conferences and events such as Business Victoria's Small Business Festival, or the Melbourne Food and Wine festival. In each of these, attendees used a common hashtag to bring together 'backchannel' discussions during the event. Even the managers who did not post content would often glance through the feed while at the event, or after the event ended.

In some cases, hashtags were used to create discussion about a topic. Two of the hospitality managers were involved in a charity benefit after the 2011 Queensland and Victorian floods. This resulted in a one-day event where restaurant and cafe owners raised money for the Red Cross appeal. Early plans for the benefit were discussed on Twitter, with other businesses becoming involved after hearing about it. The event 
hashtag (\#vicrestunite) was used to discuss and coordinate with participating businesses, with diners and restaurants also using it to generate publicity for the event.

\section{Conflict between personal and professional Twitter accounts}

The conflict between managing one or multiple accounts was more pronounced here than for other services such as Facebook. Some business managers had personal accounts first, and created an account for their business later on. Over time, these became difficult to manage: it was no longer helpful to draw a line between "personal" and "professional" as there was valuable crossover between the two.

More established accounts tended to have more contacts, allowing content to reach a larger audience. Twitter did not allow users to merge accounts, and so less popular accounts tended to be discontinued in favour of posting to an account with more followers. In one such example, Mary attempted to maintain parallel accounts: one personal account that connected her to many members of the management consulting community, and a second account for Inner Circle. At the beginning of the study, she used the Inner Circle account in an attempt to build a more focused network than the personal account. However, as the study progressed, she began to use the business account less frequently in favour of the personal account with its much larger audience.

Where a business account was used only to publish business-related information, managers reported less engagement with their content. Retweets from a businessfocussed follower list tended to reach a more relevant audience, but this effect was also possible to replicate by using relevant hashtags when posting from a personal account. Longer and more frequent conversations (in the form of back-and-forth @replies) happened through accounts that posted some non-business content. These included personal accounts that incorporated business-related tweets, and business accounts that had shifted focus to include more personal content.

\subsection{Forums}

Four managers in this study used forums intensively, spending far more time on forums than any other social media services like Facebook or Twitter. The forums used by these managers catered to specialised niche communities. Most of the forum-using managers 
had actively used forums prior to starting their businesses, and they were already familiar with the places where others sharing their interests could be found online.

Where relevant forum communities were available, they proved to be valuable resources for the managers working in those areas. IT technical support, often sought on the Whirlpool broadband industry forums, was a topic well suited to the medium: threaded conversations allowed members to easily drop in or out of conversations as needed. Whirlpool has a large and active membership of IT professionals operating at all levels in the broadband and telecommunications industry, and so questions could be reliably answered - prompting onlookers to come forward with their own topics.

In contrast, where suitable communities were not available, managers turned to other social media channels. Fashion on Wheels was an example of this. Christine had looked for relevant forums that she could monitor or use to promote her business, and was unable to find a good match: most online activity centred around cycling advocacy groups that concentrated on policy issues, or sporting groups focused on competition and racing. Neither of these was an exact match for her ideal customer profile.

Forums featured heavily in Videogame Network's online strategy. The company first operated an online gaming forum, and had later moved into developing specialist software for engaging and managing large communities. The original forum had remained, expanding in scope as new gaming platforms were released.

\section{Forums as an information gathering tool}

Forums were also used as an information source, allowing managers to identify trends, new releases and customer sentiment that affected their business. Much of the early work into online communities has drawn on studies of forums, such as Kim (2000)'s 'membership lifecycle' model. The description of most forum users as 'lurkers and listeners' is appropriate here: each of the business managers who used forums to source information spent far more time reading than contributing to forum discussions. This behaviour is important for new forum members, allowing them to contribute more effectively after forming a more accurate impression of the community before joining in (Kraut et al, 2011). In some cases, managers were reluctant to become more active as they felt that participating as a business representative would discourage people from talking freely. To avoid this problem, the managers used their forum accounts primarily for watching and listening to their chosen communities. 
Most forums did not offer much in the way of monitoring or listening tools, beyond the ability to subscribe to particular discussions and search for content. This meant that in order to use the forums as information discovery tools, managers needed to be active readers: continually reading discussion threads, watching for interesting discussions. These managers enjoyed spending time doing this, but all noted that it required significant amounts of time to do effectively.

At Network Solutions, Luke spent several hours each week "keeping on top of things" in his industry by reading forums, whitepaper reports and blogs, and instructed his staff to spend some of their time doing the same. For most managers in the study, however, there was no formal arrangement over when or where staff would monitor these sites. At Toys \& Games, Jennifer described checking for overlap between her own forum activity and that of another staff member:

\footnotetext{
Late at night I'll get a host of emails from him going "ooh, look at this cool product, and look at what these people are saying about this," and often I'll find that he's sending me the same products that I've stumbled across on other sites. Between the two of us, I feel like we're covering all the forums in the world... we're obviously not, but it feels like we cover a lot between the two of us.
}

This informal checking mechanism helped answer the question of "how much information gathering is enough?" among the managers: when they encountered the same items again, or discovered the same material as other staff, they felt that they had been comprehensive enough. Information seeking was typically a task performed when time allowed, around other jobs, as a way of using otherwise unproductive time. As long as the forums provided new leads and a sense of completeness in the scope of their research, the managers were satisfied that they were serving an appropriate purpose.

\section{Customer communication via forums}

Forums were also used to communicate with customers, and to let customers talk amongst themselves. Both Model Madness and Toys \& Games ran small forums on their business websites, in order to engage local customers. Matt and Jennifer had started these forums to encourage customers to organise games and competitions, and as another platform to advertise store announcements. However, these forums were rarely used, with customers preferring to use larger forums that already had many active members. 
Technical issues were also commonplace: both managers ran their own websites, but had difficulty maintaining complex software when anything went wrong. The Model Madness site was regularly offline, and Toys \& Games discontinued their forum during the study.

Matt discussed how he used third-party forums to generate more traffic for his website, joining in discussions about products that Model Madness sold. While some sites offered paid advertising options such as banner ads, Matt preferred to take a more active role - using links in his forum signature to connect people back to his business.

Our forum at the moment is still very quiet, so I'm trying to draw traffic back to our forum by including in my signature on different forums: linking back to our website, or directly back to our forums. Articles that I post on other forums, I repost on our forums as well.

Luke used technical support forums to encourage his staff to develop their customer service and problem-solving skills, during times when they were not working on client projects. He saw this as a form of staff development, exposing them to a range of current issues that they might encounter in their other work. While there was generally no direct link between offering advice through the forums, and landing new clients, Luke valued his forum activity as it reinforced the values that he considered important to his business. By providing advice on the forums, his staff presented an image of the company as being knowledgeable, helpful, and approachable: important reputation management work, which could help them to win paid work on more complex projects in future.

Christine also noted that there were difficulties in fitting a 'business' role into a community. She understood that it would take time to fit in with other members of a forum, instead of being seen as an outsider attempting to sell things to them, and did not feel that she could spare enough time to do this properly:

\footnotetext{
I don't use forums as much because I find it, because the purpose of a forum is for members to share information, and because I am not a member of a forum as a person, I am a member of a forum as a business, it makes it very hard for me to contribute to the conversation without sounding like I'm selling something. But at the end point, my time has to be allocated to activities where I think I'm actually going to sell something.
}

This echoed similar concerns raised about blogging and Twitter: forums were seen as a communal place where people talk and share information. Unlike a business page on Facebook, or a professional-focussed LinkedIn profile, the audience members are not 
there for messages about a specific business, and in some cases will actively reject commercial content in their community.

\section{Using forums to facilitate networking activities}

The managers used forums for informal topic-related discussions, where participants could drop in or out at any time. As such, forums were not used to make or maintain direct links with others in the manner as on social networking services or Twitter. Over time, the managers did establish relationships with regular forum users, but these networks formed in a far more organic fashion than those seen in other social media platforms.

Among the Professional Services business managers, forums were used to bring together industry peers for networking and information sharing. These managers pitched their service offering to large corporate and government clients, and valued memberonly forums such as Thought Leaders Australia that allowed them to make contacts and share information among their peers in private, away from potential clients.

The retail managers were the most active forum users, as these services provided access to niche communities of their potential customers. However, they did not use forums to discuss industry issues with other retailers, and typically had little direct contact with business owners that operated in a similar area, or sold similar products. Jennifer noted that this lack of communication within her industry had caused problems, and had planned to create a private forum for industry discussion. However, she did not launch her planned industry forum during the study period, due to resourcing problems and uncertainty over how many businesses would actually participate.

None of the hospitality business managers used forums during the study. These managers were not personally forum users prior to starting their businesses, and gravitated towards more 'mainstream' social media services like Facebook and Twitter. When asked about forums, they were unaware of any sites that had direct relevance to their business, and preferred to use services with high user numbers in an attempt to appeal to the largest possible range of potential customers.

\subsection{YouTube}

Few of the business managers used YouTube as a 'social' technology, maintaining a channel with regular content or using the comments feature to interact with other users. 
Instead, almost half the managers used YouTube as a video hosting service, uploading videos to embed these into blogs and other web pages.

Matt was the most active user of YouTube during the study, and had used the site for several years prior to starting Model Madness. Before leaving a software engineering career to start his new retail venture, he had begun to make videos about his hobby joining a community of model-makers who used the service to post video tutorial and showcases of their work. He began posting videos for his store through a personal account, and later added a second channel that carried the business name. He explained that the motivation for starting a video channel came from seeing what others in the community were doing:

I used to watch a lot of YouTube a few years back, and originally opened a channel that I'd never really used. So it was sitting around, and I was doing research and saw that there were a lot of people out there ... showcasing their pieces, or doing small tutorials, that sort of thing. So I jumped in and tried making my own.

Matt actively engaged the viewers of his channel, and the wider model-making community on YouTube. He achieved this by responding to comments left on his own videos, and commenting on other videos that covered related topics. In addition to this, he incorporated a regular 'shout outs' segment into his videos, acknowledging other community members by helping to promote their latest videos, and addressing questions that had been left in the comments area on his previous videos. By the time his store opened its doors, he had already established a reputation online, and regularly had new customers discover the store through his videos.

A far more common use of YouTube was as an alternative to hosting videos on the business website. Managers using the service in this fashion typically undertook little or no active monitoring of their channel, and often disabled comments on their videos seeing little value in these. Instead, these managers used the service for the relative ease at which it allowed videos to be embedded in websites and posted on social networking services. Any viewers finding the content through YouTube itself were considered to be an additional benefit, but not the primary focus. Eric described this practice when discussing video content on the SocialSearch website: 
and the landing page on our website has a video embedded ... YouTube really opens up the ability for anyone to see the video, whether or not they're in the context of our website. It doesn't have a huge number of hits at all, but people who search for social media videos on YouTube may see ours come up in those results and watch that video.

Central $P R$ took an unusual approach to using YouTube, commissioning more established users develop and post content for them. Jess discovered a business focussed on delivering entertaining 'infomercial' videos through the service, presented as an inside look at interesting small businesses and their products. Despite these being paid advertisements, the channel had attracted over 4,500 subscribers and provided a readymade audience. When launching a new arm of her business in the United States, Jess hired the infomercial business to produce five short video segments on Central PR's products and services. The videos received almost 3,000 views, reaching a much wider audience than the business was able to access on their own.

As the most active YouTube user among the managers, Matt was also the only manager to explore the service's analytics function - using it to regularly check on who had watched his videos, and which had been the most popular. He used these statistics to adjust and refine his content strategy, preparing more of the types of video that had proven to be the most popular among his viewers.

\subsection{Discussion and implications}

During the study, it soon became apparent that the business managers did not limit their online activity to any particular type of social media. Similarly, each business used several different social media services, trialling and observing new services as they became available, and abandoning others when they failed to fit the needs of their business.

The most commonly used services were Facebook and Twitter, used by managers across all four industry types. All of the managers used Facebook in some capacity during the study, typically in the form of a personal account. In addition to these accounts, most had created a business page, or a second profile using the business name.

Many of the managers also experimented with using Twitter, though the degree to which they continued using it varied greatly: some conducted a short trial and then discontinued their accounts, while others treated it as their primary news source. Several managers ran multiple Twitter accounts. The most common reason given for this was to 
separate personal and business activity, though one IT startup also used additional accounts to help define different branding for new product lines.

Most of the business managers had a LinkedIn profile, though most admitted that they did not use the service actively: instead, they had created a public profile and did not regularly update it. The few managers who actively used the professional networking service did so frequently, and also used additional features such as the LinkedIn Answers forum, job listings and discussion groups.

Beyond the 'big three' platforms of Facebook, Twitter and LinkedIn, the managers used a wide range of other services. Industry-specific blogs and forums, either hosted by the business or on third-party websites, provided valuable news and information on customer needs, industry trends and competitor activity. Technology news blogs such as Mashable and Techcrunch were relied upon for information about new social media services. Services like YouTube, Flickr and Instagram were used to upload media such as video and images, which could then be posted to the other social networks.

Common themes emerge from the ways each manager has adopted and used various social media services in this study. These are summarised in Figure 5.1 below. They concern perceived low risk and a fear of missing out as key drivers for the adoption of social media services, and the business outcomes in the form of visibility, insight and social capital benefits that are derived from these. These themes are explored in detail in the remainder of this chapter.

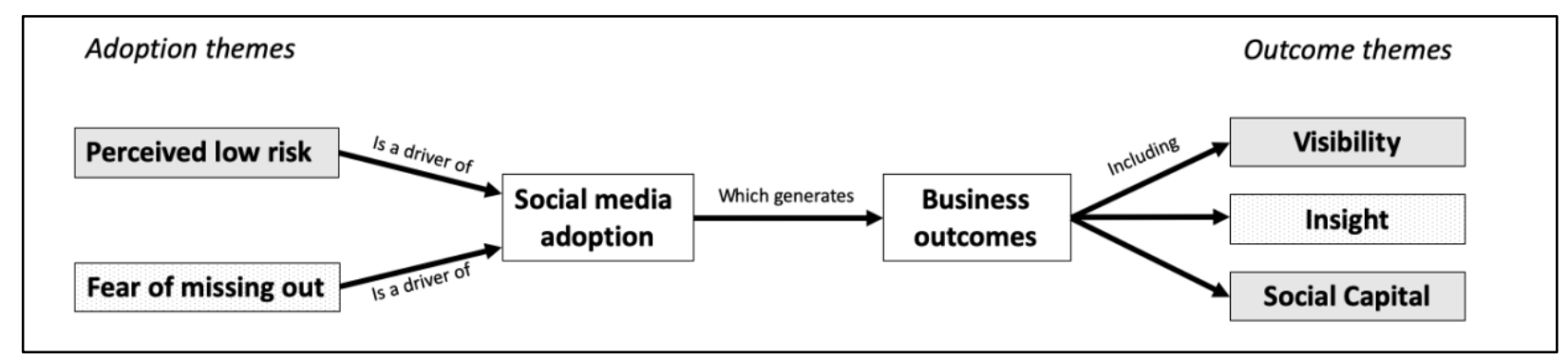

Figure 5.1: Key themes in social media adoption and outcomes 


\section{Adoption theme - Perceived low risk}

This theme contributed towards social media adoption, due to the low perceived risk involved in creating a business account on social media. Managers discussed this in terms of three key factors, shown below in Figure 5.2: low cost (in financial terms), ease of use, and low consequences associated with any mistakes made while learning to use these new services. The level of perceived risk in these areas directly affected each manager's degree of adoption. Each manager followed a broadly similar path when bringing new technologies in to their business: developing initial awareness of a service, observing how others used it, and ongoing experimentation before and during deployment.

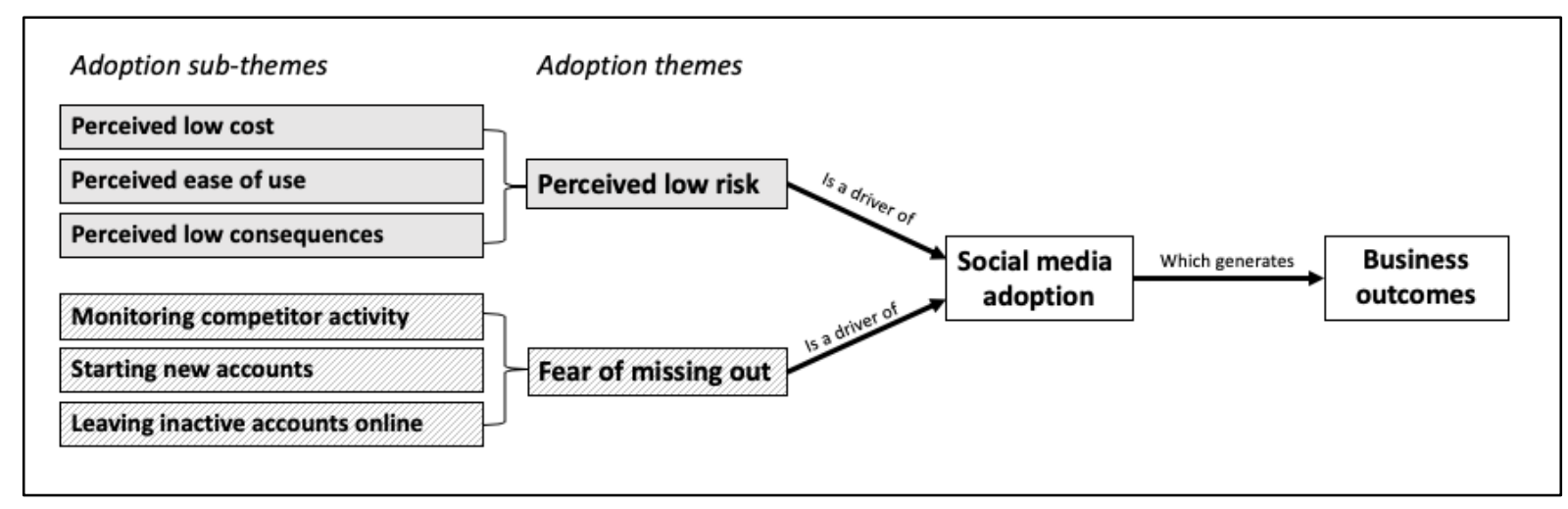

Figure 5.2: Adoption sub-themes

\section{Perceived low cost}

With an abundance of free or 'freemium' services available, managers were all reluctant to pay for any form of social media services, whether these involved advertising, premium account features, or software applications. The managers viewed social media services as a promotional tool, and compared these services with other marketing techniques such as paid directory listings, or printed marketing collateral. A common observation was that any service requiring a monetary cost was expected to produce quantifiable results: any 'paid' service should provide a direct return on investment. The relationship between marketing activities and sales was not well understood, with one manager commenting on his marketing mix, "All I know is that if I stopped doing everything, we probably wouldn't get customers in the door." This was further complicated by adding new social media services, with little strategic planning involved in finding a role for these. The lack of clarity over potential outcomes for social media meant that managers were reluctant to adopt any paid social media services in this study. 
The managers typically did not expect free services to directly generate income for their business. These services required an investment of 'soft' resources such as staff time and training or independent learning, which the managers did not place a dollar value on. As a result, managers were more likely to experiment with free social media services, and to continue trials for a longer period of time before deciding to adopt or reject them.

\section{Perceived ease of use}

The managers rarely accounted for the amount of staff time required to use social media services, but they were aware that it could be significant. To reduce the risk of these activities taking up too much time, there was a strong preference for services that were easy to use - both in terms of initial learning curve, and for ongoing access once a new account had been established.

Jennifer explained that her early attempts to use Twitter had been hampered by a lack of knowledge: "If I knew how to use it properly it would be different, but I don't use it myself, so for me I'd have to learn how to use it first, and then remember how to use it."

Managers preferred to use services that they already had some experience with, or that had features they recognised. When they needed to learn how to use other technologies, the managers turned first to their personal networks - looking for staff, friends or family members who understood how to use a new service. Where a new service offered a relatively shallow learning curve, it was more likely to be experimented with. For example, several managers set up Facebook Pages for their business, because of prior experience with personal Facebook profiles. Others had maintained personal blogs, writing about travel or food, and then learned to use more sophisticated WordPress business plugins when beginning to maintain a blog for their business.

\section{Perceived low consequences}

Another contributing factor in social media adoption was the perceived lack of consequences associated with misuse or failure to use social media accounts. This was closely related to the theme of low cost: where free-to-use services were adopted without financial goals, the managers' expectations of business outcomes were low. When adopting a new social media service with a goal of finding new customers, producing insufficient results (i.e. not enough customers) would simply lead to the manager abandoning the channel, no longer actively using it, but leaving the account online. A less 
common scenario was the service producing undesired results: for example, negatively influencing the business' reputation. The managers who discussed this consequence suggested that they would consider closing and removing social media accounts in this case, though none had needed to do so.

All managers in this study followed other businesses in order to see what they were doing online, looking for ideas on how to use social media more effectively. The public nature of early-stage social media adoption provided opportunities for each manager to see their peers involved in trial and error experimentation. Where managers saw little consequence for public mistakes, this contributed to their willingness to try new technologies. Early adopters were particularly open to testing out new ways of using social media, as they were open to deleting posts or simply changing tactics if any given method failed to work with their online audience.

The reverse of this was also true: in cases where managers did feel uncomfortable with the potential consequences of a public 'failure', they were far less likely to experiment with social media services for their business. This is illustrated by cases such as Fusion, where Lee felt frustrated by her lack of knowledge about what would be considered appropriate when posting or replying to other users on Twitter. Similarly, SocialSearch were very cautious about their adoption of blogging - they considered any public material to be essentially permanent once it had been indexed by search engines, and spent a considerable amount of time preparing to publish new content.

\section{Adoption theme: Fear of missing out}

The second major adoption theme focuses on the perceived consequences associated with not adopting social media services. The 'fear of missing out' drives adoption in order to avoid a negative - contrasting against the previous theme, where adoption was motivated by perceived positives. This theme is seen when managers discuss their awareness of competitor activity, watching other businesses launch new social media profiles. Each manager was keenly aware of which competitors were already active on social media, and they watched competing business accounts closely. Managers saw a competitive advantage in being visible and accessible to the users of each social media service, and feared losing potential customers to rival businesses.

This theme is also seen in the way managers assessed new services in terms of total user numbers, and rates of growth. They were aware that services like Facebook and 
Twitter were growing rapidly, much as business websites had become ubiquitous over the previous decade, and managers like Eric and Jennifer discussed their fear of missing out on the 'next big thing' that would shape their industries, or the ways in which customers sought information about local businesses.

This contributed to the rapid uptake of new social media services during the study, with managers frequently creating new accounts for their businesses. This was partially motivated by a desire to test out and explore the potential uses of each new service. However, the desire to claim brand-related account names was also widespread among the managers - staking a claim to their business title, in case it was needed later. This theme is also seen in the way that managers treated inactive accounts. Limited time and other resources meant that new accounts could not be sustainably maintained, and so the managers frequently changed their focus. Unused social media accounts were not closed or deleted, remaining inactive in case they were needed again in future.

\section{Outcome themes: Visibility, insight and social capital}

The outcomes of successful social media usage can be grouped into three major categories, shown in Figure 5.3 below. These relate to the visibility of the business to its various audiences; insight into the business' local environment, and the social capital benefits associated with actively cultivating a network of contacts.

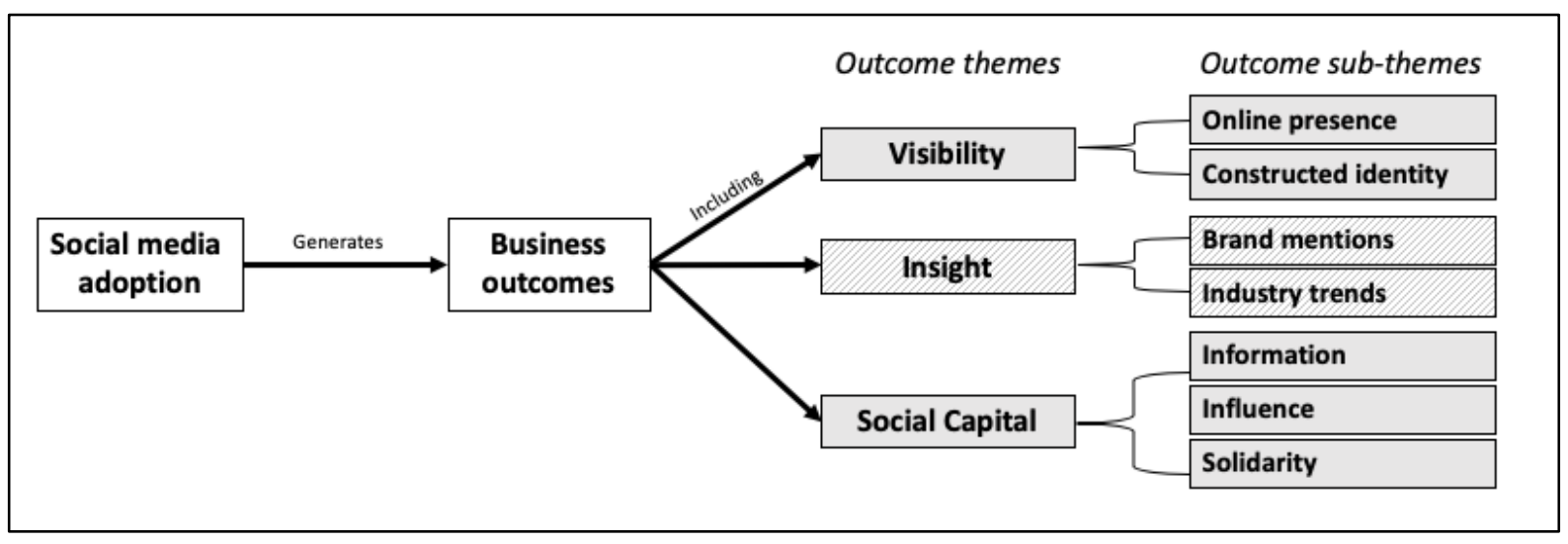

Figure 5.3: Outcome sub-themes

\section{Outcome theme: Visibility}

This theme concerns two aspects relating to online visibility. The first was simply establishing a presence for the business - claiming an account name on a new social media service, and attempting to publish content that could be seen by customers. While 
this was typically the primary objective for each business, it was later supported by a second aspect: the deliberate construction of a business identity, used to support the manager's reputation and branding.

All of the managers experimented with using multiple social media services, and different methods for posting content to them. This was seen as an ongoing process, where each manager sought to continually refine their approach. The managers also varied their publishing methods, often seeking a balance between 'broadcast' messages and two-way conversations. Some managers also experimented with posting times and frequency, trying to determine what received the best response. This varied with each service - for example, content on Twitter flows past users very quickly. This led to managers re-posting links and comments at different times of day to broaden their audience reach. To accomplish this, they experimented with automated posting using tools that allowed content to be queued up in advance, and then posted at specified times.

Most of the managers also discussed difficulties in finding an appropriate balance between personal and professional content, as they were aware that this would shape the way that others perceived their business. This was commonly seen on social networks that the managers spent a large amount of time on, such as Twitter. It was also discussed in relation to joining established communities, such as the most popular food blogs, and speciality forums. Here, the managers often struggled to fit in as a business owner among an environment of individuals. Managers continued developing a specific voice to use on each social media service throughout the study, and could attribute their choices about what and how they posted on their accounts to deliberate attempts to influence this.

\section{Outcome theme: Insight}

Insight refers to the passive information benefits that managers received through their use of social media. Creating an account and establishing connections to a network of related provided them with access to information that directly concerned their business, such as brand mentions and a new channel for receiving direct messages. It also allowed them to monitor competitor activity, watching how other businesses conducted promotions and used their own social media accounts. Finally, managers gained access to a new way of monitoring industry trends among customers or peers.

All of the managers were interested in tracking messages and responses to their social media posts. However, knowledge about the range of tools available to do this varied 
greatly within the group. Most tracked these directly on each of the social media platforms, requiring them to actively spend time logged into each service on a regular basis. Managers with technical or marketing backgrounds, such as Liz from Bandwagon and Eric from SocialSearch, used more advanced tools to assess the impact of different social media services. These included Google Analytics, "Insight" tools provided by Facebook and YouTube to business pages and channel accounts, and third-party apps. While many of the managers were aware that more specialised monitoring tools existed, the cost of these was considered too high, and the managers preferred to combine multiple cheap or free tools to handle different aspects of their monitoring needs.

Social networks were a valuable source of news. The managers initially sought to increase the size of their networks, seeing these as a potential audience for their content. While this was true, it overlooked the important role that these networks play in information discovery. Beyond the roles of broadcaster and listener, the other members of a network are continually talking, listening, and transmitting information - both within the original network, and beyond it to their own circles. Mel discussed how valuable her Twitter account was for answering questions from a surprisingly wide range of topic areas - a feature that had developed as her network grew larger, and as she had deliberately tried to connect with people who had interesting points of view. These features improved the range and diversity of contacts that she could draw upon.

\section{Outcome theme: Social capital}

As discussed in Chapter 2, I have chosen to explore social capital in terms of the information, influence and solidarity that it makes available to the business managers. This is a key outcome of their social media use. It is important to highlight the distinction here between the information component of social capital, and the 'insight' outcome described above. I use insight to describe the passive benefits associated with using social media to observe customer and competitor behaviour. The information component of social capital requires active immersion within a network of contacts. It represents a manager's ability to get answers to questions they ask of their network, and the ability of the network to surface useful information and direct it towards that manager.

The managers who cultivated direct relationships with their customers had greater access to this type of information. For some businesses, this feedback was available through a wide range of rating and review websites, providing further information on 
emerging issues. Contacts helped to draw attention to new reviews, by sending links to articles as they found them. Feedback from customers and peers helped other business managers to test out ideas - making decisions about which products the store should carry, or what type of menu items to introduce.

Managers also benefited from cultivating a reputation among current and potential customers and industry peers. By sharing information and knowledge about their industry, and being visibly connected to other influential peers, the business managers could establish a functional reputation as thought leaders in their industry. This provided the managers with influence and is explored in more detail in Chapter 7. That chapter also addresses structural elements of network building and maintenance, exploring how managers are able to use their networks as information resources.

\subsection{Conclusions}

This chapter has explored the range of social media services used by the business managers, and the ways in which these have been used within each business. Facebook and Twitter were the most popular, reflecting their widespread popularity in Australia throughout the study period. The managers also used LinkedIn, Google Plus, YouTube, and various blogs and forums, for a combination of personal and professional activities.

Each manager used many different social media services during the study, and they used these to varying degrees of sophistication. A period of experimentation typically follows the adoption of a new social media service, when managers attempt to learn how they can best apply it to their business: trying different approaches, and observing the activity of other users such as industry peers and customers, in order to learn from what others were doing. Over time, the managers began to use their social media accounts in more sophisticated ways, delivering a broader range of business outcomes.

On social networking services and Twitter, the managers were more likely to begin with an emphasis on posting (or broadcasting) content to their contacts. In these cases, the social media services were selected primarily for their audience size, and the perceived benefits of increasing the 'reach' of the business' messages. Over time, this approach shifted in one of two ways. Some managers saw little immediate success from their broadcasting activity, and reduced the amount of time they devoted to that channel. This resulted in the abandonment of many social media profiles as they gradually fell into 
disuse. Other managers discovered greater value in using their channels for a combination of publishing and information gathering. This was particularly common in the Twitter-using businesses, where several managers discussed their surprise at finding how much they valued the links and resource sharing available from their network.

'Lurking' behaviour, or passive consumption of content (also described as "legitimate peripheral participation" - see Lave \& Wenger, 1991) was more common when managers used forums and blogs as information sources. Managers described several reasons for doing so. For some, this was seen as a preliminary stage of 'learning the ropes' that would allow them to participate more fully in future discussions. Others were mindful of the way that their presence as a business owner made them an outsider among customer communities, and chose to remain silent in favour of observing these communities to gain insight into their own customers.

The business outcomes that managers generated through their use of social media can be broadly described in terms of visibility, insight and social capital. While the specific outcomes varied between businesses, each of the managers used a range of social media services to generate these three outcomes. Managers typically began with an intention to increase the visibility of their business via online promotions, and then progressed through insight and social capital-generating activities, as the manager's understanding of the technology grew. These observations are consistent with Atanassova \& Clark's (2015) notes on the importance of understanding the role of social media use in market intelligence gathering by SMEs, and the role of social media in networking and social capital development identified by He et al (2015).

The following chapters present a more detailed examination of these themes. Chapter 6 uses Diffusion of Innovations (Rogers, 2013) theory to examine properties of the managers and the social media services they adopt and use, and the ways in which those properties affect technology adoption. In Chapter 7, I use social capital theory to explore the range of business outcomes the managers derived from active participation within their social networks. 


\section{Adopting and using technology}

This chapter addresses the ways in which business managers adopt new technologies, building on the major themes of fear of missing out and perceived low risk that drove social media adoption. Here, I focus on the process of social media adoption, and properties of both the managers and the social media services they chose to use.

Numerous theories have been proposed to explain patterns of technology adoption, both by individuals and organisations. The theoretical framework that I have used to explore this theme is Rogers' (2003) Diffusion of Innovations, also referred to here as DoI or diffusion theory. This examines the stages involved when learning about, deciding to use and implementing an innovation, and has been applied to a range of technologies and industry types. Since its first publication in 1962, DoI has become a highly influential model, subject to many refinements by later studies. Although the current edition of Rogers' work pre-dates the rapid worldwide adoption of social media services, Rogers comments upon the diffusion of technologies that experienced similar rates of growth in an earlier period of internet development: presenting case studies on the explosive growth of Microsoft's Hotmail service, and the near-total dominance achieved by Nokia in the pre-smartphone mobile handset market.

This chapter addresses the key features of diffusion theory, exploring its application in small business social media research. I draw upon Rogers' work to argue that both social media services and small business managers possess characteristics that can predispose them towards rapid adoption. Support organisations and technology developers aiming to increase technology adoption among small business managers can learn from this, identifying features that can improve the diffusion of their chosen innovations. I explore three elements from DoI: the Innovation-Decision process, properties of the innovation in question (social media services), and properties of the innovators (small business managers). Finally, I explore the potential for a combined model to form a more powerful exploratory tool. 


\subsection{The Innovation-Decision process}

During the study, each of the business managers considered using (and in many cases, began to implement) new social media platforms for their business. In addition to these, all managers had examples of social media that they had begun using relatively recently, for various reasons. The majority of businesses in this study were less than five years old at the beginning of the study, and the social media platforms that they used had been launched within the past decade. This provided several opportunities to explore the process that each manager used when adopting new technology for their business.

In this section, I focus primarily on three stages of Rogers' (2003) Innovation-Decision process: knowledge, implementation and confirmation. The intermediate stages of persuasion and decision to adopt are explored briefly, but are limited by the inability to directly observe each of these internal processes. Knowledge acquisition, implementation and confirmation behaviours are clearly visible in the small business case studies, assisting managers in their decision to adopt or reject a new technology.

\section{Awareness, technical and principles knowledge}

Knowledge contributes to social media adoption in several ways, and is an important factor in the perception of social media use as a low risk activity. I examine this in three sub-phases, as managers develop awareness, technical and principles knowledge.

\section{Awareness}

Awareness is knowledge about an innovation: knowing that it exists, and what it might be capable of. Most of the social media platforms used by managers were widely known of by the end of the study: Facebook had become a global social networking giant, and LinkedIn was well established as the dominant professional networking service. However, many other services were either less widely known about, or had only recently become available. Examples of the former included geo-location services such as Foursquare and Facebook Places: during the research period these services had only attracted small numbers of users in Australia, and the managers of businesses with a physical 'bricks and mortar' presence had just begun to take an interest in them. Examples of the latter include dedicated business or company pages within Facebook and LinkedIn, and the launch of the Google+ social networking service. 
The managers primarily relied on word of mouth (both in person and online) information to develop awareness of new social media technologies. Personal contacts helped them to discover new products and services, which they would then consider potential applications for. At Videogame Network, Robert best described the sentiment shared by each of the managers in the study:

I'm an entrepreneur. When I hear people talking about a new bit of tech, I start thinking about how I could use it in my business.

All managers in the study shared this ongoing curiosity about other types of social media. Several managers deliberately extended their personal networks in order to benefit from access to information on new technology developments, achieving this by joining groups with notable innovators and early adopters: for example, Sarah and Mary had both joined industry roundtable and networking groups such as Thought Leaders Australia. Jess frequently attended conferences in order to meet people on the leading edge of trends in her industry, while Luke and Jennifer joined online forums in order to access this information. The managers using Twitter all discussed how that service had made it much easier to head about other new social media technologies.

Specialist news sources were also considered important. These fall into two major categories: services dedicated to social media news, and industry publications. Surprisingly few news websites appear in the former category: almost all managers relied on the same two sites (Mashable and TechCrunch) for social media news, with few other sites being used. Both sites cover new developments in social media technology, such as new service launches, changes to the features of existing products, and the release of mobile hardware. The hospitality managers still considered industry magazines to be as an important indicator of new trends and innovations for their sector, providing managers with an indication of what the thought leaders in their industry were using via case studies showing how the technology was used and its outcomes for other businesses. Both Lee and Alex had first considered Twitter after an influential publication featured an article showing how a local cafe owner was using the service for his own business.

\section{Technical proficiency}

Technical proficiency is the 'how to' knowledge that business managers draw upon to create and use a social media account. We acquire this knowledge through several 
mechanisms. Basic proficiency can often be attained by simply following user guides for each new service, combined with a willingness to experiment. More advanced technical proficiency typically involves using a wider range of the settings and options available, and using third-party services to further customise the tool.

The managers described a process of trial-and-error behaviour: testing out each new social media service with varying degrees of caution or confidence. The first posts on business social media accounts often contain candid statements about the business' intentions, often showing an apparent lack of strategy or purpose behind setting up the accounts: "Finally joined Twitter!" one manager exclaimed in her opening message. Though ahead of many others in her industry, this manager already felt like a latecomer to social media in early 2008.

In his modification of the Technology Acceptance Model, Venkatesh (2000) introduced concepts of computer self-efficacy (control), playfulness (intrinsic motivation) and computer anxiety (emotion) as anchors that determine a user's early perceptions of the ease of use of a new system. With increasing experience, he argues, system-specific perceived ease of use will adjust to reflect the objective usability of the system in question. These three anchors can also be considered in light of DoI, helping or hindering the ability of each manager to develop technical proficiency with their chosen social media platforms. At Network Solutions, Luke demonstrated high computer selfefficacy (he had chosen a highly technical career, and possessed postgraduate IT qualifications) and a high level of intrinsic motivation that drove him to constantly tinker with new technology in order to develop proficiency. However, the high perceived ease of use was not the deciding factor in his adoption of social media. Luke did not consider the technologies to be useful to a goal of reaching his target customers, and without a correspondingly high perception of usefulness, his adoption of that technology failed.

Many concepts translate well between different social media services, enabling managers to re-use technical proficiency gained from using similar services. Examples of this include many introductory aspects such as registering a new account, uploading a profile image or posting a status update. The processes and user interface design of the major social media services are often similar, helping each social media platform to bring in customers from other services. After creating an initial social media account, most of the business managers went on to create several others. By the end of the study, both 
Bandwagon and Building Blocks operated over 10 social media accounts each; all active to varying degrees, and containing business-related content. Once a basic level of proficiency had been developed with any individual service, this could quickly be applied to create and use accounts on other platforms.

Many of the managers also described how they sought the expertise of others who were also using the technology, looking to their friends, family, and other close business contacts. Some of the managers had existing mentors for guidance on their business strategy, finances or marketing, but they did not use these contacts for advice on using social media. Formal mentoring arrangements typically involved working with older, established business people who were highly valued for their experience and insights into running a business. These mentors were not considered to be a good source of information on social media. The managers regarded social media as too new a technology to approach business mentors about, as they considered it to be the domain of younger users - 'digital natives' who had grown up using the internet, and who were active users of social networking services.

\section{Developing social media principles knowledge}

Principles knowledge involves an understanding of the underlying principles that allow an innovation to work. Rogers (2003, p. 173) notes that "it is usually possible to adopt an innovation without principles-knowledge, but the danger of misusing a new idea is greater and discontinuance may result." This type of knowledge is typically the hardest to develop, and was a major cause of anxiety and self-doubt discussed in interviews with business managers who had not used social media in a professional context before. It is developed throughout the adoption and use of an innovation, and can contribute to the discontinuance of an innovation. I examine principles knowledge in terms of technical and social skills. Both assist in understanding the types of outcomes that can arise from social media use, and the reasons why particular actions will work.

Technical principles knowledge encompasses aspects such as how newsfeed and search algorithms function, and the effects of privacy settings on when and where content will be visible. This type of knowledge can be highly technical in nature, and assists managers to understand how social media services process and deliver their content. Managers from non-technical backgrounds, such as Lee and Sarah, often viewed these systems as impossibly complex, incomprehensible or too time-consuming to master. In 
contrast, managers who had existing technical skills, such as Luke and Eric, viewed these underlying rules represent tangible, discoverable knowledge - even when they are intentionally obscure (as in the case of Google's search algorithms). The presence of usable and exploitable rules helped to reduce the perceived complexity in the nebulous task of "using social media" for their businesses.

Social principles knowledge encompasses an understanding of social context and appropriateness, including the role of trust, reputation and influence in operating social media profiles. This is typically acquired via self-reflection and observation of how others use the technology. It requires a level of critical examination - identifying what works or does not work, and then examining what is responsible for success or failure. Despite this, the development of social principles knowledge was typically not a conscious stage for each business manager. During the interviews, managers expressed these elements in terms of 'intuition' or 'gut feeling,' described more frequently in terms of things they would avoid. Mary, Jennifer and Matt all discussed how they had not explicitly considered their values before the interview, but they could each identify types of social media content or behaviour that irritated them when they encountered it online.

Of the three knowledge stages, principles knowledge development is the most difficult to measure, as success or failure is highly subjective. This is most obvious in the development of social skills, where concepts such as appropriateness and sensitivity to context are major factors. Similar problems exist in technical systems where the underlying rules are not clearly understood, or deliberately obscured. This is the case in the example of search engine rankings or social media newsfeeds. In these cases, visibility is governed by sophisticated algorithms that are continually changing, and details these mechanisms are not made public. Instead, 'best practice' methods for improving the ranking of a website are guessed at and approximated by trial and error.

At Fusion, Lee explained how she had struggled to understand how to use Twitter appropriately when trying to raise the profile of her restaurant. She knew how to post updates, send messages to other members and use hashtags. However, she felt that there was an unwritten system of etiquette behind using the service.

On Twitter there's an etiquette, a protocol. I'm still at this stage where I'm not quite sure what is the right way to do it. How do you do it? You need to be a bit careful. 
She was wary about how others would react to being mentioned directly when she had no direct relation to them, such as messages to high-profile celebrity chefs and food bloggers. Similarly, she wanted to reach a broader audience with her posts but was uncomfortable asking directly for retweets. Lee looked up to several well-established Twitter and Facebook members, both for their wealth of connections and the seeming effortlessness with which they communicated online. During the first three months of the study, she actively followed these accounts but only rarely posted content for her business. Eventually, she began to cautiously experiment with different ways of posting in an attempt to find out how best to have her own voice heard.

In contrast, Matt was highly comfortable using his YouTube channel to promote Model Madness. He had used the service intensively for several years before starting his own business, and understood both the technical and social aspects involved in communication through videos, channel pages and comments. Matt was far less comfortable using Facebook and Twitter, but wanted to maintain a steady stream of content on both platforms. As he had limited time to spend publishing and promoting content, he tried using a technical solution that ignored the social aspects of these services. Automatically syndicating content across all of the business' social media accounts ensured that each was regularly updated. However, his business failed to attract significant numbers of followers or fans on either Twitter or Facebook, and eventually discontinued the use of both services. Customers regarded Matt's stream of impersonal, automated updates on Facebook and Twitter as another form of spam, and chose not to connect with the business on those channels.

Similar examples can be found for Videogame Network, Vitae and Central PR, where the business managers experimented briefly with Twitter before discontinuing with the service. In each of these cases, Robert, Sarah and Jess had invested significantly more time into learning to use other services, and tried unsuccessfully to repurpose content from those for Twitter. Automatic reposting of other content, over-reliance on pre-scheduled updates, reposting multiple times each day and ignoring messages from individual users all contributed to the failure of these business accounts, and their subsequent discontinuance. These managers had developed both awareness and technical proficiency with Twitter, but did not progress on to develop principles knowledge that could have helped them to understand how to improve their use of that service. 


\section{Applying social and technical principles knowledge}

Allana and Dean, of recruitment firm Building Blocks, expressed a strong opinion on how they 'should' use the various social media profiles belonging to the company and its two founders. Allana described her approach:

We don't push business at all, in what we post online ... I would rather that the type of person who approaches us has done some sort of homework to find us.

Accordingly, the company drew a line between business and personal posts - carefully avoiding any entanglement between the two. Personal Twitter and Google+ accounts served as channels for conversation and information discovery, while only the branded Building Blocks accounts contained posts about the business itself.

At SocialSearch, Eric used his understanding of search engine algorithms to guide his content strategy. Blog posts on his business websites didn't attract many comments, but conversation was a secondary goal compared to visibility in search results. To Eric, blogs are long-tail SEO: "When you write a blog post, it's there for ever and it's indexed for ever." His primary audience is Google, and the ways that potential customers will describe his products and services when they search for information. This led Eric and John to carefully analyse keywords and search terms before setting up the company blog, optimising their content to use those keywords in a way that helped their business to maintain a high profile in web searches.

At the highest level of skill, managers could intentionally break or subvert unwritten rules of social engagement, to achieve specific aims. For example, Cover Story manager Mel was a prolific social media user, maintaining accounts across virtually all services that were used by the other managers. Her exposure to many different potential ways of using these accounts led her to a conscious rejection of the rules and conventions often described by her peers. As a professional writer, she was highly conscious of the way her choice of writing style and content affected the way her business was perceived online. By deliberately bending or breaking unwritten rules, she established a distinctive voice across each of her many social media accounts. This helped her to build a large and diverse network of contacts, who became a valuable source of information for her business. She commented that: 
I'm really surprised that, for the breadth of stuff that I tweet, they put up with a lot. You know, apparently it's a faux pas to be tweeting about the food you eat and where you eat it, but that's the basis for basically all of my feed...

This method of establishing an identity and personality online shows a sophisticated understanding of the social principles behind online communication. Despite joking about breaking unwritten rules, Mel had a clear understanding of how different behaviours affect the way her peers and potential clients will perceive her business. She noted that while her choice of content is often seemingly unrelated to her business goals, she carefully moderates her tone. Her posts were typically upbeat and humorous, even while writing reviews or critiques. Her audience didn't expect overly negative comments from her, and so she maintained a carefully constructed persona online: sharing a cheeky sense of humour with her offline communications, but toning down her use of sarcasm in order to present a more positive image that was harder to misread.

\section{Persuasion}

In this phase, the perceived characteristics of an innovation are major factors in its adoption. Rogers' (2003) five key characteristics relative advantage, compatibility, complexity, trialability and observability are discussed further in section 6.4. This phase contributes to the fear of missing out as managers assess their competitors and look for gaps in their own capabilities.

The managers selected new technologies through a combination of internal evaluations and discussions with their peers. During the study there was little discussion of the adoption of the largest services such as Facebook, Twitter and LinkedIn. These were seen as such major developments that their adoption was inevitable, with each manager creating at least a token presence on each. In these cases, managers had already been persuaded to use the new technologies, although they often lacked a clear purpose for them. This purpose was more often developed during implementation, exploring the question of 'how can we best use this?' rather than asking 'will we use this?'

A notable exception to this was Luke's experience at Network Solutions. He resisted the idea of setting up a formal business presence on Facebook, considering other platforms such as industry forums to be a better use of his time. Despite this, he discussed receiving business enquiries from his customers via Facebook, noting that private 
messages were increasingly used as "an alternative to email" for these customer groups. Additionally, many of his customers were first contacted through his extended personal social network, using Facebook as a means of brokering 'friends of friends' relationships. This made his decision to avoid using social networking services (which he described as 'pretentious') appear to be driven more by personal values than by pragmatism.

While most of the business managers were already determined to stick with major social media services like Facebook or Twitter, they showed no such loyalty to the software applications used to read, post to or track their social media activities. They frequently asked their followers for opinions on the best apps to use for monitoring or posing content, discussing what they were trying out, and asking for suggestions. Their choice of mobile apps, browser add-ons and other third-party software was at a much earlier stage of persuasion, with most managers trialling several alternatives.

When new social media services appeared, managers were much more active in discussing them with their peers, both on- and off-line. Twitter feeds commonly contained questions about Google+, Foursquare and Pinterest, asking for recommendations and examples of other businesses using these. Some managers were early adopters, and posted links to their accounts and promotional content. These posts were largely intended for an audience of potential customers, but were also seen by other business owners - contributing in turn to the persuasion and potential adoption by a wider group of business owners.

\section{Decision and implementation}

Each business used a series of partial implementation stages to 'test the water' when adopting new social media services. This blurred the boundary between two phases in Rogers' model, combining activities associated with decision and implementation.

Importantly, no social media service was considered to be critical to the operation of a business. Instead, combinations of multiple services were used to achieve tasks. Even for businesses that conducted the entirety of their promotion and marketing online, such as Lunch Spot and Model Madness, lack of access to any specific social channel would not prevent the business from conducting these tasks. The high degree of redundancy between platforms allowed managers to trial aspects of each new social media platform, gradually shifting their emphasis between different services. This delayed the need for a formal decision about whether the business would adopt a new platform: rather than 
'yes' or 'no', a more accurate answer for most of the small businesses would be 'some of the time, for some purposes.'

The structure of the businesses in this study and their lack of formal approval processes also contributed to this blurred line between decision and implementation. Even the largest businesses in the study group used a relatively flat organisational structure, and many of the micro businesses had few or no additional staff. With no need to pass through the series of approvals more typically required by larger organisations, decisions to adopt or reject new technologies were typically made directly by the manager, and implemented soon afterwards.

Similarly, few technical barriers existed between decision and implementation. Unlike many other ICT innovations, social media accounts rarely require users to purchase hardware or install software, working from within web browsers on existing devices. The process of creating new accounts quickly moved from basic account set-up to publishing content. This highly streamlined process meant that there was rarely any need to delineate 'trial' activity from 'live' activity on social media accounts, and so most managers tested and experimented with the technology directly on their business accounts. This behaviour was most often seen on Twitter and Tumblr; two services with simple posting features and relatively basic privacy controls.

Facebook business pages offer the best example of a tangible separation between the two phases. A newly created page is typically 'unpublished' and only viewable to the page's manager. This gave the manager an opportunity to set it up before a public launch: configuring privacy settings, uploading content, and preparing the page for the arrival of customers. However, success or failure of most social media accounts depended on how others used those accounts: how many people connected to them, how valuable they could be as a source of news and information, and how they could engage users in conversation about their brand, products or services. First contact with a public audience could only occur after implementation had taken place. This forced the managers of these pages to move through an initial decision phase ('Do I use this tool?'), through an implementation phase (setting up the tool - creating an account and posting content to it), and then deciding when to make the account public. 


\section{Confirmation}

The final phase in Rogers' innovation-decision process is that of confirmation: reviewing the innovation to decide whether it is worth continuing with. Given the tangled nature of the decision and implementation phases described above, this final phase is of particular importance. Only after significant public trial can the business managers assess whether a social media service is working effectively for them, as the involvement of the public is crucial to determining success or failure.

Discontinuance involves adopting an innovation, and then later rejecting or abandoning it. Typically this occurs when the innovation fails to deliver outcomes that it was expected to provide. Central PR and Vitae both discontinued their Twitter accounts during the study, despite being early adopters of the service. Both Jess and Sarah stopped posting to or monitoring their business Twitter accounts early in the study. The accounts were not closed or deleted, and no formal decision was made to stop using them. Instead, time constraints had caused the two managers to prioritise other tasks, and their accounts had fallen silent. This had been a gradual process, supported by a lack of tangible benefits from their use of the accounts.

Matt had tested and later discontinued accounts for Model Madness on several forums. In one case, the tone of conversations in the forum was a major factor in this discontinuance. While the topics were relevant to his business, Matt found that the conversations were dominated by cliques of long-term users who were often hostile to outsiders - particularly those entering the community to advertise a business. This did not provide an appropriate environment for the promotion of his business, and so he stopped visiting this site. In other cases, forums that had initially appeared promising were rejected as they didn't provide relevant enough discussion to justify the time that Matt would spend following and contributing to them. Many different communities exist online, and some of these occupy very tightly focussed niches. Where relevant, these provide a valuable source of in-depth knowledge - for example, Jennifer successfully used forum communities as a source of information on market trends, helping her to order in new product lines for Toys \& Games. However, Matt described negative experiences with communities that were too specialised for his needs, and discontinued these accounts.

Reinforcement describes the opposite outcome: positive feedback that contributes further support to an adoption decision. Allana and Dean were early adopters of Google+, 
and received positive reinforcement on their decision to use it as Building Blocks' primary social networking service. In the first six months that the service was available, many other early users were abandoning Google+ due to a perception of a lack of network diversity or content when compared to Twitter, and lacking a critical mass of close contacts when compared to Facebook. In contrast to this, the Building Blocks managers had found an active community that was made up almost entirely of their target market: tech savvy early adopters. By frequently posting updates and sharing content on Google+ at a time when few other users were doing so, they established a more prominent online presence than they had been able to on any previous social media platforms.

At Inner Circle, Mary had tentatively begun using Facebook to promote a new product for the business. This rapidly became a major focus for the business, supported by her wide range of industry contacts on Twitter and LinkedIn. These people helped to spread the word about the new product, attracting large numbers of highly engaged fans on the product's Facebook page. The page and the product it promoted had both initially been trials, designed to assess a new revenue stream and test out another social media platform. Rapid, early growth in terms of page fans, discussions and product sales reinforced the viability of both product and platform, and Inner Circle began putting more resources into supporting them.

Similarly, Central PR reviewed their use of Twitter after seeing that a significant number of potential customers had begun to use it. Jess was well connected with other prominent Twitter users in her industry, and their reported benefits from using the service convinced her to give it another chance for her business. They re-launched their social media presence after almost 18 months of inactivity, on both Facebook and Twitter. This allowed Central PR to quickly reconnect with the many followers and fans they had accumulated on the two platforms, without needing to rebuild from scratch.

\subsection{Characteristics of the innovators}

This section takes a more detailed look at the characteristics of the innovators, and the ways that the small business managers may be predisposed to adopt or reject new technology for their organisations. Rogers (2003, p. 287) groups variables that relate to the innovativeness of individuals into three generalised categories: socio-economic status, personality values, and communication behaviour. 
It is important to note that each of these characteristics is relative to the innovativeness of the group under consideration. Among small businesses in Australia, those with an established social media presence at the end of 2009 were in the minority (Sensis, 2009). This suggests that the managers of these businesses were innovators and early adopters on a national scale. However, few of the managers considered themselves as such. Instead, they each had focused upon other, more advanced groups of social media users - either within a different part of their industry, or from other industry sectors. The managers looked to these other groups for innovation and leadership, and saw their own technology use either as a means to remain competitive with industry peers, or as an advantage when compared to their local competition.

Even business managers identified as innovators and thought leaders by others in the study did not consider themselves as such. Eric (SocialSearch) and Lunch Spot's Ben and Eleanor were highly regarded by other managers in the study, and respected for their insight into business applications for social media. However, they based their appraisals of their own innovativeness on comparison with national or international industry leaders, and considered themselves to be implementing ideas they had been exposed to elsewhere. This observation will be explored in more detail under communication behaviour, at the end of this chapter, and in the following chapter on networks.

\section{Adopter categories}

The concept of adopter categories is perhaps the best-known element of Rogers' Diffusion of Innovations model. Rogers' five categories were developed to explain the Sshaped curve commonly observed in the adoption of innovations: beginning first with slow and limited uptake by a small subset of the population; shifting to a rapid growth as the innovation finds mainstream acceptance, before the rate of adoption slows once more as the innovation is taken up by the last adopters in the population.

In Rogers' model, the criteria for categorising adopters is innovativeness - defined as "the degree to which an individual or other unit of adoption is relatively earlier in adopting new ideas than other members of a social system" (Rogers, 2003, p. 280). This treats innovativeness as a continuous variable, which can be divided into five adopter categories as a conceptual device that assists in understanding the properties of these groups. Rogers notes that these categories are ideal types, designed to make comparisons between the groups possible. Later work by Moore (2002) focussed more on the 
characteristics of these adopter types, suggesting that significant differences exist between the groups. This is most notable between the early adopters and the early majority: Moore asserts that the first two groups seek disruptive innovation to revolutionise some aspect of their lives. In contrast, the later groups prefer continuous innovation that can refine existing tasks or processes, rather than transforming them.

The business managers occupied various positions within the Innovator, Early Adopter and Early Majority categories of the DoI model, relative to other businesses in their industry sector. Some managers possessed high opinion leadership among other members of the study group, and were described as innovators by the other managers. Despite this, those managers considered themselves to be later adopters than their own peers - focussing on innovators from other regions or industries. Other business, such as Vitae and Videogame Network, saw themselves as highly innovative early adopters of new technology. The managers of these businesses often experimented with services like Twitter, Facebook and Foursquare very early on - in some cases, among the first accounts in their local networks. However, these managers rarely implemented the results of this social media experimentation into their businesses.

\section{Socioeconomic variables}

The perceived low risk of adopting social media was an important theme in this study. Early adoption of any new technology carries several risks. The technology may not prove suitable to the use it was intended for. It may be made obsolete and replaced by other, more appropriate technology. A product or service may be discontinued or transformed significantly with little warning. In any of these cases, the cost of implementation can be significant, and the risks are high for any software that is critical to business operations. Even free or 'freemium' social media services require staff time to develop proficiency with the new technology, and may potentially need new hardware to enable effective use. To make early adoption viable, the business must be capable of absorbing the cost of potential failed adoption.

For these reasons, DoI studies examine several socioeconomic status variables including the age, education level, income and wealth of the innovators. Of these, it is notable that age has no clear relationship with time of adoption. Evidence from numerous studies into this variable have shown inconsistent results, with around half showing no relationship between the two (Rogers, 2003, p. 288). Age was a key area of interest during 
many discussions that I have had about my research, with business owners and academic peers. The use of information technology - and particularly social media services like Facebook and Twitter - was considered by many to be an activity for 'young people'. By selecting a group of managers actively using social media platforms for their business, the assumption was that the pool of potential case studies would be dominated by young 'Generation-Y' entrepreneurs. That assumption is not supported by the case studies in this research: social media services have been widely available for longer than many Australian small businesses expect to operate for, and there have been ample opportunities for a range of different age groups to bring these technologies into their organisations. The managers ranged in age from mid-twenties to mid-fifties, with no marked difference in social media use between age groups.

Other DoI studies described by Rogers (2003, p. 288) suggest that education levels are a factor in early adoption: specifically, more years of formal education is correlated with higher innovativeness. Many of the business managers possessed tertiary qualifications, but there was no direct link between these and their adoption of social media technologies. Contradicting Rogers' generalisation, the managers of Vitae and Network Solutions were often slowest to adopt these technologies, but possessed the highest levels of tertiary education. Additionally, the managers of Shutterbug and Lunch Spot were among the most innovative in the study group, but possessed industry apprenticeships and diplomas in place of Bachelors or Masters degrees. Their experience suggests that industry knowledge and experience, rather than formal education, may be a better indicator of individuals who are likely to innovate.

Income levels and wealth varied significantly between the business managers. However, each manager was able to mitigate the financial risks of starting a small business in a variety of ways. Most businesses were in a relatively early stage of development, operating for less than five years. Almost all of the owner-managers had followed one of two paths when launching their business. The first involved a gradual shift from part-time to full-time operation, allowing the manager to test the market before committing fully. This was seen in businesses such as Network Solutions, Fashion on Wheels, Bandwagon and Toys \& Games. At Cover Story, Mel began writing as a hobby and decided to turn it into a full-time career when her workload expanded. 
My business got big enough that I didn't know if I could go full time, but I knew I couldn't take on any more work. There just wasn't any more capacity. I kind of thought, you know, there are only so many things that can happen to you in Australia if you do fail. For me, if I end up on my brother's couch or I go travelling, it's a pretty good fail plan.

The second group of managers launched their new business immediately after a previously successful venture - often taking a redundancy package from a previous employer, or selling an existing business. At Inner Circle, Mary launched her business after securing a lucrative long-term client, ensuring a reliable income stream for her new venture. Jess and Sarah started Central PR and Vitae after successful corporate careers in their respective fields. Eric also left a corporate management position to start SocialSearch, launching it after attending a startup boot camp. In each of these cases, the managers needed to minimise the costs associated with their new business, but operated from a position of relative financial stability that allowed them to take measured risks.

\section{Personality variables}

Rogers notes that several personality variables correlate with increased innovativeness, although these have not received much research attention to date - largely due to the difficulty in measuring these variables with the surveys that have been used to study diffusion. These include a higher degree of empathy, openness to new ideas, greater ability to deal with abstraction and a positive attitude towards change. The positive influence of higher empathy is particularly notable: according to Rogers' model, highly empathic managers are more likely to adopt an innovation as they are able "to take the roles of heterophilous other individuals in order to exchange information effectively with them." This allowed the innovators from Rogers' research to learn about new innovations from innovators in other social systems, change agents, scientists and researchers.

Beyond its role in the innovation-decision phases of knowledge acquisition and persuasion, high empathy should also enable an individual to use an inherently social technology more effectively. Attracting, engaging and sustaining the attention of an audience requires an understanding of what those audience members want, and how they want to communicate. In this way, high empathy also contributes to the implementation and confirmation phases: assisting a manager to use their chosen social media services more effectively, increasing the likelihood that the business will pass from trial and early implementation into full adoption of the technology. 
A positive attitude towards change and the ability to deal with abstraction were common traits among the business managers. Each sought to improve their business by introducing new services and processes, and they accepted that trial-and-error experimentation was a necessary part of this. None of the managers described rigid business plans during the interviews: where these plans existed, they were typically fluid and frequently reviewed. By focussing on broader goals such as a steady income, sustainable work-life balance or opening a second store, the managers remained flexible on the steps that would be required to reach these. This gave them more opportunity to innovate, experimenting with new services and technology, and adopting promising innovations that they observed from their industry peers and customers.

Early adopters tend to have higher aspirations than late adopters, and may see the new technology as a means to achieving these goals. This suggests that entrepreneurs may be more likely to innovate than other members of the business community, as they all seek to create a new enterprise and grow it into a larger organisation. However, the managers varied in the goals they had for their businesses. This was reflected in the degree to which each manager introduced new technology into the business.

Managers who were later adopters of social media technologies during the study tend to have more established and stable businesses, with less pressure to innovate. While these businesses typically had more resources available, they had already developed stable income streams and regular clients, regularly achieving the goals of the manager both in terms of financial targets and their desired work-life balance. For these managers, 'business as usual' was enough to sustain the business, and they were less likely to try new innovations. At Vitae, Sarah experimented with several social media services shortly after those platforms were launched, but tended to adopt and integrate these into the business much later. These late adoptions typically involved products that she viewed as important new industry trends, but that she saw no clear role for using in her business. "As marketers," she commented, "we need to understand Facebook." That drove her to create a personal account shortly after the service became available, but almost five years passed before she began to use the service actively for business purposes. Her marketing firm had already established links to high-end business and government clients before the social networking service was widely used, and her business did not need to actively use it in order to maintain their regular client base. 
Luke also fits into this model of "early experimentation, late adoption" in the longest running business covered in this study. Working in the IT industry, Luke was keenly aware of the speed at which technology develops. As a business manager, he saw his role as one of leadership and strategic planning for Network Solutions: discovering new trends and rigorously testing them for potential application on client projects. While he was typically well informed about each of the social media platforms, his business had matured before these found widespread uptake by his peers or customers, and he saw little reason to adopt them for his business.

In contrast, managers who were at earlier stages of business development were enthusiastic early adopters of many social media services, assessing and experimenting with these to find a way of building the profile of their business. These businesses included Building Blocks, Cover Story, Bandwagon and Model Madness. At Building Blocks, Allana and Dean concentrated their resources on Google+ within months of its release, shifting away from more established services like Facebook. Bandwagon's two founders were prolific adopters of new social media technology - exploring new services for a good potential fit with their business. The goals and aspirations of these managers were still in flux. Excited by the possibilities they saw for the new technology, they adapted the vision for their young businesses to encompass a broad range of social media services, in the hopes that these technologies would help them to shape and grow their businesses.

\section{Communication behaviour}

The communication behaviour of each of the business managers can also influence their degree of innovativeness, contributing to the fear of missing out described in Chapter 5. Diffusion theory suggests that both innovators and early adopters typically engage in a greater degree of social participation than later adopters, and are highly connected through interpersonal networks. Higher levels of innovativeness correlate with more cosmopolitan business managers, engaging in more contact via interpersonal communication channels. For my research, this aligns with the theme of networking as a social media outcome for business managers.

Rogers defines 'cosmopoliteness' as "the degree to which an individual is oriented outside a social system" (Rogers, 2003, p. 290), describing how an outsider can benefit from their perspective and their weak ties to several other networks. For the Iowan corn farmers that were the focus of Rogers' early work into the diffusion of innovation, this 
could typically be observed via the amount of travel conducted by each individual. The cross-pollination of ideas between rural innovators in the 1950s was largely dependent on travel to urban centres, or meeting with sales representatives who travelled out from those areas. In contrast, small business managers are far less dependent on physical travel in an age of widespread broadband internet and near-ubiquitous social networking services. The structure and functions of networks is the focus of the following chapter, and will be discussed in more detail there. The managers in this study fit Rogers' description of cosmopoliteness by having interpersonal networks that are likely to be outside their system, and by their involvement in matters beyond their local borders. They were all connected to a broad range of contacts, and used social media to maintain and expand these networks.

Interpersonal communication plays an important role in assisting the earlier adopters to learn about an innovation. The interpersonal communication networks surrounding each business manager were often built on, or at least supported by, the social media services that they sought to use for marketing and promotion of their businesses. LinkedIn groups and Twitter news feeds became an important source of information, and a place to ask peers about their experiences with a particular technology or application. Conferences and business networking events were supported by online networking activities, allowing managers to develop stronger and more diverse networks of contacts who were at various stages in the adoption of social media for their own businesses providing easily observed examples that could support the persuasion and confirmation phases of the innovation-decision process. This activity is discussed further in Chapter 7.

The managers using social media most intensively also sought information more actively than the later adopters. These managers continually gathered information about new tools and ways to use these more actively, via technology news sites, blogs, other business owners and their extended networks on LinkedIn and Twitter. This is best illustrated in the case of Cover Story. Mel constantly sought new information about social media and the ways it could be used by business owners, and introduced several of these innovations into her business. However, proactive information seeking behaviour was not always an indicator of innovativeness. Among the study group, Luke and Sarah were among the slowest to adopt social media technologies, despite being well informed about the range of technology available. Access to information and a proactive approach to 
seeking it out supported managers when adopting new technologies, but this behaviour alone was not enough to identify early adopters among the group.

Lack of access to information did hamper the ability of some managers to adopt or implement social media, preventing them from assessing the capabilities or requirements of new services. At Fusion, Lee described her lack of knowledge about Facebook as the major reason why her business had not begun using that service. She was unsure where to start looking for relevant advice, and did not feel that she had enough time to teach herself all of the necessary skills.

Word of mouth information is heavily reliant upon each manager's network of contacts. In their study of social networks and technology adoption in small business, Gibbs et al. (2007) found that a business owner's decision to adopt various technologies will be influenced by their networks, and thus it is important to examine the salience of small business social networks. In their paper, they make three propositions related to social network theory. Firstly, extra-firm networks will positively influence technology adoption and diffusion in small businesses. Secondly, network density will also influence technology adoption, with strong ties being more influential than weak ones. Thirdly, network type will influence technology adoption, with personal networks having greater influence than business-related networks. Network structure and the use of social media to influence this is a topic covered in more detail in the following chapter.

\subsection{Characteristics of social media technologies}

Rogers (2003) defines five properties of innovations that affect their rate of adoption. These are the perceived attributes of relative advantage, compatibility, complexity, trialability and observability. This section examines these five properties in detail, focussing on how these properties manifest in each group of social media technologies that were used by small business managers in the study group.

\section{Relative advantage}

In Diffusion research, relative advantage is described as "the degree to which an innovation is perceived as being better than the idea it supersedes" (Rogers, 2003, p. 229). Perceived advantage contributes to the fear of missing out observed among managers in this study, helping to drive adoption of social media. This advantage may 
allow the user to accomplish a task in less time, or for a reduced cost. Alternatively, it may provide a social advantage in the form of increased status among their customers or peers. It is similar to the concept of 'perceived benefits' used in Davis' (1989) TAM model, and is central to the acceptance or adoption of new technologies in both models.

In order to examine the relative advantage offered by various social media platforms, it is first necessary to define the existing alternatives: what are social media services being compared to, and what purposes are they being used for? For most of the managers, their initial drive was to find promotion and marketing channels. Relative advantage in this area included reduced costs (compared to purchasing email lists, printing flyers or taking out paid advertisements in other media). It could also be derived from the perception of greater reach associated with online marketing. This could help businesses to reach more potential customers by casting a wider net. Alternatively, it could allow them to deliver more targeted promotions within niche markets.

For many of the managers, their experimentation with social media began with the belief that these technologies were a free alternative that could support or replace other promotional channels. This perception owed partly to the lack of up-front fees associated with starting an account. It also highlighted difficulties that most of the managers had in placing a value on their time. While each platform typically offered free or 'freemium' services, the cost of adopting new platforms could be significant. This was due to the amount of time spent learning to use them, and then maintaining accounts on each platform after they had been established. Most managers considered their social media activities to be separate from core activities of their business. Although these supported the business in various ways, they were not 'billable' work that directly generated income, and tended to be relegated to spare time. This contributed to the feeling that a small business manager was 'always at work' - providing a constant stream of work that occupied their attention on evenings and weekends.

Despite this, many of the managers considered their social media use to be rewarding and enjoyable. The most prolific social media users described it in terms of a hobby (or in some cases, as an 'addiction'). This was most apparent on the rare occasions when managers took time off for holidays, spending time offline and away from email and social media. For these managers, the process of disconnecting from their online activities and notifying others added significant additional work and stress in the time before and 
directly after their time offline. The immediacy that first caused social media to appeal to them also produced the expectation that businesses, like their social media accounts, were 'always on' and open to queries and comments at any time.

There were clear benefits to using social media for developing a public profile and brand identity, when compared to alternatives like editorial coverage and paid advertisements. During their interviews, managers discussed a feeling of control over the way their business presented itself to the public. Social media accounts could be updated in real time to quickly respond to changing situations, in a way that printed material could not. In several cases, even the business websites were not able to respond in this manner. Many businesses had websites that were designed and built by contractors, and provided no ability for staff to directly manage content on their pages.

By giving managers the ability to communicate directly with their chosen audiences, social media also allowed the managers to bypass intermediaries like journalists or editors. Lee discussed how this helped Fusion, commenting that she much preferred writing her own material - rather than waiting to find out how a review or article had portrayed her business.

\section{Compatibility}

Compatibility is "the degree to which an innovation is perceived as consistent with the existing values, past experiences and needs of potential adopters" (Rogers, 2003, p. 240). It contributes to the perceived low risk of social media adoption in this study. I have expanded the definition of a business' needs to explore compatibility with existing hardware, software, and business processes. This allows a more fine-grained examination of the ways that compatibility and incompatibility have affected the adoption of social media technologies.

Of the five innovation properties examined in this section, compatibility is potentially the most difficult criteria for social media services to satisfy. These technologies contain deeply embedded values that shape when, where and how a user can communicate with their audience: typically encouraging transparency, and giving customers more control over how they communicate with a business. The integration of social media into an organisation can force the transformation of existing roles and processes that conflict with these values. Failure to adapt is more likely to result in discontinuance, rather than the modification of that technology to suit the business' needs. 
The development of 'social' aspects to other internet technologies has involved a gradual shift in both the underlying technologies and the ways that services are presented to users. The interactive aspects of Web2.0 have been progressively added to websites throughout the past decade, while social or community elements have been part of the internet since its earliest days. Despite this change in the way that websites and internet-based services operate, many organisations still rely upon one-way communication models for their promotion and marketing. These position the business as a publisher or broadcaster: delivering their messages to a wider audience, and leaving the audience - composed of industry peers and competitors, suppliers, current or potential customers - as a passive recipient of these messages.

Social media services disrupt this communication model in three major ways. They allow the business manager to take a more direct role in shaping the information that the business makes available to the public, giving their organisation an active voice. Each of the business managers used their various social media accounts to publish authoritative, 'from the source' content relating to their products or services. Beyond this, social media facilitates two-way communication with the audience. This allows each business to gather and respond to feedback, refining their product offering, and addressing issues raised by individual customers. Finally, the highly public nature of social media conversations about a business, industry or product range gives businesses a greater ability to listen to conversations between customers or other stakeholders. We see this in the case of Fusion, where Lee and her staff monitor review aggregation sites like UrbanSpoon to see how their business is perceived relative to their competitors. We also see it in the case of Toys \& Games, where Jennifer reads forum discussions to identify trends, discovering new product lines when they generate excitement overseas.

The businesses examined in this study share many features that are highly compatible with the adoption of social media. Even the largest of these businesses has a relatively flat organisational structure, and the managers describe "engaged and committed staff" as an important part of their operation. Decisions about how each business will use their social media channels are made by the managers, and shared with all people who will operate each account. Dialogue, rather than directives, is the primary means of communication between management and staff. This approach is carried across into their relationship with clients and customers: the small business managers valued being 'close' 
to their customers - not necessarily in geographical terms, but in their understanding of the needs of these individuals. As such, they were accustomed to talking with and listening to their customers, rather than simply talking at them. This approach fits well with the type of communication that is facilitated by social media.

Rogers also introduces the concept of a technology cluster (Rogers, 2003, p. 249) consisting of a group of linked technologies, which users can see the interrelations between. Although each social media service has distinct differences, managers have treated them as a single cluster of technologies to explore the business implications of. This is made possible by the high degree of compatibility between each of the technologies. On a technical level, it is often possible to cross-post content to several different services, and to access each service through the same software. Additionally, each of these will function in a similar fashion. Managers who adopted more than one social media platform typically used many different platforms. Those who had difficulty seeing how one social media service could fit into their business were unlikely to experiment with any others. This was seen in Luke's IT business, and in Sarah's marketing consultancy. In both cases, the managers could not understand why a business might encourage potential customers to contact them through Facebook, when more traditional channels still existed. Neither business went on to use other popular services like Twitter, LinkedIn or Google+, as these were similarly incompatible with the ways that Luke and Sarah ran their businesses.

Compatibility with existing hardware was another consideration for some managers. Many social media platforms are designed with a focus on real-time interaction, posting and responding to status updates and other content when and where an event has happened. For some business managers, this caused problems as they had limited access to broadband internet or mobile devices. This was most commonly seen in the cases of hospitality managers, who spent the majority of their working day away from a desk. Both Lee and Ben described how access to smartphones enabled much more effective use of platforms like Twitter, Facebook and Instagram. Rather than finishing in a kitchen and then sitting at a computer to catch up on social media content, they could to use quiet periods to respond to enquiries and post new updates. At Fusion, Lee's initial choice of social media platform was further guided by the hardware she had available: on her Blackberry, Twitter was simple and easy to use, while Facebook loaded slowly and was 
difficult to navigate. Knowing that she wanted to experiment with one of the two major platforms, she chose the one that was easiest to use in her normal routine.

Compatibility with existing software was less of a problem. The social media services used in this study could all be accessed through web browsers. Most managers relied on their business website as a primary source of business information including contact details, product lists and sales or other promotions. This approach was highly compatible with the use of social media to provide additional sources of information, as content from major services such as YouTube, Twitter, LinkedIn and Facebook could be easily embedded into business web pages. No social media services were linked directly to business systems that handled sales transactions or other financial processes. Instead, these were used to circulate links to other content, supporting sales, marketing and customer service activities without needing direct integration.

\section{Complexity}

The complexity of an innovation is the degree to which it is perceived as being difficult to understand and to use, and is a factor in the perceived low risk theme observed in this study. Rogers suggests that for many innovations, complexity is less important than perceived advantage or compatibility. The concept of complexity used in Diffusion research is similar to that of perceived ease of use; the second major factor used in Davis' (1989) Technology Acceptance Model, and a sub-theme of the perceived low risk seen in my research. In general terms, perceived complexity is negatively related to the rate of an innovation's adoption (Rogers, 2003, p. 257).

Managers discussed two types of complexity in relation to their use of social media. These were the technical aspects to the technology, and the social implications of using the technology in particular ways. The former was more commonly seen as a barrier by managers who had recently begun using any a social media service, and was less of a concern to those who were already using several other services. The latter was discussed in interviews with managers at all stages of adoption, but primarily became a matter of concern for the managers who had developed basic technical proficiency.

Technical complexity was often more of a perceived barrier than an actual impediment. During interviews at the beginning of the study, managers discussed social media services that they had not yet started using. They described the large number of features they had heard of, and some managers expressed concern about how they would 
find time to learn how to use these. New social media services were not seen as impossibly difficult to learn- instead, the focus was on the amount of time that would be required to learn how to use their features. There was a marked difference between these early interviews, and subsequent discussions with those managers after they had begun using new services. The initial perception of a complex range of different features receded quickly after beginning to use a new social media service, when it became apparent that the technical proficiency required to use the service was less than initially feared. The role of experimentation and trialability is covered in the following section.

The perception that using social media involved mastering a complex range of social behaviours was also raised by some managers early in their trial of new social media services. Like technical complexity, this became less of a concern as manager experience grew. This issue arose as managers developed a sense of appropriateness - and inappropriateness - in online behaviour on different social media platforms. After mastering the technical skills required to begin posting content and participating in conversations with customers, critics and industry peers, the managers began to focus on using their social media accounts to more effectively engage others. The managers who expressed concern were aware of unwritten rules of social conduct online, felt that these rules differed from face-to-face situations, and that the rules appeared to vary depending on the social media platform being used for the conversation. Their concerns were typically voiced as examples of what they felt they 'should not' do: often accompanied by descriptions of particular social media faux pas committed by other businesses. While inappropriate behaviour (observed after the fact) appeared clearly defined, the managers struggled define what they would consider appropriate, and therefore how they 'should' use their social media accounts.

This perceived degree of complexity in navigating the social conventions of each platform slowed the rate at which managers adopted their first social media services. It became less of a concern among managers who actively used several different platforms. These managers developed a clearer sense of how they wished to conduct themselves online - such as in the case of Network Solutions, with overarching goals of being seen as "friendly, approachable, helpful and knowledgeable" in their chosen media. For Cover Story, these concerns were alleviated by the results of experimentation with each service, trying to establish a particular online voice and receiving a positive response from their 
audiences. "Apparently it's a faux pas to be tweeting about the food you eat," Mel commented, "but that's the basis for my feed ... it's what I do and it seems to work."

\section{Trialability}

Trialability describes the degree to which potential adopters can test the new technology before using it, and the information gained through these trials is a factor in the perceived low risk of social media adoption. This is a property that most social media services excel at: all of the managers used services that were available in free trial versions, and could easily be deployed in the staged implementations described earlier. As a large part of the value in using any form of social media comes from access to an existing community of users, most new services allow people to quickly sign up for a free account. This encourages potential users to experiment with the product, learning what it can do, and seeing whether it can provide useful solutions to problems that they face.

Managers also frequently tried out new social media services by creating personal accounts before starting to use a new service for their business. This gave them an opportunity to develop vital 'how to' knowledge, better understanding how each platform worked. However, this caused issues when managers found it difficult to separate their work from other aspects of their online identities. At Central PR, Jess tried to delineate her work and personal contacts by using different services for each: "To me, Facebook was always family and friends, LinkedIn was the business, and never the two shall meet." However, she found herself receiving an increasing number of Facebook connection requests from her clients. This led to the creation of a Facebook Page for her business, to maintain more separation between personal and business contacts.

At Inner Circle, Mary had created a personal Twitter account, and a branded company account for work related posts. Her personal account was established earlier, posted to more regularly, and contained a combination of industry-related posts and more personal content. The personal account proved far more successful than her company account, attracting more contacts and industry discussion that her business profile.

Mel encountered a different problem after launching Cover Story. Previously she had separated her online profiles into two distinct areas. A professional identity linked to her corporate day job, while other social media accounts for her hobby identity used her pen name, including two different LinkedIn profiles. After starting her a business that drew upon both of these backgrounds, she found it less relevant to keep the two areas separate. 
In some cases, a personal account on a social networking service was a prerequisite for creating a company presence. This was the case with both Facebook and LinkedIn, where individual accounts are used to set up and manage business pages. When Google+ launched, it only allowed users to create individual accounts. When that service began offering company pages several months later, these managers were able to apply skills and knowledge developed through their trial of individual accounts, assisting them to quickly establish accounts for their businesses.

\section{Observability}

Finally, we consider the observability of the technology: the degree to which the results of its use can be seen by others. This contributes to both key social media adoption themes: driving the fear of missing out by making competitor activity visible, and providing examples to learn from in order to support the perceived low risk of adoption. In DoI, the observability of an innovation is positively related to its rate of adoption (Rogers, 2003, p. 258). All of the social media platforms used by each business manager were highly observable, allowing each manager to easily find examples of social media use by their friends, peers and competition. This helped them to see a wider range of potential uses for the technologies, providing them with ideas about how they might implement these technologies in their own business. It also gave them an opportunity to learn from these other users, observing and reflecting on their successes and failures.

Observability was often controlled via the privacy settings for each social media platform. More complex services such as Facebook and Google+ gave users access to several degrees of privacy, choosing different degrees of visibility for individual pieces of content. Simpler services like Twitter offered only two options: all content fully visible to the public, or protecting all content so that it is viewable only to accounts that the user follows. Most social media accounts used by managers in this study were publicly accessible without needing form of login. These included blogs, Facebook business pages, Pinterest boards and Twitter accounts. This 'public by default' approach was commonly used where the accounts were used to directly market and promote the business.

Some services required a basic login, but did not require any kind of direct connection with other accounts. Examples of this group included LinkedIn and forum profiles, where profile information was displayed in a semi-public fashion to other users. These profiles were used primarily as an online resume or $\mathrm{CV}$, and to connect with friends and business 
associates. Generally, full LinkedIn profiles were only viewable to a manager's contacts. However, the high degree of interconnectedness between other LinkedIn users meant that second or third degree 'friends of friends' pathways existed to a many other users, allowing managers to observe how those individuals used LinkedIn.

Finally, there were a small number of services that could only be accessed by other users of that service, while logged in, and after the account owner had approved a direct connection. These private, reciprocal connections were used when privacy was a major consideration for the business manager. The most common use of this group of privacy settings was for the personal Facebook accounts of each business manager, although similar settings were used on closed forums and LinkedIn discussion groups intended for discussions between industry peers. Even within this group, managers still had an opportunity to observe how others were using each social media platform.

\subsection{Conclusions}

This chapter has examined how the business managers adopted new social media technologies and introduced these to their business. I have drawn upon Rogers' (2003) Diffusion of Innovations theory to examine the process of technology adoption among the study group, addressing three aspects of this theory. The first of these is the InnovationDecision process itself, and its applicability to social media adoption. I then examined the properties of both innovators (small business managers) and innovations (social media technologies). This revealed several characteristics that can predispose social media to rapid diffusion among the small businesses in this study.

Each of the case studies in this research displays stages identified by the InnovationDecision process: knowledge, persuasion, decision, implementation and confirmation. These were most visible during the adoption of new social media services. The process was also explored during interviews, where managers were asked about their prior adoption of services such as LinkedIn, Twitter and Facebook. Knowledge development, implementation and confirmation were the most visible stages, with three important substages present within knowledge development: awareness about an innovation, technical knowledge about using it, and principles knowledge that governed 'social' use of the technology in a way deemed appropriate by customers and peers. 
The persuasion and decision stages were often combined, with no clear distinction between the two. In each case study, managers were either the sole owner-operator for their business, or they ran the business in partnership with one other manager. They were also responsible for implementing new social media initiatives, although some managers left day-to-day social media activity to other staff members. This led to a rapid transition between stages of the Innovation-Decision process: when a manager was persuaded to try out something new, it could be launched almost immediately.

Diffusion theory provides a valuable tool for examining social media adoption among small businesses. By focusing on perceived characteristics such as relative advantage, compatibility, trialability and observability, it is possible to identify features that contributed to the widespread adoption of social media.

Social media was highly compatible with the businesses in this study. A lack of compatibility with existing business processes could be a significant barrier to adoption in larger organisations, where tasks such as marketing, public relations, customer support and sales are separated into different teams. Among the businesses in this study, these public-facing tasks were already the responsibility of a single member of staff. This made social media highly compatible with the operation of these businesses.

Another important adoption factor is the high degree of observability provided by the public nature of most social media use. Some degree of visibility to other users is required even within the private, 'closed' social networks used by the managers of Vitae and Inner Circle. The overwhelming majority of business social media activity by managers in this study occurred in public on Facebook pages and Twitter accounts. This created some barriers to adoption, where managers were initially reluctant to experiment and risk making mistakes in view of their competitors. However, public social media activity by friends, family, customers and peers is an important factor in overcoming these barriers. This allows managers to see and learn from the mistakes encountered by others, enabling faster learning about how best to use the new technology.

Similarly, the emphasis that DoI places upon the properties of innovators provides insight into the advantages and disadvantages shared by the small business managers. In particular, an examination of communication behaviour reveals that the study participants were all highly social individuals, connected to diverse interpersonal networks of friends and family, customers and business peers. This fits with the 
expectations of Diffusion theory regarding the innovator and early adopter categories to which the study participants belong. It also provides insight into the ways that these managers learn about, and learn how to use new technology. In every case, managers in the study described how they first heard of their chosen social media via their networks, typically from contacts they relied upon as sources of information on new technology. After setting up a personal profile or account on services such as Facebook, LinkedIn or Twitter, they rapidly became exposed to more information from broader networks. This enabled observation and interaction with a much larger group of social media users, accelerating their rate of adoption of other social media platforms. After creating their first social media account, managers frequently began to experiment widely with other services in an attempt to find those that best fit with their business requirements.

While DoI gives some attention to the communication behaviour of innovators, the theory lacks a more detailed focus on the ways that other people influence the business owners in their technology adoption decisions. Those social ties are the focus of the following chapter, where social network theory and social capital will be explored in more detail. These theories complement the work presented in the current chapter, combining to provide a more powerful tool for understanding the adoption of social media by small business managers.

In their review of SME e-business studies, Parker \& Castleman (2007) proposed the use of an integrated model, drawing on Diffusion of Innovations and work done in the area of Social Network Theory. They developed this further in a critical analysis of theoretical models used in small business technology adoption research (Parker and Castleman, 2009), arguing that the commonly used theories are inadequate tools for explaining small firm e-business adoption, when applied independently. Instead, they propose incorporating elements of social network theory such as embeddedness (Granovetter, 1985) and social ties (Granovetter, 1973) (Granovetter, 1983) into an overarching theoretical framework, such as Diffusion of Innovations. This would allow SNT to consider "social structure, the existence and type of relations, and the strength of relations known as social ties" (BarNir and Smith, 2002). A detailed examination of social networks and networking activities will follow in Chapter 7. 


\section{Building and maintaining social capital}

Social media outcomes have previously been introduced in Chapter 5, where I described the three outcome themes (information, visibility and social capital) observed in this research. This chapter on the social capital outcomes associated with building and maintaining networks, presented in three sub-themes.

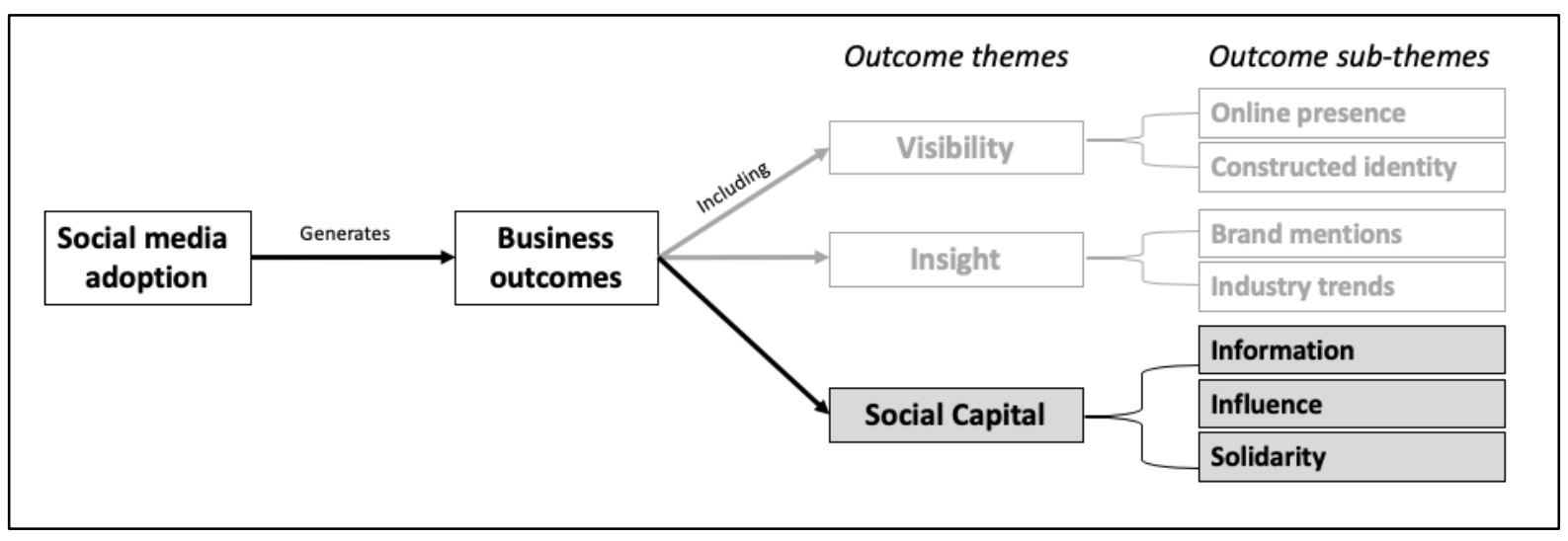

Figure 7.1: Outcome themes and social capital sub-themes

Small business managers use social media services to maximise their access to social capital, enhancing or replacing their other business networking activities. This provides them with access to network resources, in the form of information, influence and solidarity, which enable the managers to more effectively run their businesses.

Each of the managers in this study maintained a complex array of interpersonal networks that assisted with many aspects of running their business. In some cases, these networks included formal professional groups such as a local chamber of commerce or industry association. Other professional networks included business advisors in the form of bankers, financial planners, bookkeepers, accountants and lawyers. Managers and their businesses also became part of the networks of their customers, who consulted them for information and discussed, reviewed or recommended those businesses to their own contacts - influencing others to support or oppose that business. The managers also relied heavily on personal networks composed of friends and family members: using these for advice, information, and as a sounding board for new ideas. In many cases these networks overlapped as customers became friends, or a family became advisors. 
Small business managers are a valuable group to study the development of social capital, as they possess qualities associated with both individuals and brands. They rely heavily upon network contacts to overcome resource scarcity within their businesses, particularly regarding access to information. The small businesses in this study were highly personal ventures, built upon the unique combinations of skills, knowledge and industry contacts possessed by their founders. By identifying so strongly with the businesses that they managed, the success or failure of their business reflects strongly on their personal standing among their industry peers. This leads managers to spend significant amounts of time developing and maintaining their social media accounts: driven by the perceived value in accessing social capital resources, and also by a fear that negative perceptions of their business will directly affect them as individuals.

The remainder of this chapter explores the three major sub-themes relating to social capital: information, influence and solidarity. I examine the tactics and services the managers use to access these resources, noting how specific features of each social media service affect the types of connections, content and interaction that occur between their members. These variations lead each platform to be better suited to particular types of networking activity, hosting different types of networks. I also examine the benefits that each resource brings to a small business, and discuss the ways that social media has been employed to support the formation and maintenance of business networks.

\subsection{Information}

Establishing a network of business contacts is an important task for any new manager, placing them into contact with people who can help them to perform their business tasks more effectively. Information, gathered from diverse sources and then acted on appropriately, is a key resource accessed via a manager's social capital. Miller, Besser and Malshe (2007, p. 653) noted that the sharing of information was among the highest rated resources that firms were willing to 'invest' in their networking activities, and also regarded as an important advantage gained from these activities. Similarly, Bharati et al. (2015) describe knowledge as a key resource for sustainable competitive advantage, exploring the role of social media in organisational knowledge management and social capital development. The effective use of this resource requires managers to cultivate a 
diverse network of contacts, and then recognise how and where to apply information to generate business advantage.

This section explores the range of ways that managers used social media to support their network-building activities: identifying new potential contacts, facilitating introductions to these people, and accessing information shared by members of the manager's network. Social media services also provided the managers with a range of options for supporting off-line conferences and other face-to-face networking events. This enabled them to more effectively follow up after initial contact, converting new acquaintances into more deeply embedded network contacts.

\section{Finding new contacts}

When establishing business networks, managers described how they began with existing personal contacts such as friends and family members. Each of the businesses in this study was formed either as a natural progression of the manager's previous line of work, or as the evolution of a personal interest. In both cases the managers already had a core group of relevant contacts they could call upon before they launched their business. Each manager made a conscious effort to expand this network during the study: increasing the number of contacts, and also the range of different types of contact. Connections to influential peers such as high-profile entrepreneurs and industry leaders were highly valued. These high-profile contacts typically had access to significantly larger networks than the managers, often by several orders of magnitude. These were relied upon for their insight, access to information and potential to influence others. Insight and wisdom came from business experience, and from their ability to bring a different perspective to discussions and commentary about their industry.

Managers used social media searches to find relevant new contacts more easily than they were able to via offline activities alone. LinkedIn and Twitter were both used frequently for this purpose, exposing managers to many potential contacts. These contained profile information (brief, in the case of Twitter; work-focused in the case of LinkedIn), and also provided examples of how these people communicated. This allowed managers to find others who shared similar interests, skills and outlook. They did this by observing the people taking part in discussions that their own contacts were involved in, using 'tagged' account names to view public profiles. Twitter lists were not commonly 
used by managers in the study, but highly valued by those who did. Many other social media services have similar methods of making network connections visible: for example, both LinkedIn and Facebook groups display a list of group members, and active members can be identified through the replies and Likes that they leave on any discussion topic.

Most of the social media services in this study also offered some form of automated suggestions of similar accounts to follow, typically based on mutual contacts or interests. There were displayed in a range of ways, appearing in a sidebar on Facebook and LinkedIn, under the Discover tab in Twitter's web interface, or sent to users via email. The relevance of these suggestions varied considerably, but several managers discussed how they had discovered new contacts via these methods.

Attitudes varied about adding contacts on each social media platform. All the managers considered their individual Facebook profile to be 'private' due to the presence of family members and close friends, and were unwilling to accept invitations from people they did not already know. Some managers had received business-related messages or invitations through Facebook - this was mentioned by Luke at Network Solutions, and also by Jess at Central PR. When this occurred, those managers suggested alternative channels they preferred to use for business connections. On Twitter, connecting behaviour varied based on how long the manager had been using their account, and how many contacts they currently had. Most were open to following back virtually all new contacts early on, and only became more selective about who they would follow as their network grew.

Criteria for reciprocating included information in the new contact's bio, and the type, frequency and tone of content they had recently posted. Other managers considered the number and type of connections they shared with the new follower, or the likelihood of encountering them on a regular basis on- or off-line. Managers who sought to have their own content shared with a larger audience considered the size of the new follower's network. All of these factors contributed to the perceived value of adding the new follower to a manager's own network.

\section{Facilitating introductions}

The managers also used social media to facilitate introductions to people they had no opportunity to meet in person, such as those separated by geographic distance, or those 
who simply moved within different social circles. The public, conversational nature of most online discussions meant that newcomers could join a conversation with relative ease, or 'lurk' as a passive observer in order to learn from those present. This behaviour was common in niche, interest-based communities such as forums and LinkedIn Groups, where members could safely assume that others in these communities would share similar traits. This created an environment where introductions and new network connections could more easily be made.

Each social media service varies in the way it allowed network ties to form. Twitter is a non-reciprocal network, with the vast majority of its accounts publicly visible. This allows any user to freely 'follow' other users, subscribing to updates from their account without any requirement for their contacts to approve or even acknowledge the link. This mechanism is well suited to the formation of broad, weak-tie networks, positioning users to take advantage of the information brokerage opportunities that it presents. However, users with few dense ties may find it difficult to exert influence and get others to adopt their ideas. The managers most frequently used Twitter as an information discovery tool, using their networks to gather and filter information on business trends.

Similar patterns of behaviour were seen where managers used blogs or YouTube channels, subscribing to additional blogs or channels that provided interesting or valuable information. While many of the managers had primarily sought to promote their own content at first, they soon recognised the value in subscribing to and reading a wide range of other content on their chosen platforms. This was more than just a source of new information: it placed them into contact with other active users of these platforms. The content provided by each user shared an insight into their interests and personality, helping those who had previously been strangers to establish new relationships based on mutual interests. In this way, these platforms assisted their users in discovering, qualifying and introducing themselves to other users in order to form broad network ties.

In contrast, personal profiles on LinkedIn and Facebook required each user to approve any new contact requests. This favours the formation of dense, high-closure networks where members already have some form of contact with each other. However, both services also allow asymmetric, non-reciprocal links in various ways: 'following' public posts from a user profile or company page, and joining forum-style group discussions that can help users to find new contacts. The managers avoided using their 
Facebook profiles for business purposes, preferring instead to separate 'personal' discussions (often involving family or close friends) from 'business' channels where peers and customers were encouraged to talk shop. LinkedIn was used more frequently to connect with business-related contacts, though the managers varied in their approaches to this. Some would only accept or initiate a connection with individuals they had done business with, while others treated LinkedIn invitations like an exchange of business cards: simply passing on contact details for future use, with no implied endorsement of the other contact. These managers used LinkedIn to form broad, weaktie networks, and often had little ongoing contact with their connections.

Forums differed from the social media platforms described above, by removing the requirement to establish any formal connection with specific individuals. While some of the managers used forums that allowed for content searches, topic subscriptions and other methods to follow a specific user's posts, these tools were rarely used. Instead, forums played host to numerous discussions, mimicking offline conversations more closely than on many other social media services. Here the managers described their contacts in terms of friends and acquaintances, customers and community regulars: without the formality of 'following' or 'inviting' contact, relationships were more organic and less constrained by the technology used to host the discussions.

\section{Supplementing offline events}

Managers also regularly used social media to supplement offline, 'face to face' networkbuilding activities such as attending networking groups, meetups and conferences. These activities were considered to be important ways of developing relationships with new business contacts. Rather than replacing these physical events, social media played an important supporting role before, during and after these events. Regular events tended to develop their own network of attendees, and these networks developed their preferred online spaces for discussion. Examples of these included adopting a shared Twitter hashtag for group discussions, or creating a Facebook or LinkedIn group. Managers took part in these online discussions to remain abreast of new developments even if they could not attend a meeting. This enabled them to remain an active part of the networking group while travelling, working or otherwise unable to attend events. 
In the lead up to an event, managers used LinkedIn and Twitter to identify people who would be attending. Meetup groups often included some degree of pre-event chatter on social media. Other events were often preceded by online chatter among the manager's existing network contacts. These conversations enabled managers to learn more about potential contacts, ensuring that they would not be going in to the event 'cold,' with no information on other participants.

All the managers cited a chronic lack of time as the major problem they faced in their business. Social media platforms gave managers a range of options that allowed them to fit networking activity into their schedules, with each platform used for different tasks. Real-time Twitter updates and 'live blogging' from attendees enabled onlookers to share in an event from afar. The asynchronous conversations found in forums and comment threads allowed them to pick up a discussion at a time more convenient to them - often causing group and forum topics to remain active for days or weeks. This also enabled truly location-independent communication: discussions could be read and added to at any time of day, by participants from any time zone, allowing the managers to benefit from discussions surrounding relevant events from around the world.

After any face-to-face event, social media played an important role in following up with new contacts. This added an additional dimension to the ubiquitous exchange of details for future follow-up - whether by an exchange of business cards or less formal methods. Social media contact details such as profile URLs, Twitter handles and even scannable QR barcodes enabled the managers to pass on a wealth of information about who they were, how they could be contacted, and why others might want to do so. Two managers described their activities after attending a conference as a post-event 'ritual' following Twitter accounts and business Facebook pages, and sending contact requests on LinkedIn. They considered these details to be an important way of continuing a relationship with their new contacts, as described by the manager of SocialSearch:

People move jobs and change phone numbers, but they'll keep the same LinkedIn account. If I'm connected with them on there, I know I can get in contact with them if something comes up in six months, a year, five years from now. 


\section{Listening in}

Social media assisted the managers in creating much larger and more diverse networks. However, the scale of these networks posed an additional problem: in order to draw value from their networks, managers needed to find effective ways of keeping up to date on the activity of their large networks of contacts. To achieve this, the managers relied heavily on the same social media services they used to identify and connect with these contacts.

The value of regularly listening in to contacts cannot be understated: it provides information on current events within the network, allowing the managers to quickly identify any issues that required a more detailed follow-up response. Burke, Kraut \& Marlow (2011) describe the passive consumption of contacts' updates as an activity that can provide value by increasing knowledge of the resources those contacts have available. Features like the News Feed seen in Facebook, Twitter and LinkedIn made it relatively easy to stay in touch with a large number of contacts. However, each social media service provided a different set of features that altered the way these platforms assisted managers to maintain their networks.

Many of the managers valued Twitter for its ability to help them identify and connect with a large network of relevant individuals outside their usual circle of contacts. However, the Twitter news feed was displayed in real time during the study period displaying every update, from every account the user follows. When combined with the large number of Twitter contacts that each manager followed, this swiftly lead to information overload: the huge number of incoming posts makes it easy to miss updates.

Other social media services take different approaches to the 'information fire hose' problem. For example, Facebook's filtered News Feed selectively presents only a limited subset of available network updates. This attempts to reduce incoming information to a more usable collection of higher-value posts of greater relevance to each individual user. More recently, Twitter has adopted a similar approach. The managers using LinkedIn typically relied on 'network update' emails, rather than spending large amounts of time browsing the site. These provided daily or weekly digest summaries of activity across a user's network, and within any groups they had joined. Forum users quickly identified specific sub-forums that were more relevant to their interests, and ignored other areas when visiting a forum site - typically bookmarking and viewing the most relevant subforum pages directly, and spending little time on other parts of the website. 
A common theme to these activities is recognition of the capacity of social networks to provide information that far exceeds the time any individual can spend consuming or contributing to it. Even managers such as Lee, who jokingly described herself as a 'Twitter addict' in her first interview, soon abandoned any attempt to read all posts made by her contacts. Instead, managers browsed through network updates when time allowed. This prevented them from being able to keep on top of all changes and discussions within their extended networks, but still allowed them to gather useful information.

\subsection{Influence}

Influence is the second major resource that social capital makes available. This is the domain of trust and reputation, describing how other network members perceive an individual or business. Influence and information are closely linked. Brokerage activities are one component of this, but the processes that fuel influence are more strongly tied to network closure and embeddedness. After making a business decision, influence describes the manager's ability to persuade others to follow it. Burt, Kilduff and Tasselli (2013, p. 541) describe embeddedness as a "critical contingency factor" to receiving returns on network brokerage. There are two reasons for this: brokerage returns rely upon being known as trustworthy (structural embedding), and qualities like trust, understanding and collaboration are more likely occur across strong ties compared to weaker ones (relational embedding).

\section{Becoming influential}

For several of the managers, being seen as a thought leader in their industry was an important goal for their social media activities. To achieve this, they sought to emulate qualities that they identified in other, more influential users. These included attaining large numbers of followers, connections to (and interaction with) other industry leaders, and publicly displaying high-level insights into their chosen industry niche.

Most social media services displayed some form of audience network size indicator from the number of contacts on LinkedIn, to Facebook friends and Twitter followers. At Videogame Network, Robert saw his low follower count as a handicap to effectively using Twitter: compared with the dense connections built up on his own forum platform, his 
personal and business Twitter accounts placed Videogame Network on an even footing with far less established startups. Robert commented that:

People questioned whether we were really such a big player in our industry, given that we had so few Twitter followers...

However, as the managers became more familiar with their chosen social media services, they relied less heavily on these measurements to identify influence and quality. The content posted on each account was regarded as more important: valuable contacts shared interesting links and added their own insights. This was particularly valued on Twitter, and in LinkedIn groups containing high-volume, relatively low-value updates. Consistently providing high-quality content was seen as an advantage that helped them to attract more knowledgeable and influential contacts.

Leading discussion was another important feature that managers identified in other thought leaders. The managers of Central PR and Vitae were both members of industry leadership groups, and paid annual membership fees to have access to successful industry leaders. These leaders were well informed via their own information networks, and able to shape discussions about changes to their industry. This quality was highly valued by the Professional Services managers. Each of the Services businesses in this study were small, highly specialised organisations, and frequently collaborated with other specialists on larger projects. Being looked up to by other business managers had two benefits: it allowed them to position themselves at the premium end of the market, and gave them more freedom to pick and choose from potential collaborators.

Social influence was a valuable resource for the managers of SocialSearch, allowing them to push into international markets. Late in the study, a major competitor announced that they would no longer support their product. This immediately generated a great deal of social media discussion over potential replacements. Eric's co-founder wrote about SocialSearch's product on a prominent industry blog, which attracted interest from around the world. Both managers began intensively using Twitter and blog articles to capitalise on the surge of interest in their business. This assisted them in consolidating a reputation as influential developers with a deep understanding of both software development practices and their industry niche, ultimately leading to their business being acquired by a US software company. 


\section{Cultivating an online persona}

Influence relies upon trust in the reputation of a manager or their business. From a structural perspective, trust can only develop within networks that have some degree of closure, where there is some degree of contact between a manager's contacts. Coleman (1988, p. 107) notes that "reputation cannot arise in an open structure, and collective sanctions that would ensure trustworthiness cannot be applied." However, being part of a dense, highly inter-connected network must also be supported by actions that increase trust in the manager and their business. This section addresses the 'content' elements that complement the structural prerequisites of network closure and reputation development, from content marketing strategies aimed at demonstrating domain expertise, through to the deliberate construction and presentation (Goffman, 1959; Papacharissi, 2002) of an online persona for the manager and/or their business.

In the first interview stage, all managers could readily identify the qualities that they wanted their business (and by extension, themselves as managers) to be known for. Established businesses had developed these qualities over time. Newer businesses had recently decided upon their concept and selling points. Qualities that were commonly discussed at this stage included approachability, customer focus, specialist knowledge, trustworthiness and high-quality service. In most cases, the managers had already worked to develop this reputation among their current and past customers, and hoped to convey this to future customers and potential collaborators.

However, when they first began using social media to promote their business, the managers could not rely on the functional reputation they had previously established offline. Aware of their way that new accounts required them to create a new identity from scratch, the managers sought to make a favourable impression on potential new contacts with no prior knowledge of their business. For many managers, this was the first time they had considered how elements such as their choice of writing style, tone, topics of discussion and the balance between personal and professional content could be used to cultivate specific properties, enhancing or harming the reputation of their business.

An important early choice concerned the decision to represent the business via branded or personal accounts. This was discussed in Chapter 5, with some managers attempting both options and later abandoning or merging Twitter profiles. Even among the managers who chose to use profiles branded with their business names and logos, 
there was a degree of experimentation with including personal content. This was considered to add a human face to the business, and allowed some of the manager's personality to show: important features for a micro-business that wished to emphasise a personal touch. In contrast, personal content was consciously avoided by the two startup businesses. Both sought to appear larger than they were, and the managers used impersonal, business-focussed content on their branded accounts. This helped them to attract clients that may have been uncomfortable dealing with one- or two-person organisations, bringing in work and income that would enable the businesses to hire new staff and grow into the large companies that their managers aspired towards.

Language use played an important part in the development and maintenance of these personas. With the exception of the Model Madness YouTube channel, almost all the managers in this study used heavily text-based social media services. Managers recognised that their written style and tone were elements that would affect perceptions of both the manager and their business: the use of abbreviations, spelling and grammar and emoticons all had implications for the intended tone of voice conveyed by social media updates. These were further complicated by the constraints of the social media services the managers used: status updates on Twitter, Facebook and LinkedIn often had hard limits on the number of characters that could be used, or gave limited visibility to long messages by truncating these updates. Hashtag use on Twitter and Facebook was considered a sign of understanding or misunderstanding those platforms: over-use of hashtags risked looking too desperate for an audience, or being too overtly promotional. Naturally, there were exceptions to this - playful or ironic overuse of hashtags could demonstrate a higher level of familiarity with the medium.

Managers typically had a clear understanding of what would conflict with their chosen persona - "unmeant gestures" (Goffman, 1959, p. 203) that would harm the intended outcome of such a performance, making the account persona less genuine. As a professional writer, the manager of Cover Story was keenly aware of how her use of language would affect the way audiences perceived her. When discussing her decision to maintain a playful, upbeat tone for all her updates, she noted that:

People who read my Twitter feeds think that I would be this sugar-and-spice, lovely kind of a person... but you know, I'm far more sarcastic. 
Complaints and sarcastic comebacks were avoided, as their inclusion would conflict with her intended business persona. Other managers were less explicit about their decision to adopt an online persona. However, the presence of these personas was shown by their responses to questions about what they would or would not choose to post on their accounts.

\section{Increasing the visibility of the business}

Managers used social media to assist in building far larger networks than they were able to via purely offline methods. This created broad, weak-tie networks that required the managers to interact with a wide range of contacts, taking a significant commitment of time and energy, in order to remain 'top of mind' to these audiences. This section examines the ways that managers used social media to help them maintain contact with their networks, remaining visible among increasingly crowded news feeds.

Maintaining these networks is a vital and ongoing task, as social capital cannot effectively be banked and stored for future use. Social networks are maintained by active participation, checking in with contacts. This helps the managers to learn what others are doing, remain visibly active to other network members, and participate in a regular exchange of information and favours. This is a significant difference between 'social' and other forms of capital, as the value of an individual's social capital declines if it is not used.

This behaviour is often taken for granted among smaller networks based on face-toface contact: this is the realm of small talk, office conversations, phone calls and coffee meetings. Without it, an individual can fall out of touch with parts of their network. This is a gradual process, differing from actively severing a tie: the reasons for the initial contact still remain, and distant contacts may still provide some assistance out of trust in the friendship, partnership or reputation of the individual. However, infrequent contact and one-way demands on others in the network erodes the strength of these bonds. Maintaining social capital is as much a process of 'giving' as it is of 'taking' and spending this resource within the network.

Managers who were already embedded within strong-tie networks typically had frequent interaction with their contacts as a matter of routine, such as meetings, networking events, email and phone calls. The broad, weak-tie structures characteristic of many of the online networks in this study presented additional challenges. Contacts 
may be geographically distant, making face-to-face meetings difficult and presenting time zone difficulties for calls. The networks may involve the manager's friends, family members, suppliers, competing businesses and customers - contacts dispersed through many different 'circles' and rarely encountered together.

To address these issues, each of the managers used a wide range of social media services to stay in contact with their networks. In their study of social capital development among Facebook users, Burke, Kraut \& Marlow (2011, p.577) found that the development of bridging social capital was primarily associated with "directed, person-to-person exchanges," that included both public messages tagging in a manager's contacts, and private messages sent directly to an individual.

Broadcast-style status updates still serve an important function by providing a loweffort method for managers to remain visible to others in their network. These 'checking in' updates show other contacts that the individual is online and active. However, several managers were cautious about over-using these updates, particularly when posting on business profiles. These managers worried that too much activity would drive away their audience, and could readily describe others they had stopped following for this reason.

Discovering the balance of post frequency and content types to provide a business with the right level of visibility required managers to understand their audiences on each social channel, and the results differed for each individual. For example, the freelance writer knew that photos of food (the oft-derided 'breakfast pictures') were well received by her network: they were relevant to her audience of hospitality businesses and food writers, and publishing a regular stream of images from Melbourne cafes had resulted in strong and sustained growth in the number of subscribers to her various social media accounts. When deciding what, when and how often to post, managers primarily relied upon instinct and 'gut feelings' developed through their observation of other users of their chosen social channels. These instincts were occasionally reinforced or brought into question by quantitative data such as the number of new followers, comments, re-tweets or clicks that a link received. However, interviews revealed that none of the managers examined this data in detail. Instead, they used this data to determine trends and quickly gauge whether their business appeared to be 'on the right track'. 


\subsection{Solidarity}

Solidarity provides managers with the ability to count on support from other members of their social networks. Like influence, it is closely tied to the structural properties of network closure (Burt, 2005) and embeddedness (Granovetter, 1985). However, it differs from influence in its effects: solidarity reinforces and validates the actions of group members. These differences qualify it to act as a third type of social capital resource, distinct from information and influence, but still made available by the structure and content of a manager's social relations.

This section examines three aspects to solidarity: identity and belonging; the formation of customer/supporter communities, and challenges associated with managing potential disadvantages caused by solidarity.

\section{Identity and belonging}

Formal and informal groups have been discussed previously as a source of information. These groups offer an additional advantage that goes beyond their value as networkbuilding tools, providing access to diverse contacts and information. Group membership encourages a sense of belonging and community: allowing members to identify as part of a broader group, supporting or calling on support from other group members.

This membership may be formally established, in cases such as the professional associations and private social networking platforms joined by managers of Vitae and Central PR. It can also apply to the bonds that form between regular users of a particular discussion space - whether that is a shared Twitter hashtag used to host a regular group discussion, a LinkedIn group or a forum. In such cases, there may be no clear distinction between those 'inside' or 'outside' the community - following Rheingold's (1993, p. 5) broad definition of online community as a social aggregation that emerges when "enough people carry on those public discussions long enough, with sufficient human feeling, to form webs of personal relationships in cyberspace".

Managers joined communities on all types of social media services. These ranged from alliances of YouTube content creators to customer-led forums; Twitter groups comprised of local business owners, and networks of bloggers. Not all online gatherings of users would qualify as a 'community' under Rheingold's definition, lacking a critical mass of people or emotional involvement. Without a shared sense of community, these offered 
little in the way of solidarity to a new participant. This was most commonly seen where managers attempted to use a platform to become the central hub of a broadcast-style network: aiming to amplify the reach of their own messages, without seeking to develop either reciprocal ties from audience members, or cross-linkages between them. Most Facebook business pages fell into this category, and Twitter accounts were frequently used in this fashion early in the manager's period of experimentation and learning.

Some managers attempted to form new online communities. These included starting LinkedIn groups aimed at a particular industry niche, adding forums to the business website, and starting Facebook pages or groups in parallel to the main business presence. During the study, few of these succeeded in reaching a self-sustaining critical mass that would allow them to operate without the direct action of their founders. These groups failed for a multitude of reasons: some were too obviously focused on promoting a particular angle (in many cases, the manager's business) to find wider appeal. Others were too broad in focus, replicated existing niches, or were too specific to attract new members in any significant numbers. Social media users are spoiled for choice when it comes to thriving, active communities, and competition for the time and attention of potential members is fierce. With the sole exception of Inner Circle's industry roundtable, the most successful online communities used by managers in this study were already established prior to the managers joining them.

\section{Customer communities}

The formation of customer communities was an important consideration for the managers of Toys and Games and Model Madness. Both Matt and Jennifer wished to strengthen ties with regular customers in order to encourage repeat business, and took pride in their ability to remember and chat to regular customers. These managers recognized the value in establishing this rapport, but such activities could not easily scale up as their businesses grew: with more customers and heavier workloads, managers and other staff would have less time available to communicate with customers. Instead, the both managers encouraged their customers to talk to each other. This reduced staff workload, while still ensuring that customers were part of ongoing conversations about the store's products. It also addresses the issue of solidarity among these customer groups by fostering the development of cross-linking ties to improve network closure. 
These managers used online methods including setting up forums on their websites, and using Facebook pages and groups to encourage discussions between customers.

At Inner Circle, Mary coordinated a national industry roundtable group that placed her in direct contact with peers and potential customers. When establishing her business, she relied heavily on her network contacts for referrals and leads. Group members were an important source of information on new tenders and work available in their own organisations or departments. As the roundtable community matured, fellow members also provided valuable referrals to other government and corporate departments. By working with her and seeing her expertise and capabilities, group members trusted her ability to deliver on consulting projects. Members demonstrated this by vouching for Mary's expertise among their own networks and advocating for her inclusion in new projects. In return, she was could recommend other members to her own clients.

In both of these examples, the managers use a combination of social media and offline events to form or join highly interconnected communities of customers. Members of these groups share common interests, and gradually begin to take on group membership as part of their personal identity: becoming more willing to support or advocate for other group members as their trust in those members, and in the community as a whole, grows.

\section{Advantage and disadvantage}

To date, social capital research has largely focussed on the positive qualities that it makes available to individuals or groups: described in terms of benefits (Bourdieu, 1986), "information, influence and solidarity" (Adler and Kwon, 2002, p. 23) or general 'goodwill' that it makes available to the actor. If we examine its ability to render poorlycirculated information available to actors outside the immediate network of the information holder, social capital undoubtedly improves the actor's situation. When a business manager is assessing the merits of different IT systems, constructing a marketing plan or seeking customer feedback, access to a broader range of information is generally considered to be an advantage, and the opinions of trusted sources help to make decisions about this information.

Where social capital is used to mobilise solidarity, however, its uses become harder to define as an objective 'good.' Burt (2004, p. 354) briefly mentions examples where social capital has facilitated "returns of a less desirable kind," such as success in organised 
crime, fraud or corporate misgovernance. The negative consequences of social capital have been explored in detail by Portes \& Landolt (1996) and Portes \& Sensenbrenner (1993), and were highlighted as an area requiring future work by Adler \& Kwon (2002). Further, Wachs et al. (2019) show excessive bonding capital in high-solidarity networks to be a predictor for corruption, highlighting the risk posed by this form of capital to individuals outside these networks.

Portes (1998) identifies several negative consequences that social capital can create. The first of these is the exclusion of outsiders, particularly notable in groups possessing high degrees of closure. For the managers in this study, this was most commonly seen in the development of cliques: groups within a network that benefit from extremely tightknit bonds between members, to the extent that their network becomes essentially closed to outsiders. At Toys and Games, Jennifer expressed concern over customer cliques driving away potential new customers in her store. At Fusion, Lee felt the effects of this more personally - noting that the influential food blogger community seemed effectively closed off to restaurant managers.

Other risks associated with high solidarity include the potential for excessive claims to be placed on group members, preventing group members from successful business operation. This may apply in any situation where managers felt that turning down requests for favours would harm their reputation in a group. In practice, managers in these situations were more likely to decrease their involvement unless these groups aligned very strongly with their personal preferences and business goals. This reduced their potential access to solidarity resources from these groups, but also reduced the risk that other group members could unfairly take advantage of them.

\subsection{Conclusions}

This chapter has explored the ways that the managers used social media to support their business networking activities, primarily in the form of establishing new contacts and maintaining regular contact with others. In both cases technology was used to supplement offline activities, and to create opportunities that would otherwise not have been possible. The managers all placed a high value on being active and well-connected online. This provided direct benefits in the form of information from network contacts. It also indirectly affected their reputation, helping the businesses and their managers to be 
seen as influential members of the business community. Each manager worked to improve the network of contacts surrounding their business, and their personal network as a business manager. However, they had difficulty in defining the benefits they received from their networking activities: describing these in terms such as goodwill, trust, reputation and favours.

To examine these benefits in detail, I have adopted Adler \& Kwon's (2002, p. 23) definition of social capital as the goodwill available to individuals and groups, providing "information, influence and solidarity" that flow from the structure and content of the actor's social relations. These three categories were then used to explore the range of network-related benefits each manager had described, enabling a detailed examination of the tools and tactics that managers used to access these resources.

I combine this with Burt's (2005) theory of social capital as a combination of brokerage and closure effects to examine the ways that network structure affected access to social capital resources. In particular, Burt's work on structural holes provides valuable insight into the information resources the managers were able to access from their participation in diverse, weak-tie networks on platforms like Twitter and forums. Here, the majority of interaction between other network members does not require any direct link to the individual user. This property facilitated the development of 'bridging' ties and their associated brokerage opportunities, allowing managers to access and share information that was unevenly distributed among their contacts.

\section{Information outcomes, and implications for the fear of missing out}

Managers relied heavily on social media services to help them form larger and more diverse networks of business contacts, improving their access to information. When building their networks, managers searched networks such as LinkedIn and Twitter to identify people they shared common interests with. Other potential contacts were found via discussion forums, group discussions on Facebook and LinkedIn, or simply observing the people involved in conversations with their existing contacts. Where available, automated suggestions of similar profiles also assisted in this task.

Online conversations surrounding 'face-to-face' industry events provided another opportunity to find new contacts, allowing managers to virtually participate in events they could not otherwise attend due to time, distance or cost. This crossover went in both 
directions: many of the managers described arranging face-to-face meetings with contacts they had met online, and using online channels to continue discussions started at physical events such as networking evenings and conferences.

Information is derived primarily from broad-spanning 'weak tie' connections, and the ability of managers to strategically position themselves to take advantage of brokerage effects within their networks. By exposing managers to a greater range of other businesses using social media, this contributed towards the key fear of missing out theme discussed in Chapter 5. This outcome affected social media adoption in two ways. It makes other users of the technology more observable, and increased use of social media reveals a greater number of business peers using each service. This supported a narrative that managers would miss out on the 'next big thing' if they did not commit to adopting social media for their own business. A secondary factor was the type of story presented on social media. Aware that their activities were public, business managers were more likely to present 'good news' stories about their experiences on social media accounts. This biased the type of information that new users were exposed to, further contributing to a sense of urgency associated with missing out on potential benefits.

\section{Influence and solidarity outcomes, and implications for social media use as a low-risk strategy}

Influence was another valued quality, resulting from the strength and density of a manager's network contacts. During their interviews, most of the managers described aspirations to be influential within their industry - leading trends and discussions. Managers attempted to emulate properties displayed by other influential members of their networks. In most cases, this involved making decisions about how they would represent their brand online. These included choosing to focus on personal or branded accounts when promoting their business, identifying which topics to discuss or avoid, and selecting an appropriate style and tone to match the image they wished to convey.

Maintaining visibility within these large social networks was an area of concern for many of the managers. They recognised that their ability to assert influence or call in favours was reliant on the strength of their relationships with others, and that this would also be eroded by infrequent contact. This led them to use their chosen social media services to contact individuals directly, share 'broadcast' updates about their own 
activity, and observe what their network contacts were up to. Passive 'listening' behaviour became a common default activity for the managers during periods when they could not devote time to active involvement in their networks. While this was unlikely to result in further social capital development (see Burke, Kraut \& Marlow, 2011), it provided an alternative to abandoning network contacts entirely. This allowed the managers to remain aware of potential resources available within their network, prompting them to renew contact with those individuals when they were able to do so.

The final category of network-derived advantage was solidarity. Like influence, this was also closely tied to network closure. This resource encompasses issues of group identity and belonging, and describes the willingness of others to support the actions of another group member. Being part of a group could have considerable benefits: the managers of Vitae and Central PR paid membership fees to access specialist groups that gave them access to industry leaders and provided networking opportunities, helping managers improve their access to information. However, the primary value in joining these groups was the resultant solidarity from other group members. The groups were intentionally small, exclusive, and formed close-knit ties between members through regular online contact. These properties increased the likelihood that members would actively support each other, standing up for 'one of their own' when needed.

Other efforts to increase solidarity among customers could be observed where managers attempted to create online communities to help customers become connected and engaged with the business and its products. The managers of Toys \& Games and Model Madness both put considerable time and energy into this, creating forums and actively supporting groups that their customers were part of.

In some cases, managers were required to find ways of overcoming problems created by high solidarity among groups they wished to join. The nature of their role as small business managers often placed them as outsiders in other networks, with relatively few strong ties to reinforce their position. This required the managers to negotiate access into established groups that were potentially resistant to the inclusion of newcomers. At Fusion, this made it difficult for Lee to enter an influential community of reviewers and bloggers. By concentrating on gradual integration and shared value, she was eventually able to become a part of these groups and benefit from the solidarity advantages made available to its members. Services businesses that relied upon consulting work for larger 
organisations frequently dealt with networks that were difficult for outsiders to access. At Inner Circle, Mary chose to develop closer ties with other small business operators. This allowed her to form connections and draw on support from these contacts, when attempting to enter new markets.

Both influence and solidarity offer potentially valuable outcomes for small business managers. However, they also affect the perceived low-risk nature of social media use. There are two key implications for the underestimation of risk. The first affects the perception of social media as a low-cost strategy. Information and solidarity are derived from strong-tie 'closure' mechanisms in social networks, requiring the managers to become embedded within a network in order to produce these outcomes. Managers discovered that this could take a significant amount of time, finding, joining, and establishing relationships with other users of each social media service that they chose to use for their business. The second factor concerns the underestimation of reputational consequences. When beginning to use any social media service, managers were dealing with existing users who had stronger ties between each other, compared to their connections to the business manager. In order to effectively generate business outcomes from their activities, the managers needed to establish a reputation among other users of that service. They also need to deal with relatively closed groups of users that share different values to the business manager - seen in this chapter when managers negotiated interactions with cliques of their customers or peers. 


\section{Conclusions}

\subsection{Overview of thesis}

This thesis has explored the ways in which a group of Australian small business managers have used social media to support a range of business activities. It contributes longitudinal data that covers a period in which several major developments occurred: Facebook achieved mainstream adoption and became the dominant social media platform used within Australia, while Twitter and LinkedIn also attracted large numbers of users. Beyond these three, a vast array of other social media services were launched or discontinued. Of particular note are the social networking Google+ (launched in late 2011) and photo-sharing service Instagram (launched in October 2010).

This research aims to understand how small business managers adopt and use social media, and the outcomes that this provides to each business and its manager. There are four major findings: two key adoption themes (the fear of missing out and the perception of social media adoption as a low-risk strategy), the implications that these themes have for social capital theory, and the contextual factor that social capital outcomes provide for the success of social media adoption in a small business.

I have examined which social media services were used by the managers, the purposes that these were used for, and the outcomes generated for each business. Most social media services were used for multiple business applications, with varying degrees of success. These applications evolved as the managers developed greater technical skills and awareness of how other businesses used each service. Social media services also added, removed or changed their features throughout the study, with other services launching or closing during this time. This changing technological environment was a constant factor in the ways each manager used social media. Chapters 4 and 5 introduced the case studies involved in this research, and explored the types of social media services that were used. This revealed two common themes driving the adoption of social media: a fear of missing out on potential business advantage, and the perceived low risk of using social media to augment or replace other business activities. Social media adoption was then explored in detail throughout Chapter 6, using Rogers' (2003) Diffusion of Innovations framework. 
I have also examined the business outcomes generated by social media. Throughout the study I have observed managers attempting to secure an intangible, ill-defined resource that they referred to as goodwill, reputation or image. These managers dealt in the currency of social capital - accessing information and mobilising influence among networks, based on the success of their on- and off-line activities. Chapter 5 examined how social media was used to provide a business with visibility to its customers and peers, and how it can provide managers with insights into their operating environments. In Chapter 7, I have used social capital theory to explore how social media supported networking activities - providing managers with access to information, insight and solidarity from their networks of contacts on each social media service.

I also reflect upon the implications for social capital theory, raised by the two key adoption themes. The effects of social capital are more complex than simply providing an outcome from social media use. Instead, the interactions between social capital outcomes and the adoption themes of perceived low risk and the fear of missing out provides a contextual factor that affects the success of social media adoption within a business.

\section{Methodology and methods}

I have taken an exploratory qualitative approach to conducting this research, exploring the ways in which a relatively new technological development was used by small business managers. To achieve this, I have used a multiple case-study approach to building theory (Eisenhardt, 1989), using case studies for their ability to address "how and why" research questions (Eisenhardt \& Graebner, 2007). In many cases, these managers began with no clear vision for what they wanted to achieve with the technology or how to use it. Longitudinal data allows an exploration of the ways business goals changed throughout the study, in response to success or failure while experimenting with social media use. It also provides scope for examining how social media services have changed: both in terms of the range of features offered to users, and the effects of a changing technological landscape where new services launched, and others were discontinued. I have explored the range of potential business uses for social media that were identified by the managers in this study, and the ways that social media has supported each manager's activities.

A total of 15 small businesses took part in this longitudinal study, which involved interviews and online observation of each business across a period of 12-18 months. These businesses were selected from the hospitality, retail and professional services 
sectors, within the greater Melbourne area. I sought examples of managers who were the founders or co-founders of their businesses, already active on at least one social media platform, and who attempting to integrate social media into their businesses.

To address my research questions, I have used a combination of methods drawn from digital ethnography and traditional qualitative interviewing techniques, combining faceto-face interviews with a period of online participant observation. These methods enabled me to build a composite picture of each manager's online activity during the study, exploring their progress as they integrated social media into their organisation.

\subsection{Social media services and business outcomes}

This section reviews the social media services that were used by each business manager during the study, and the major business outcomes that social media supported.

\section{Types of social media used}

Social networking profiles and business pages were the most widely used forms of social media in this study. During the initial interviews, all managers discussed the ways that these services could affect their business. In particular, Facebook was considered to be the most important service due to its vast audience size and potential reach. Twitter, LinkedIn and blogs were also popular, used by many of the managers. Four managers made extensive use of forums, and several managers had begun experimenting with YouTube. The methods in which these platforms were used are discussed below.

For many of the managers, Facebook was their starting point when considering social media for their business. Even relatively late adopters such as Inner Circle and Vitae had used Facebook prior to the study. Facebook was considered the default for any social media activity. When discussing their reasons for choosing other services, managers described these in terms of how those differed from Facebook in potential audience or functionality. The few managers who did not use business pages on Facebook had all considered doing so, and could provide specific reasons to support their decisions. Network Solutions did not maintain a formal company presence on Facebook as the manager felt that business pages were too 'pretentious' and sales-driven. SocialSearch preferred to allocate resources to services containing a higher concentration of potential customers, and didn't feel that Facebook was appropriate this. Similarly, Building Blocks 
saw little value in using a service that had achieved mainstream adoption, when their target audience was early-adopter technology developers.

Twitter was the second most popular social media service among the study group, used intensively by many of the managers. Many managers attempted to use the platform for both personal and business purposes, using multiple accounts. This was problematic for two main reasons. Time constraints presented an obvious difficulty. However, these were eclipsed by problems caused by crossover in subject material between the various accounts. Each manager had started their business in an area they were passionate about and deeply involved in, and their personal identity was already tied strongly to that industry niche. Their personal Twitter accounts often pre-dated business accounts, and contained commentary and links relevant to the user's industry sector. Building a separate business profile duplicated their existing work, and managers struggled to attract followers to newer business accounts that had a significant degree of overlap with their personal followers - often abandoning their business accounts entirely.

LinkedIn was also popular, with all managers creating a personal LinkedIn profile prior to the study. These showed each manager's personal and entrepreneurial journey, as they changed job type and industry multiple times during their transition to running a small business. Business pages were a relatively new feature on LinkedIn during the study, but no managers used these. Unlike on Twitter, they saw little value in attempting to separate their 'business' and 'manager' profiles on that service.

Several managers experimented with the use of blogs for their businesses. In most cases, blogs were updated sporadically: unlike the shorter updates common to other social media services, blog articles were typically longer and more time-consuming to write. The managers maintained social media accounts as an addition to their regular workload, and business blogs were often the first to fall into disuse during busy periods. Manager experience with blogging services varied significantly, informing the ways they used these during the study. Some had created successful hobby-related blogs prior to launching their businesses, and focused heavily on interaction with their audience. In contrast, the SocialSearch manager saw blog articles as a source of 'long-tail SEO' providing an archive of content relating to issues that his products were designed to solve. Comments and discussion were not the primary focus: instead, his articles contributed to improving visibility in search engines. 
The managers of Network Solutions, Model Madness and Toys \& Games all used forums extensively. Each of these managers was active in multiple forum communities, taking various roles within these. Model Madness hosted a forum on their website, to host discussions among a small, local community. Toys \& Games used a large Australian gaming forum to raise awareness of their business by visibly taking part in discussions about news and events that related to the store. The managers of these businesses were also casual members of several international forums, using these to gather information on potential new products that could interest their local customers.

Finally, the managers used YouTube in several different ways. At Model Madness, Matt used YouTube as his primary social media channel: regularly publishing videos about developments in his store or industry, and sharing links to other members of the YouTube community. This channel pre-dated the launch of his retail business, and documented the transition from a hobby activity into a full-time occupation. Other managers made more limited use of YouTube, using it to host videos advertising their products or services.

\section{Outcomes derived from social media use: a three-stage model}

The business outcomes that managers used social media to support can be grouped into three broad categories that I label visibility, insight and social capital. While the specific applications for each activity varied between businesses, each manager used social media to support these outcomes. Additionally, the three categories are presented in order of increasing complexity and sophistication. All the managers began using social media to increase the visibility of their business, and then progressed through the following activity types as their understanding of the medium grew.

Visibility describes the range of promotional and marketing activities conducted by each manager, and includes both brand awareness and reputation. The perceived need for these activities was the driving force behind each manager's initial adoption of various social media services for their business.

Brand visibility aimed to improve awareness of the business and its products. This typically began with the creation of a profile or account on one or more social media platforms, such as a Twitter account or Facebook page. This provided a place to display the business name and basic information about their products or services. Profiles typically linked to the business website, and social media updates were used to promote the business or provide additional links to the site. Managers described their business 
website as the fundamental building block for all other forms of promotion - "if you're not on the web," stated the manager of SocialSearch, "you might as well not exist." This fear of missing out drove managers to create social media profiles on many different services, even in cases where they had no other goals: these managers saw the emergence of services like Facebook and Twitter as a repeat of the shift towards businesses having websites. If a business with no website was invisible today, they reasoned that businesses with no presence on social media would soon be similarly invisible.

Paid advertising was notably absent from the activities of each business, despite the prominent role of targeted ads on services such as Facebook and LinkedIn. While each manager sought to improve the visibility of their business, they saw social media as a free alternative to 'traditional' marketing activities.

Reputation development aimed to present the business in a specific way: using style, tone and choice of content to portray a particular image of the business on social media. This was considerably more complex than simply establishing a 'presence' on a social media platform. Managers used their accounts to enter into public discussion, giving the business (and its manager) a voice. This allowed them to demonstrate knowledge and expertise in their chosen niche. Curating and sharing relevant resources was an important part of these reputation-building activities. This required less time to produce than original content, but still enabled managers to build a reputation for being wellconnected and knowledgeable about their industry.

Insight activities are those that relate to awareness of what others are doing. At a basic level, they included listening and monitoring activities such as reading forums; news feed updates, and notifications of replies to, or mentions of, their accounts. At a more advanced level, these activities were used to answer specific questions about the activity of customers or competitors.

In order to learn about current or potential customers, managers first needed to find where these people were active online. Some managers located online communities through their connection to offline events such as conferences, trade shows or networking groups. Others relied on web searches to find where people were discussing their products. Services used for this purpose included forums, Facebook and LinkedIn; all places where niche communities of interest had already been established. By using 
these services, managers had access to information about how customers and industry peers regarded different products and service providers.

The public nature of most social media activity also allowed managers to monitor their competitors. General business information such as pricing, promotions and sales, opening hours and stock availability were more readily accessible from businesses that were active online. This type of activity helped the managers to directly compete against other businesses, though they downplayed the extent to which they relied on this information. Managers also watched other businesses for ideas on how to use social media. Ideas from one business, such as using a new service or posting a different type of content, were often watched and copied by others.

This combination of customer and competitor information allowed managers to use social media services to research market trends and customer behaviour. When competing businesses launched a new product range or service offering, managers could rapidly discover and assess these changes. Similarly, if customers began discussing unreleased products (previewed by their manufacturer, or available in other regions) this enabled the business manager to respond by adjusting their ordering accordingly. Retail managers from businesses such as Toys \& Games and Fashion on Wheels used these insights to become local trendsetters in their chosen niches, identifying and sourcing popular new products before local competitors were able to do so.

Managers also used their social media accounts to test the waters for potential new business ideas. These included new products, new service offerings, and promotional activity aimed at further engaging with the audience of their social media accounts. In one case, early feedback on a product lead to the development of an entirely new revenue stream: the manager of Inner Circle created a Facebook page to gauge demand for a new product, and received an overwhelmingly positive response. Subsequent refinement of her prototype with input from early adopters allowed the business to expand, using the product in consulting work, and also selling the new service to other consultants.

Finally, social capital activities allowed managers to access the information, influence and solidarity available to them through their network of contacts. These share some degree of overlap with the previous two categories, often enabling more efficient gathering of information, or supporting the goal of business visibility. However, I place them in a category of their own as these activities are not inherently aimed at either of 
the previous goals. Rather than striving for greater visibility or insight, these activities seek to develop the network structures described in Chapter 7.

Building a network of contacts involved connecting with both individuals and communities - an ongoing process that was sustained throughout each manager's use of each social media service. The gradual accumulation of new contacts contributed to the value that managers placed in their social media accounts, recognising the amount of work that would be required to duplicate this on a new platform. These networks were more than simple contact lists: the process of identifying new contacts and then brokering a connection with each occupied a significant amount of time. This was most apparent on platforms requiring reciprocal connections, such as LinkedIn.

The information-gathering aspects of engaging with online communities were discussed previously as an insight-related outcome. The strategic process of finding and joining online communities is distinct from this: it is the groundwork that positions a business manager to take advantage of the social capital resources available to members of those communities. The methods of joining varied with each community and with the level of involvement required: at the most basic level, simple reading of discussions could typically be done as soon as the community had been located. Active participation in the form of commenting on updates, forum conversations or blog posts required the creation of an account, or joining a group with an existing social networking profile. More significant involvement had additional requirements: bloggers responded more favourably to other bloggers, while regular users of forums and discussion boards were more likely to interact with other members who posted regularly.

Creating new communities to host discussions between customers or industry peers was a more complex task. New communities often suffered from a lack of the momentum or 'critical mass' that existing communities would have access to. The managers of Building Blocks, Inner Circle and Model Madness all experimented with creating new communities of customers or business peers, to varying degrees of success. The demands that these placed on the managers' time caused each community to remain dormant for long periods when the manager's priorities shifted to other areas. Only those communities that attracted other active, engaged members continued to operate in a sustained fashion, without the direct attention of the business manager. 
At a micro level, there were numerous actions that helped managers to strengthen network ties with their social media contacts. Regular interaction with other members helped to reinforce the relationships between each manager and their contacts. This included 'check in' status updates, commenting on posts, and providing a steady stream of information about work in progress or links to items of interest that the manager had encountered in their daily routine.

\subsection{Social media adoption}

Two key adoption themes emerged from this study. The first was the fear of missing out - an early driver for adoption, arising from the high visibility managers had over competing businesses adopting new social media services. The second was the perception of social media adoption as a low-risk strategy - appearing to have little cost associated with high potential rewards. These were identified in Chapter 5, and explored in more detail during Chapter 6 using the theoretical lens of Diffusion of Innovations (Rogers, 2003). This involved three aspects: the process by which decisions are made about adopting a new innovation, characteristics of the business managers, and characteristics of the technologies they chose to use. Several distinctive features of the individuals, businesses and social media services were well suited to the rapid diffusion of innovations. These included the small size of firms, entrepreneurial owner-managers, highly interconnected personal and professional networks, and the public nature of social media usage. This combination of individual, organisational and technological features is of interest when considering how other small businesses may react to new developments, and suggests ways that other organisations may improve their own ability to identify, trial and adopt social media.

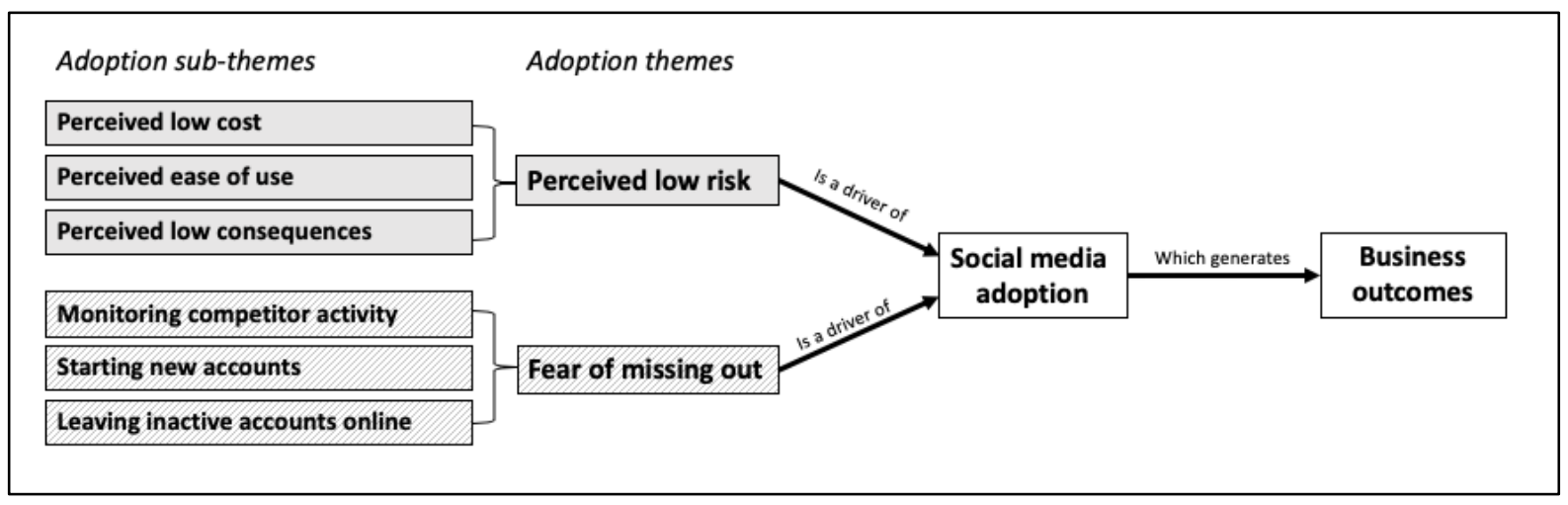

Figure 8.1: Adoption themes and sub-themes 


\section{The Innovation-decision process}

I examined each manager's adoption of social media services using Rogers' (2003) innovation-decision process, which describes a set of phases commonly used in the adoption of a new technology. The phases of knowledge development, implementation and confirmation were clearly visible as managers assessed new social media channels for their businesses. However, the intermediate stages of persuasion and decision to adopt were not given the same emphasis, as these were indirectly observed via the manager's progression to later phases in the process.

All three sub-phases of knowledge development (awareness, technical and principles) were directly applicable to the process of social media adoption within businesses. Each manager's network of friends, family, customers and business contacts provided visible examples of how others were using social media, and contributed to the discovery of new and emerging social media services. Managers typically developed technical knowledge through experimentation and asking peers for assistance. Technical knowledge was not considered to be difficult to acquire, due to the wealth of tutorials and guides available. Instead, managers saw time shortage as the main barrier to developing their skills. In contrast, principles knowledge was viewed as more complex, and developed at a far slower rate. Few managers identified this as an issue during their first interviews, when they were more concerned with technical 'how-to' issues. The concept of socially appropriate or inappropriate communication emerged later, after the managers had spent more time using their chosen social media services.

Each business used a series of partial implementation stages to 'test the water' when adopting new social media services, blurring the boundary between the phases of decision and implementation in Rogers' model. The overlap in functions between different social media platforms allowed managers to trial aspects of each new social media services, gradually shifting their emphasis between these. In this regard, decision and implementation did not appear as distinct phases. This resulted in part from technology characteristics such as access to trial accounts. The social media services they used were typically free to join, although paid 'premium' accounts were offered by LinkedIn and some forums. Free accounts allowed managers to try out new services, learning how to use these and testing whether the service would be appropriate for their business. Any new offering that lacked a free option was regarded warily: even minimal 
purchase or subscription costs were considered a significant barrier. The managers were generally not concerned over the compatibility of social media with existing customer service, sales or marketing: their organisations were small, staff typically shared many areas of responsibility, and the ad-hoc nature of managing clients and customers via social media was no more chaotic than their way of doing this previously.

Finally, confirmation describes the phase where managers review a technology to decide whether it is worth continued use in their business. Given the tangled nature of the decision and implementation phases described above, this final phase is of particular importance. In most cases, it is only after the public trial of a service that each manager could assess its value, as public involvement was crucial to understanding how each service functioned. Based on their experiences, managers selected one of two options: either discontinuing their use of it, or reinforcing their decision to adopt it.

Discontinuance occurred when a service failed to deliver outcomes that it was expected to provide, or when it appeared riskier (in terms of cost, ease of use or consequences for misuse) than the manager's initial perception. During the study, business social media accounts were almost never deleted or removed: instead, discontinued accounts simply fell silent. This process often happened by degrees, as the manager's focus shifted to other tasks. In rare cases these accounts were revived later on, driven by manager awareness of changing social media use among their customers.

Reinforcement took place when managers found active, relevant communities using their chosen social media service. These included communities of interest containing potential customers, and communities of practice relating either to the manager's industry, or to business social media use in general. These provided a source of information on the business' industry or product lines, and were also used to seek feedback on business decisions. Some community members assisted in word-of-mouth promotion, in ways that were traceable and measurable - aspects that were largely missing from offline referrals. These outcomes provided managers with tangible benefits to their social media use, and contributed helped reinforce the decision to use a service.

\section{Innovator properties}

The managers possessed broadly similar characteristics, as would be expected among a group of relatively early adopters of a technology. Diffusion theory uses five adopter categories based on an individual's level of innovativeness: beginning with Innovators, 
then Early Adopters, Early and Late Majority, and finally the Laggards who are last to adopt an innovation. On a national scale, the managers were exploring and experimenting with social media at a time before this became commonplace among other small businesses. However, none of the managers considered themselves to be true innovators in this area. Instead they described themselves as early adopters, as each could identify more innovative individuals and organisations among their peers.

Further exploration of this revealed two insights into the communication behaviour of the business managers. Firstly, they were highly cosmopolite communicators, bridging many different groups among their friends, family and business contacts. This placed the managers into contact with innovators and early adopters, and also with less advanced groups who looked to those managers for guidance on business and technology issues. Secondly, contact with social media innovators was facilitated through the medium of social media itself. When the managers joined conversations in LinkedIn groups, on Twitter, or in the comments of blogs and forums, they were able to expand their own networks to encompass experts from around the world. This expanding sense of scale contributed to each manager's perception of themselves as just another step in the diffusion of new ideas. Their online activity made them more likely to discover innovations, but also more likely to appreciate where those innovations came from and how the innovation had been applied in other industry sectors.

Social media adoption involved a process of change: learning to use a new technology, modifying or creating processes to manage the requirements of time and skill development, using new services to conduct research and promotional activity. Managers also developed greater awareness of how their communication activities affected their reputation, causing them to consider how style and tone could change perceptions of their business. However, as entrepreneurs the managers had a generally positive attitude towards change - a quality regarded as an important personality variable in many diffusion studies. Managers had changed their own careers during the process of starting their small businesses, either through a gradual shift from part-time hobby to full-time business, or as part of a more sudden transformation when launching their new enterprise after a redundancy or similar event. In doing so, they actively sought further change: attempting to deliver products or services in new ways. These were not individuals seeking 'more of the same,' and their use of technology reflected this. 


\section{Innovation properties}

The social media services used during this study possessed several characteristics that supported their rapid diffusion into widespread use. Diffusion theory examines five characteristics of innovations: relative advantage, compatibility, complexity, trialability and observability. Understanding these characteristics and the ways they can be applied in the design and marketing of technology is of value to any technology developer; particularly those targeting their products at small business managers.

Relative advantage directly contributed to a major social media adoption theme in this research. Each manager described a fear of missing out on access to customers, if they did not develop a business presence on new social media services. Interviews and online observation revealed that managers were keenly aware of the need to go where their customers were active, and who saw little or no use in traditional advertising channels. Managers saw two major benefits in using social media to reach their audience. It made their businesses visible and active in fast-growing online environments, ahead of many competitors. This gave them access to potential customers more effectively than competitors that were slower to adopt social media. Businesses were also better able to attract customers to highly specialised niche products and services, by finding and using the social media channels used most by their intended audiences.

Compatibility with existing technology or business processes was not an area of concern for the managers. This was not due to any special properties of the social media services they adopted. Instead, the flexible and often ad hoc nature of daily operation within each small business was well suited to the introduction of new tools. Unlike many larger organisations, the small businesses in this study regularly changed both tools and processes in order to achieve the business outcomes they required. If a piece of technology was incompatible with other elements of the business, it could either be supported by additional technology or other elements could be adapted to suit it. The rapid growth of major social media platforms such as Twitter and Facebook proved to be an advantage in this regard: these platforms quickly attracted a large community of developers who created apps and other supporting tools that allowed managers to change and customise social media tools to better fit their businesses.

Few managers considered complexity to be a significant barrier to their adoption of any social media services, but it was still a factor in choosing which services to use first. 
Some managers opted to begin with a Twitter account, as it had relatively fewer features to master. Others opted for Facebook as they were already familiar with it from their personal accounts. Technical knowledge requirements for creating and maintaining an account on any service were seen as a matter of simply putting time in to develop the relevant skills. At a basic level, managers perceived using social media for their business as an easy task, based on their experience with personal accounts.

Trialability was an important factor for most social media services used during this study. Widespread access to free accounts enabled managers to test many different services before settling on those best suited to their needs. Several managers in the study created trial accounts on more platforms than they could recall, resulting in many inactive accounts that I re-discovered while preparing the case study profiles. Trialability enabled managers to bypass many 'what if' questions that would typically be explored during the innovation-decision process; allowing them to experiment directly.

The greatest strength of the social media services used in this study was their high degree of observability. This directly supported the adoption themes of perceived low risk and fear of missing out by allowing managers to readily see examples of how they could use each service, and making competitor activity visible. Twitter accounts, blogs and Facebook business pages were public by default, providing each manager with countless examples to learn from. Even on relatively closed networks like LinkedIn and Facebook, managers quickly found examples of others using profiles and groups from among their immediate contacts. Services with more limited observability included the private forums used by some professional networking groups, and new services offering inviteonly access to early adopters. These were rarely adopted by the managers: lacking a critical mass of users, new users experimented with these services in relative isolation before abandoning them in favour of more active communities.

The following section reviews the role that social media has played in supporting business networking activities. It also discusses the ways that social capital and social network theory have been used to explore the benefits that managers received from their active participation within these networks. 


\subsection{Using social media to support networking activities}

The final area of my research has explored the ways that small business managers used social media to support their networking activities, both in person and online. This is a key component of the social capital outcome described in Chapter 5, as managers used their personal networks to develop influence, access information, and benefit from solidarity among their contacts. During interviews with the managers it became clear that online and offline networking activities were closely linked. While each manager had some contacts they only knew online, this was most common when geographic location made offline contact difficult. Among their local contacts, managers used social media to set up meetings or continue conversations that had started at face-to-face events.

Social capital theory provides a powerful tool for understanding the online activities of each manager on their various social media accounts. All the managers sought to improve their business use of social media in order to access better contacts, information, influence, reputation, trust and goodwill - the "structural, relational and trust" aspects described by Inkpen and Tsang (2005). These were linked to the manager's personal and professional reputation and the way they chose to conduct themselves online. While few managers in the study had an explicit strategy guiding their social media use, each participant could describe the types of activity that they believed would harm their reputation, or that of their business. In doing so, they recognised that particular activities could provide them with better access to the resources they sought.

I have used Adler \& Kwon (2002, p. 23)'s definition of social capital as "the goodwill available to individuals or groups, [derived] from the structure and content of the actor's social relations," where the effects of social capital flow from the "information, influence, and solidarity" that it makes available. While broad, this definition identifies that the resource is derived from both structural and content aspects, and succinctly describes the three major benefits that social capital is used to access. Information allowed the managers to solve problems that they encountered in their businesses. The unequal flow of information across networks is a key aspect of the brokerage model of social capital. Influence, drawing upon the reputation of a manager and their business, was seen as a key means of getting referrals from customers and other businesses. Finally, solidarity provided managers with access to favours or other positive support from other group members. These were not necessarily formal requests for help on a specific issue. For 
example, managers in networks with a high degree of solidarity could reliably expect their social media posts to be shared by others, helping them to reach a larger audience. They could also expect other network members to provide recommendations, or step in to defend the manager or their business if they were attacked on a public forum.

This definition of social capital requires both structure and content for the generation of these resources. Content elements were discussed in Chapter 5, where the online activities of each manager were explored in detail. In order to understand the effect of network structure on social capital, I have drawn upon the tradition of social network research that began with Granovetter (1973)'s concept of strong and weak ties. This was developed further by Burt (2005), who described social capital as a combination of brokerage and closure opportunities afforded by the structure of a network. Together, these assist in identifying how network structures affect access to social capital.

The structural characteristics of a manager's social network included the number of individual contacts, and the ways these contacts are grouped together by their links to each other. Not all connections were equal: these are the differences between close friends and acquaintances; trusted business partners and peripheral contacts. These relationships influenced the types of information shared across networks. They are reflected in the choices that managers made when creating social media accounts, configuring visibility and privacy settings, and selecting what types of content to post.

Unequal access to information across a network provided a key source of social capital by creating brokerage opportunities for those able to bridge between groups that possess different types of information. Burt (2000) described these information gaps as 'structural holes,' arguing that any group will become more homogeneous over time. The brokerage opportunities presented by these structural holes assisted managers to share valuable information with their business contacts, allowing them to develop reputations for being well connected and informed about their industry. It also helped these managers to solve problems that fell outside their area of expertise: a common problem in businesses where managers were frequently required to be a 'jack of all trades'.

Diverse networks were important both for information discovery, and for the ability to evaluate this information. Managers who focused too heavily on the development of a strong, close-knit network of contacts risked information problems where echo-chamber effects could disproportionately amplify the signal of some messages. A common example 
among retail managers was the decision to stock new products based on forum chatter only to later discover that these discussions had been dominated by a vocal minority, not representative of the customer opinion. In another case, the opposite occurred: leading a manager to overlook a market that they believed to be over-supplied, not realising that few businesses outside their highly specialised network were aware of the new trend. As they became aware of these negative aspects, managers began to mitigate this by forming broader networks that enabled them to better find and assess new information.

Influence and solidarity both derive from closure effects within a social network, defined as the degree of redundancy in network connections. Network closure acts in opposition to information brokerage, but is an essential precursor to the development of reputation: the more embedded a relationship, "the more likely bad behaviour by either party will become known" (Burt, Killduff and Tasselli, 2013). This assists in the development of trust by placing reputational costs on negative behaviour.

Each manager sought to become influential within their networks: trusted by customers and respected by peers. They noted that traditional hierarchies in their industry were not always reflected online. The manager of Fusion described how on Twitter, the most influential hospitality figures were often from newer businesses, while many of Melbourne's established 'fine dining' elite lagged behind in their adoption of social media. This provided an opportunity for new managers to gain an advantage. Managers in the services and retail sectors told similar stories. These managers watched how influential peers used their own social media accounts, and attempted to mimic actions that would help them to become influencers in their own right.

Emulating influential peers helped the managers to make decisions about how to use their accounts, ranging from writing style and tone of voice, to preferred topics of discussion. In rare cases such as Cover Story and Network Solutions, managers could clearly describe the decisions made when constructing a persona used to represent their business online, and the intended outcome of these. More commonly, managers described these in terms of behaviours and activities they would avoid. Building Blocks avoided 'sales' posts, preferring to talk about industry trends to develop their reputation as a knowledgeable insider contact. SocialSearch tried to avoid personal topics, preferring to use their accounts to show a professional, 'corporate' persona. These showed an 
awareness of the business persona as a performance (Goffman, 1959) - based upon the preferences of the manager, but open to unwanted consequences if a misstep occurred.

The final resource examined in Chapter 7 was solidarity. This offered the potential for great benefits, but came with a higher cost in the form of reciprocating for other network contacts. Solidarity is generated by high-closure network structures. During the study, many managers either attempted to join existing groups of peers or customers, or form new groups of their own. Activities that improved network closure helped to increase solidarity. For example, using social media accounts to regularly converse with the same group of contacts helped to establish stronger ties with other members, and more crosslinkages between them. This contributed to the development of a sense of community: a feeling of belonging to a group, and sharing a bond with other group members.

Although it is typically described as a resource to support positive activity, managers were also hampered by negative aspects of solidarity. These included the reinforcement of negative behaviour by group members, and the development of a 'clique' environment that hampered the ability of newcomers to join. This caused problems where new members were required, and was most visible when managers tried to join established business communities such as those found in LinkedIn groups and forums. The retail managers were also mindful of the way that closed groups of customers could deter potential new customers. These managers recognised similar problems from their experience operating physical stores. For example, the manager of Toys \& Games described how she needed to strike a balance between providing a comfortable environment for her regular customers to meet, while still being open and welcoming to new customers. On or offline, the effect of cliques could be reduced by group members actively welcoming and introducing newcomers.

\subsection{Implications}

\section{Theoretical implications}

This study has explored the adoption and use of social media by small business managers, using aspects of Diffusion of Innovations (Rogers, 2003) and social capital theory. When combined, these two approaches enable a better examination of the complex interactions between factors involved in social media adoption, and the business outcomes that 
successful adoption provides to small business managers. I summarise the key findings here, and reflect on their implications for theory in the case of social media use.

Within Diffusion of Innovations, there is a great deal of synergy between important characteristics of social media innovations and specific stages in the innovation-decision process. By nature, most social media use is public, making it highly observable to outsiders. This contributed to the fear of missing out that drove managers in this study towards more rapid adoption. However, it also provided them with ample opportunity for social learning with their peers, accelerating the development of awareness, technical and principles knowledge. The interaction between learning to use a technology, and that technology actively making each user's experimentation and results public, has contributed toward the explosive rates of social media adoption during this study.

An examination of the innovator characteristics from DoI suggests that entrepreneurial small business managers are likely to be active and cosmopolite communicators. This is amplified by the network effects associated with connection to a community of peers - building upon the structural concepts of brokerage and closure, from social capital theory. This predicts that such individuals are likely to have better access to information, in the form of brokerage opportunities, and that they are more likely to find support from their contacts, provided by network solidarity. The managers in this study were publicly launching their business social media profiles, identifying themselves as newcomers to their chosen online environments, and actively seeking advice and suggestions from their contacts. As their networks developed, it became easier to acquire these resources, providing further perceived advantages to reinforce social media use. This continued to support other aspects of the innovation-decision model, assisting with persuasion, implementation and confirmation of their decisions.

Diffusion of Innovations provides an important degree of granularity when exploring how small business managers use social media. This allows a detailed examination of each social media service as a technological innovation, and the properties that may predispose it towards rapid adoption. Similarly, it provides a framework for examining the innovators themselves, and draws attention to traits such as the communication behavior of the business managers.

For example, managers in this study valued free-to-use social media services for their trialability, countering the potential risk of high complexity by allowing managers to 
readily experiment with new services. Public social media use is also highly observable, allowing managers to find and learn from other businesses around the world. These factors combined to produce a low barrier to entry, high perceived advantage in being active on social media platforms, and a ready source of examples that helped to guide each manager's adoption and ongoing use of social media.

Innovator and Innovation factors combine with the innovation-decision framework to provide detailed insights into the current stage of adoption. However, focusing too closely on individual technologies and innovators risks overlooking additional context from each innovator's social network around the outcomes generated by social media.

In contrast, social capital theory provides a powerful mechanism for explaining the outcomes that managers described during their adoption of social media. In this research, I have described three broad categories of business outcomes generated by social media. Visibility encompasses promotional and marketing activities, including brand awareness and reputation. Insight includes listening and monitoring activities, and active research providing specific information about customers or competitors. Social capital activities cultivate and draw upon the resources available to managers through their networks.

Where managers initially looked only for increased visibility to their customers, they found that the ways in which they used social media could also make qualitative changes to the way their audience of customers or peers would perceive them. A model that encompasses 'information, influence and solidarity' prompts greater awareness of these potential outcomes, and of the structural features of each manager's network that generate these. Social capital provides important context on the ways that each manager's network can help or hinder them when using social media. However, it does not provide the same degree of fine-grained information about a specific technology, or why a manager might succeed or fail at integrating it into their business.

There are significant benefits to combining these approaches, when examining the adoption and outcomes of social media. For example, managers who form broad networks that assist in the brokerage of information have much greater exposure to new technologies (gaining awareness knowledge), and access to examples of those technologies in action (developing principles knowledge). Diffusion theory would suggest that these managers can more easily progress to later stages of the innovationdecision process, and that many of these stages are further assisted by the social capital 
outcomes produced by each manager's network of contacts. In this way, social capital is not simply an outcome of social media adoption: it provides valuable context into the potential success of that adoption.

\section{Managerial implications}

The primary implications for business managers in this research are the range of potential business outcomes that social media can generate, and the hidden costs associated with successful social media implementation. These are detailed below.

Managers in this study initially sought to use social media as a marketing and promotional tool, hoping to cheaply increase their visibility to a wider customer audience. While many found some degree of success with this approach, the managers also broadened their focus to encompass information-gathering and network building activities as they became more familiar with using these services. These provided additional outcomes, in the form of insight and social capital. In most cases, these outcomes required a different approach to social media use: drawing from different types of network structures, and different types of online behavior. By raising awareness of these from the outset, managers could more effectively direct their social media activities to generate visibility, insight and social capital related outcomes.

As the managers shifted their focus away from business promotion, they began to use social media to develop their professional networks: broadening their networks and strengthening ties with key contacts. Social media was used to identify influencers and clusters of potential customers or peers, providing new methods for establishing contact with these groups and individuals. Where possible, managers should explore their options for using social media to support their networking activity. These networks provided the managers with greater access to the social capital resources of information, influence and solidarity.

The information benefits of networks were derived from a combination of access to more diverse sources of information, and the brokerage opportunities associated with bridging between clusters of contacts. This was a role that the small business managers in this study were well suited to: all were active and strategic networkers, continually seeking out new contacts. Where the small size of their businesses precluded relying too heavily on internal sources of information, the managers used social media to establish external networks that provided better access to information. 
The strong emphasis that each manager placed on developing a positive reputation among their contacts positioned them well to take advantage of the influence and solidarity benefits of their networks. Managers used social media to present themselves and their businesses as professional, trustworthy and experts in their particular niche: using techniques they observed from other industry figures, in order to become more influential. This was assisted by using news feeds and updates to remain on top of activity from other network members, and to remain visible and 'top of mind' to their contacts. By using regular, ongoing conversations to establish and develop a rapport with other network members, the managers increased their degree of embeddedness in these networks. In some cases this was also supported by joining or forming online communities, providing a sense of belonging and group identity: either as members of an industry group, or for regular customers of a business. This provided the managers with greater solidarity and support from their network contacts.

Throughout this study, the managers considered social media to be a free or low-cost alternative to other forms of business promotion, using free services where possible. This supported their perception of social media as a low-risk strategy. However, I challenge this perception, as this research has identified hidden financial costs, complexity and potential consequences for misuse of social media - all of which suggest that managers often underestimate the risks involved.

Interviews revealed that the managers generally did not account for their time outside of billable client work, and they did not factor in the time required to set up and learn to use these services. In each business, this required significant time both during setup, and as part of ongoing operations. Other managers hoping to use social media effectively should plan accordingly: while there are many potential benefits available, these all come at a cost, and that cost typically involves the manager's limited time.

Learning how to effectively use social media involved three phases of knowledge development. Awareness of the available technologies typically came via the managers' network contacts, and technical 'how-to' knowledge was relatively easy to acquire from help centre articles and blog posts. Principles knowledge was more difficult to acquire, helping the managers to navigate their online social interactions, and to understand appropriate or inappropriate action. This could only be learned through active participation in the groups present on each social media service. Planning for this, 
managers can choose to spend more time 'lurking' on each service before they begin using new accounts, and watching how other users interact.

Failing to develop principles knowledge contributes to the third area of risk: underestimating the consequences of poorly representing a business online. While the managers were conscious of how they experimented with different ways of presenting their business, most approached this in a very casual way - regarding their social media activity as something that could easily be deleted or overlooked if something went wrong. This changed as the managers focused more on developing personal and professional reputation. The highly observable nature of social media use helped to drive technology adoption, but it also risked putting any mistakes into public view. This could be mitigated by treating reputation-building as an important goal from the outset: a distinct but complementary form of visibility, separate to customer reach.

\subsection{Future research directions}

The primary limitations of this research design are sample size, location, and the time period that it covers. This section discusses future directions that build upon the findings of the study; proposing directions for further research into small businesses, their managers, and their adoption and use of social media.

Conducting a similar study with a larger sample size may provide results that can be generalised across other small business managers. However, as the methodology and methods used here were designed for a small study group, simply replicating this study with a larger sample size would not be ideal. Instead, the following suggestions would provide valuable insight into different aspects of small business social media use.

Changing the geographic setting would provide insight into the ways that small business use of social media is developing in other regions. Local contacts were an important source of information and inspiration for the participants in this study, with many managers looking to their peers for examples of what they should do. By focussing on businesses based in Melbourne, managers in this study had widespread access to the information and infrastructure needed to operate online. Social media services such as Facebook and Twitter had extremely high uptake among the wider population, providing a critical mass of customers and other businesses. Another location factor involves a comparison of urban, regional and rural locations, exploring the relative importance of 
visibility, insight and networking activities to managers in these locations. Conducting further research in other locations could assess whether the mechanisms of technology adoption and social capital generation described in this research can be applied in a more general fashion to social media adoption by small business managers.

More focused studies concentrating on specific industry sectors would enable direct comparisons between very similar businesses, providing deeper insight into those industries. The cross-sector approach used in the current study is better suited to providing an overview of potential areas of interest. Industry-specific studies would provide opportunities for a more detailed analysis of the specific challenges facing managers in a given sector.

Given the important role that social media played for the managers in this study as an information gathering tool, a more detailed examination of that particular aspect would be valuable. This could address areas such as absorptive capacity (Bosua, Evans \& Sawyer, 2013), market intelligence (Atanassova \& Clark 2015) and knowledge management (Bharati, Zhang \& Chaudhury, 2015), providing greater understanding of how social media can help managers to acquire and use information from their networks.

Selecting managers who had no prior experience with social media technologies would allow further exploration of the Diffusion of Innovations theory as it applies to social media. In an environment where social media adoption is now widespread, this would involve focusing on members from the Late Majority or Laggard innovator categories. This study has deliberately focused on businesses that were already active on at least one social media platform, resulting in a study population who self-identified as Early Adopters or Early Majority, and who had already been through the process of experimenting and learning to use some form of social media. A study of managers during their first experience using social media may provide greater insight into the InnovationDecision process and its application to social media.

Additionally, further research into the effects of adopting multiple simultaneous innovations would provide more clarity into the Innovation Decision model. Despite recommendations from researchers such as He et al. (2015) that small businesses should aim to concentrate on a single social network at a time, managers in this research all divided their attention between many different services. The number and variety of social media services available seems likely to continue growing. Any future research that seeks 
to examine technology adoption by small business managers should be prepared to deal with a complex mix of inter-related innovations, all at different stages of adoption.

Finally, there has been a strong shift towards the monetisation of social media services during the years immediately following this research. This was seen during the study in the form of premium LinkedIn accounts and Facebook advertising, but most managers did not use these options. Platform changes designed to drive business users towards paid options have now become far more prevalent, such as the steady decline in the organic reach of business pages on Facebook, encouraging businesses to pay for visibility. These changes may produce quite different behaviour, when compared to the managers in the current study. Future research in this new environment could focus on how managers incorporate paid services into their social media activities. These increase the technical learning curve and add to the complexity of social media use. That may slow down adoption rates, or force managers to focus more on specific channels - rather than creating free accounts on each new service that appears. It may also drive managers to outsource their business social media activity to specialists, calling on professional advice rather than attempting to learn and do everything on their own. 


\section{References}

Adams, P. (2010). The real-life social network. Presentation from Voices That Matter Web Design Conference, June 2010. URL <http://www.slideshare.net/padday/the-reallife-social-network-v2> (Accessed 13 July 2010).

Adler, P.S., Kwon, S.-W. (2002). Social capital: prospects for a new concept. The Academy of Management Review, vol. 27, no. 1, pp. 17-40.

Ahuja, V., Medury, Y. (2010). Corporate blogs as e-CRM tools - Building consumer engagement through content management. Journal of Database Marketing \& Customer Strategy Management, vol. 17, no. 2, pp. 91-105.

Al-Qirim, N. (2007). The Adoption of eCommerce Communications and Applications Technologies in Small Businesses in New Zealand. Electronic Commerce Research and Applications, vol. 6, no. 4, pp. 462-473.

Anderson, T.H.C. (2008). Not all social network users alike. Four types of LinkedIn users which type are you? Anderson Analytics. URL <http://www.andersonanalytics.com/index.p hp? mact=News,cntnt01, getfile, $1 \&$ cntnt01filen ame=20081105.pdf \&cntnt01returnid=46\&pag $\mathrm{e}=46>$ (Accessed 18 April 2011).

Atanassova, I. \& Clark, L. (2015). Social media practices in SME marketing activities: A theoretical framework and research agenda. Journal of Customer Behaviour, vol. 12, no. 2, pp. 163-183.

Australian Bureau of Statistics [ABS] (2001). ABS 1321.0 - Small Business in Australia. URL
<http://www.abs.gov.au/Ausstats/abs@.nsf/ 0/97452F3932F44031CA256C5B00027F19> (Accessed 8 May 2009).

BarNir, A., Smith, K.A. (2002). Interfirm alliances in the small business: The role of social networks. Journal of Small Business Management, vol. 40, no. 3, pp. 219-232.

Barry, C.A. (1998). Choosing Qualitative Data Analysis Software: Atlas.ti and Nudist Compared [WWW Document]. URL

<http://www.socresonline.org.uk/3/3/4.html $>$ (Accessed 23 January 2012).

Beal, G.M., Rogers, E.M., Bohlen, J.M. (1957).

Validity of the concept of stages in the adoption process. Rural Sociology, vol. 22, no. 2, pp. $166-168$.

Belliveau, M.A., O’Reilly, C.A., Wade, J.B. (1996). Social capital at the top: Effects of social similarity and status on CEO compensation. Academy of Management Journal, vol. 39, no. 6, pp. 1568-1593.

Bharati, P., Zhang, W., Chaudhury, A. (2015). Better knowledge with social media? Exploring the roles of social capital and organizational knowledge management. Journal of Knowledge Management, Vol. 19 No. 3, pp. 456-475.

Bolton, J.E. (1971). Report of the Committee of Inquiry on Small Firms. Cmnd.4811, HMSO, London.

Bosua, R., Evans, N. \& Sawyer, J. (2013). Social networks, social media and absorptive capacity in regional Small and Medium 
enterprises (SMEs) in Australia. Australian and International Journal of Rural Education, vol. 23, no. 1 , pp.117.

Bosua, R., Evans, N. (2017). Extending Social Capital through Online Social Networks (OSNs) in Rural Australia SMEs. The 38th International Conference on Information Systems (ICIS), Seoul, 2017, pp. 1-17.

Bourdieu, P. (1980). Le capital social: notes provisories. Actes de la Recherche en Sciences Sociales, vol. 31, pp. 2-3.

Bourdieu, P. (1986). The forms of capital, in: Richardson, J.G. (Ed.), Handbook of Theory and Research for the Sociology of Education. Greenwood, New York, pp. 241-258.

boyd, d., Ellison, N. (2007). Social Network Sites: Definition, History, and Scholarship. Journal of Computer-Mediated Communication, vol. 13, no. 1 , pp. $210-230$.

Braojos-Gomez, J., Benitez-Amado, J., LlorensMontes, F.J. (2015). How do small firms learn to develop a social media competence? International Journal of Information Management, vol. 35, no. 4, pp. 443-458.

Brewer, J.D. (2000). Ethnography, Understanding social research. Open University Press, Buckingham, UK.

Brundin, E. (2007). Catching it as it happens. In Neergaard, H., Ulhøi, J.P. (Eds.), Handbook of Qualitative Research Methods in Entrepreneurship. MPG Books, Cornwall, UK, pp. 279-307.

Bryman, A., Bell, E. (2007). Business Research Methods, 2nd Edition. Oxford University Press, Oxford, UK.
Burgess, S. \& Bingley, S. (2014). The small business social media web presence: an Australian snapshot. In Rospigliosi, A. \& Greener, S. (eds) Proceedings of the European Conference on Social Media. pp.72-79. July 2014, Brighton, UK.

Burgess, S. \& Paguio, R. (2016). Examining ICT application in Australian home-based businesses: an Innovation-Decision Process approach. Journal of Enterprise Information Management, vol. 29, no. 2, pp. 276-299.

Burgess, S., Sellitto, C., Buultjens, J. \& Cox, C. (2015). How Australian SMEs engage with social media. In Peres, P. \& Mesquita, A. (eds) Proceedings of the 2nd European Conference on Social Media. pp.45-51. July 2015, Porto, Portugal.

Burgess, S., Sellitto, C., Cox, C., Buultjens, J., Bingley, S. (2017). An Innovation Diffusion Approach to Examining the Adoption of Social Media by Small Businesses: an Australian Case Study. Pacific Asia Journal of the Association for Information Systems, vol. 9, no. 3, pp.1-24.

Burke, M, Kraut, R.E., Marlow, C. (2011). Social capital on Facebook: differentiating uses and users. In CHI '11: Proceedings of the 29th Computer-Human Interaction Conference, Vancouver, Canada, pp. 571-580. URL <http://www.thoughtcrumbs.com/publication s/burke_chi2011_socialcapitalonfacebook.pdf > (Accessed 5 November 2011).

Burt, R.S. (1992). Structural Holes: The Social Structure of Competition. Harvard University Press, Cambridge, MA, USA.

Burt, R.S. (1997). The contingent value of social capital. Administrative Science Quarterly, vol. 42, no. 2, pp. 339-365. 
Burt, R.S. (2000). The network structure of social capital. Research in Organizational Behavior, vol. 22, pp. 345-423.

Burt, R.S. (2004). Structural holes and good ideas. American Journal of Sociology, vol. 110, no. 2 , pp. 349-399.

Burt, R.S. (2005). Brokerage and Closure: An Introduction to Social Capital. Oxford University Press, Oxford, UK.

Burt, R.S., Kilduff, M., Tasselli, S. (2013). Social network analysis: foundations and frontiers on advantage. Annual Review of Psychology, vol. 64, pp. 527-547.

Caldeira, M.M., Ward, J.M. (2003). Using resource-based theory to interpret the successful adoption and use of information systems and technology in manufacturing small and medium-sized enterprises. European Journal of Information Systems, vol. 12, no. 2, pp. 127-141.

Calli, L. \& Clark, L. (2015). Overcoming SME Barriers to Gaining Competitive Advantage through Social Media. In Peres, P. \& Mesquita, A. (eds) Proceedings of the 2nd European Conference on Social Media. pp.59-64. July 2015, Porto, Portugal.

Canning, S. (2012). LinkedIn hits 3 million locals... and counting. The Australian, March 15, 2012. URL <http://www.theaustralian.com.au/media/lin kedin-hits-3-million-locals-andcounting/story-e6frg996-1226299745684> (Accessed 7 June 2014).

Cesaroni, F.M. \& Consoli, D. (2015). The adoption and use of social media by micro and small enterprises. In Peres, P. \& Mesquita, A. (eds) Proceedings of the 2nd European Conference on Social Media. pp.65-72. July 2015, Porto, Portugal.

Chau, S. (2003). The use of E-commerce amongst thirty-four Australian SMEs: An experiment or a strategic business tool? Journal of Systems and Information Technology, vol. 7, no. 1-2, pp. 49-66.

Clark, M., Eaton, M., Lind, W., Pye, E., Bateman, L. (2011). Key Statistics: Australian Small Business. Australian Government Department of Innovation, Industry, Science and Research.

Coleman, J.S. (1988). Social Capital in the Creation of Human Capital. American Journal of Sociology, vol. 94, pp. S95-S120.

Cope, J., Jack, S., Rose, M.B. (2007). Social capital and entrepreneurship. International Small Business Journal, vol. 25, no. 3, pp. 213-219.

Coser, R. (1975). The complexity of roles as seedbed of individual autonomy. In: Coser, L.A. (Ed.) The idea of social structure: papers in honour of Robert K. Merton. Harcourt Brace Jovanovich, New York, NY, USA, pp. 237-263.

Crotty, M. (1998). The foundations of social research: Meaning and perspective in the research process. Sage Publishing, Thousand Oaks, CA, USA.

Culkin, N., Smith, D. (2000). An emotional business: a guide to understanding the motivations of small business decision takers. Qualitative Market Research, vol. 3, no. 3, pp. 145-157.

Dahnil, M.I., Marzuki, K.M., Langgat, J., Fabel, N.F. (2014). Factors influencing SMEs adoption of social media marketing. Procedia - Social and Behavioural Sciences, vol. 148, pp. 119-126. 
Dandridge, T., Levenburg, N.M. (2000). High-

Tech Potential? An Exploratory Study of Very

Small Firms' Usage of the Internet.

International Small Business Journal, vol. 18, no. 2, pp. 81-91.

Davis, F.D. (1989). Perceived Usefulness,

Perceived Ease of Use, and User Acceptance of Information Technology. MIS Quarterly, vol. 13 , no. 3 , pp. 319-340.

Dawson, R. (2010). Some thoughts on why Australians are \#1 globally on social media usage (from a slow start). Trends in the Living Networks. URL <http://rossdawsonblog.com/ weblog/archives/2010/01/some_thoughts_o. html> (Accessed 19 July 2010).

Denzin, N.K. (1970). The research act: a theoretical introduction to sociological methods. Transaction Publishers, NJ, USA.

Denzin, N.K., Lincoln, Y.S. (1998). Handbook of Qualitative Research, 2nd Edition. Sage Publishing, Thousand Oaks, CA, USA.

Department of Trade and Industry, Commonwealth of Australia (1971) Report of the Committee on Small Business ("The Wiltshire Report"), Government Publisher. Canberra, Australia.

Dodd, S.D., Jack, S., Anderson, A.R. (2002). Scottish entrepreneurial networks in the international context. International Small Business Journal, vol. 20, no. 2, pp. 213-219.

Douglas, N. (2007). Twitter blows up at SXSW Conference. Gawker. URL <http://gawker.com/243634/twitter-blowsup-at-sxsw-conference> (Accessed 22 March 2012).
Durkin, M., McGowan, P., McKeown, N. (2013). Exploring social media adoption in small to medium-sized enterprises in Ireland. Journal of Small Business and Enterprise Development, vol. 20 , no. 4 , pp. 716-734.

Eisenhardt, K.M. (1989). Building theories from case study research. Academy of Management Review, vol. 14, no. 4, pp. 532-550.

Eisenhardt, K.M., Graebner, M.E. (2007). Theory building from cases: opportunities and challenges. Academy of Management Journal, vol. 50 , no. 1 , pp. 25-32.

Eisenegger, M. (2009). Trust and reputation in the age of globalisation. In J. Klewes, R. Wreschniok (eds.), Reputation Capital, Springer-Verlag Berlin, Heidelberg.

European Commission, (2003). Commission Recommendation of 6 May 2003 Concerning the Definition of Micro, Small and MediumSized Enterprises. Official Journal of the European Union, vol. L124, no. 36. URL <http://ec.europa.eu/enterprise/enterprise_p olicy/sme_definition/index_en.htm> (Accessed 29 May 2009).

Facebook, (2010). Facebook company information pages, July 2010. URL <http://www.facebook.com/press/info.php?st atistics> (Accessed 6 April 2010)

Facebook, (2011). Facebook company info pages April 2011. URL < http://www.facebook.com/ press/info.php?statistics> (Accessed 30 April 2011)

Frazier, B.J., Huddleston, P. (2009). The Role of Market Embeddedness in Market Scanning and Marketing Competence. Journal of Small 
Business and Entrepreneurship, vol. 22, no. 2, pp. $165-180$.

Frazier, B.J., Niehm, L.S. (2004). Exploring Business Information Networks of Small Retailers in Rural Communities. Journal of Developmental Entrepreneurship, vol. 9, no. 1, pp. 23-42.

Fullilove, M., Flutter, C. (2004). Diaspora: the world-wide web of Australians (No. 04), Lowy Institute Paper. Lowy Institute for International Policy, Double Bay, NSW, Australia.

Future Exploration Network, (2007). Future of Media Report 2007: Future of Media.

Future Exploration Network. URL <http://www.rossdawsonblog.com/Future_of _Media_Report2007.pdf> (Accessed 19 July 2010)

Gibbs, G.R. (2007). Thematic coding and categorising, in: Analyzing Qualitative Data, Qualitative Research Kit. Sage Publishing, UK.

Gibbs, S., Sequeira, J., White, M.M. (2007). Social Networks and Technology Adoption in Small Business. International Journal of Globalisation and Small Business, vol. 2, no. 1, pp. 66-87.

Gillespie, T. (2010). The politics of 'platforms.' New Media \& Society, vol. 12, no. 3, pp. 347 364.

Golafshani, N. (2003). Understanding reliability and validity in qualitative research. The Qualitative Report, vol. 8, no. 4, pp. 597-607.

Google (2018). Project Strobe: Protecting your data, improving our third-party APIs, and sunsetting consumer Google+. Google Company Blog. URL < https://www.blog.google/technology/safety- security/project-strobe/> (Accessed $30 \mathrm{Dec}$ 2018)

Grandon, E., Pearson, M. (2004). Electronic Commerce Adoption: An Empirical Study of Small and Medium US Businesses. Information \& Management, vol. 42, pp. 197-216.

Granovetter, M. (1973). The strength of weak ties. American Journal of Sociology, vol. 78, no. 3, pp. 1360-1380.

Granovetter, M. (1983). The strength of weak ties: a network theory revisited. Sociological Theory, vol. 1, pp. 201-233.

Granovetter, M. (1985). Economic Action and Social Structure: The Problem of Embeddedness. The American Journal of Sociology, vol. 91, no. 3, pp. 481-510.

Gruzd, A., Wellman, B., Takhteyev, Y. (2011). Imagining Twitter as an Imagined Community. American Behavioral Scientist, vol. 55, no. 10, pp. 1294-1318.

Guba, E.G., Lincoln, Y.S. (1994). Competing paradigms in qualitative research. In Denzin, N.K., Lincoln, Y.S. (Eds.) Handbook of Qualitative Research, Sage Publishing, Thousand Oaks, CA, USA, pp. 105-117.

Hardwick, J., Cruickshank, D. \& Anderson, A.R. (2012). Innovation in small business: comparing face-to-face with virtual networking. Journal of Business Strategy, vol. 33 , no. 5, pp.51-58.

Harris, L. \& Rae, A. (2009). Social networks: the future of marketing for small business. Journal of Business Strategy, vol. 30, no. 5, pp. 24-31.

Harris, L. \& Rae, A. (2010). The online connection: transforming marketing strategy 
for small businesses. Journal of Business

Strategy, vol. 31, no. 2, pp. 4-12.

Hassan, S., Nadzim, S., Shiratuddin, N. (2015).

Strategic use of social media for small business based on the AIDA model. Procedia - Social and Behavioral Sciences, vol. 172, pp. 262-269.

He, W., Wang, F., Chen, Y. \& Zha, S. (2015). An exploratory investigation of social media adoption by small businesses. Information Technology Management, vol. 18, no. 2, pp. 149-160.

Hine, C. (2008) Overview, Virtual Ethnography: Modes, Varieties, Affordances, in N.G. Fielding, R.M. Lee and G. Blank (eds), Handbook of Online Research Methods, Sage, London. pp. 257-270.

Jack, S.L., Dodd, S.D., Anderson, A.R. (2004). Social structures and entrepreneurial networks: the strength of strong ties. The International Journal of Entrepreneurship and Innovation, vol. 5, no. 2, pp. 107-120.

Jack, S., Moult, S., Anderson, A.R., Dodd, S. (2010). An entrepreneurial network evolving: Patterns of change. International Small Business Journal, vol. 28, no. 4, pp. 315-337. Jeyaraj, A., Rottman, J.W., Lacity, M.C. (2006). A Review of the Predictors, Linkages, and Biases in IT Innovation Adoption Research. Journal of Information Technology, vol. 21, no. 1, pp. 1-23.

Johnstone, B.A. (2007). Ethnographic methods in entrepreneurship research, in: Neergaard, H., Ulhøi, J.P. (Eds.), Handbook of Qualitative Research Methods in Entrepreneurship. MPG Books, Cornwall, UK, pp. 97-121.

Kaplan, A.M., Haenlein, M. (2011). The early bird catches the news: Nine things you should know about micro-blogging. Business Horizons, vol. 54, no. 2, pp. 105-113.

Kietzmann, J.H., Hermkens, K., McCarthy, I.P., Silvestre, B.S. (2011). Social media? Get serious! Understanding the functional building blocks of social media. Business Horizons, vol. 54 , no. 3, pp. 241-251.

Kietzmann, J.H., Silvestre, B.S., McCarthy, I.P., Pitt, L.F. (2012). Unpacking the social media phenomenon: towards a research agenda. Journal of Public Affairs, vol. 12, no. 2, pp. 109119.

Kim, A. (2000). Community Building on the Web : Secret Strategies for Successful Online Communities. Peachpit Press, San Francisco, CA, USA.

Krishen, A.S., Leenders, M.A.A.M., Muthaly, S., Ziółkowska, M., LaTour, M.S. (2018) Social networking from a social capital perspective: a cross-cultural analysis. European Journal of Marketing. https://doi.org/10.1108/EJM12-2016-0892

Kozinets, R.V. (1997). 'I Want To Believe': A netnography of The X-Philes' subculture of consumption. Advances in Consumer Research, vol. 24 , no. 1 , pp. 470-475.

Kozinets, R.V. (2010). Netnography: Doing ethnographic research online. Sage Publishing, Thousand Oaks, CA, USA.

Kraut, R.E., Burke, M., Reidl, J., Resnick, P. (2011). The challenges of dealing with newcomers. In: Kraut, R.E. \& Resnick, P. (Eds) Building successful communities: evidencebased social design, pp. 231-280. MIT Press, Cambridge, MA, USA. 
Lave, J., Wenger, E. (1991). Situated Learning: Legitimate Peripheral Participation. Cambridge University Press, New York, NY, USA.

LeCompte, M.D., Goetz, J.P. (1982). Problems of reliability and validity in ethnographic research. Review of Educational Research, vol. 52 , no. 1 , pp. $31-60$.

Lee, S.-H., DeWester, D., Park, S. (2008). Web 2.0 and opportunities for small businesses. Service Business, vol. 2, no. 4, pp. 335-345.

Lin, N. (1999). Social Networks and Status Attainment. Annual Review of Sociology, vol. 25, pp. 467-487.

Lin, N., Ensel, W.M., Vaughn, J.C. (1981). Social Resources and Strength of Ties: Structural Factors in Occupational Status Attainment. American Sociological Review, vol. 46, no. 4, pp. 393-405.

Lincoln, Y.S., Guba, E.G. (1985). Naturalistic Inquiry. Sage Publishing, Thousand Oaks, California.

Luotonen, A. (1995). WIT - WWW Interactive Talk. URL <http://www.w3.org/WIT/> (Accessed 26 May 2014).

Luotonen, A., Berners-Lee, T., n.d. W3 Interactive Talk: Overview. URL <http://www.w3.org/WIT/User/Overview.ht $\mathrm{ml}>$ (Accessed 26 May 2014).

Lynch, C.G. (2008). LinkedIn's Most Unusual Members: Meet The Super-Connected. CIO Online. URL <https://www.cio.com/article/2431799/cons umer-technology/linkedin-s-most-unusualmembers--meet-the-super-connected.html> (Accessed 21 November 2017)
Lyytinen, K., Damsgaard, J. (2001). What's wrong with the diffusion of innovations theory?, in: Ardis, M.A., Marcolin (Eds.), IFIP Advances in Information and Communication Technology. Presented at the Fourth Working Conference on Diffusing Software Product and Process Innovations, Kluwer Academic Publishers, Banff, Canada.

MacGregor, R.C. (2004). Factors associated with formal networking in regional small business: some findings from a study of Swedish SMEs. Journal of Small Business and Enterprise Development, vol. 11, no. 1, pp. 60-74.

Mahler, A., Rogers, E.M. (1999). The diffusion of interactive communication innovations and critical mass: the adoption of telecommunications services by German banks. Telecommunications Policy, vol. 23, no. 10-11, pp. 719-740.

Malecki, E.J., Veldhoen, M/E. (1993). “Network Activities, Information and Competitiveness in Small Firms." Geografiska Annaler. Series B, Human Geography vol. 75, no. 3, pp. 131-147.

Martin, L. (2005). Internet adoption and use in small firms: internal processes, organisational culture and the roles of the owner-manager and key staff. New Technologies, Work and Employment, vol. 20, no. 3, pp. 190-204.

Marwick, A.E., boyd, d. (2011). I tweet honestly, I tweet passionately: Twitter users, context collapse, and the imagined audience. New Media \& Society, vol. 13, no. 1, pp. $114-133$.

McAnany, E.G. (1984). The diffusion of innovation: Why does it endure? Critical Studies in Mass Communication, vol. 1, no. 4, pp. 439-442. 
Mehrtens, J., Cragg, P.B., Mills, A.M. (2001). A

Model of Internet Adoption by SMEs.

Information \& Management, vol. 39, no. 3, pp. 165-176.

Millen, D.R., Fontaine, M.A. \& Muller, M.J. (2002).

Understanding the benefit and costs of communities of practice. Communications of the ACM, vol. 45 , no. 4 , pp. 69-73.

Miller, N.J., Besser, T. \& Malshe, A. (2007). Strategic Networking among Small Businesses in Small US Communities. International Small Business Journal, vol. 25, no. 6, pp. 631-665.

Miller, N.J., Besser, T. \& Sattler-Weber, S. (2010). Networking as marketing strategy: a case study of small community businesses. Qualitative Market Research: An International Journal, vol. 13, no. 3, pp. 253-270.

Moore, G.A. (2002). Crossing the chasm. HarperCollins, New York, NY, USA.

Moore, G.C., Benbasat, I. (1991). Development of an Instrument to Measure the Perceptions of Adopting an Information Technology Innovation. Information Systems Research, vol. 2, no. 3, pp. 192-222.

MYOB Technology, (2014). MYOB Business

Monitor, Information page. URL:

<http://myob.com.au/myob/backing-aussiebusiness/myob-business-monitor1258090877325> (Accessed 24 August 2014)

Neergard, H. (2007). Sampling in entrepreneurial settings, in: Neergaard, H., Ulhøi, J.P. (Eds.), Handbook of Qualitative Research Methods in Entrepreneurship. MPG Books, Cornwall, UK, pp. 253-278.

Ngai, E.W.T. (2003). Internet Marketing Research (1987-2000): A Literature Review and Classification. European Journal of

Marketing, vol. 37, no. 1-2, pp. 24-49.

NielsenWire, (2010). Social media dominates Asia Pacific internet usage. Nielsenwire. URL <http://blog.nielsen.com/nielsenwire/global/ social-media-dominates-asia-pacific-internetusage/> (Accessed 30 April 2011)

New Zealand Ministry of Economic Development [NZMED] (2008). SMEs in New Zealand: Structure and Dynamics 2008. Ministry of Economic Development, New Zealand. URL <http://www.med.govt.nz/ templates/MultipageDocumentTOC__38373. aspx> (Accessed 11 May 2009).

Papacharissi, Z. (2009). The virtual geographies of social networks: a comparative analysis of Facebook, LinkedIn and ASmallWorld. New Media and Society, vol. 11, no. 1-2, pp. 199-220.

Parker, C.M., Castleman, T. (2007). New directions for research on SME-eBusiness: insights from an analysis of journal articles from 2003 to 2006. Journal of Information Systems and Small Business, vol. 1, no. 1-2, pp. 21-40.

Parker, C.M., Castleman, T. (2009). Small firm ebusiness adoption: a critical analysis of theory. Journal of Enterprise Information Management, vol. 22, no. 1-2, pp. 167-182.

Perren, L., Ram, M. (2004). Case-Study Method in Small Business and Entrepreneurial Research: Mapping Boundaries and Perspectives. International Small Business Journal, vol. 22, no. 1, pp. 83-101.

Pinch, T.J., Bijker, W.E. (1987). The social construction of facts and artefacts: or, how the sociology of science and the sociology of 
technology might benefit each other. In: Bijker, W.E., Hughes, T.P., Pinch, T.J. (Eds.) The social construction of technological systems: New directions in the sociology and history of technology. MIT Press, Cambridge, MA, USA, pp. 17-50.

Poon, S. (1999). An Exploratory Study of Small Business Internet Commerce Issues. Information \& Management, vol. 35, no. 1, pp.9-18.

Poon, S., Swatman, P.M.C. (1997). Small Business Use of the Internet Findings from Australian Case Studies. International Marketing Review, vol. 14, no.5, pp. 385-402.

Poon, S., Swatman, P.M.C. (1998). A Longitudinal Study of Expectations in Small Business Internet Commerce. In Proceedings of the 11th Bled International Conference on Electronic Commerce, pp. 295-309.

Poon, S., Swatman, P.M.C. (1999). An exploratory study of small business internet commerce issues. Information and Management, vol. 35, no. 1 , pp. 9-18.

Portes, A. (1998). Social capital: its origins and applications in modern sociology. Annual Review of Sociology, vol. 24, pp. 1-24.

Portes, A., Landolt, P. (1996). The downside of social capital. American Prospect, vol. 26, pp. 18-22.

Portes, A., Sensenbrenner, J. (1993).

Embeddedness and Immigration: Notes on the Social Determinants of Economic Action. American Journal of Sociology, vol. 98, no. 6, pp. 1320-1350.

Postill, J. \& Pink, S. (2012) Social Media

Ethnography: The digital researcher in a messy web. Media International Australia, vol. 145 , pp. 123-134.

Putnam, R.D. (2000). Bowling alone: The collapse and revival of American community. Simon \& Schuster, New York, NY, USA.

Premkumar, G. (2003). A Meta-Analysis of Research on Information Technology Implementation in Small Business. Journal of Organizational Computing \& Electronic Commerce, vol. 13, no. 2, pp. 91-121.

Ratcliffe, D. (2002). Validity and Reliability in Qualitative Research. Qualitative Research Resources. URL

<http://qualitativeresearch.ratcliffs.net/Validi ty.pdf> (Accessed 6 April 2010)

Rheingold, H., 1993. The virtual community: homesteading on the electronic frontier. Addison-Wesley, Boston, MA, USA.

Richards, L. (2009). Handling qualitative data: $A$ practical guide, 2nd Edition. SAGE publishing, London.

Richbell, S.M., Watts, H.D., Wardle, P. (2006). Owner-managers and business planning in the small firm. International Small Business Journal, vol. 24, no. 5, pp. 496-514.

Rogers, E.M. (2003). Diffusion of Innovations, 5th ed. Free Press, New York, NY, USA.

Saunders, M.N.K., Lewis, P., Thornhill, A. (2003). Research methods for business students, 3rd Edition. Prentice Hall, NJ, USA.

Schaper, M.T. (2012). Developments in the Australian Small Business sector since 1970. International Council for Small Business World Conference Proceedings, Massey University, Wellington. 6/1/2012, p1 
Sensis (2008). Sensis E-Business Report: The Online Experience of Small and Medium Enterprises. Sensis Inc., July 2008. URL <http://about.sensis.com.au/IgnitionSuite/ uploads/docs/2008_Sensis_e-Business_ Report.pdf> (Accessed 30 May 2014).

Sensis (2009). Sensis Business Index - Small and Medium Enterprises. Sensis Inc., February 2009. URL <http://about.sensis.com.au/ IgnitionSuite/uploads/docs/2009_Sensis_eBusiness_Report.pdf> (Accessed 30 May 2014).

Sensis (2010). Sensis eBusiness Report 2010. URL <http://about.sensis.com.au/IgnitionSuite/upl oads/docs/Sensis\%20e-

Business\%20Report\%20September\%202010 \%20FINAL.pdf> (Accessed 30 May 2014).

Sensis (2011a). Sensis eBusiness Report 2011.

URL < http://about.sensis.com.au/ IgnitionSuite/uploads/docs/2011\%20Sensis \%20e-Business\%20Report\%20FINAL.pdf> (Accessed 30 May 2014).

Sensis (2011b). Yellow Social Media Report 2011. Sensis Inc., May 2011. URL <http://about.sensis.com.au/IgnitionSuite/upl oads/docs/final_sensis_social_media_report_2 011.pdf> (Accessed 30 May 2014).

Sensis (2012a). Sensis eBusiness Report 2012. URL < http://about.sensis.com.au/ IgnitionSuite/uploads/docs/2012SensisE_Busi ness_Report.pdf> (Accessed 30 May 2014).

Sensis (2012b). Yellow Social Media Report 2012. Sensis Inc., May 2012. URL

<http://about.sensis.com.au/IgnitionSuite/upl oads/docs/yellow_socialmediareport_2012.pd f> (Accessed 30 May 2014).
Sensis (2013a). Sensis eBusiness Report 2013.

URL < http://about.sensis.com.au/

IgnitionSuite/uploads/docs/Sensis\%20eBusin ess\%20Report\%202013_240913.pdf>

(Accessed 30 May 2014).

Sensis (2013b). Yellow Social Media Report 2013. Sensis Inc., May 2013. URL

<http://about.sensis.com.au/IgnitionSuite/upl oads/docs/Yellow\%20Pages\%20Social\%20M edia\%20Report_F.PDF> (Accessed 30 May 2014).

Sensis (2014). Yellow Social Media Report 2014. Sensis Inc., May 2014. URL

<http://www.yellowadvertising.com.au/conte nt/dam/sensis/yas/Knowledge/Insights/Yell owSocialMediaReport2014/Yellow-SocialMedia-Report-2014.pdf> (Accessed 30 May 2014).

Sensis (2017a). Yellow Social Media Report 2017. Chapter 1 - Australians and social media. Sensis Inc., June 2017. URL < https://www.sensis.com.au/asset/PDFdirecto ry/Sensis-Social-Media-Report-2017.pdf> (Accessed 12 Jan 2018)

Sensis (2017b). Yellow Social Media Report 2017. Chapter 2 - Australian businesses and social media. Sensis Inc., June 2017. URL < https://www.sensis.com.au/asset/PDFdirecto ry/Sensis-Social-Media-Report-2017.pdf> (Accessed 12 Jan 2018)

Silverman, D. (2000). Doing qualitative research: a practical handbook. Sage Publishing, Thousand Oaks, California.

Simmons, G., Armstrong, G.A., Durkin, M.G. (2008). A Conceptualization of the Determinants of Small Business Website 
Adoption. International Small Business Journal, vol. 26, no. 3, pp. 351-389.

Spradley, J.P. (1980). Participant observation. Wadsworth Thomson Learning, USA.

Stone, B. (2011). Happy Birthday Twitter!

Twitter Blog. URL < http://blog.twitter.com/ 2011/03/happy-birthday-twitter.html> (Accessed 22 March 2012)

Stake, R.E. (2006). Multiple Case Study Analysis. The Guilford Press, New York, NY, USA.

Storey, D.J. (2010). Understanding the small business sector. Cengage Learning, Hampshire, UK.

Taylor, C. (2011). Social networking 'utopia' isn't coming. CNN Blog. URL <http://edition.cnn.com/2011/TECH/social.m edia/06/27/limits.social.networking.taylor/in dex.html> (Accessed 19 March 2012)

Telsyte (2012). Android sneaks past iOS as most popular smartphone operating system in Australia. Telsyte press release blog. URL <https://www.telsyte.com.au/?p=1995> (Accessed 26 May 2014)

Teo, T.L., Chan, C., Parker, C. (2004). Factors Affecting E-Commerce Adoption by SMEs. In ACIS 2004 Proceedings, Paper 54. URL http://aisel.aisnet.org/acis2004/54> (Accessed 16 February 2010).

Twitter (2011). Your world, more connected. Twitter Blog. URL <http://blog.twitter.com/2011/08/yourworld-more-connected.html> (Accessed 19 March 2012)

Twitter (2016). Never miss important Tweets from people you follow. Twitter Blog. URL <https://blog.twitter.com/official/en_us/a/20 16/never-miss-important-tweets-frompeople-you-follow.html> (Accessed 4 November 2017)

Twitter (2019). Q1 '19 Shareholder Letter.

Twitter Investor Relations site. URL < https://investor.twitterinc.com/financialinformation/quarterly-results/default.aspx> (Accessed 26 April 2019)

US Small Business Administration [US SBA] (2013). Summary of size standards by industry. URL <http://www.sba.gov/content/summarysize-standards-industry> (Accessed 9 January 2014)

van Dijk, J. (2013). The culture of connectivity: A critical history of social media. Oxford University Press, New York, USA.

Venkatesh, V. (2000). Determinants of Perceived Ease of Use: Integrating Control, Intrinsic Motivation, and Emotion into the Technology Acceptance Model. Information Systems Research, vol. 11, no. 4, pp. 342-365.

Wachs, J., Yasseri, T., Lengyel, B. \& Kerte'sz, J. (2019). Social capital predicts corruption risk in towns. Royal Society Open Science, vol. 6, issue 4 .

http://dx.doi.org/10.1098/rsos.182103 (Accessed 5 June 2019)

Wakkee, I., Englis, P.D., During, W. (2007). Using e-mails as a source of qualitative data. In: Neergaard, H., Ulhøi, J.P. (Eds.), Handbook of Qualitative Research Methods in Entrepreneurship. MPG Books, Cornwall, UK, pp. 331-358.

Walker, G., Kogut, B., Shan, W. (1997). Social capital, structural holes and the formation of 
an industry network. Organization Science, vol.

8, no. 2, pp. 109-125.

Wang, C., Walker, E.A., Redmond, J. (2007).

Explaining the lack of strategic planning in

SMEs: The importance of owner motivation.

International Journal of Organisational

Behaviour, vol. 12, no. 1, pp. 1-16.

Welsh, J.A., White, J.F. (1981). Small Business is not a little Big Business. Harvard Business Review, vol. 59, no. 4, pp. 46-58.

Westlund, H. (2006) Social capital and entrepreneurship. In: Social Capital in the Knowledge Economy: Theory and Empirics, Springer, Berlin, Heidelberg, pp.65-86

Yellow Pages (1995). Yellow Pages Special Report: Technology in the Small Business Sector. Yellow Pages Australia, June 1995. URL $<$ http://about.sensis.com.au/IgnitionSuite/upl oads/docs/YellowPagesSpecialReport_Techno logy_July95.pdf> (Accessed 2 May 2014).

Yin, R.K. (2009). Case Study Research: Design and Methods, 4th Edition. Vol. 5. Applied Social Research Methods. Sage Publishing, Thousand Oaks, CA, USA.

Zuckerberg, M. (2012). One Billion People on Facebook. Facebook Newsroom, October 4, 2012. URL <http://newsroom.fb.com/news/2012/10/on e-billion-people-on-facebook/> (Accessed 3 July 2014)

\section{Legislation}

Companies Act 2006 (UK) c 15, s 382

Small Business Act, 1953 (US) 15 U.S.C. ch. 14A § 632 